\title{
Variação Espaço-Temporal do Ictioplâncton e Condições Oceanográficas na Região de Cabo Frio (RJ)
}

\footnotetext{
Tese apresentada ao Instituto Oceanográfico da Universidade de São Paulo, como parte dos requisitos para obtenção do título de Doutor em Ciências, área de Oceanografia Biológica.
}

Orientador:

Prof. Dr Mario Katsuragawa

São Paulo 
Universidade de São Paulo

Instituto Oceanográfico

\title{
VARIAÇÃO ESPAÇO-TEMPORAL DO ICTIOPLÂNCTON E CONDIÇÕES OCEANOGRÁFICAS NA REGIÃO DE CABO FRIO (RJ)
}

\author{
Clarice Leão Lopes
}

Tese apresentada ao Instituto Oceanográfico da Universidade de São Paulo, como parte dos requisitos para obtenção do título de Doutor em Ciências, área de Oceanografia Biológica.

Julgada em

Conceito

Prof. Dr.

Conceito

Prof. Dr.

Conceito

Prof. Dr.

Conceito

Prof. Dr.

Prof. Dr.

\author{
Conceito
}




\section{Índice}

Índice

Lista de Tabelas

iv

Lista de Figuras

ix

Agradecimentos

xiv

Resumo

xvii

Abstract

xviii

1 - INTRODUÇÃO

2 - OBJETIVOS

3 - DESCRIÇÃO DA ÁREA DE ESTUDO

4 - METODOLOGIA

4.1 - Dados Abióticos

4.2 - Clorofila-a

4.3 - Volume de Plâncton e Ictioplâncton 15

4.4 - Análise dos Dados

5 - RESULTADOS

5.1 - Dados Abióticos

5.2 - Clorofila-a

5.3 - Volume de Plâncton 25

5.4 - Ictioplâncton 26

5.4.1 - Ovos 26

5.4.2 - Larvas 27

5.4.2.1 - Engraulidae 30

5.4.2.1.a - Engraulis anchoita 30

5.4.2.2 - Myctophidae 
5.4.2.3 - Sternoptychidae

5.4.2.3.a - Maurolicus sthemanni

36

5.4.2.4 - Scombridae

40

5.4.2.5 - Bregmacerotidae

41

5.4.2.5.a - Bregmaceros atlanticus

5.4.2.5.b-Bregmaceros cantori

5.4.2.6 - Phosichthydae 46

5.4.2.6.a - Pollichthys mauli 48

5.4.2.7 - Trichiuridae

50

5.4.2.8 - Outros Grupos

51

5.5 - Análises Estatísticas

57

6 - DISCUSSÃO

61

7 - CONCLUSÕES

81

8 - REFERÊNCIAS BIBLIOGRÁFICAS

83 


\section{LISTA DE TABELAS}

Tabela 1. Valores de temperatura (média, desvio padrão, valores mínimos e máximos) do cruzeiro de verão de 2001, na região do cabo Frio (RJ).

Tabela 2. Valores de temperatura (média, desvio padrão, valores mínimos e máximos) do cruzeiro de inverno de 2001, na região do cabo Frio (RJ).

Tabela 3. Valores de salinidade (média, desvio padrão, valores mínimos e máximos) do cruzeiro de verão de 2001, na região do cabo Frio (RJ).

Tabela 4. Valores de salinidade (média, desvio padrão, valores mínimos e máximos) do cruzeiro deinverno de 2001, na região do cabo Frio (RJ).

Tabela 5. Estimativa do volume de plâncton $\left(\mathrm{ml}^{\left.-\mathrm{m}^{-3}\right)}\right.$ dos diferentes estratos amostrados com a rede Multinet durante o cruzeiro de verão de 2001, na região do cabo Frio (RJ).

101

Tabela 6. Estimativa do volume de plâncton $\left(\mathrm{ml}^{-\mathrm{m}^{-3}}\right)$ dos diferentes estratos amostrados com a rede Multinet durante o cruzeiro de inverno de 2001, na região do cabo Frio (RJ).

Tabela 7. Estimativa da densidade de ovos de peixes $\left(n^{0}\right.$ de ovos. $\left.m^{-3}\right)$ dos diferentes estratos amostrados com a rede Multinet durante o cruzeiro de verão de 2001, na região do cabo Frio (RJ).

Tabela 8. Estimativa da densidade de ovos de peixes $\left(n^{0}\right.$ de ovos. $m^{-3}$ ) dos diferentes estratos amostrados com a rede Multinet durante 0 cruzeiro de inverno de 2001, na região do cabo Frio (RJ).

Tabela 9. Estimativa da densidade de larvas de peixes $\left(n^{\circ}\right.$ de larvas. $\mathrm{m}^{-3}$ ) dos diferentes estratos amostrados com a rede Multinet durante o cruzeiro de verão de 2001, na região do cabo Frio (RJ).

Tabela 10. Estimativa da densidade de larvas de peixes $\left(n^{\circ}\right.$ de larvas. $\mathrm{m}^{-3}$ ) dos diferentes estratos amostrados com a rede Multinet durante o cruzeiro de inverno de 2001, na região do cabo Frio (RJ).

Tabela 11. Freqüência relativa e freqüência de ocorrência das famílias identificadas nos cruzeiros de verão e inverno de 2001, na região do cabo Frio (RJ).

Tabela 12. Resultados da Análise de Componentes Principais realizada com as variáveis ambientais obtidas no cruzeiro de verão de 2001, na região do cabo Frio (RJ).

Tabela 13. Resultados da Análise de Componentes Principais realizada com as variáveis ambientais obtidas no cruzeiro de inverno de 2001, na região do cabo Frio (RJ). 
Tabela 14. Estimativa da densidade de larvas de Engraulis anchoita $\left(n^{\circ}\right.$ de larvas.100m-3) dos diferentes estratos amostrados com a rede Multinet durante o cruzeiro de verão de 2001, na região do cabo Frio (RJ).

Tabela 15. Estimativa da densidade de larvas de Engraulis anchoita $\left(\mathrm{n}^{\circ}\right.$ de larvas. $\left.100 \mathrm{~m}^{-3}\right)$ dos diferentes estratos amostrados com a rede Multinet durante o cruzeiro de inverno de 2001, na região do cabo Frio (RJ).

Tabela 16. Estimativa da densidade de larvas de Myctophidae $\left(n^{\circ}\right.$ de larvas. $100 \mathrm{~m}^{-3}$ ) dos diferentes estratos amostrados com a rede Multinet durante o cruzeiro de verão de 2001, na região do cabo Frio (RJ).

Tabela 17. Estimativa da densidade de larvas de Myctophidae $\left(n^{\circ}\right.$ de larvas. $100 \mathrm{~m}^{-3}$ ) dos diferentes estratos amostrados com a rede Multinet durante o cruzeiro de inverno de 2001, na região do cabo Frio (RJ).

Tabela 18. Estimativa da densidade de larvas de Sternopthychidae $\left(\mathrm{n}^{\circ}\right.$ de larvas. $100 \mathrm{~m}^{-3}$ ) dos diferentes estratos amostrados com a rede Multinet durante o cruzeiro de verão de 2001, na região do cabo Frio (RJ).

Tabela 19. Estimativa da densidade de larvas de Sternopthychidae $\left(\mathrm{n}^{\circ}\right.$ de larvas. $100 \mathrm{~m}^{-3}$ ) dos diferentes estratos amostrados com a rede Multinet durante o cruzeiro de inverno de 2001, na região do cabo Frio (RJ).

Tabela 20. Estimativa da densidade de larvas de Maurolicus stehmanni $\left(\mathrm{n}^{\circ}\right.$ de larvas. $\left.100 \mathrm{~m}^{-3}\right)$ dos diferentes estratos amostrados com a rede Multinet durante o cruzeiro de verão de 2001, na região do cabo Frio (RJ).

Tabela 21. Estimativa da densidade de larvas de Maurolicus stehmanni $\left(\mathrm{n}^{\circ}\right.$ de larvas. $\left.100 \mathrm{~m}^{-3}\right)$ dos diferentes estratos amostrados com a rede Multinet durante o cruzeiro de inverno de 2001, na região do cabo Frio (RJ).

Tabela 22. Estimativa da densidade de larvas de Scombridae $\left(n^{\circ}\right.$ de larvas. $100 \mathrm{~m}^{-3}$ ) dos diferentes estratos amostrados com a rede Multinet durante o cruzeiro de verão de 2001, na região do cabo Frio (RJ).

Tabela 23. Estimativa da densidade de larvas de Scombridade $\left(\mathrm{n}^{\circ}\right.$ de larvas.100m-3) dos diferentes estratos amostrados com a rede Multinet durante o cruzeiro de inverno de 2001, na região do cabo Frio (RJ).

Tabela 24. Estimativa da densidade de larvas de Bregmacerotidae $\left(\mathrm{n}^{\circ}\right.$ de larvas. $100 \mathrm{~m}^{-3}$ ) dos diferentes estratos amostrados com a rede Multinet durante o cruzeiro de verão de 2001, na região do cabo Frio (RJ). 
Tabela 25. Estimativa da densidade de larvas de Bregmacerotidae $\left(\mathrm{n}^{\circ}\right.$ de larvas. $100 \mathrm{~m}^{-3}$ ) dos diferentes estratos amostrados com a rede Multinet durante o cruzeiro de inverno de 2001, na região do cabo Frio (RJ).

Tabela 26. Estimativa da densidade de larvas de Bregmaceros atlanticus $\left(\mathrm{n}^{\circ}\right.$ de larvas. $100 \mathrm{~m}^{-3}$ ) dos diferentes estratos amostrados com a rede Multinet durante o cruzeiro de verão de 2001, na região do cabo Frio (RJ).

Tabela 27. Estimativa da densidade de larvas de Bregmaceros atlanticus ( $\mathrm{n}^{\circ}$ de larvas. $100 \mathrm{~m}^{-3}$ ) dos diferentes estratos amostrados com a rede Multinet durante o cruzeiro de inverno de 2001, na região do cabo Frio (RJ).

Tabela 28. Estimativa da densidade de larvas de Bregmaceros cantori $\left(\mathrm{n}^{\circ}\right.$ de larvas. $\left.100 \mathrm{~m}^{-3}\right)$ dos diferentes estratos amostrados com a rede Multinet durante o cruzeiro de verão de 2001, na região do cabo Frio (RJ).

Tabela 29. Estimativa da densidade de larvas de Bregmaceros cantori $\left(\mathrm{n}^{\circ}\right.$ de larvas.100m-3) dos diferentes estratos amostrados com a rede Multinet durante o cruzeiro de inverno de 2001, na região do cabo Frio (RJ).

Tabela 30. Estimativa da densidade de larvas de Phosichthyidae $\left(\mathrm{n}^{\circ}\right.$ de larvas. $100 \mathrm{~m}^{-3}$ ) dos diferentes estratos amostrados com a rede Multinet durante o cruzeiro de verão de 2001, na região do cabo Frio (RJ).

Tabela 31. Estimativa da densidade de larvas de Phosichthyidae $\left(\mathrm{n}^{\circ}\right.$ de larvas. $100 \mathrm{~m}^{-3}$ ) dos diferentes estratos amostrados com a rede Multinet durante o cruzeiro de inverno de 2001, na região do cabo Frio (RJ).

Tabela 32. Estimativa da densidade de larvas de Pollichthys mauli $\left(\mathrm{n}^{\circ}\right.$ de larvas. $100 \mathrm{~m}^{-3}$ ) dos diferentes estratos amostrados com a rede Multinet durante o cruzeiro de verão de 2001, na região do cabo Frio (RJ).

Tabela 33. Estimativa da densidade de larvas de Pollichthys mauli $\left(\mathrm{n}^{\circ}\right.$ de larvas. $100 \mathrm{~m}^{-3}$ ) dos diferentes estratos amostrados com a rede Multinet durante o cruzeiro de inverno de 2001, na região do cabo Frio (RJ).

Tabela 34. Estimativa da densidade de larvas de Trichiuridae $\left(n^{\circ}\right.$ de larvas. $100 \mathrm{~m}^{-3}$ ) dos diferentes estratos amostrados com a rede Multinet durante o cruzeiro de verão de 2001, na região do cabo Frio (RJ).

Tabela 35. Estimativa da densidade de larvas de Trichiuridae $\left(n^{\circ}\right.$ de larvas. $100 \mathrm{~m}^{-3}$ ) dos diferentes estratos amostrados com a rede Multinet durante o cruzeiro de inverno de 2001, na região do cabo Frio (RJ). 
Tabela 36. Estimativa da densidade de larvas de Anguiliformes $\left(\mathrm{n}^{\circ}\right.$ de larvas. $100 \mathrm{~m}^{-3}$ ) dos diferentes estratos amostrados com a rede Multinet durante o cruzeiro de verão de 2001, na região do cabo Frio (RJ).

Tabela 37. Estimativa da densidade de larvas de Anguiliformes $\left(n^{\circ}\right.$ de larvas. $100 \mathrm{~m}^{-3}$ ) dos diferentes estratos amostrados com a rede Multinet durante o cruzeiro de inverno de 2001, na região do cabo Frio (RJ).

Tabela 38. Estimativa da densidade de larvas de Bothidae $\left(\mathrm{n}^{\circ}\right.$ de larvas. $100 \mathrm{~m}^{-3}$ ) dos diferentes estratos amostrados com a rede Multinet durante o cruzeiro de verão de 2001, na região do cabo Frio (RJ).

Tabela 39. Estimativa da densidade de larvas de Carangidae $\left(\mathrm{n}^{\circ}\right.$ de larvas. $100 \mathrm{~m}^{-3}$ ) dos diferentes estratos amostrados com a rede Multinet durante o cruzeiro de verão de 2001, na região do cabo Frio (RJ).

Tabela 40. Estimativa da densidade de larvas de Clupeidae $\left(n^{\circ}\right.$ de larvas. $100 \mathrm{~m}^{-3}$ ) dos diferentes estratos amostrados com a rede Multinet durante o cruzeiro de verão de 2001, na região do cabo Frio (RJ).

Tabela 41. Estimativa da densidade de larvas de Cynoglossidae $\left(\mathrm{n}^{\circ}\right.$ de larvas.100m-3) dos diferentes estratos amostrados com a rede Multinet durante o cruzeiro de inverno de 2001, na região do cabo Frio (RJ).

Tabela 42. Estimativa da densidade de larvas de Mullidae $\left(n^{\circ}\right.$ de larvas. $100 \mathrm{~m}^{-3}$ ) dos diferentes estratos amostrados com a rede Multinet durante o cruzeiro de inverno de 2001, na região do cabo Frio (RJ).

Tabela 43. Estimativa da densidade de larvas de Ophidiidae $\left(n^{\circ}\right.$ de larvas. $100 \mathrm{~m}^{-3}$ ) dos diferentes estratos amostrados com a rede Multinet durante o cruzeiro de verão de 2001, na região do cabo Frio (RJ).

Tabela 44. Estimativa da densidade de larvas de Paralepididae $\left(n^{\circ}\right.$ de larvas. $100 \mathrm{~m}^{-3}$ ) dos diferentes estratos amostrados com a rede Multinet durante o cruzeiro de verão de 2001, na região do cabo Frio (RJ).

Tabela 45. Estimativa da densidade de larvas de Paralichthyidae $\left(\mathrm{n}^{\circ}\right.$ de larvas. $100 \mathrm{~m}^{-3}$ ) dos diferentes estratos amostrados com a rede Multinet durante o cruzeiro de verão de 2001, na região do cabo Frio (RJ).

Tabela 46. Estimativa da densidade de larvas de Phycidae $\left(\mathrm{n}^{\circ}\right.$ de larvas.100m-3) dos diferentes estratos amostrados com a rede Multinet durante o cruzeiro de inverno de 2001, na região do cabo Frio (RJ). 
Tabela 47. Estimativa da densidade de larvas de Pleuronectiformes $\left(\mathrm{n}^{\circ}\right.$ de larvas.100m-3) dos diferentes estratos amostrados com a rede Multinet durante o cruzeiro de inverno de 2001, na região do cabo Frio (RJ).

Tabela 48. Estimativa da densidade de larvas de Scaridae $\left(\mathrm{n}^{\circ}\right.$ de larvas.100m-3) dos diferentes estratos amostrados com a rede Multinet durante o cruzeiro de verão de 2001, na região do cabo Frio (RJ).

Tabela 49. Estimativa da densidade de larvas de Serranidae $\left(\mathrm{n}^{\circ}\right.$ de larvas.100m-3) dos diferentes estratos amostrados com a rede Multinet durante o cruzeiro de verão de 2001, na região do cabo Frio (RJ).

Tabela 50. Estimativa da densidade de larvas de Synodontidae $\left(\mathrm{n}^{\circ}\right.$ de larvas.100m-3) dos diferentes estratos amostrados com a rede Multinet durante o cruzeiro de inverno de 2001, na região do cabo Frio (RJ).

Tabela 51. Resultados da Análise de Componentes Principais realizada com as variáveis ambientais obtidas no cruzeiro de verão de 2001, na região do cabo Frio (RJ).

Tabela 52. Resultados da Análise de Componentes Principais realizada com as variáveis ambientais obtidas no cruzeiro de inverno de 2001, na região do cabo Frio (RJ). 


\section{LISTA DE FIGURAS}

Figura 1. Área de estudo com a localização das estações de coleta dos cruzeiros realizados no verão e inverno de 2001, na região do cabo Frio (RJ).

Figura 2. Perfis verticais de temperatura $\left({ }^{\circ} \mathrm{C}\right)$ das radiais realizadas durante o cruzeiro de verão de 2001, na região do cabo Frio (RJ).

Figura 3. Perfis verticais de temperatura $\left({ }^{\circ} \mathrm{C}\right)$ das radiais realizadas durante o cruzeiro de inverno de 2001, na região do cabo Frio (RJ).

Figura 4. Perfis verticais de salinidade das radiais realizadas durante o cruzeiro de verão de 2001, na região do cabo Frio (RJ).

Figura 5. Perfis verticais de salinidade das radiais realizadas durante 0 cruzeiro de inverno de 2001, na região do cabo Frio (RJ).

Figura 6. Diagramas TS produzidos com os parâmetros obtidos durante os cruzeiros de (a) verão e (b) inverno de 2001, na região do cabo Frio

Figura 7. Distribuição percentual de massas de água durante cruzeiro realizado no verão de 2001, na região do cabo Frio (RJ).

Figura 8. Distribuição percentual de massas de água durante cruzeiro realizado no inverno de 2001, na região do cabo Frio (RJ).

Figura 9. Perfis de concentração de clorofila-a das radiais realizadas durante cruzeiro realizado no verão de 2001, na região do cabo Frio (RJ).

Figura 10. Perfis de concentração de clorofila-a das radiais durante cruzeiro realizado no inverno de 2001, na região do cabo Frio (RJ).

Figura 11. Distribuição espacial de volume de plâncton coletado no verão de 2001, na região do cabo Frio (RJ).

Figura 12. Distribuição espacial de volume de plâncton coletado no inverno de 2001, na região do cabo Frio (RJ).

Figura 13. Distribuição espacial da densidade de ovos de peixes coletados no verão de 2001, na região do cabo Frio (RJ).

Figura 14. Distribuição espacial da densidade de ovos de peixes coletados no inverno de 2001, na região do cabo Frio (RJ

Figura 15. Distribuição espacial de larvas de peixes coletadas no verão de 2001, na região do cabo Frio (RJ).

Figura 16. Distribuição espacial de larvas de peixes coletadas no inverno de 2001, na região do cabo Frio (RJ).

Figura 17. Freqüência relativa dos grupos de larvas de peixes com freqüência de ocorrência igual ou maior de $50 \%$ e freqüência relativa igual ou maior de $3 \%$ em pelo menos um dos cruzeiros, verão ou inverno, realizados em 2001, na região do cabo Frio (RJ). 
Figura 18. Distribuição espacial de larvas de Engraulis anchoita coletadas no verão de 2001, na região do cabo Frio (RJ).

Figura 19. Distribuição espacial de larvas de Engraulis anchoita coletadas no inverno de 2001, na região do cabo Frio (RJ).

Figura 20. Engraulis anchoita: distribuição da freqüência relativa total de larvas por classe de comprimento nos estratos amostrados no verão de 2001, na região do cabo Frio (RJ)

Figura 21. Engraulis anchoita: distribuição da freqüência relativa nerítica de larvas por classe de comprimento nos estratos amostrados no verão de 2001, na região do cabo Frio (RJ)

Figura 22. Engraulis anchoita: distribuição da freqüência relativa diurna e noturna de larvas por classe de comprimento nos estratos amostrados no verão de 2001, na região do cabo Frio (RJ)

Figura 23. Engraulis anchoita: distribuição da freqüência relativa total de larvas por classe de comprimento nos estratos amostrados no inverno de 2001, na região do cabo Frio (RJ).

Figura 24. Engraulis anchoita: distribuição da freqüência relativa nerítica e oceânica de larvas por classe de comprimento nos estratos amostrados no inverno de 2001, na região do cabo Frio (RJ).

Figura 25. Engraulis anchoita: distribuição da freqüência relativa diurna e noturna de larvas por classe de comprimento nos estratos amostrados no inverno de 2001, na região do cabo Frio (RJ).

Figura 26. Distribuição espacial de larvas de Myctophidae coletadas no verão de 2001, na região do cabo Frio (RJ).

Figura 27. Distribuição espacial de larvas de Myctophidae coletadas no inverno de 2001, na região do cabo Frio (RJ).

Figura 28. Distribuição espacial de larvas de Sternoptychidae coletadas no verão de 2001, na região do cabo Frio (RJ).

Figura 29. Distribuição espacial de larvas de Sternoptychidae coletadas no inverno de 2001, na região do cabo Frio (RJ).

Figura 30. Distribuição espacial de larvas de Maurolicus stehmanni coletadas no verão de 2001, na região do cabo Frio (RJ).

Figura 31. Distribuição espacial de larvas de Maurolicus stehmanni coletadas no inverno de 2001, na região do cabo Frio (RJ).

Figura 32. Maurolicus stehmanni: distribuição da freqüência relativa total de larvas por classe de comprimento nos estratos amostrados no verão de 2001, na região do cabo Frio (RJ).

Figura 33. Maurolicus stehmanni: distribuição da freqüência relativa nerítica e oceânica de larvas por classe de comprimento nos estratos amostrados no verão de 2001, na região do cabo Frio (RJ). 
Figura 34. Maurolicus stehmanni: distribuição da freqüência relativa diurna e noturna de larvas por classe de comprimento nos estratos amostrados no verão de 2001, na região do cabo Frio (RJ)

Figura 35. Maurolicus stehmanni: distribuição da freqüência relativa total de larvas por classe de comprimento nos estratos amostrados no inverno de 2001, na região do cabo Frio (RJ).

162

Figura 36. Maurolicus stehmanni: distribuição da freqüência relativa nerítica e oceânica de larvas por classe de comprimento nos estratos amostrados no inverno de 2001, na região do cabo Frio (RJ).

Figura 37. Maurolicus stehmanni: distribuição da freqüência relativa diurna e noturna de larvas por classe de comprimento nos estratos amostrados no inverno de 2001, na região do cabo Frio (RJ).

Figura 38. Distribuição espacial de larvas de Scombridae coletadas no verão de 2001, na região do cabo Frio (RJ).

Figura 39. Distribuição espacial de larvas de Scombridae coletadas no inverno de 2001, na região do cabo Frio (RJ).

Figura 40. Distribuição espacial de larvas de Bregmacerotidae coletadas no verão de 2001, na região do cabo Frio (RJ)

Figura 41. Distribuição espacial de larvas de Bregmacerotidae coletadas no inverno de 2001, na região do cabo Frio (RJ).

Figura 42. Distribuição espacial de larvas de Bregmaceros atlanticus coletadas no cruzeiro realizado no verão de 2001 , na região do cabo Frio (RJ).

Figura 43. Distribuição de larvas de Bregmaceros atlanticus coletadas no inverno de 2001, na região do cabo Frio (RJ).

Figura 44. Bregmaceros atlanticus: distribuição da freqüência relativa total de larvas por classe de comprimento nos estratos amostrados no verão de 2001, na região do cabo Frio (RJ).

Figura 45. Bregmaceros atlanticus: distribuição da freqüência relativa nerítica e oceânica de larvas por classe de comprimento nos estratos amostrados no verão de 2001, na região do cabo Frio (RJ).

Figura 46. Bregmaceros atlanticus: distribuição da freqüência relativa diurna e noturna de larvas por classe de comprimento nos estratos amostrados no verão de 2001, na região do cabo Frio (RJ)

Figura 47. Bregmaceros atlanticus: distribuição da freqüência relativa total de larvas por classe de comprimento nos estratos amostrados no inverno de 2001, na região do cabo Frio (RJ).

Figura 48. Bregmaceros atlanticus: distribuição da freqüência relativa nerítica e oceânica de larvas por classe de comprimento nos estratos amostrados no inverno de 2001, na região do cabo Frio (RJ) 
Figura 49. Bregmaceros atlanticus: distribuição da freqüência relativa diurna e noturna de larvas por classe de comprimento nos estratos amostrados no inverno de 2001, na região do cabo Frio (RJ)

Figura 50. Distribuição de larvas de Bregmaceros cantori coletadas no verão de 2001, na região do cabo Frio (RJ).

Figura 51. Distribuição de larvas de Bregmaceros cantori coletadas no inverno de 2001, na região do cabo Frio (RJ).

Figura 52. Bregmaceros cantori: distribuição da freqüência relativa total de larvas por classe de comprimento nos estratos amostrados no inverno de 2001, na região do cabo Frio (RJ).

Figura 53. Bregmaceros cantori: distribuição da freqüência relativa nerítica e oceânica de larvas por classe de comprimento nos estratos amostrados no inverno de 2001, na região do cabo Frio (RJ).

Figura 54. Bregmaceros cantori: distribuição da freqüência relativa diurna e noturna de larvas por classe de comprimento nos estratos amostrados no inverno de 2001, na região do cabo Frio

Figura 55. Distribuição espacial de larvas de Phosichthyidae coletadas no verão de 2001, na região do cabo Frio (RJ).

Figura 56. Distribuição espacial de larvas de Phosichthyidae coletadas no inverno de 2001, na região do cabo Frio (RJ).

Figura 57. Distribuição espacial de larvas de Pollichthys mauli coletadas no verão de 2001, na região do cabo Frio (RJ).

Figura 58. Distribuição espacial de larvas de Pollichthys mauli coletadas no inverno de 2001, na região do cabo Frio (RJ).

Figura 59. Pollichthys mauli: distribuição da freqüência relativa total de larvas por classe de comprimento nos estratos amostrados no verão de 2001, na região do cabo Frio (RJ).

Figura 60. Pollichthys mauli: distribuição da freqüência relativa nerítica e oceânica de larvas por classe de comprimento nos estratos amostrados no verão de 2001, na região do cabo Frio (RJ).

Figura 61. Pollichthys mauli: distribuição da freqüência relativa diurna e noturna de larvas por classe de comprimento nos estratos amostrados no verão de 2001, na região do cabo Frio (RJ).

Figura 62. Pollichthys mauli: distribuição da freqüência relativa total de larvas por classe de comprimento nos estratos amostrados no inverno de 2001, na região do cabo Frio (RJ).

Figura 63. Pollichthys mauli: distribuição da freqüência relativa nerítica e oceânica de larvas por classe de comprimento nos estratos amostrados no inverno de 2001, na região do cabo Frio (RJ).

Figura 64. Pollichthys mauli: distribuição da freqüência relativa diurna e noturna de larvas por classe de comprimento nos estratos amostrados no verão de 2001 , na região do cabo Frio (RJ). 
Figura 65. Distribuição espacial de larvas de Trichiuridae coletadas no verão de 2001, na região do cabo Frio (RJ).

Figura 66. Distribuição espacial de larvas de Trichiuridae coletadas no inverno de 2001, na região do cabo Frio (RJ).

Figura 67. Diagrama de ordenação da Análise de Componentes Principais, em função das variáveis ambientais, das amostras do cruzeiro de verão de 2001, na região do cabo Frio (RJ).

Figura 68. Diagrama de ordenação da Análise de Componentes Principais, em função das variáveis ambientais, das amostras do cruzeiro de inverno de 2001, na região do cabo Frio (RJ),.

Figura 69. Análise de classificação TWINSPAN, do cruzeiro de verão de 2001, na região do cabo Frio (RJ).

Figura 70. Análise de classificação TWINSPAN, do cruzeiro de inverno de 2001, na região do cabo Frio (RJ). 


\section{$\mathcal{A G R A D E C I M E \mathcal { N T O S }}$}

Primeiramente agradeço ao Prof. Dr Mario Katsuragawa, meu orientador desde a inícíação cientifica, por sempre acreditar em mim. Obrigada por sempre compreender e apoiar os seus alunos.

$\dot{\mathcal{A}} J u n e$, por milhares de ensinamentos ao longo destes anos, principalmente quando era do laboratório. Por ter sído uma amiga especial nos momentos que eu maís precísei!

Gostaria aqui de fazer uma homenagem especial à uma pessoa que me ensinou muito na época de estágio, que foi um exemplo de profíssional e, infelizmente, não está mais conosco, Prof. Matsuura! ’̀ Suzuki por também fazer parte da minha formação científica, pelos conselhos, conversas e muito conhecimento transmitido na parte de identíficação.

Lourdes, você além de cumprír seu trabalho como técnica do laboratório, consegue ser amiga, irmã, mãe, conselheira e companheira, tudo ao mesmo tempo!! Você é realmente maravilhosa. Sem a sua ajuda este trabalho não seria o mesmo!! Se eu citasse aqui tudo que você me ajudou neste trabalho, a tese viraria um apêndice!

$\mathcal{A}$ todas as pessoas que me ensinaram durante o convivio nos Laboratórios de Ictioplâncton e Biologia Pesqueira: June, Lourdes, Suzuki, Elô, Carol, Bur, Cássia, Mari, Robertinha, Daniel, Carlos, Gymel, Camila, Michael, Ricardinho, Paulo, Venâncio, Roberta. Im especial, não posso esquecer de agradecer ao Bur, Cássia, Mari e Lourdes, pela ajuda na triagem, à Cássia e à Mari pela identificação das famílias Phosichthyidae e Sternopthychidae, e à Lourdes, Daniel e Carlos, pela ajuda na medição das larvas.

Aos Profs Ilson e Gaeta, super obrigada pelos dados cedidos: foi essencial para o enriquecimento do trabalho! Rafinha, devo a você um agradecimento muito especial! Acho que cada vez que você me encontrava no corredor devia querer sair correndo, pois eu realmente te "dei trabalho"! Muito obrigada pela sua paciência com minhas burrices matlabenses e, quem sabe um dia eu venha a detestar o Bill Gates! Mayza, obrigada por sempre estar disposta a ajudar! Kampel e Lu também! André, Leandro e Sueli, obrigada por sempre atenderem aos meus berros de socorro!

Aos tripulantes do $\mathcal{N}$.Oc. Prof W. Besnard, em especial o Jura e o Rans (paroooou!!). Aos pesquisadores que embarcaram na onda do famoso "fogãozinho": Luiz Nonato (Katchuuunga!!), Mario, June, Gaeta, Ilson, Mayza, Tomás, Áurea, Kampel, PH, Leandro, Lu, Mari, Bur, Fabiano, Valter, Wilson Natal, Lourdes (mesmo que por poucos dias!), e outros todos! 
Às Profas June e Thaís, pelos "pepinos" resolvidos como coordenadoras de área. Ao Prof. Michel pelas inclusões sempre de última hora na pauta da CPG.

Ao pessoal da minha turma: André, Andressa, Carl, Carol, Cinthia, Fabio, Jú, Marinella, Nat e Venâncio!! Cỉ e Nê, desde o começo juntas...tenho saudades! Fabio, valeu por toda a ajuda na época das disciplinas e do projeto (deu trabalho, lembra?). Vevê, sempre me dando mil conselhos e ajudas!! Beijo grande à vocês!

À todos os professores, muito obrigada!! Desde os que administraram as disciplinas, até os que sempre me ajudam nos mais variados aspectos!! Rubens, valeu pela impressora e pela "conversinha" que tivemos depois da qualificação! Foi importante para eu "pensar um pouco na vida"!

À todos funcionários, principalmente aqueles com quem eu converso, brinco, e me divirto. Valter Laranjão, D. Cída, Tomás, Manelão, Cídinha, Ruthinha, Crís, Cído, D. Rai, Clau, Didi, Bertão, Mendigos! Sem o apoío de vocês, nada sería possivel! Im especial agradeço ao Seu Amaro, Jorge, Silvana, Ana Paula e Edna por sempre fazerem tudo por nós!

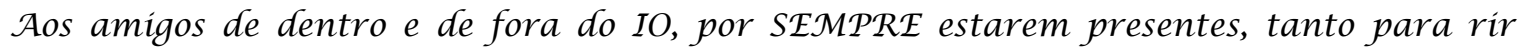
como pra chorar: Drics, Marlos, Elô, Miguelito, Paulinho, Léo, Paula, Fabiano, Sandrinha, Fabio, Melina, Kátía, Gabi, Fran, Amanda, "meninas" da Lucy, Marília, Renatão, Ricardo, Carlão, Filipe, Gabera, Déia, Jah, Fernandinha, Ritinha, Franguito, Lelê, Lilian, Dri, $\mathcal{N}$ ewton, Zédu, Mauro, Thais, Carol, Cris Mala, Denis, Rafa, Betinho, Pisetta, Evelyn e Marí. Ao ARRASO (o grupo de amigas que todo mundo gostaría de ter!), pessoal do $3^{\circ} \mathcal{A}$, Mackenzie e Ubatuba por sempre (ou nem sempre!) entenderem minha ausência! Incluo também aqui a Cris e a Cecília... com certeza, juntas venceremos! Sorte minha ter encontrado essas 2 pessoas maravilhosas!

ג̇ $\mathcal{F} \mathcal{A} \mathcal{P E S P}$ (quando ainda era mestrado) e à CAPES pela bolsa de doutorado.

Às minhas queridas amigas $\mathcal{N a t}$ e Cintia um SUPER obrigada por tudo que elas me ajudaram e pelo que representam na minha vida! Migs, espero que realmente fronteira nenhuma separe nossa amizade!! Ao Goma (meu bem!) por ter ser tornado meu irmão de coração, pelos anos de convivência e aprendizagem na casinha e por toda a sua amizade! Obrigada também ao grande amigo, Marquito, e ao Pablo. $\mathcal{A}$ ajuda nas análises estatísticas, figuras, discussões, Groncas merecidas, apoío e incentivo me ajudaram muito! Ao grande amor da minha vida, por sempre me dar todo o apoio que eu precisei, principalmente na fase final deste trabalho. Desculpe os momentos que eu não pude te dar todo o carinho que você merece, mas ainda temos a vida inteira pela frente! Te amo 


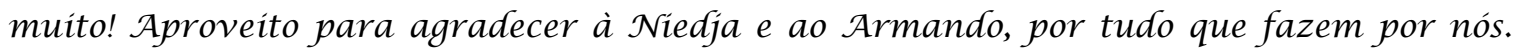
Quando eu não encontrava mais as palavras, aquele dicionário foi essencial, sogrinha! $\mathcal{A}$ Vênus e à Luna, que mesmo atrapathando de vez em quando, foram as que mais fizeram companhia enquanto eu escrevia!

Por último, gostaria de agradecer às pessoas que desde cedo contribuiram para a minha educação e formação, e que, grande parte do que sou, devo eternamente à eles! Pai, obrigada por sempre confiar em mim, por apoiar as minhas escolhas, e, enfim, por me fazer chegar até aquí! Mãe, tudo o que você me ensinou quando eu era jovem, nunca será esquecido! o respeito, amor, humildade, amizade, são apenas alguns dos valores que você me deixou... Irmão, espero que sempre sejamos muito amigos e continuemos aprendendo um com o outro! E obrigada pelo computador, Sé, "metade dele" está até agora me acompanhando. Tía Ce, Jú, Kika e João, vocês sabem o quanto participaram desta fase da minha vida! Vocês me ajudaram em todos os aspectos possiveis: nas noites em claro nas vésperas de relatórios ou trabalhos das disciplinas, por me darem a "outra metade" do computador, mas, principalmente, por me darem a certeza de que ai eu sempre terei um porto seguro!! Um beijo muito especial aos novos agregados da família: Cris, Dri, Pepeu, Goma, Nat, e de novo, você, Beto! Amo demais vocês! 


\section{RESUMO}

O presente trabalho teve como objetivo principal descrever a distribuição espaço-temporal do ictioplâncton da região do cabo Frio (RJ) em relação aos processos físicos de mesoescala, com ênfase na distribuição vertical. A amostragem foi realizada em verão e inverno de 2001, com o N/Oc. Prof. W. Besnard, durante dois cruzeiros do projeto DEPROAS. O ictioplâncton foi coletado com rede Multinet, com 5 redes de $333 \mu \mathrm{m}$, sendo que cada estrato amostrado teve $20 \mathrm{~m}$, até os $100 \mathrm{~m}$ de profundidade. Em laboratório, foram realizadas a triagem do ictioplâncton e identificação das larvas. A análise dos dados foi realizada através de testes estatísticos paramétricos e não paramétricos e análises multivariadas. Não houve um padrão claro de distribuição vertical das larvas em função das classes de comprimento, salvo em alguns casos particulares, como Bregmaceros cantori que teve maior frequência de larvas em pré-flexão associadas à termoclina e também baixa frequência de larvas em pós-flexão próximas à superfície. O padrão de distribuição do ictioplâncton foi determinado, em parte, pelas porcentagens de ACAS, de AC e a concentração de clorofila-a, tanto nos dois períodos. Com base nos resultados obtidos, foi possível demonstrar a influência direta dos processos físicos de mesoescala (i.e. ressurgência e subsidência) e dos padrões de distribuição de clorofila-a sobre a distribuição vertical do ictioplâncton na região do cabo Frio.

Palavras-chave: ictioplâncton, distribuição vertical, larvas de peixes, ressurgência, subsidência, cabo Frio-RJ 


\section{ABSTRACT}

The aim of the present work was to describe the spatial and temporal distributions of the ichthyoplankton in the cabo Frio $(\mathrm{RJ})$ region in relation to mesoscale physical processes, with emphasis on its vertical distribution. Samples were taken in the summer and winter 2001 onboard the R/V Prof. W. Besnard, during the two sampling surveys of the DEPROAS project. The ichthyoplankton was collected using a Multinet device with 5 nets of $333 \mu \mathrm{m}$ meshed; being that each layer had $20 \mathrm{~m}$ up to $100 \mathrm{~m}$ depth. Ichthyoplankton sorting and larvae identification were done in the laboratory. Data analyses were performed using parametric and non-parametric statistical tests, and also multivariate analyses. A clear vertical distributional pattern of larvae in relation to their length classes was not observed, except in some particular cases such as Bregmaceros cantori, which had a higher frequency of pre-flexion larvae associated to the thermocline and also a low frequency of pos-flexion larvae near the surface. The distributional pattern of ichthyoplankton was determined in part, by the percentages of SACW, $\mathrm{CW}$ and chlorophyll-a concentration in both periods. Based on these results, it was possible to demonstrate the direct influence of mesoscale physical processes (i.e. upwelling and downwelling) and chlorophyll-a distribution patterns on the vertical distribution of the ichthyoplankton in the cabo Frio region.

Key words: ichthyoplankton, vertical distribution, fish larvae, upwelling, downwelling, cabo Frio-RJ 


\section{1 - INTRODUÇÃO}

A maioria dos peixes marinhos passa os primeiros estágios de seu ciclo de vida no plâncton, sendo que o conjunto de seus ovos e larvas é denominado ictioplâncton. O estudo do ictioplâncton contribui em vários campos da biologia marinha e da ciência pesqueira, possibilitando o estabelecimento de conhecimentos sobre sistemática e biologia, além da compreensão da dinâmica populacional das espécies, de modo que se possa investigar as possíveis causas das variações dos estoques pesqueiros. O conhecimento sobre a ontogenia, o comportamento, a taxonomia e a zoogeografia do ictioplâncton, bem como estudos sobre o crescimento, mortalidade e alimentação, e ainda a detecção de recursos pesqueiros e a estimativa de biomassa, constituem alguns exemplos destes estudos (Hempel, 1979).

Os padrões de distribuição espacial e temporal, bem como a abundância dos ovos e larvas de peixes, são influenciados pela interação de vários processos bióticos e abióticos. Os fatores biológicos incluem o local, momento e tipo de desova, a abundância dos adultos, a duração do estágio larval, o comportamento larval, a presença de predadores potenciais e a disponibilidade de alimentos adequados, entre outros (Norcross \& Shaw, 1984; Leis, 1991; Sassa et al., 2004), enquanto os fatores físicos incluem eventos hidrográficos e climatológicos como correntes, ventos, vórtices, ressurgências e estratificação da coluna de água (Denman \& Powell, 1984; Norcross \& Shaw, 1984). Na região de cabo Frio, por exemplo, a ressurgência sobre a plataforma continental é caracterizada pela inclinação da termoclina, cuja oscilação vertical determina os padrões de flutuação das comunidades planctônicas (Valentin et al.,1987). Santos et al. (2004) concluíram que eventos de ressurgência durante a época de 
desova da sardinha alteram significantemente a distribuição de seus estágios iniciais do ciclo de vida.

$\mathrm{Na}$ costa sudeste e sul brasileira, o ictioplâncton vem sendo intensivamente estudado desde a década de 60 , sendo que os trabalhos publicados abordam principalmente aspectos da identificação e descrição das fases do desenvolvimento embrionário e larval, exploração dos recursos pesqueiros, avaliação da biomassa desovante, e distribuição e abundância de ovos e larvas (Matsuura, 1990; Katsuragawa \& Matsuura, 1992; Kurtz, 1999, entre outros). Mais recentemente, os trabalhos realizados sobre estrutura da comunidade têm sido acompanhados daqueles sobre associações/assembléias, crescimento, mortalidade, condição nutricional, alimentação e cultivo de larvas, seguindo uma tendência mais ecológica e de relações e respostas aos fatores ambientais, em busca de um entendimento sobre os fenômenos que envolvem o recrutamento e a dinâmica das populações (por exemplo, Yoneda, 1987; Dias, 1995; Freire, 1995). Estes estudos têm se preocupado em identificar relações entre a estratégia de desova dos peixes e a dinâmica das massas de água da região, especialmente com o regime da Água Central do Atlântico Sul (ACAS). De acordo com Matsuura (1990), a presença da ACAS no verão favorece as condições de sobrevivência das larvas de Sardinella brasiliensis. Esta relação com a dinâmica das massas de água é reforçada pelo constatado para Engraulis anchoita, cuja intensidade de desova está mais ligada às condições oceanográficas do que às estações do ano, segundo Spach (1990). Outros trabalhos têm utilizado a distribuição de larvas em função da ontogenia com o intuito de interpretar os processos físicos atuantes na área de estudo. Por exemplo, Muelbert \& Sinque (1996) encontraram larvas de Pomatomus saltatrix 
de menor tamanho restritas à plataforma interna da região sul do Brasil e observaram um aumento no comprimento das larvas quanto mais próximo à costa, indicando um transporte "inshore" que pode explicar a presença de juvenis nas áreas costeiras e estuarinas da região. Franco et al. (2006) ressaltam a importância de estudos que combinem a dinâmica oceânica com observações de satélite e in situ, permitindo uma melhor compreensão do papel dos processos físicos de mesoescala sobre a distribuição de larvas de peixes.

Com relação à distância da costa, estudos sobre ictioplâncton no sudeste se concentram na área nerítica, havendo carência de estudos na oceânica. Historicamente não se têm feito uma amostragem sistemática nessa área, exceto em duas localidades, uma ao largo de cabo Frio e outra ao largo do cabo de Santa Marta Grande, que foram amostradas até cerca de 140 milhas náuticas $(260 \mathrm{~km})$ da costa, durante os cruzeiros do projeto FINEP/IOUSP (Exploração e avaliação dos estoques de peixes pelágicos no sudeste do Brasil) entre os anos de 1975 e 1983. Nos recentes cruzeiros oceanográficos do projeto PADCT/IOUSP ("Importância e caracterização da quebra da plataforma continental para recursos vivos e não vivos") foram efetuadas coletas de ictioplâncton de forma mais intensiva na área entre o cabo de São Tomé e cabo de Santa Marta Grande, incluindo a quebra da plataforma e talude continental, até aproximadamente a isóbata de $1200 \mathrm{~m}$.

Fatores ambientais, como luz, temperatura e pressão, e fatores biológicos, como concentração de alimento, apresentam gradientes muito mais evidentes no sentido vertical da coluna de água do que no horizontal, justificando o comportamento de larvas de peixes, como de outros organismos planctônicos, que realizam migrações verticais diárias, proporcionando desta maneira 
variações no volume do plâncton nas diferentes profundidades no decorrer de um dia. A posição vertical da larva na coluna de água pode ser determinada pela sua flutuabilidade, sua capacidade de natação ou pelo seu senso de orientação (Power, 1984). A flutuabilidade pode ser regulada através de uma vesícula gasosa ou, no caso de larvas que não possuem este órgão, pela falta de tecidos ósseos ou presença de tecidos com alta porcentagem de água (Power, 1984). No caso dos ovos de peixes, sua posição na coluna de água, em função das massas de água e da flutuabilidade, permite identificar preferências nos locais da postura, já que eles não possuem mecanismos próprios que alterem sua posição.

A ampla ocorrência de migração vertical em larvas de peixes sugere que existam vantagens adaptativas relacionadas à este comportamento (Haldorson et al.,1993), como, por exemplo, manutenção da posição em relação à distribuição horizontal (Parrish et al., 1981; Bjorkstedt et al., 1997), concentração (de Lafontaine \& Gascon, 1989) e garantia de alimento (Neilson \& Perry, 1990), conservação de energia quando a intensidade de luz é baixa para a alimentação (Hunter \& Sanchez, 1976) e influência de fatores hidrográficos (Gray, 1996; Smith \& Suthers, 1999), como transporte (Grioche et al., 2000) e retenção (Stephenson \& Power, 1989).

Alterando sua posição vertical na coluna de água, a larva pode mudar tanto seu "ambiente imediato", como também sua posição geográfica, já que as interações entre a distribuição vertical e os processos físicos podem ter importantes efeitos na distribuição horizontal de organismos planctônicos. Ovos e larvas de peixes são altamente susceptíveis à dispersão quando concentrados na camada de mistura. Sendo assim, desova em águas profundas e migração 
vertical são mecanismos que, por exemplo, parecem reduzir a perda por advecção de ovos e larvas como sugerem Parrish et al. (1981) em estudo na região da corrente da Califórnia. Nesta mesma área, Peterson et al. (1979) observaram que o zooplâncton encontrado próximo à costa não se dispersa pelo movimento advectivo das águas superficiais durante a ressurgência devido ao fato destes organismos realizarem migração vertical.

O grau de migração e a amplitude de profundidade, na qual as espécies migram verticalmente, podem mudar durante a ontogenia. Em estudo sobre a distribuição vertical nas fases iniciais do ciclo de vida de Scomber scombrus (Scombridae), de Lafontaine \& Gascon (1989) observaram que os valores máximos de densidade de ovos ocorrem nos primeiros 3 metros da coluna de água e, logo após a eclosão, as larvas afundam, formando agregados entre 6 e 9 $\mathrm{m}$ de profundidade. Além disso, a proporção de larvas próximas à superfície aumenta conforme elas crescem, de modo que a maioria das larvas em estágios mais avançados do desenvolvimento foi coletada nos primeiros 3 metros. Brewer \& Kleppel (1986) verificaram, na região da Baía de Santa Mônica (Califórnia), que larvas recém eclodidas de Engraulis mordax (Engraulidae) são mais abundantes na superfície, enquanto larvas maiores ocorrem em maior abundância nos estratos mais profundos. Também foi observado que larvas de Genyonemus lineatus (Sciaenidae) com $2 \mathrm{~mm}$ de comprimento ocorreram em número moderado na superfície e estrato intermediário, enquanto larvas com mais de $3 \mathrm{~mm}$ ocorreram em maior freqüência próximas ao fundo.

Estes exemplos indicam que o conhecimento sobre os padrões de distribuição vertical de larvas de peixes marinhos é crucial não só para o entendimento dos processos ecológicos, mas também proporciona estimativas 
mais realistas da abundância do ictioplâncton, já que amostradores que integram toda coluna de água subestimam, por exemplo, grupos que vivem na camada superficial (Ahlstrom,1959; Kendall \& Naplin, 1981).

Na costa sudeste brasileira, poucos trabalhos contribuíram até o momento para o estudo da distribuição vertical do ictioplâncton. Katsuragawa \& Matsuura (1990) fizeram estudos comparativos entre coletas realizadas com rede de nêuston, que amostra somente os primeiros centímetros da camada superficial, e com rede bongô, que integra toda a coluna de água. Um resultado apresentado por estes autores é que as larvas das famílias Gerreidae e Blenniidae comportam-se mais como neustônicas facultativas, ou seja, concentram-se na superfície somente durante algumas horas do dia e, portanto, realizam migração vertical.

Em estudo realizado na plataforma interna da região de São Sebastião, Katsuragawa et al. (no prelo) observaram que o número de grupos taxonômicos do nêuston foi proporcionalmente menor em relação ao da coluna de água, durante dois cruzeiros realizados em fevereiro de 1994 e outubro de 1997. Além disso, nem sempre o táxon mais abundante na coluna de água foi o mais abundante no nêuston e vice-versa. Os Pleuronectiformes, por exemplo, foram importantes na coluna de água, porém sua presença no nêuston foi relativamente rara.

Um estudo sobre distribuição vertical de larvas de Engraulis anchoita até os 80 metros de profundidade foi realizado por Matsuura \& Kitahara (1995) na região do cabo de Santa Marta Grande (SC) na costa sudeste brasileira. As larvas de anchoíta em fases de pré-flexão e flexão foram mais abundantes na camada de mistura, enquanto que a maioria das larvas em pós-flexão e 
metamorfose foram encontradas próximas à termoclina, indicando que as anchoítas conseguem migrar mais profundamente conforme elas crescem e melhoram sua capacidade natatória.

Apesar do grande acúmulo de conhecimento existente sobre 0 ictioplâncton da costa sudeste e sul do Brasil, especialmente sobre a distribuição horizontal e abundância, pouco se sabe sobre a distribuição vertical de ovos e larvas. Deste modo, pretendeu-se, com este estudo, obter uma descrição da variação espaço-temporal do ictioplâncton em águas ao largo de Arraial do Cabo (RJ), principalmente em relação à distribuição vertical, integrando estes resultados aos processos de mesoescala observados. Sendo assim, espera-se contribuir para o conhecimento da ecologia das larvas e ovos de peixes, visto que, dentro da dinâmica do ecossistema da costa sudeste do Brasil, a intrusão ou recuo da ACAS, bem como os processos físicos de mesoescala, devem representar um impacto importante na distribuição e abundância do ictioplâncton, tanto horizontal como vertical. 


\section{OBJETIVOS}

\section{1 - OBJETIVO GERAL}

Descrever a distribuição espaço-temporal do ictioplâncton da região do cabo Frio $(\mathrm{RJ})$ em relação aos processos oceanográficos de mesoescala, com ênfase na distribuição vertical.

\section{2 - OBJETIVOS ESPECÍFICOS}

- descrever os processos físicos de mesoescala e o padrão de distribuição de clorofila-a observados na região em duas situações: verão e inverno de 2001;

- comparar a composição do ictioplâncton durante o verão e inverno de 2001;

- comparar a composição do ictioplâncton das águas neríticas e oceânicas;

- descrever a distribuição vertical de ovos e larvas de peixes ao largo do cabo Frio $(\mathrm{RJ})$, durante os dois períodos;

- estudar a distribuição vertical das larvas de peixes em função de classes de tamanho;

- interpretar os padrões de distribuição do ictioplâncton em função de processos hidrográficos e biológicos. 


\section{DESCRIÇÃO DA ÁREA DE ESTUDO}

A região de cabo Frio $(\mathrm{RJ})$ consiste em uma área de transição em relação às características da plataforma continental. Ao norte de cabo Frio (região leste da costa brasileira) a plataforma continental é estreita e a massa de água predominante é a Água Tropical, enquanto que ao sul, na costa sudeste, a plataforma é larga e formada por massas de água que resultam da mistura entre a Água Tropical (AT), quente e salina $\left(T>20^{\circ} \mathrm{C}\right.$ e $\left.\mathrm{S}>36,40\right)$, a Água Central do Atlântico Sul (ACAS), relativamente fria $\left(T<20^{\circ} \mathrm{C}\right.$ e $\left.\mathrm{S}<36,40\right)$, e a Água Costeira (AC), resultante da mistura da água doce continental e água da plataforma continental (Emílsson, 1961; Mascarenhas et al., 1971; Miranda, 1982; Castro Filho, 1996). Nas proximidades do cabo Frio a plataforma continental tem, aproximadamente, $50 \mathrm{~km}$ de extensão. A profundidade de quebra da plataforma continental sudeste varia entre 120 e $180 \mathrm{~m}$.

O domínio interno da plataforma continental sudeste é ocupado principalmente pela Água Costeira e tende a apresentar uma coluna de água verticalmente homogênea devido ao processo de mistura causado principalmente pelo vento. Seu limite externo é definido por uma frente térmica profunda que pode variar sazonalmente, estando mais próxima à costa no verão (entre 10 e $20 \mathrm{~km}$ ) e mais distante no inverno (entre 40 e $50 \mathrm{~km}$ ). A plataforma continental média apresenta uma estratificação de massas de água bem definida principalmente durante o verão, quando ocorre o desenvolvimento de uma termoclina sazonal, sendo a camada inferior preenchida principalmente pela ACAS. A plataforma continental externa, limitada por uma frente salina superficial localizada entre 80 e $120 \mathrm{~km}$ da costa e a quebra da plataforma, é ocupada por uma água altamente salina característica da AT na camada 
superficial, enquanto na camada inferior observa-se uma forte influência da ACAS (Castro \& Miranda, 1998). Acredita-se que esta intrusão da ACAS na plataforma continental sudeste está relacionada ao fenômeno da ressurgência em cabo Frio, à meandros e vórtices da corrente do Brasil e à mudanças no padrão de ventos.

A hidrologia na região de cabo Frio depende diretamente de condições meteorológicas, sendo que o padrão de ventos é o principal responsável pela distribuição das massas de água. Segundo Castro (1996), durante o verão, os ventos predominantes são paralelos à costa e provenientes de NE. Este vento causa um transporte em direção ao mar aberto, e se o vento persistir, ocorre abaixamento do nível do mar na costa causando uma força de gradiente de pressão em direção à costa que, em equilíbrio geostrófico com a força de Coriolis, resulta em correntes geostróficas paralelas à costa no mesmo sentido do vento. No inverno, os ventos de SW sopram com freqüência, causando transporte do mar aberto para a costa na camada superficial, e em direção ao mar aberto na camada subsuperficial, sendo que a inversão de gradiente de pressão normal à costa causa correntes de SW para NE.

As feições topográficas também influenciam o padrão de circulação e parecem participar diretamente da indução de vórtices na corrente do Brasil que, nesta região, flui para o sul, ocupando a parte externa da plataforma e região do talude continental. Quando a linha de costa muda de direção passando de NE para E-W em cabo Frio, a corrente do Brasil é forçada a girar ciclonicamente para o oeste, voltando a atingir a quebra da plataforma continental por volta de $24^{\circ} \mathrm{S}$. Após alcançar a região costeira, cruzando a plataforma externa quase perpendicularmente, a corrente do Brasil meandra em torno da quebra da 
plataforma (Mascarenhas et al., 1971; Valentin et al.,1987; Castro \& Miranda, 1998; Silveira et al., 2000).

O principal evento oceanográfico desta área é a ocorrência de uma ressurgência costeira, fenômeno no qual uma água profunda, fria e rica em nutrientes aflora à superfície. Um dos primeiros trabalhos realizados sobre a ressurgência de cabo Frio foi o de Allard (1955), que correlacionou os eventos de afloramento de águas frias com o vento predominante de leste. Emílsson (1956; 1961) descreveu o processo e atribuiu sua causa ao processo termohalino da região e Silva \& Rodrigues (1966) afirmaram que o fenômeno deve-se às mudanças na direção do vento predominante. Posteriormente, Mascarenhas et al. (1971) concluíram que a ressurgência é causada por uma interação entre vários fatores: mudanças no sistema de ventos, oscilação do eixo principal e força da corrente do Brasil e topografia do fundo.

$\mathrm{Na}$ região do cabo Frio a ressurgência ocorre com maior freqüência e intensidade durante o verão, quando predominam os ventos E-NE. Estes ventos arrastam a água superficial em direção ao mar aberto, proporcionando o afloramento da ACAS de uma profundidade de aproximadamente 300 metros. Esta massa de água atinge a superfície numa faixa costeira com até $5 \mathrm{~km}$ de largura, caracterizada por grande instabilidade hidrológica. Sobre a plataforma continental, a ressurgência é caracterizada pela inclinação da termoclina. A inversão dos ventos de NE para SO, decorrente da passagem de frentes frias, provoca o fenômeno inverso, chamado de subsidência, que inibe o afloramento da ACAS. Durante o inverno, com uma maior freqüência destas frentes frias, ocorre uma condição quase permanente de subsidência (Mascarenhas et al., 1971; Valentin et al., 1987). 
Os estudos preliminares sobre o zooplâncton na região de cabo Frio abordaram aspectos sobre a biologia, taxonomia, abundância e distribuição deste grupo. Valentin (1984) encontrou alta abundância de zooplâncton, com valores comparáveis aos observados em importantes áreas de ressurgência, e valores relativamente baixos de biomassa fitoplanctônica. O autor sugere que isso aconteça devido à ocorrência simultânea das comunidades de fitoplâncton e zooplâncton, induzindo um aumento na taxa de predação pelo zooplâncton herbívoro. Em outro trabalho na região do cabo Frio, Valentin e Monteiro-Ribas (1993) observaram valores altos de abundância de zooplâncton e baixa diversidade, mas estas características podem ser alteradas em função da influência da ACAS. Além disso, da costa em direção ao mar aberto ocorre um decréscimo de biomassa e aumento de diversidade. Já em relação ao ictioplâncton, os estudos realizados na região do cabo Frio provêm de trabalhos que amostraram a região sudeste como um todo, como por exemplo, Matsuura (1983), Katsuragawa (1985) e Spach (1990). 


\section{4 - METODOLOGIA}

O presente trabalho foi desenvolvido como parte do projeto DEPROAS (Dinâmica do Ecossistema de Plataforma da Região Oeste do Atlântico Sul), projeto multidisciplinar desenvolvido pelo IOUSP e financiado pelo PRONEX / CNPq / FINEP, que teve como objetivo geral o estudo dos mecanismos físicos que possibilitam a intrusão sazonal da ACAS na plataforma continental situada entre cabo de São Tomé e São Sebastião, e do impacto que essa penetração tem sobre os processos biológicos do ecossistema da região.

A amostragem foi realizada com o N/Oc. "Prof. W. Besnard", durante dois cruzeiros oceanográficos de mesoescala, em uma radial na região do cabo Frio, na costa sudeste brasileira (figura 1). As coletas foram realizadas entre os dias 7 e 13 de fevereiro de 2001 (verão) e entre 12 e 19 de julho de 2001 (inverno). A estratégia de amostragem adotada foi a de efetuar coletas em uma série espaço-temporal, sobre uma mesma radial. Neste estudo foram abordadas somente as estações que tiveram coleta estratificada do ictioplâncton, totalizando 19 estações no verão e 17 no inverno (Figura 1). Os dados de latitude, longitude, data de coleta, profundidade local, horário de início da estação e horário de lançamento da rede, referentes às estações realizadas estão nos apêndices 1 (verão) e 2 (inverno).

\section{1 - DADOS ABIÓTICOS}

Os dados hidrográficos foram coletados através de um CTD, aparelho que registra a condutividade, a temperatura e a profundidade, fornecendo perfis verticais contínuos destas propriedades. 
Para visualizar melhor a estrutura termohalina da coluna de água em cada estação, foram elaborados perfis de temperatura e salinidade em função da profundidade para os dois cruzeiros realizados.

Em conjunto com o Laboratório de Dinâmica Oceanográfica, a partir de diagramas T-S (obtidos com os dados do CTD), foram determinadas as distribuições percentuais de massa de água presentes na região durante o estudo. Na determinação das distribuições percentuais de Água Costeira, Água Tropical e Água Central do Atlântico Sul, foi empregada a análise percentual de massas de água. Esta metodologia fundamenta-se na aplicação do método clássico do triângulo de mistura a fim de estimar a contribuição relativa dos diferentes tipos de água na formação das características físicas das massas de água em estudo. A mistura das massas de água é representada no plano TS, por uma variação quase-linear dos pares $(T, S)$ amostrados entre dois outros pares extremos. Já a mistura entre três massas de água, superpostas verticalmente, conduz ao chamado triângulo de mistura, onde os pares extremos delimitam seus vértices. Portanto, conhecendo-se a temperatura T e a salinidade S e os índices termohalinos (ou pares extremos) $\left(T_{1}, S_{1}\right),\left(T_{2}, S_{2}\right)$ e $\left(T_{3}, S_{3}\right)$, é possível determinar as quantidades percentuais $m_{1}, m_{2}$ e $m_{3}$ destas massas através da resolução do seguinte sistema:

$$
\left\{\begin{array}{l}
m_{1} T_{1}+m_{2} T_{2}+m_{3} T_{3}=T \\
m_{1} S_{1}+m_{2} S_{2}+m_{3} S_{3}=S \\
m_{1}+m_{2}+m_{3}=1
\end{array}\right.
$$

Os indices termohalinos característicos da AC, AT, e ACAS são identificados diretamente dos diagramas T-S espalhados dos pontos amostrados 
nas duas campanhas oceanográficas. Pela fraca assinatura de AC no verão foi utilizado um índice já estabelecido em trabalhos anteriores (temperatura $28^{\circ} \mathrm{C} \mathrm{e}$ salinidade 34,3$)$.

\section{2 - CLOROFILA-a}

Com o sistema coletor de amostras d'água do tipo rosette foram coletados dados para a determinação das concentrações de clorofila a.

As análises de produção primária foram realizadas pelo Laboratório de Produtividade Primária. Para a determinação da concentração de clorofila foi utilizado o método fluorimétrico, após extração em $5 \mathrm{ml}$ de acetona a $-4^{\circ} \mathrm{C}$ por 12 horas. A metodologia detalhada encontra-se descrita por Kampel (2003).

Nas análises de comparação entre verão e inverno ou estações neríticas e oceânicas foram utilizados os dados das seguintes profundidades: $0,5,10,25$, 50, 75 e 100 metros. Nas análises multivariadas, para cada estrato foi atribuído um valor de concentração de clorofila. Quando, no mesmo estrato, mais de uma medida havia sido tomada, foi feito uma média destes valores.

\section{3 - VOLUME DE PLÂNCTON E ICTIOPLÂNCTON}

O ictioplâncton analisado neste estudo foi coletado com uma rede do tipo Mult-Plankton Sampler (denominada Multinet) com 5 redes de abertura e fechamento, que permite um arrasto horizontal estratificado da coluna de água. As redes da Multinet possuem malha $0,333 \mathrm{~mm}$ e boca de $0,25 \mathrm{~m}^{2}$. Na maioria das estações foram amostrados 5 estratos de $20 \mathrm{~m}$, desde os $100 \mathrm{~m}$ de

profundidade até a superfície. As amostras foram fixadas em solução neutralizada de formaldeído a 4\%. 
Foram utilizados fluxômetros nas bocas das redes para estimar o volume de água filtrado pela rede, visando a quantificação das amostras. O volume de água filtrado por cada rede foi obtido através da seguinte fórmula:

$$
\mathbf{V}=\mathbf{a} \cdot \mathbf{n} \cdot \mathbf{c},
$$

sendo $\mathrm{V}=$ volume de água filtrado pela rede $\left(\mathrm{m}^{3}\right)$;

$\mathrm{a}=$ área da boca da rede;

n = número de rotações do fluxômetro; e

c = taxa de calibração do fluxômetro.

O volume de plâncton coletado foi estimado pelo método de deslocamento de líqüidos, conforme o descrito por Kramer et al. (1972), no qual a amostra (plâncton e solução fixadora) é colocada em uma proveta e o volume é medido. Depois filtra-se o plâncton e mede-se o volume da solução. A diferença entre os dois volumes indica o biovolume de plâncton.

A triagem do ictioplâncton foi realizada, em placas de Petri sob estereomicroscópio, sendo os ovos e larvas contados e guardados em frascos separados.

O cálculo do número de ovos e larvas por $\mathrm{m}^{3}$ para cada amostra foi feito dividindo o número de larvas coletadas pelo volume de água filtrada pela rede.

Foi realizada a identificação das famílias de larvas de peixes baseada em bibliografia pertinente, como Fahay (1983), Leis \& Rennis (1983), Leis \& Trnski (1989) e Moser (1996). As larvas das famílias mais abundantes de cada cruzeiro foram identificadas até o menor nível taxonômico possível. Os exemplares que não puderam ser identificados foram incluídos na categoria NI (Não Identificado). 
Das espécies identificadas foram obtidos, com o auxílio de uma mesa digitalizadora, o comprimento das larvas. Nas larvas em estágio de pré-flexão ou flexão os comprimentos foram tomados da ponta do focinho à extremidade final da notocorda, e em larvas em pós-flexão, foi feita a medida do comprimento padrão.

Nas figuras de densidade, os valores de volume de plâncton, ovos e larvas de peixe por $\mathrm{m}^{3}$ foram multiplicados por 100 .

As estações consideradas neríticas são aquelas localizadas sobre a plataforma, com profundidades de até 200 metros (Mascarenhas et al., 1971). As estações oceânicas são as que possuem mais de 200 metros de profundidade.

A freqüência de ocorrência das famílias identificadas foi calculada a partir da fórmula de Guille (1970):

$$
F=(p i / p) \cdot 100
$$

sendo que "pi" é o número de estações de coleta onde a família "i" esteve presente e "p" o número total de estações de coleta.

\section{4 - ANÁLISE DOS DADOS}

A possível existência de diferenças nos valores de temperatura, salinidade e clorofila-a entre os cruzeiros de verão e inverno e entre as estações neríticas e oceânicas foram testadas realizando testes "t" (para variâncias iguais) e de Mann Whitney (para variâncias diferentes). A igualdade das variâncias foi verificada, a priori, com o teste "F" e quando o resultado indicava variâncias desiguais os dados foram transformados em raiz quadrada para novamente serem testados. 
Para testar as mesmas diferenças, mas em relação ao volume de plâncton, densidade de ovos e larvas de peixes e densidade de cada família e espécie identificada, também foram aplicados os testes " $t$ " e de Mann Whitney, porém a transformação utilizada foi log $x+1$. Também foi aplicado o teste "F" a fim de verificar a homogeneidade das variâncias.

Para verificar a existência de diferenças significativas na distribuição vertical de ovos e larvas de peixes ao largo do cabo Frio (RJ), e a variação sazonal desta distribuição, foram realizadas análises de variância não paramétrica (Kruskal Wallis). Quando foi detectada diferença significativa entre os dados testados aplicou-se o teste de Dunn, a posteriori, para identificar quais estratos diferiram entre si (Zar, 1996).

A distribuição vertical das larvas de peixes, em função das classes de comprimento, foi testada também através de análises de variância. Quando os dados apresentaram variâncias iguais, foi realizada ANOVA e, quando não, foi aplicado Kruskal-Wallis (Zar, 1996). Para verificar a diferença entre as estações neríticas e oceânicas, e diurnas e noturnas, em relação ao tamanho das larvas em cada estágio de desenvolvimento, foram aplicados teste t ou Mann-Whitney, dependendo da igualdade ou não entre as variâncias. Os limites de comprimento das fases de desenvolvimento larval (pré-flexão, flexão e pós-flexão) foram obtidos na literatura (Ahlstrom \& Moser, 1970; Fahay, 1984; Ribeiro, 1996) e não a partir da observação das larvas aqui estudadas.

Visando determinar quais das variáveis ambientais consideradas explicam melhor o padrão de distribuição e abundância dos grupos cuja freqüência de ocorrência foi superior a $30 \%$ e das espécies identificadas foi realizada uma análise de regressão múltipla (Valentin, 2000). 
Para ordenar as estações em função das variáveis abióticas foi aplicada a análise de componentes principais (ACP) utilizando os dados de profundidade local, temperatura, salinidade, porcentagem de Água Tropical, Água Costeira, Água Central do Atlântico Sul e concentração de clorofila. Os mesmos foram previamente padronizados, ou seja, centrados e reduzidos, visto que os intervalos de variação de cada parâmetro utilizado são muito diferentes entre si (Clarke \& Warwick, 1994).

Com o intuito de identificar padrões de associação das estações amostradas em função da abundância de larvas de peixe, foi utilizado o método de classificação TWINSPAN (two ways indicators species analyses) (Hills, 1979). Para realizar esta análise, os dados de abundância de larvas foram transformados em log $(X+1)$ para normalizar a distribuição de freqüências (Zar, 1996). Foram incluídas nesta análise somente as famílias que apresentaram freqüência de ocorrência maior ou igual a 30\%, visando diminuir o "ruído" causado pela ocorrência de famílias raras.

Com o intuito de verificar a existência de diferenças significativas na composição da fauna dos três grupos obtidos na ACP, foi realizada uma análise de similaridade (ANOSIM). Esta análise é análoga à ANOVA, mas não paramétrica, que pode ser aplicada às matrizes de dados biológicos com grande número de zeros (Clarke \& Warwick, 1994). A ANOSIM testa a hipótese de que não existem diferenças entre os grupos de amostras, partindo de uma matriz de similaridade construída a partir dos valores de abundância das famílias nas estações de coleta. A cada amostra coletada foi atribuído um fator em função do grupo formado na ACP. 
A avaliação da influência dos fatores ambientais sobre a distribuição das larvas foi feita através da análise BIOENV (Clarke \& Warwick, 1994), que consiste em cruzar a matriz de distância construída a partir dos dados abióticos e a matriz de similaridade construída com os dados biológicos. Todas as combinações possíveis entre as variáveis ambientais são testadas, a fim de que se possa estimar qual é a variável ou o conjunto de variáveis ambientais que explica melhor o padrão biológico observado. 


\section{5 - RESULTADOS}

\section{1 - DADOS ABIÓTICOS}

Os valores de temperatura média, desvio padrão e valores mínimos e máximos para cada estrato amostrado estão nas tabelas 1 e 2, referentes, respectivamente, aos cruzeiros de verão e inverno.

No verão, entre 0 e 100 metros de profundidade, a temperatura média foi $21,11 \pm 3,41^{\circ} \mathrm{C}$ variando entre 13,87 e $27,67^{\circ} \mathrm{C}$. Já no inverno, a temperatura

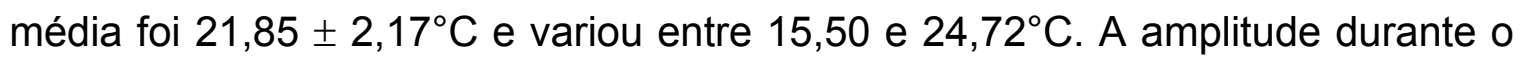
verão $\left(13,8^{\circ} \mathrm{C}\right)$ foi maior que no inverno $\left(9,22^{\circ} \mathrm{C}\right)$. Considerando as médias de todos os estratos amostrados (ou seja, a coluna de água integrada) não houve diferença significativa entre os dois cruzeiros. Porém, ao verificar a diferença sazonal entre as médias de cada estrato em separado, houve diferença significativa nos estratos de 0 a $20 \mathrm{~m}$ de profundidade $(U=60 ; p=0,0007)$ e de 80 a 100 metros (teste $t ; p=0,04$ ).

A figura 2 apresenta o perfil de temperatura para cada radial do cruzeiro de verão. A temperatura na camada superficial variou entre $15^{\circ} \mathrm{C}$, aproximadamente, e $28^{\circ} \mathrm{C}$. Na camada de 0 a 60 metros, até $40 \mathrm{~km}$ de distância da costa, a área foi ocupada por águas mais frias, com temperaturas menores de $20^{\circ} \mathrm{C}$, sendo que as estações mais afastadas da costa apresentaram temperaturas maiores de $20^{\circ} \mathrm{C}$. Entre 60 e 100 metros de profundidade, a maior parte da área foi ocupada por águas com temperaturas menores de $20^{\circ} \mathrm{C}$. Principalmente nas radiais 3 e 4 do cruzeiro de verão (Fig. 2) pôde-se observar uma frente térmica superficial na região nerítica.

Os perfis de temperatura das radiais do cruzeiro de inverno estão na figura 3. No inverno a temperatura superficial se manteve, aproximadamente, 
entre 22 e $25^{\circ} \mathrm{C}$. A coluna de água entre 0 e 60 metros apresentou-se mais homogênea em relação à temperatura do que no cruzeiro de verão, sendo os valores maiores do que $20^{\circ} \mathrm{C}$. Dos 60 aos 80 metros de profundidade, a maior parte da área também foi preenchida por águas de temperaturas maiores de $20^{\circ} \mathrm{C}$, e entre 80 e 100 metros, apenas as estações neríticas apresentaram águas frias, com menos de $20^{\circ} \mathrm{C}$, próximas ao fundo.

As tabelas 3 e 4 apresentam os valores de salinidade média, desvio padrão e os valores mínimos e máximos para cada estrato amostrado referentes, respectivamente, aos cruzeiros de verão e inverno. A média de todos os estratos foi $36,48 \pm 0,51$ no verão e $36,40 \pm 0,46$ no inverno. Durante o verão a salinidade variou entre 35,33 e 37,24 e, no inverno, entre 35,36 e 37,16. Não houve diferença entre as médias de salinidade dos dois cruzeiros, tanto considerando todos os estratos juntos, como para cada estrato em separado. As amplitudes no período de verão e de inverno foram, respectivamente, 1,91 e 1,80.

Os perfis de salinidade (Fig. 4) das radiais percorridas durante o verão mostram que as águas superficiais e mais distantes da costa (mais de $40 \mathrm{~km}$ ) apresentaram os maiores valores. Águas próximas ao fundo e ressurgidas rente à costa apresentaram salinidade menor do que 36 .

Já no inverno nota-se, na seqüência das radiais, um domo de água mais salina se afastando da plataforma (Fig. 5). Somente próximo ao fundo ou em profundidades maiores do que 100 metros as águas tiveram valores de salinidade menores do que 36 .

Os perfis verticais de temperatura e salinidade de cada radial percorrida durante o cruzeiro de verão (Figs 2 e 4, respectivamente) mostram que ocorreu uma frente de ressurgência na região costeira. As radiais 1, 2, 3 e 4, realizadas 
em uma seqüência temporal, evidenciam o afloramento da massa de água com temperaturas menores do que $18^{\circ} \mathrm{C}$ e valores de salinidade inferiores a 36 , características típicas da ACAS, chegando a atingir a superfície. Além disso, pode-se observar a extrusão de águas com temperaturas maiores do que $24^{\circ} \mathrm{C}$ em direção ao mar aberto, indicando afastamento de águas superficiais costeiras e, conseqüente, ressurgência.

Já os perfis verticais de temperatura (Fig. 3) e salinidade (Fig. 5) do cruzeiro de inverno indicam o processo de subsidência, evidenciado pela intrusão na região costeira de águas com temperaturas maiores que $22^{\circ} \mathrm{C} e$ salinidades superiores a 36, características da Água Tropical.

Os diagramas T-S de cada cruzeiro realizado estão apresentados na figura 6. As massas de água presentes no verão (Fig. 6a) foram a AT e a ACAS. Os pontos acima do triângulo podem indicar a assinatura da AT nas estações mais oceânicas, que possuem temperatura mais elevada. Os índices termohalinos da AT foram $23^{\circ} \mathrm{C}$ e 37,3 , da ACAS $13^{\circ} \mathrm{C}$ e 35,2 e, por último, a AC que, como já dito na metodologia, devido à sua fraca assinatura na região durante este período, teve seu índice termohalino estabelecido em $28^{\circ} \mathrm{C}$ e 34,3 . No inverno (Fig. 6b) ocorreram três massas de água (AC, AT e ACAS), sendo que os índices termohalinos da AT e ACAS foram os mesmos do verão e a AC apresentou $22,1^{\circ} \mathrm{C}$ de temperatura e 35,0 de salinidade.

A descrição das características oceanográficas baseadas nos perfis apresentados anteriormente foi reforçada pela análise de distribuição percentual de massas de água apresentada nas figuras 7 (verão) e 8 (inverno). No verão, a ACAS move-se em direção à superfície, atingindo-a na radial 3. Além disso, a Água Tropical é empurrada em direção ao mar aberto nas camadas superficiais 
(radiais 3 e 4), evidenciando a ressurgência costeira. Já no inverno, com o processo de subsidência da ACAS, a Água Tropical é deslocada em direção à costa e a camada superficial das estações mais costeiras é preenchida por alta porcentagem da Água Costeira.

\section{2 - CLOROFILA-a}

Os valores de clorofila-a durante o verão (Fig. 9) variaram, entre os estratos de 0 a 100 metros, de 0 a $1,58 \mathrm{mg} \cdot \mathrm{m}^{-3}$, e no inverno (Fig. 10) entre 0,05 a $1,79 \mathrm{mg} \cdot \mathrm{m}^{-3}$.

As concentrações de clorofila-a não apresentaram diferença significativa entre o verão e o inverno nos estratos de 0 a 100 metros, porém, ao analisar cada estrato em separado, os estratos de 60 a 80 metros apresentaram diferença significativa, sendo maiores os valores no verão $(U=56 ; p=0,0024)$. Tanto as estações neríticas, analisadas separadamente, como as oceânicas não apresentaram diferença significativa entre os dois períodos.

Em relação à distribuição vertical houve diferença significativa entre os estratos, tanto no verão $(H=17,28 ; p=0,0017)$ como no inverno $(H=43,45$; p<0,0001). No verão (Fig. 9) os valores do estrato de 0 a 20 foram maiores que os de 40 a 80 metros. No inverno os estratos de 40 a 60, de 60 a 80 e de 80 a 100 metros não foram agrupados pelo teste de Dunn, sendo as médias de clorofila-a decrescentes a partir do estrato de 40 a 60 metros (Fig. 10).

Em relação à distância da costa, tanto no verão (Fig. 9) como no inverno (Fig. 10), os maiores valores foram aqueles das estações costeiras (teste t; $p<0,0001$ e $U=1475 ; p<0,0001$, respectivamente).

\section{3 - VOLUME DE PLÂNCTON}


Analisando-se o volume de plâncton $\left(\mathrm{ml} \cdot \mathrm{m}^{3}\right)$ por estação e por estrato (Tabs 5 e 6; Figs 11 e 12) podemos notar, de um modo geral, valores mais elevados no verão em relação ao inverno $(U=1670 ; p=0,0001)$. No verão a média de volume de plâncton coletado foi $0,50 \pm 0,73 \mathrm{ml} \cdot \mathrm{m}^{-3}$, variando entre 0,02 e $3,81 \mathrm{ml} \cdot \mathrm{m}^{-3}$. Já no inverno a média obtida foi $0,14 \pm 0,22 \mathrm{ml} \cdot \mathrm{m}^{-3}$, sendo o valor mínimo 0,00 e o máximo $1,32 \mathrm{ml} \cdot \mathrm{m}^{-3}$. Se cada estrato for analisado separadamente, os estratos de 0 a 20 e de 20 a 40 metros não apresentaram diferença significativa entre os dois períodos. Tanto as estações costeiras como as oceânicas apresentaram maiores valores de volume de plâncton no verão $(U=680,5 ; p=0,0001$ e $U=206 ; p=0,0005)$.

O padrão de distribuição vertical foi diferente em cada período. No verão o maior valor foi observado entre 20 e 40 metros (média $=0,68 \mathrm{ml} \cdot \mathrm{m}^{-3}$; d.p. $=0,94$ ), seguido pelos estratos de 40 a 60 metros (média $=0,67 \mathrm{ml} \cdot \mathrm{m}^{-3}$; d.p. $=0,93$ ) e de 60 a 80 metros (média $=0,51 \mathrm{ml} \cdot \mathrm{m}^{-3} ;$ d.p. $=0,77$ ). A camada de 0 a 20 metros apresentou um valor médio menor (média $=0,48 \mathrm{ml} \cdot \mathrm{m}^{-3}$; d.p. $=0,51)$ em relação às três camadas anteriores. A camada mais profunda $(80 \mathrm{a}$ 100 metros) revelou-se a mais pobre com média igual a $0,16 \mathrm{ml} \cdot \mathrm{m}^{-3}$ e desvio padrão 0,17 . Estatisticamente não houve diferença significativa entre os estratos durante o verão. No inverno observou-se o maior valor na camada superficial (média $=0,33 \mathrm{ml} \cdot \mathrm{m}^{-3} ;$ d.p. $=0,38$ ) e diminuindo em direção ao fundo, conforme os seguintes valores médios: $0,18 \mathrm{ml} \cdot \mathrm{m}^{-3}(\mathrm{~d} . \mathrm{p.}=0,12)$ de 20 a 40 metros, $0,08 \mathrm{ml} \cdot \mathrm{m}^{-3}$ (d.p. $\left.=0,05\right)$ de 40 a 60 metros, $0,04 \mathrm{ml} \cdot \mathrm{m}^{-3}$ (d.p. $=$ 0,02 ) de 60 a 80 metros e $0,03 \mathrm{ml} \cdot \mathrm{m}^{-3}$ (d.p. $=0,03$ ) de 80 a 100 metros, o que foi confirmado pelo teste estatístico $(H=43,36 ; p=0,0001)$, sendo significativas as diferenças entre os estratos de 0 a 40 e de 60 a 100 metros. 
As estações mais próximas à costa apresentaram maior volume de plâncton tanto no cruzeiro de verão $(U=263 ; p=0,0001)$, como no de inverno $(U=4811 ; p=0,0006)$.

Em relação à distribuição percentual de massas de água, os maiores valores de volume de plâncton, durante o verão (Fig. 11), aparentemente, estiveram associados às zonas de mistura com predominância da AT, em estações mais neríticas. Durante o inverno (Fig. 12) os maiores volumes de plâncton também estiveram em estações costeiras, porém associados à AC.

\section{4 - ICTIOPLÂNCTON}

\section{4 .1 - OVOS}

No verão a abundância média de ovos foi $12,43 \pm 111,72$ ovos $\cdot \mathrm{m}^{-3}$, variando entre 0 e 1036,37 ovos $\cdot \mathrm{m}^{-3}$ (Tab. 7). Já no inverno a média obtida foi 0,35 \pm 0,63 ovos $\cdot \mathrm{m}^{-3}$, sendo 0 o valor mínimo e 4,36 o valor máximo (Tab. 8). Mesmo sendo observado um valor de abundância extraordinariamente alta no cruzeiro de verão $\left(1036,37\right.$ ovos $\left.\cdot \mathrm{m}^{3}\right)$, não houve diferença significativa entre as duas épocas, nem para a coluna de água, nem para cada estrato analisado separadamente (Figs 13 e 14). Considerando somente as estações neríticas ou as oceânicas também não houve diferença sazonal entre as densidades de ovos.

No verão, devido ao valor excepcional encontrado na camada de 20 a 40 metros, esta se apresentou como a de maior abundância média (54,84 ovos $\cdot \mathrm{m}^{3}$; d.p. $=237,69)$ seguida pela camada de 0 a 20 metros $\left(0,92\right.$ ovos $\cdot \mathrm{m}^{3} ;$ d.p. $\left.=1,96\right)$. Nas demais camadas ocorreram em ordem decrescente: 0,23 ovos $\cdot \mathrm{m}^{3}$ (d.p. $=$ 0,30 ) de 40 a 60 metros, 0,22 ovos $\cdot \mathrm{m}^{3}$ (d.p. $=0,20$ ) de 60 a 80 metros, e 0,18 ovos $\cdot \mathrm{m}^{3}$ (d.p. $\left.=0,16\right)$ de 80 a 100 metros. No inverno o valor de densidade média 
foi mais elevado no estrato de 0 a 20 metros $\left(0,54\right.$ ovos $\cdot \mathrm{m}^{3}$; d.p. $\left.=0,99\right)$, ocorrendo gradual diminuição em direção ao fundo, com as seguintes médias: 0,49 ovos $\cdot \mathrm{m}^{3}$ (d.p. $\left.=0,81\right)$ de 20 a 40 metros, 0,27 ovos $\cdot \mathrm{m}^{3}($ d.p. $=0,21)$ de 40 a 60 metros, 0,22 ovos $\cdot \mathrm{m}^{3}$ (d.p. $\left.=0,20\right)$ de 60 a 80 metros, e 0,21 ovos $\cdot \mathrm{m}^{3}$ (d.p. $=$ 0,45) de 80 a 100 metros. Estatisticamente, em relação à distribuição vertical, no verão (Fig. 13) a abundância foi significantemente maior nos primeiros $20 \mathrm{~m}$ da coluna de água em relação aos estratos de 40 a 100 metros $(H=10,32 ; p=$ $0,0353)$, apesar de valores relativamente altos terem ocorrido em camadas mais profundas. Já no inverno (Fig. 14) os estratos não apresentaram diferença significativa em relação à abundância de ovos.

Em relação à distância da costa, as estações neríticas apresentaram maiores valores de densidades de ovos do que as oceânicas $(U=419 ; p=0,0011$ no verão; $U=545,5 ; p=0,0046$ no inverno) (Figs 13 e 14).

As figuras 13 e 14 representam a abundância de ovos em função da distribuição percentual de massas de água, respectivamente, para o verão e inverno. Com base nas figuras, observa-se que as maiores concentrações ocorreram principalmente associadas à $\mathrm{AT}$, no verão, e à $\mathrm{AT}$ e $\mathrm{AC}$, no inverno.

\subsection{2 - LARVAS}

Embora estatisticamente não se tenha constatado diferença significativa na abundância total de larvas entre o verão e o inverno, tanto na coluna de água como em cada estrato amostrado, observa-se que os valores de abundância do verão (Tab. 9) foram ligeiramente mais elevados em relação aos do inverno (Tab. 10). A média da abundância de todos os estratos foi $1,13 \pm 3,1$ larvas $\cdot \mathrm{m}^{-3}$ no verão e $0,62 \pm 0,68$ larvas $\cdot \mathrm{m}^{-3}$ no inverno. No verão os valores variaram entre 0 e 22,73 larvas $\cdot \mathrm{m}^{-3}$ e no inverno entre 0 e 3,49 larvas $\cdot \mathrm{m}^{-3}$. Analisando somente 
as estações costeiras ou somente as oceânicas, as análises indicaram que também não houve diferenças significativas entre os cruzeiros de verão (Fig. 15) e de inverno (Fig. 16).

Em relação à distribuição vertical da abundância de larvas de peixes durante o cruzeiro de verão, o maior valor foi o da camada entre 0 e 20 metros (média $=2,02$ larvas $\cdot \mathrm{m}^{-3} ;$ d.p. $=5,08$ ), diminuindo gradualmente até a última camada. A média da abundância de larvas entre 20 e 40 metros foi 1,68 larvas $\cdot m^{-3}$ (d.p. $\left.=3,97\right)$, entre 40 e 60 foi 0,89 larvas $\cdot m^{-3}$ (d.p. $\left.=1,18\right)$, entre 60 e 80 metros a média foi 0,43 larvas $\cdot \mathrm{m}^{-3}($ d.p. $=0,20)$ e, por último, entre 80 e 100 metros foi 0,35 larvas $\cdot \mathrm{m}^{-3}$ (d.p. $\left.=0,35\right)$. No inverno, o estrato de maior abundância média foi o de 20 a 40 metros $\left(1,19\right.$ larvas $\cdot \mathrm{m}^{-3}$; d.p. $\left.=0,82\right)$, seguido do estrato de 0 a 20 metros $\left(0,93\right.$ larvas $\cdot m^{-3}$; d.p. $\left.=0,83\right)$, de 40 a 60 metros $\left(0,42\right.$ larvas $\cdot m^{-3} ;$ d.p. $\left.=0,27\right)$, de 60 a 80 metros $\left(0,26\right.$ larvas $\cdot m^{-3} ;$ d.p. $\left.=0,22\right)$. Por último, a camada de menor abundância média de larvas foi o de 80 a 100 metros, com média igual a 0,17 larvas $\cdot \mathrm{m}^{-3}$ e desvio padrão 0,16 . Estatisticamente, em relação à distribuição vertical, as larvas foram mais abundantes nos primeiros 60 metros no verão $(H=10,6651 ; p=0,0306)$ e, no inverno, nos primeiros 40 metros $(H=38,88 ; p=0,001)$ (Figs 15 e 16).

Em relação à distância da costa, não houve diferença significativa entre as abundâncias das estações neríticas e oceânicas tanto no verão como no inverno (Figs 15 e 16).

As figuras 15 e 16 representam a abundância e a distribuição de larvas coletadas no verão e inverno, respectivamente, em relação à distribuição percentual de massas de água. Nota-se que as maiores concentrações de larvas 
ocorreram associadas principalmente à AT, ocorrendo também concentrações elevadas na AC.

As larvas identificadas estão distribuídas em 17 ordens e 61 famílias (Nelson, 1994), sendo que algumas larvas foram identificadas somente até o nível de ordem (Apêndice 3).

Os grupos comuns aos dois períodos foram Anguilliformes, Argentinidae, Blenniidae, Bothidae, Bregmacerotidae, Callionymidae, Carangidae, Clupeidae, Cynoglossidae, Engraulidae, Gobiidae, Gonostomatidae, Labridae, Lophiidae, Melamphaidae, Mullidae, Myctophidae, Ophidiidae, Paralepididae, Paralichthyidae, Phosichthyidae, Pleuronectiformes, Pomacanthidae, Scaridae, Sciaenidae, Scombridae, Scopelarchidae, Scorpaenidae, Serranidae, Sternoptychidae, Stomiidae, Synodontidae, Tetraodontidae, Trichiuridae e Triglidae (Tab. 11).

As seguintes famílias ocorreram exclusivamente no verão: Balistidae, Carapidae, Dactylopteridae, Echeneidae, Fistularidae, Gempylidae, Gerreidae, Holocentridae, Lutjanidae, Malacanthidae, Monacanthidae, Moridae, Ostracidae, Pinguipedidae, Priacanthidae, Sparidae, Stromateidae e Uranoscopidae (Tab. 11).

No inverno as famílias exclusivas foram: Acanthuridae, Acropomatidae, Chaetodontidae, Hemiramphidae, Macrouridae, Mugilidae, Nomeidae, Notosudidae, Phycidae e Syngnathidae (Tab. 11).

A figura 17 indica a freqüência relativa dos grupos taxonômicos que apresentaram freqüência de ocorrência igual ou maior de $50 \%$ e freqüência relativa de no mínimo $3 \%$ em pelo menos um dos cruzeiros. Os grupos mais abundantes no verão (Tab. 11) foram Engraulidae (35,67\%), Myctophidae 
$(14,33 \%)$, Sternoptychidae $(8,33 \%)$ e Scombridae $(4,45 \%)$. Neste cruzeiro $19,19 \%$ das larvas não foram identificadas. As famílias mais abundantes no inverno (Tab. 11) foram Engraulidae (18,82\%), Myctophidae (12,91\%), Bregmacerotidae (11,75\%) e Sternoptychidae (8,86\%). As larvas não identificadas totalizaram $17,54 \%$.

\subsubsection{1 - FAMÍLIA ENGRAULIDAE}

A família Engraulidae apresentou a maior freqüência relativa (Tab. 11) durante os cruzeiros de verão e inverno, representando, respectivamente, 35,67 e $18,82 \%$ do total de larvas coletadas. A freqüência de ocorrência no verão foi $42,1 \%$ e no inverno $50 \%$ (Tab. 11). Todos os exemplares coletados nos cruzeiros de verão e inverno foram identificados como Engraulis anchoita.

\subsubsection{1.a - Engraulis anchoita}

Não houve diferença significativa entre os dois períodos em relação à abundância desta espécie, tanto na coluna de água integrada, como em cada estrato amostrado. No verão, a alta freqüência relativa obtida foi devido a grande abundância de larvas em uma estação da radial 4 (Fig. 18), sendo que a maioria das ocorrências em menor densidade da espécie foi em estações mais próximas à costa. No inverno (Fig. 19) houve um maior número de arrastos positivos para esta espécie do que no verão. Considerando somente as estações neríticas, houve diferença entre o verão e inverno $(U=356 ; p=0,029)$, sendo maiores os valores de abundância durante o verão. As estações oceânicas, no entanto, não apresentaram diferença significativa entre os dois cruzeiros em relação à abundância de larvas.

Em relação à distribuição vertical de larvas de anchoíta, no verão não houve diferença nos valores de abundância entre os estratos amostrados. Já no 
inverno os estratos de 0 a 40 metros apresentaram maior abundância do que os de 40 a 80 metros $(H=9,49 ; p=0,04)$. Em nenhum dos cruzeiros foram coletadas larvas de engraulídeos entre 80 e 100 metros de profundidade (Tab. 14 e 15; Figs 18 e 19).

A diferença entre as abundâncias de engraulídeos das estações neríticas e oceânicas foi significativa no verão $(U=563 ; p=0,0032)$. No inverno, as estações com maiores concentrações de larvas de $E$. anchoita ocorreram mais próximas à costa, o que foi confirmado pelo teste de Mann Whitney $(\mathrm{U}=$ $331 ; p=0,0001)$.

Em relação à distribuição percentual de massas de água, no verão (Fig. 18) as larvas de anchoita, apesar da baixa ocorrência, estiveram presentes em regiões de mistura, fato evidenciado pela regressão múltipla realizada (Tab. 12), onde a relação com a porcentagem de AT foi negativa. No inverno (Fig. 19) ocorreram na AC e principalmente em zonas de mistura entre a AC e a AT.

As medidas de comprimento de 1333 larvas de Engraulis anchoita foram tomadas, o que equivale a $78 \%$ das larvas. Não foram medidas aquelas deterioradas ou quando, devido ao tamanho, não foi possível a visualização da notocorda.

A figura 20 indica a freqüência percentual das classes de comprimento das larvas de anchoíta $(n=1041)$ coletadas durante o verão. Os valores variaram entre as classes de comprimento 1 e $16 \mathrm{~mm}$, sendo que a grande maioria foram larvas das classes 2 e $3 \mathrm{~mm}$. Além disso, nota-se que as larvas destas classes de comprimento se concentraram nos primeiros 40 metros de profundidade, sendo que as larvas da classe de $3 \mathrm{~mm}$ também foram freqüentes no estrato de 40 a 60 metros. Durante o verão, a diferença do 
comprimento das larvas nos diferentes estratos amostrados foi significativa $(H=82,05 ; p=0,0001)$. Pelo método de Dunn as larvas do estrato entre 40 e 60 metros foram maiores do que as de 0 a 20 e 20 a 40 metros de profundidade.

Analisando somente as estações costeiras do verão (Fig. 21), foi observado que a grande maioria das larvas ocorreu nos dois primeiros estratos amostrados da coluna de água (0 a 40 metros), e possuíam medidas menores do que $8,00 \mathrm{~mm}$ de comprimento da notocorda. Entre 40 e 60 metros de profundidade ocorreram $13 \%$ das larvas menores de $8,00 \mathrm{~mm}$, sendo que apenas $1 \%$ foi coletada dos 60 aos 80 metros. As larvas com comprimento entre 8,00 e 12,99 $\mathrm{mm}$ foram coletadas entre 0 e 60 metros de profundidade, somando, nos 3 estratos, apenas $2,5 \%$ do total de larvas medidas. Apenas $0,2 \%$ das larvas apresentou comprimento maior do que $13,00 \mathrm{~mm}$, sendo a ocorrência restrita aos primeiros 20 metros da coluna de água. Em relação aos comprimentos das larvas, houve diferença significativa entre os estratos nas estações neríticas $(H=82,35 ; p=0,0001)$, sendo que as menores larvas ocorreram nos dois estratos superiores da coluna de água. Somente uma larva coletada em estações oceânicas foi medida $(5,8 \mathrm{~mm})$, sendo que ela ocorreu no estrato de 60 a 80 metros.

Em relação às estações diurnas e noturnas (Fig. 22), pôde-se observar que, no período noturno, a porcentagem de larvas menores de $8,00 \mathrm{~mm}$, em comparação ao período diurno, foi maior no estrato de 0 a 20 metros de profundidade, manteve-se aproximadamente igual no estrato de 20 a 40 metros, e menor no de 40 a 60 metros. Nas estações diurnas a maior porcentagem de larvas menores de $8 \mathrm{~mm}$ ocorreu de 20 a 40 metros. Já as larvas maiores de $8,00 \mathrm{~mm}$ apresentaram menores porcentagens nas estações 
noturnas do que nas diurnas, entre 0 e 20 metros. Não houve diferença significativa entre as diferentes profundidades de coleta em relação ao comprimento das larvas $(H=1,26 ; p=0,5319)$ durante as estações realizadas durante o período diurno. Considerando apenas as estações noturnas, a diferença entre os estratos em relação ao comprimento das larvas foi significativa $(H=81,89 ; p=0,0001)$, sendo maiores as larvas no estrato de 40 a 60 metros.

No cruzeiro de inverno as larvas de anchoita medidas $(n=291)$ variaram entre as classes de comprimento 2 e $16 \mathrm{~mm}$, sendo que a grande maioria das larvas pertenceu às classes de comprimento de 2 a $10 \mathrm{~mm}$, na camada de 0 a 20 metros, e nas classes de comprimento de 2 a $8 \mathrm{~mm}$, entre 20 e 40 metros de profundidade (Fig. 23). Em relação ao comprimento das larvas, não houve diferença significativa entre os estratos verticais no inverno. Quando comparandas com as larvas coletadas no cruzeiro de verão (Fig. 20), pôde-se notar que as de inverno apresentaram maior freqüência nas classes de comprimento de 4 a $10 \mathrm{~mm}$. Em todos os estratos, exceto de 60 a 80 metros, foram encontradas larvas de anchoita de maiores tamanhos no inverno, se comparadas com as de verão ( 0 a 20 metros: $U=10263,50 ; p=0,0001 ; 20$ a 40 metros: $U=6257 ; p=0,0001$ e 40 a 60 metros: teste $t ; p=0,007)$.

A figura 24 indica a freqüência porcentual de larvas de anchoita coletadas nas estações neríticas e oceânicas, em função da profundidade dos arrastos no inverno. As larvas das estações neríticas $(n=215)$, em sua maioria, tinham menos de $8,00 \mathrm{~mm}$ e se distribuíram preferencialmente nos 2 primeiros estratos da coluna de água. Já nas estações oceânicas $(n=76)$ a grande maioria das larvas ocorreu de 0 a 20 metros de profundidade, sendo $45 \%$ com 
comprimentos menores de $8,00 \mathrm{~mm}$ e $38 \%$ entre 8,00 e $12,99 \mathrm{~mm}$. No estrato de 20 a 40 metros ocorreu menor freqüência de larvas com menos de 8,00 mm (8\%) em relação ao estrato superior. Tanto nas estações neríticas como nas oceânicas, não houve diferença significativa entre os estratos em relação ao comprimento das larvas.

Em relação às estações realizadas no cruzeiro de inverno, tanto durante o período diurno como no noturno (Fig. 25), nota-se que a maior parte das larvas menores de $8,00 \mathrm{~mm}$ ocorreu no estrato de 0 a 20 metros. Larvas entre 8,00 e 12,99 mm de comprimento também ocorreram em maior freqüência nos primeiros 20 metros da coluna de água e larvas maiores de $13,00 \mathrm{~mm}$ só ocorreram em estações realizadas durante a noite, entre 0 e 40 metros de profundidade. Entre 40 e 80 metros, nas estações diurnas, e entre 40 e 60 nas estações noturnas, apenas ocorreram baixas freqüências de larvas menores de $8,00 \mathrm{~mm}$. Entre 60 e 80 metros, nas estações noturnas, ocorreram baixa freqüência de larvas entre 8,00 e 12,99 mm de comprimento. Em relação ao comprimento das larvas, não houve diferença significativa entre os estratos verticais nas estações diurnas ou noturnas.

\subsubsection{2 - FAMÍLIA MYCTOPHIDAE}

A família Myctophidae constituiu 14,33\% e 12,91\% do total de larvas coletadas durante o verão e inverno, respectivamente (Tab. 11). Nos dois cruzeiros foi a segunda família mais abundante, com freqüência de ocorrência de 78,9\% no verão e $88,9 \%$ no inverno (Tab. 11 ).

Considerando a abundância das larvas de Myctophidae, quando foi considerada a coluna de água integrada, o valor foi maior no verão (Figs 26 e 27). Porém, quando foram testados os estratos separados, apenas o estrato de 
40 a 60 metros apresentou diferença significativa entre o verão e inverno $(U=50$; $p=0,0012$ ). Não houve diferença sazonal entre as estações neríticas, quando consideradas separadamente, nem entre as oceânicas.

Tanto no verão como no inverno houve diferenças significativas entre os diferentes estratos da coluna de água $(H=23,1 ; p=0,0001$, para o verão e $H=$ 18,9; $p=0,0008$, para o inverno). No verão as maiores abundâncias ocorreram entre 0 e 80 metros da coluna de água (Fig. 26), e no inverno entre 0 e 40 metros (Fig. 27) (Tabs 16 e 17).

No verão não houve diferença significativa entre as estações neríticas e oceânicas (Fig. 26). Já no inverno (Fig. 27) as estações oceânicas apresentaram maior abundância do que as estações costeiras $(U=535,5 ; p=0,0137)$.

Em relação à distribuição porcentual das massas de água (Figs 26 e 27, respectivamente para o verão e inverno) a família ocorreu principalmente associada à AT apesar de, na regressão múltipla (Tab. 12), sua ocorrência estar associada às três massas de água. No inverno, onde áreas de mistura das diferentes massas de água são extensas, a regressão múltipla (Tab. 13) não evidenciou nenhuma associação entre estas e a ocorrência de Myctophidae.

\subsubsection{3 - FAMÍLIA STERNOPTYCHIDAE}

Sternoptychidae foi a terceira família mais abundante no cruzeiro de verão e a quarta no de inverno. A freqüência relativa e de ocorrência durante o verão foram 8,33 e 78,9 \%, respectivamente. Já no inverno a freqüência relativa foi $8,86 \%$ e a de ocorrência $83,3 \%$ (Tab. 11).

A abundância de larvas da família Sternoptychidae não apresentou diferença significativa entre os cruzeiros de verão e inverno, nem para coluna de água integrada até os 100 metros de profundidade, nem para cada estrato 
amostrado (Figs 28 e 29) (Tabs 18 e 19). Tanto as estações oceânicas como as neríticas, analisadas separadamente, não apresentaram diferenças entre verão e inverno.

No verão (Fig. 28) houve diferença significativa $(H=30,53 ; p=0,0001)$ entre os diferentes estratos amostrados, sendo que os estratos de 60 a 100 metros apresentaram maior abundância de larvas do que os estratos superiores. Já no inverno (Fig. 29) não houve diferença significativa entre as diversas profundidades de coleta.

Em relação à distância da costa também não houve diferenças entre as estações neríticas e oceânicas em nenhum período de coleta.

As larvas da família Sternoptychidae estiveram associadas à AT e ACAS, com maiores concentrações próximas à zona de mistura, tanto no verão como no inverno (Figs 28 e 29). Nos resultados obtidos na regressão múltipla realizada para o verão (Tab. 12), a presença da família está associada negativamente à porcentagem de AT, o que corrobora o observado.

\subsubsection{3.a - Maurolicus stehmanni}

A família Sternoptychidae, no verão, foi representada por $84 \%$ de Maurolicus stehmanni e, no inverno, por $65 \%$. Em relação ao total de larvas capturadas esta espécie representou $6,4 \%$ no verão e $6 \%$ no inverno.

As distribuições de Maurolicus stehmanni referentes aos cruzeiros de verão e inverno estão, respectivamente, nas figuras 30 e 31 (Tabs 20 e 21). Não houve diferença significativa entre a abundância de larvas do verão e inverno, tanto para coluna de água integrada, como para cada estrato separadamente. Analisando somente as estações costeiras, ou somente as estações oceânicas, não houve diferença entre o verão e inverno. 
No cruzeiro de verão foram significativas as diferenças entre os estratos amostrados $(H=26,55 ; p=0,0001)$, sendo que as maiores abundâncias foram encontradas entre 60 e 100 metros de profundidade. No inverno os estratos também apresentaram diferenças entre as abundâncias de Maurolicus stehmanni $(H=15,44 ; p=0,0039)$, porém somente foi significativa a diferença entre as camadas de 80 a 100 metros e de 20 a 40 metros.

Em relação à distância da costa, as estações neríticas e oceânicas não apresentaram diferença significativa tanto no verão e como no inverno.

As larvas de M. stehmanni tiveram distribuição semelhante à da família, isto é, estiveram associadas à AT e ACAS, com maiores concentrações próximas à zona de mistura, tanto no verão como no inverno (Figs 30 e 31). Nos resultados obtidos na regressão múltipla realizada para o verão (Tab. 12), a presença da espécie está associada negativamente à porcentagem de AT e de AC, apesar de, na representação da composição das massas de água na região de Cabo Frio no verão, não ficar evidente a presença da AC (Fig. 30).

Todas as larvas de M. stehmanni foram medidas $(n=247)$, pertencendo à classe de comprimento mínima $2 \mathrm{~mm}$ e máxima $15 \mathrm{~mm}$. Os gráficos da figura 32 indicam a freqüência percentual por classes de comprimento no cruzeiro de verão, de cada estrato amostrado. As larvas estiveram concentradas nos estratos de 40 a 100 metros, com maior freqüência no estrato de 80 a 100 metros (53\%) e nas classes de 3 a $5 \mathrm{~mm}(61 \%)$. A freqüência nos dois estratos superiores foi muito baixa, somando $2 \%$. Porém, estatisticamente, não houve diferença significativa entre as diferentes profundidades de coleta em relação ao comprimento das larvas de Maurolicus stehmanni durante o verão. 
Analisando somente as larvas coletadas nas estações neríticas, pôde-se notar que ocorreram larvas de todos os estágios de desenvolvimento bem distribuídas entre os 40 e 100 metros (Fig. 33). Já nas estações oceânicas, larvas de $M$. stehmanni foram mais freqüentes entre 80 e 100 metros (78\%), compostas basicamente por larvas menores de $4,70 \mathrm{~mm}(58 \%)$ e, entre 40 e 80 metros, somente de larvas menores de $4,70 \mathrm{~mm}$. Tanto para as estações neríticas como para as oceânicas não houve diferença significativa entre os estratos em relação ao comprimento das larvas.

A figura 34 indica a freqüência de larvas por classes de comprimento, em estações diurnas ou noturnas. As larvas coletadas durante o dia tinham, em grande parte $(80 \%)$, comprimento inferior a $4,70 \mathrm{~mm}$ e apresentaram maior freqüência de ocorrência entre 80 e 100 metros de profundidade (57\%). Já nas estações noturnas, houve uma distribuição mais homogênea das larvas nas diferentes classes de comprimento, de 40 a 100 metros de profundidade, mas também apresentando maior freqüência no estrato de 80 a 100 metros (47\%). Não houve diferença entre as estações realizadas durante o dia e no período noturno, em relação ao comprimento das larvas.

No cruzeiro de inverno de 2001, a freqüência porcentual por classes de comprimento de Maurolicus stehmanni (Fig. 35) indica que os dois estratos inferiores apresentaram freqüências muito próximas $(35 \%$ e $33 \%$, respectivamente). A classe de maior freqüência foi a de $8 \mathrm{~mm}$ no estrato de 80 a 100 metros (14\%). Não houve diferença significativa entre os diferentes estratos de coleta em relação ao comprimento das larvas durante o inverno. As larvas neste período ocorreram em maior tamanho se comparadas com as 
coletadas durante o verão (Fig. 32), porém estatisticamente somente o estrato de 80 a 100 metros apresentou diferença significativa ( $U=916 ; p=0,0002)$.

Nas estações neríticas durante o inverno (Fig. 36), as larvas ocorreram nos estratos de 40 a 100 metros, sendo mais freqüentes, em todos eles, a classe de indivíduos maiores de $6,00 \mathrm{~mm}$ de comprimento, totalizando $69 \%$. As classes de larvas menores de $4,70 \mathrm{~mm}$ e entre 4,70 e $6,00 \mathrm{~mm}$ também ocorreram nos três estratos. Já nas estações oceânicas (Fig. 36), aproximadamente $10 \%$ das larvas ocorreram nos primeiros 20 metros da coluna de água, distribuídas nas três classes de comprimento e entre 40 e 60 metros a freqüência foi bem distribuída entre diferentes classes. No estrato entre 60 e 80 metros a maior parte das larvas eram maiores de $4,70 \mathrm{~mm}$, e entre 80 e 100 metros a maior freqüência foi de larvas maiores de $6,00 \mathrm{~mm}$ de comprimento. Tanto nas estações neríticas, como nas oceânicas, não houve diferença significativa nos comprimentos das larvas.

A figura 37 indica a freqüência porcentual das larvas de Maurolicus stehmanni durante o inverno de 2001, em função das classes de comprimento, das estações realizadas durante o dia ou à noite. Nas estações diurnas $90 \%$ das larvas ocorreram entre 40 e 100 metros, nas três classes de comprimento, sendo a maioria pertencente à classe igual ou superior a $6 \mathrm{~mm}(55 \%)$. O restante das larvas esteve restrito ao estrato de 0 a 20 metros e também com ocorrência nas três classes de comprimento. Nas estações noturnas a ocorrência das larvas esteve restrita aos estratos de 60 a 100 metros. A classe de comprimento igual ou superior a $6,00 \mathrm{~mm}$ foi a mais freqüente (59\%). No estrato de 60 a 80 metros, a classe de 4,70 a $6,00 \mathrm{~mm}$ foi tão abundante quanto à de comprimento igual ou superior a 6,00 $\mathrm{mm}$. As larvas menores de 
$4,70 \mathrm{~mm}$ apresentaram freqüência similar às iguais a $6,00 \mathrm{~mm}$ ou maiores no estrato de 40 a 60 metros, não ocorreram na camada de 60 a 80 metros, e apresentaram baixa freqüência (3\%) no estrato inferior. Não houve diferença nos comprimentos das larvas nos diferentes estratos nas estações diurnas e noturnas.

\subsubsection{4 - FAMÍLIA SCOMBRIDAE}

No verão a família Scombridae constituiu o quarto grupo em termos de freqüência relativa $(4,45 \%)$, com freqüência de ocorrência de $78,9 \%$, enquanto que no inverno mostrou-se muito rara, com freqüência relativa de apenas $0,08 \%$ e freqüência de ocorrência de 5,6\% (Tab. 11).

As maiores concentrações de larvas no verão (Fig. 38) foram observadas nas camadas superficiais, sendo que no inverno (Fig. 39) só houve um arrasto positivo para esta família na primeira radial percorrida, na camada de 40 a 60

metros. Não foi coletada nenhuma larva desta família no estrato de 80 a 100 metros nos dois cruzeiros (Tabs 22 e 23).

Em relação à distribuição vertical, no verão a diferença foi significativa $(H=20,61 ; p=0,0004)$. Os estratos superiores apresentaram maiores valores de abundância do que os estratos mais profundos (60 a 80 metros).

No verão, a partir da análise da distribuição vertical das larvas da família Scombridae, é possível verificar que sua presença está associada à AT, tanto em zonas onde sua presença é mais forte, como em outras onde ocorre mistura, não intensa, com as outras massas de água, ACAS e AC (Fig. 38). No inverno, a família ocorreu em local onde havia predominância de AT, mas tendo ocorrido em apenas uma única amostra, não é possível concluir que tenha ocorrência semelhante à do verão. 


\subsubsection{5 - FAMÍLIA BREGMACEROTIDAE}

Essa família mostrou-se mais representativa na composição taxonômica do ictioplâncton de inverno (freqüência relativa $=11,75 \%$ e freqüência de ocorrência $=83,3 \%$ ) do que no verão (freqüência relativa $=$ $1,58 \%$ e freqüência de ocorrência $=57,9 \%)($ Tab. 11$)$.

A família Bregmacerotidae ocorreu com valores de abundância maiores no inverno do que no verão $(U=2981,5 ; p=0,049)$, tanto para a coluna de água integrada, como para os estratos de 0 a 20 metros $(U=95,5$; $p=0,022)$ e de 20 a 40 metros $(U=89 ; p=0,013)$. No restante dos estratos $(40$ a 100) não houve diferença significativa entre o verão e inverno (Figs 40 e 41). Considerando somente as estações neríticas, no inverno os valores de abundância foram maiores do que no verão $(U=288,5 ; p=0,002)$. Nas estações oceânicas não houve diferença entre os dois períodos de coleta.

No verão (Fig. 40) não houve diferença significativa entre a abundância dos bregmacerotídeos dos diferentes estratos amostrados. Já no inverno (Fig. 41) pelo menos um estrato se diferenciou dos outros em relação à abundância de larvas. $\mathrm{O}$ estrato de 20 a 40 metros foi o que apresentou maiores valores (Tabs 24 e 25).

Em relação às estações neríticas e oceânicas, tanto no verão como no inverno, não houve diferença significativa nos valores de abundância de Bregmacerotidae.

As larvas de Bregmacerotidae estiveram associadas, no verão, e mais intensamente no inverno, a zonas de mistura onde houve maior predominância de AT (Fig. 40). No inverno, houve maior ocorrência de larvas em zonas de maior mistura entre AC e AT foi mais evidente (Fig. 41). Em 
nenhum dos dois períodos,, as análises de regressão múltipla indicaram essas associações.

Foram identificadas duas espécies da família Bregmacerotidae: Bregmaceros atlanticus e B. cantori.

\subsubsection{5.a - Bregmaceros atlanticus}

As larvas de Bregmaceros atlanticus representaram $80 \%$ da família Bregmacerotidae no verão e $7,6 \%$ no inverno. Em relação ao total de larvas esta espécie representou $1,2 \%$ e $0,85 \%$, no verão e inverno respectivamente.

Analisando as figuras 42 e 43 (Tabs 26 e 27), que mostram a distribuição de $B$. atlanticus no verão e inverno, respectivamente, observa-se que ocorreu maior abundância de larvas no verão, nas camadas mais superficiais e próximas à costa. Porém, os resultados dos testes estatísticos não confirmaram esta observação. No inverno, ocorreram poucos arrastos positivos para a espécie.

As larvas de $B$. atlanticus, no verão, estiveram associadas à zona de mistura onde predominou AT (Fig. 42). No inverno, essas larvas estiveram presentes, apesar de em poucas estações, em zonas de mistura entre AC e AT (Fig. 43). Os resultados da regressão múltipla realizada (Tabs 12 e 13) mostraram, apenas para o verão, haver uma associação negativa entre a presença de $B$. atlanticus e a porcentagem de AT.

Tanto durante o verão como no inverno não houve diferença significativa nos valores de abundância de larvas entre os diferentes estratos de profundidade. Quando analisadas separadamente, as estações neríticas e oceânicas também não apresentaram diferença sazonal significativa.

A figura 44 mostra a freqüência por classes de comprimento de $B$. atlanticus no cruzeiro de verão de 2001. As classes de comprimento variaram 
entre 1 e $7 \mathrm{~mm}$. As maiores freqüências ocorreram entre 20 e 60 metros, totalizando $74 \%$, e as menores freqüências nos estratos de 0 a 20 e de 80 a 100 metros. A classe mais freqüente foi a de $2 \mathrm{~mm}$, entre 20 e 60 metros, somando $37 \%$. Entre 60 e 80 metros, baixa freqüência de larvas das classes de 2 a 5 mm ocorreram, além de larvas da classe de $7 \mathrm{~mm}$. Não houve diferença significativa entre os tamanhos das larvas nas diferentes camadas de coleta no verão.

Nas estações neríticas realizadas no verão (Fig. 45) $76 \%$ das larvas ocorreu de 20 a 60 metros, sendo que larvas menores de 4,00 $\mathrm{mm}$ foram as mais freqüentes. Nas estações oceânicas a maior freqüência também foi de larvas menores de $4,00 \mathrm{~mm}$, de 20 a 100 metros de comprimento, sendo $40 \%$ na camada entre 20 e 40 metros. Entre as estações neríticas houve diferença entre os comprimentos das larvas dos diferentes estratos $(F=286, p=0,03)$, sendo que o estrato de 60 a 80 metros apresentou os maiores valores.

No verão (Fig. 46), nas estações noturnas, B. atlanticus ocorreu de 0 a 80 metros, sendo $73 \%$ de 20 a 60 metros. Nas estações diurnas não houve registro no estrato superior, sendo que larvas menores de $4,00 \mathrm{~mm}$ ocorreram de 20 a 100 metros, mas foram mais freqüentes no estrato de 20 a 40 metros. Entre as estações diurnas não houve diferença entre os estratos, em relação ao comprimento das larvas, porém nas estações noturnas a diferença foi significativa $(F=3,97 ; p=0,03)$.

No inverno as larvas de $B$. atlanticus (Fig. 47) variaram entre as classes de comprimento 3 a $11 \mathrm{~mm}$, sendo o tamanho máximo de ocorrência maior do que o do verão $(7 \mathrm{~mm})$. As larvas ocorreram apenas nos três primeiros estratos, sendo que $92 \%$ entre 0 e 40 metros. Não ocorreram diferenças significativas nos comprimentos das larvas entre os diferentes estratos. 
Nas estações costeiras (Fig. 49), as larvas de B. atlanticus ocorreram nos primeiros 40 metros da coluna de água, e as três classes de comprimento estiveram presentes nos dois estratos. Já nas estações oceânicas só ocorreram larvas nos estratos de 20 a 60 metros e menores do que $4,00 \mathrm{~mm}$. Não houve diferença entre os estratos em relação aos comprimentos das larvas, tanto nas estações neríticas como nas oceânicas.

A figura 49 indica a freqüência porcentual das larvas de $B$. atlanticus em função de suas classes de comprimento, nas estações diurnas e noturnas realizadas no inverno. Durante o dia as larvas ocorreram de 0 a 40 metros e com representantes nas três classes de comprimento, sendo a classe de maior freqüência a de larvas maiores de $6,00 \mathrm{~mm}$ no estrato superior (33\%). Nas estações noturnas, as larvas ocorreram em freqüência igual nos três primeiros estratos de coleta e com comprimentos menores de 4,00 mm Não ocorreu nenhuma outra classe de comprimento de larvas de $B$. atlanticus nas estações noturnas. Não ocorreram diferenças significativas nos comprimentos das larvas entre os diferentes estratos tanto nas estações diurnas como nas noturnas.

\subsubsection{5.b - Bregmaceros cantori}

No verão Bregmaceros cantori totalizou $1,7 \%$ das larvas de Bregmacerotidae e $0,03 \%$ do número total de larvas capturadas. No inverno representou $64,3 \%$ desta família e $7,11 \%$ do total. As figuras 50 e 51 (Tabs 28 e 29) indicam a distribuição e abundância nos cruzeiros de verão e inverno, respectivamente. Não ocorreu nenhuma larva desta espécie durante o verão nos quatro estratos mais superficiais ( 0 a 80 metros) e somente ocorreu uma única amostra positiva com baixa densidade no estrato de 80 a 100 metros. Já no inverno a abundância de larvas foi maior do que no verão, e com estações 
positivas mais próximas à costa e à superfície. Não ocorreu nenhuma larva no estrato de 80 a 100 metros neste período. Considerando a coluna de água de 0 a 100 metros de profundidade a diferença foi significativa entre o verão e inverno $(U=2827.50 ; p=0,015)$, sendo maior a abundância no inverno. Analisando somente as estações oceânicas, não houve diferença significativa entre verão e inverno.

Em relação à distribuição vertical, não ocorreu diferença significativa entre os estratos amostrados tanto no verão, como no inverno.

No inverno, não houve diferença significativa entre os valores de abundância das estações oceânicas e neríticas. No verão, não foi coletada nenhuma larva de $B$. cantori nas estações neríticas.

B. cantori ocorreu em associação às zonas de mistura entre AC, AT e ACAS (Fig. 51), o que não foi corroborado pela regressão múltipla realizada. No verão, a única ocorrência foi em zona de mistura entre AT e ACAS, com prevalência de AT (Fig. 50).

A figura 52 mostra a freqüência porcentual de larvas de $B$. cantori por classes de comprimento no cruzeiro de inverno. As larvas variaram entre as classes de comprimento 1 e $13 \mathrm{~mm}$ entre 0 e 80 metros, com maior freqüência de 0 a 40 metros (89\%). As classes de 2 e $3 \mathrm{~mm}$ foram mais freqüentes no estrato de 20 a 40 metros (46\%). Entre os diferentes estratos amostrados, houve diferença significativa $(H=11,01 ; p=0,01)$ em relação ao tamanho das larvas de B. cantori, sendo maiores as larvas do estrato de 20 a 40 metros.

Na região nerítica $73 \%$ das larvas foram coletadas entre 20 e 40 metros, sendo mais abundantes as de comprimento menor de $4,00 \mathrm{~mm}$ (55\%). No estrato de 80 a 100 metros não houve ocorrência de larvas. Já nas estações 
oceânicas, a maior freqüência ocorreu nos primeiros 20 metros da coluna de água, sendo a classe de comprimento maior de $6,00 \mathrm{~mm}$ a mais abundante. Nos estratos de 40 a 100 metros não ocorreram larvas. Não houve diferença significativa entre as larvas das estações neríticas e nem oceânicas.

A figura 54 mostra as freqüências de $B$. cantori nas diferentes classes de comprimento, nas estações diurnas e noturnas, do cruzeiro de inverno. Durante o período diurno, larvas menores de $4,00 \mathrm{~mm}$ foram as mais freqüentes nos estratos de 0 a 20 metros, de 20 a 40, e de 60 a 80 metros. Larvas maiores de $6,00 \mathrm{~mm}$ ocorreram entre 20 e 60 metros, e larvas de tamanho intermediário somente entre 20 e 40 metros. Já no período noturno ocorreu alta freqüência de larvas menores de $4,00 \mathrm{~mm}$ na camada de 20 a 40 metros, e freqüências menores desta classe ocorreram entre 0 e 20 e 40 e 60 metros. Larvas medindo entre 4,01 e 5,99 e maiores de 6,00 mm apresentaram freqüência semelhante entre 0 e 40 metros. Não houve diferença significativa entre os estratos das estações diurnas em relação ao comprimento das larvas, e entre as noturnas as larvas do estrato de 20 a 40 metros apresentaram a maior média $(H=16,7 ; p=0,0002)$.

\subsubsection{6 - FAMÍLIA PHOSICHTHYDAE}

A família Phosichthydae apresentou $2,19 \%$ de freqüência relativa e $73,7 \%$ de freqüência de ocorrência no verão, e 3,95\% de freqüência relativa e $72,2 \%$ de freqüência de ocorrência no inverno (Tab. 11). No verão as maiores densidades de larvas ocorreram tanto em estações mais próximas à costa, como em mais distantes (Tab. 30; Fig. 55) e em estratos intermediários (20 e 60 metros). No inverno (Tab. 31; Fig. 56) os maiores valores de densidade ocorreram em estações oceânicas, mas também entre 20 e 60 metros. 
Não houve diferença significativa entre o verão e inverno em relação à abundância das larvas desta família, tanto na coluna de água integrada, como em cada estrato separadamente. Analisando somente as estações neríticas, ou somente as oceânicas, também não houve diferença entre verão e inverno.

Tanto no verão como no inverno, não ocorreu diferença significativa entre as abundâncias dos diferentes estratos.

Entre as estações neríticas e oceânicas também não foram encontradas diferenças significativas, tanto no verão como no inverno.

A família Phosichthydae, tanto no verão (Fig. 55) como no inverno (Fig. 56) apareceu associada à AT e, com maior freqüência, às zonas de mistura entre AT, ACAS e AC. Na regressão múltipla (Tabs 12 e 13), apenas no verão foi verificada a associação, negativa, com porcentagem de AT e AC.

Foram identificadas três espécies de Phosichthyidae, Pollichthys mauli, Vinciguerria nimbaria e V. poweriae. Apenas $P$. mauli esteve presente nos dois períodos estudados e com freqüência de ocorrência acima de $70 \%$. V. poweriae esteve representada apenas no verão, com freqüência relativa $0,05 \%$ e freqüência de ocorrência 10,52\%, e V. nimbaria, no inverno, com 0,18\% e $5,88 \%$, respectivamente.

\subsubsection{6.a - Pollichthys mauli}

As larvas de P. mauli totalizaram $69,3 \%$ da família Phosichthydae no verão, e 32,1\% no inverno. Em relação ao total de larvas capturadas, esta espécie representou $1,3 \%$ tanto no verão como no inverno. A distribuição e abundância das larvas podem ser visualizadas nas figuras 57 e 58, respectivamente, para os cruzeiros de verão e inverno (Tabs 32 e 33). No verão as maiores abundâncias da espécie ocorreram nas radiais 2 e 3 e em estações 
mais próximas à costa. No inverno esta espécie teve sua distribuição principalmente em águas oceânicas.

Do mesmo modo que a família Phosichthydae, também não foi verificada nenhuma diferença significativa entre todas as comparações realizadas.

P. mauli, no verão (Fig. 57), quando representou grande parte das larvas de Phosichthyidae, e no inverno, apesar da baixa ocorrência (Fig. 58), apresentou distribuição semelhante à família, ocorrendo, além de na AT, também em zonas de mistura da AT com a ACAS.

A figura 59 mostra a freqüência percentual por classes de comprimento de Pollichthys mauli, no cruzeiro de verão de 2001 ( $n=52$ ). As larvas variaram entre as classes de comprimento 4 e $23 \mathrm{~mm}$, sendo mais abundantes de 0 a 40 metros de profundidade. Estatisticamente no cruzeiro de verão houve diferença significativa entre as diferentes profundidades de coleta em relação ao comprimento das larvas $(H=13,56 ; p=0,0088)$, mas a maior a média ocorreu somente nos primeiros 20 metros da coluna de água.

Nas estações neríticas do cruzeiro de verão larvas maiores de 7,00 apresentaram maior freqüência nos estratos de 0 a 20 e 20 a 40 metros (Fig. 60). Nas estações oceânicas só ocorreram larvas nos estratos de 40 a 100 metros, sendo que as maiores de $7,00 \mathrm{~mm}$ só ocorreram entre 40 e 80 metros de profundidade. Entre as estações costeiras a média também foi significantemente maior no estrato de 0 a 20 metros $(H=9,00 ; p=0,029)$ e entre as estações oceânicas não houve diferença entre os estratos em relação ao comprimento das larvas.

Durante o período diurno (Fig. 61) não houve ocorrência de larva de $P$. mauli nos dois primeiros estratos. Nos estratos inferiores a classe de 3,60 a 7,00 
$\mathrm{mm}$ foi a mais freqüente, sendo também freqüente larvas maiores de $7,00 \mathrm{~mm}$. Já no período noturno (Fig. 61) a maior freqüência foi de larvas maiores de 7,00 $\mathrm{mm}$, entre 0 e 20 metros de profundidade. Entre 20 e 40 metros a freqüência de larvas foi relativamente alta nas classes de comprimento de 3,60 a 7,00 e maior de 7,00 mm. Entre 80 e 100 metros não ocorreram larvas. Durante as estações diurnas não houve diferença entre as diferentes profundidades, porém nas estações noturnas as larvas do estrato superficial foram, em média, maiores do que àquelas coletadas em profundidades maiores $(F=3,83 ; p=0,03)$.

A figura 62 indica a freqüência por classes de comprimento das larvas de Pollichthys mauli coletadas no cruzeiro de inverno $(n=17)$. As larvas variaram entre as classes de comprimento 5 a $18 \mathrm{~mm}$. As larvas estiveram presentes em todos os estratos, sem apresentar maior abundância em nenhum deles. Não houve diferenças significativas entre os diferentes estratos em relação ao comprimento das larvas no cruzeiro de inverno.

Durante o inverno, nas estações neríticas (Fig. 63), somente ocorreram larvas de $P$. mauli com comprimento maior ou igual a $7,00 \mathrm{~mm}$, com maior freqüência no estrato de 0 a 20 metros (60\%). Já nas estações oceânicas ocorreu a classe de comprimento entre 3,60 e 7,00 mm, porém classes com larvas maiores de $7,00 \mathrm{~mm}$ ainda foram mais freqüentes. Estatisticamente não houve diferença entre as diferentes profundidades nas estações neríticas e oceânicas.

A figura 64 mostra a freqüência de larvas de $P$. mauli por classes de comprimento, no inverno, em estações diurnas e noturnas. Nas estações realizadas no período diurno a maior parte das larvas ocorreu entre 0 e 40 metros de profundidade, com mais de $7,00 \mathrm{~mm}$ de comprimento, e entre $60 \mathrm{a}$ 
100 metros. Somente foram encontradas larvas da classe entre 3,60 a $7,00 \mathrm{~mm}$ entre 60 e 80 metros. Nas estações noturnas as freqüências de larvas maiores de 7,00 ocorrem de 0 a 80 metros, sendo que entre 40 e 60 também ocorreram larvas entre 3,60 e 7,00 mm. Tanto nas estações diurnas como nas noturnas não houve diferença significativa entre os comprimentos das larvas nos diferentes estratos.

\subsubsection{7 - FAMÍLIA TRICHIURIDAE}

A família Trichiuridae foi $\circ 13^{\circ}$ grupo na composição taxonômica do verão, com freqüência relativa de $0,61 \%$, mas tiveram mais representatividade no inverno, quando constituíram o quinto grupo com freqüência relativa de 4,62\% (Tab. 11).

No verão (Tab. 34; Fig. 65) a família foi pouco abundante e esteve presente principalmente nas estações próximas à costa. No inverno (Tab. 35; Fig. 66) também foram mais freqüentes nas estações costeiras, porém mais abundantes. Entre 80 e 100 metros, não ocorreu nenhuma larva durante a coleta de inverno.

Não ocorreu diferença significativa entre o verão e inverno, nem para a coluna de água inteira, e nem para os estratos de 0 a 80 metros. Analisando somente as estações neríticas, no inverno a abundância foi maior do que no verão $(U=371 ; p=0,0463)$. Não houve diferença significativa entre o verão e inverno nas estações oceânicas.

Em relação à distribuição vertical, não houve diferença, tanto no verão como no inverno, entre as abundâncias de larvas de Trichiuridae. 
Entre as estações neríticas e oceânicas, durante o verão, não houve diferença, sendo que no inverno as estações neríticas apresentaram maior abundância $(U=489,5 ; p=0,0038)$.

No verão, as larvas de Trichiuridae estiveram associadas às zonas de mistura onde prevalecia a AT. Apenas um dos arrastos positivos para a família foi realizado na ACAS, mas em zona de mistura com a AT. No inverno, as larvas ocorreram em AT, AC e também em zonas de mistura entre as diferentes massas de água (Fig. 66). Na regressão múltipla (Tabs 12 e 13), apenas no inverno foi verificada associação entre a ocorrência de larvas e as massas de água, sendo positiva para a AT e negativa para a ACAS e AC.

\subsubsection{8 - Outras Larvas}

Anguilliformes - Essa ordem foi representativa na composição do ictioplâncton, quanto à ocorrência, nas duas estações amostradas, porém mais no inverno (freqüência relativa $=1,64 \%$ e freqüência de ocorrência $=61,1 \%$ ) do que no verão (freqüência relativa $=0,50 \%$ e freqüência de ocorrência $=52,6 \%$ ) (Tab. 11). No verão, ocorreu nos cinco estratos amostrados, em $16 \%$ dos arrastos, com densidade média variando de 0,34 (40 a 60 metros) a 0,94 (80 a100 metros) larva $100 \mathrm{~m}^{-3}$ (Tab. 36). No inverno, esteve presente em $18 \%$ dos arrastos e apenas nos estratos superiores ( 0 a 60 metros), sendo que a densidade média para os estratos positivos variou de 0,97 a 2,23 larvas $\cdot \mathrm{m}^{-3}$ (Tab. 37). Os valores máximos de densidade de cada estrato foram maiores no inverno, 7,59 a 12,50 larvas $\cdot 100 \mathrm{~m}^{-3}$, do que no verão, com exceção de um arrasto no estrato de 80 a 100 metros com 13,88 larvas $\cdot 100 m^{-3}$ (Tab. 15).

Bothidae - Os botídeos foram bem mais representativos no verão, quando a freqüência relativa foi igual à $1,58 \%$ e a de ocorrência $73,7 \%$. No 
inverno tiveram uma presença discreta, tanto considerando sua freqüência relativa $(0,29 \%)$ como a de ocorrência $(5,6 \%)$ (Tab. 11$)$. No verão, só não estiveram presentes no estrato de 80 a 100 metros, ocorrendo em $24 \%$ dos arrastos, aproximadamente $50 \%$ deles no primeiro estrato. A densidade média variou de 0,18 (60 a 80 metros) a 5,83 (0 a 20 metros) larvas $\cdot 100 m^{-3}$ (Tab. 38). A ocorrência e densidade das larvas nas estações do inverno estão no apêndice 5 .

Carangidae - Os carangídeos tiveram freqüência relativa e de ocorrência bem mais elevadas no verão $(0,83 \%$ e $47,4 \%$, respectivamente) do que no inverno $(0,04 \%$ e $0,56 \%$, respectivamente). No verão, eles ocorreram nos quatro primeiros estratos, em $15 \%$ de todos os arrastos realizados, com densidade média variando de entre 0,11 (60 a 80 metros) e 2,76 (0 a 20 metros) larvas $100 m^{-3}$ (Tab. 39). A ocorrência e densidade das larvas nas estações do inverno estão no apêndice 5.

Clupeidae - Apesar dos clupeídeos não estarem entre os grupos mais relevantes no período estudado, apresentaram freqüência relativa e de ocorrência elevadas no verão $(2,72 \%$ e $47,4 \%$, respectivamente), mas baixas no inverno $(0,13 \%$ e $11,1 \%$, respectivamente) (Tab. 11). No verão, esta família ocorreu em $12 \%$ dos arrastos realizados, em três estratos, 0 a 20 metros, 20 a 40 metros e 60 a 80 metros, e com densidade média variando de 0,22 (60 a 80 metros) a 13,20 (0 a 20 metros) larvas $\cdot 100 m^{-3}$ (Tab.40). No estrato mais superior, houve arrastos com densidades bastante elevadas, sendo que, em três dos sete arrastos positivos, a densidade ficou entre 60 e 90 larvas $\cdot 100 \mathrm{~m}^{-3}$ aproximadamente. A ocorrência e densidade das larvas nas estações do inverno estão no apêndice 5. 
Cynoglossidae - Os cinoglossídeos foram mais representativos no inverno, com freqüência relativa de 3,91\% e de ocorrência de 38,9\% (Tab. 11). Eles ocorreram nos três primeiros estratos ( 0 a 60 metros), com densidade média variando entre 0,24 (40 a 60 metros) e 7,60 (20 a 40 metros) larvas $100 \mathrm{~m}^{-3}$. Dos $13 \%$ de arrastos positivos para a família, $90 \%$ deles estiveram nos dois primeiros estratos (Tab. 41). No verão, as freqüências, relativa e de ocorrência, foram $0,45 \%$ e $5,3 \%$, respectivamente (Tab. 11). A ocorrência e densidade das larvas nas estações do verão estão no apêndice 4.

Mullidae - Os mulídeos, no inverno, apresentaram freqüência relativa de $1,86 \%$ e freqüência de ocorrência de $61,1 \%$ e, no verão, de $0,08 \%$ e $21,1 \%$ respectivamente (Tab.11). No inverno, esta família esteve restrita aos primeiros 20 metros amostrados, com densidade média de 5,70 larvas $100 \mathrm{~m}^{-3}$ e máxima de 18,29 larvas $100 \mathrm{~m}^{-3}$ (Tab. 42), tendo ocorrido em 14\% de todos os arrastos realizados. A ocorrência e densidade das larvas nas estações do verão estão no apêndice 4.

Ophidiidae - Os ofidídeos, no verão, tiveram freqüência relativa de 0,61\% e freqüência de ocorrência de $31,6 \%$ e, no inverno, $0,08 \%$ e 5,6\%, respectivamente (Tab. 11). No verão, esta família só não esteve presente no último estrato (80 a 100 metros), sendo que a densidade média dos estratos positivos variou entre 0,15 (60 a 80 metros) e 1,52 (20 a 40 metros) larvas $100 \mathrm{~m}^{-3}$ (Tab. 43). Em $10 \%$ dos arrastos realizados no verão, foram encontradas larvas de Ophidiidae. A ocorrência e densidade das larvas nas estações do verão estão no apêndice 4 .

Paralepididae - Os paralepidídeos tiveram maior representação no verão, com freqüência relativa de $0,46 \%$ e freqüência de ocorrência de $31,6 \%$, 
do que no verão, com freqüências de $0,98 \%$ e $16,7 \%$, respectivamente. No verão, estiveram presentes em três estratos, 0 a 20, 20 a 40 e 60 a 80 metros, ocorrendo em $10 \%$ dos arrastos realizados. A maior densidade média, 1,71 larvas $100 \mathrm{~m}^{-3}$, ocorreu no estrato mais superficial, enquanto os outros dois estratos apresentaram densidades muito próximas, 0,34 (20 a 40 metros) e 0,35 (60 a 80 metros) larvas $\cdot 100 \mathrm{~m}^{-3}$ (Tab. 44). A ocorrência e densidade das larvas nas estações do inverno estão no apêndice 5.

Paralichthyidae - As larvas da família Paralichthyidae apresentaram freqüência relativa e de ocorrência maiores no verão, 0,60 e 36,8 larvas $1100 \mathrm{~m}^{-3}$, do que no inverno, 0,98 e 16,7 larvas $100 \mathrm{~m}^{-3}$ (Tab. 11). No verão, em $15 \%$ dos arrastos realizados foram encontradas larvas distribuídas nos quatro primeiros estratos com densidade média variando de 0,20 (60 a 80 metros) a 1,84 (20 a 40 metros) larva $100 \mathrm{~m}^{-3}$ (Tab. 45). A ocorrência e densidade das larvas nas estações do inverno estão no apêndice 5 .

Phycidae - Esta família ocorreu apenas no inverno, em 15\% dos arrastos realizados, com freqüência relativa de 2,03\% e freqüência de ocorrência de 38,9\% (Tab. 11). As larvas estiveram presentes nos quatro primeiros estratos com valores de densidade média próximos nos dois primeiros $\left(2,28\right.$ e 2,30 larvas $\left.100 \mathrm{~m}^{-3}\right)$ e nos dois últimos $(0,81$ e 0,85 larvas $\left.100 \mathrm{~m}^{-3}\right)$. Em todos os estratos positivos, ocorreram valores altos de densidade, apesar de maiores e mais freqüentes entre 0 e 40 metros (Tab. 46).

Pleuronectiformes - As larvas deste grupo que só puderam ser identificadas até o nível de ordem tiveram maior ocorrência no inverno $(33,3 \%)$ do que no verão $(26,3 \%)$, com freqüência relativa de $2,72 \%$ e $0,95 \%$, respectivamente (Tab. 11). No inverno, estiveram presentes em $14 \%$ dos 
arrastos realizados e nos quatro primeiros estratos. A densidade média desses estratos variou de 0,19 (60 a 80 metros) a 5,33 (20 a 40 metros) larvas $100 m^{-3}$. Os valores máximos de densidade nos dois primeiros estratos $(23,99$ e 58,29 larvas $100 \mathrm{~m}^{-3}$ ) foram bem mais elevados do que os dos dois estratos inferiores $\left(0,47\right.$ e 0,19 larvas $\left.\cdot 100 m^{-3}\right)($ Tab. 47). A ocorrência e densidade das larvas nas estações do verão estão no apêndice 4.

Scaridae - Esta família teve freqüência de ocorrência bem maior no verão $(57,9 \%)$, do que no inverno $(11,1 \%)$, apresentando freqüências relativas de $0,68 \%$ e $0,29 \%$, respectivamente (Tab. 11). As larvas de Scaridae estiveram presentes em $17 \%$ dos arrastos realizados no verão, com maior ocorrência no estrato de 0 a 20 metros. A densidade média dos quatro primeiros estratos onde ocorreram variou de 0,17 (60 a 80 metros) a 1,56 (0 a 20 metros) larvas $100 \mathrm{~m}^{-3}$ (Tab. 48). A ocorrência e densidade das larvas nas estações do inverno estão no apêndice 5.

Serranidae - Os serranídeos tiveram freqüência de ocorrência maior no verão $(36,8 \%)$ do que no inverno $(11,1 \%)$, e freqüência relativa de $0,18 \%$ e $0,22 \%$, respectivamente (Tab 11). No verão, os $8 \%$ dos arrastos positivos para esta família foram realizados no estrato de 0 a 20 metros, com densidade média de 0,94 larva $100 \mathrm{~m}^{-3}$ (Tab. 49). A ocorrência e densidade das larvas nas estações do inverno estão no apêndice 5.

Synodontidae - Os sinodontídeos foram mais representativos no inverno do que no verão, com freqüência relativa de $1,19 \%$ e $0,15 \%$ e freqüência de ocorrência de 33,3\% e 21,1\%, respectivamente (Tab. 11). No inverno, ocorreram em $16 \%$ dos arrastos realizados e nos estratos de 0 a 80 metros de profundidade. A densidade média desses estratos variou de 0,45 (60 a 80 
metros) a 1,60 (20 a 40m) larva $100 m^{-3}$ (Tab. 50). A ocorrência e densidade das larvas nas estações do verão estão no apêndice 4.

O restante dos grupos identificados teve freqüência de ocorrência inferior a $30 \%$ nos dois cruzeiros realizados. Sua ocorrência e densidade de larvas estão nos apêndices 4 (verão) e 5 (inverno).

\section{5 - ANÁLISES ESTATÍSTICAS}

$\mathrm{Na}$ análise de componentes principais realizada com os dados do cruzeiro de verão, a porcentagem de explicação para os dois primeiros eixos foi $78,3 \%$ (Tab. 12). O eixo 1 explicou $62,8 \%$ das variâncias dos dados e correlacionou-se positivamente com temperatura, salinidade e porcentagem de AT, e negativamente com porcentagem de ACAS e clorofila-a. O eixo 2 explicou $15,5 \%$ das variações, apresentando correlação positiva para a porcentagem de AC e negativa para profundidade. Sendo assim, três grupos principais foram evidenciados. O grupo associado à ACAS (Fig. 67, em azul) foi composto pelas amostras profundas (60 a 100 metros) e por algumas superficiais onde houve ressurgência. Outro grupo (Fig. 67, em amarelo) apresentou amostras coletadas nas camadas de 0 a 20 metros, e mostrou-se associado à Água Costeira. Já o terceiro grupo (Fig. 67, em vermelho) é composto por amostras coletadas em profundidade intermediárias (de 20 a 60 metros), e indica associação com a AT.

A tabela 13 mostra os resultados da Análise de Componentes Principais do cruzeiro de inverno. Os dois primeiros eixos explicaram $84,6 \%$ da variância dos dados. O eixo 1, responsável por $51 \%$ de explicação, foi correlacionado positivamente com profundidade, salinidade e porcentagem de Água Tropical. Já o eixo 2 apresentou 33,6\% de explicação, com correlação positiva com 
temperatura, porcentagem de AC e clorofila-a e correlação negativa com a porcentagem de ACAS. Foram formados três grupos distintos de amostras (Fig. 68). O grupo azul corresponde às amostras provenientes dos estratos inferiores (60 a 100 metros), sendo associado à ACAS. O grupo amarelo compreende as estações neríticas e superficiais, sendo assim, associado à AC. Já o grupo vermelho também é composto de amostras mais superficiais, porém mais distantes da costa, relacionado à AT .

As análises de agrupamento em duas vias (TWINSPAN) do cruzeiro de verão e inverno estão representadas nas figuras 69 e 70, respectivamente.

No verão foram formados três grupos de estações. O primeiro grupo se caracterizou por alta abundância de Sternoptychidae, baixa densidade de Anguilliformes, Bregmacerotidae, Myctophidae, Phosichthyidae e Trichiuridae, e nenhum arrasto positivo (ou somente um) de Paralepididae, Scombridae, Bothidae, Paralichthyidae, Scaridae, Carangidae, Clupeidae, Serranidae, Engraulidae e Ophidiidae. Este grupo se mostrou associado às zonas de mistura entre a AT e a ACAS. O segundo grupo esteve principalmente associado à AT, e se diferencia do primeiro grupo devido a uma menor ocorrência e densidade de Sternoptychidae, alta densidade de Anguilliformes, Bregmacerotidae, Myctophidae, Phosichthyidae, Trichiuridae e praticamente ausência de Engraulidae e Ophididae. Uma subdivisão deste grupo ocorreu em função da profundidade de coleta, sendo que as famílias Bothidae, Paralichthyidae, Scaridae, Carangidae, Clupeidae e Serranidae ocorreram em maior densidade em arrastos superficiais. $\mathrm{O}$ último grupo formado mostrou-se associado às áreas de mistura entre a AT e a ACAS, mais particularmente a ACAS. São estações costeiras com baixa ocorrência, porém alta densidade, de Sternoptychidae, 
nenhuma ocorrência de Anguilliformes, Bregmacerotidae, Myctophidae, Phosichthydae, Trichiuridae, Paralepididae e Scombridae, baixa abundância de Bothidae, Paralichthydae, Scaridae, Carangidae, Clupeidae e Serranidae e ampla ocorrência Engraulidae e Ophididae com valores altos de densidade.

No inverno também foram formados três grupos de estações. O primeiro grupo, associado à Água Costeira, se destacou por uma alta densidade de Bregmacerotidae, Engraulidae, Mullidae, Trichiuridae, além de apresentar densidades relativamente altas de Cynoglosidae, Pleuronectiformes, Anguilliformes, Myctophidae, Phosichthydae e Phycidae. A família Sternoptychidae ocorreu em poucos arrastos de baixa densidade. O segundo grupo se diferenciou por apresentar alta densidade de Myctophidae, Phosichthydae e Phycidae, baixa abundância de Cynoglosidae, Pleuronectiformes, Bregmacerotidae, Engraulidae, Mullidae, Trichiuridae, Anguilliformes e Synodontidae e baixa ocorrência, mas altas densidades de Sternoptychidae. Este grupo foi associado à Água Tropical. O último grupo ocorreu principalmente em zonas de mistura entre AT e ACAS e não houve ocorrência de Cynoglosidae e Pleuronectiformes, baixa ocorrência e densidade de Bregmacerotidae, Engraulidae, Mullidae, Trichiuridae, Anguilliformes e Synodontidae, baixa ocorrência de Myctophidae, Phosichthydae e Phycidae e alta ocorrência e densidade de Sternoptychidae.

Os resultados da análise de similaridade ANOSIM demonstraram tanto para a coleta de verão, como para a coleta de inverno, que existem diferenças na composição do ictioplâncton entre os grupos de estação obtidos na Análise de Componentes Principais. 
No verão o valor de $R$ global foi igual a 0,337 , com um nível de significância $0,1 \%$. Todos os grupos definidos na ACP apresentaram diferença significativa entre eles, com nível de significância 0,1\%. Entre o grupo caracterizado pela presença de ACAS e AC o $R$ foi 0,384 , para os grupos associados à ACAS e AT o R foi 0,302 e, por último, entre a AC e a AT o R foi igual a 0,386 .

No inverno o $\mathrm{R}$ global foi igual a 0,398 , com um nível de significância 0,1\%. Os grupos definidos na ACP como ACAS, AT e AC apresentaram diferença significativa entre si, em relação à matriz biológica. $\mathrm{O} R$ entre o grupo da ACAS e AC foi igual a 0,499, entre ACAS e AT foi 0,326 e entre AC e AT foi 0,142, em um nível de significância de 0,1\%.

Os resultados da análise BIOENV do cruzeiro de verão indicam que as variáveis que melhor explicam a variabilidade dos dados foram as porcentagens de ACAS e AC, com uma correlação de 0,431. Com uma correlação de 0,399 a concentração de clorofila-a também entra na explicação em conjunto com as porcentagens de ACAS e AC.

No inverno, o mesmo padrão foi encontrado. O conjunto de variáveis que melhor explica a variação dos dados foi a porcentagem de ACAS e a porcentagem de $A C$, com uma correlação de 0,292. Em seguida a variável clorofila-a também foi responsável pela distribuição e abundância das famílias, com uma correlação de 0,281 junto com as porcentagens de ACAS e AC. 


\section{6 - DISCUSSÃO}

\section{1 - FATORES ABIÓTICOS E BIÓTICOS}

Os dados de temperatura e salinidade registrados durante os cruzeiros de verão e inverno de 2001, na região de Cabo Frio, indicam que a coluna de água esteve verticalmente estratificada no verão e mais homogênea no inverno. Este padrão é comumente descrito para a plataforma sudeste da costa brasileira (Castro et al., 1987; Campos et al., 1995; entre outros). As principais características hidrográficas encontradas na região de estudo nos dois cruzeiros realizados, coincidem com as descrições feitas por Miranda (1982), Matsuura (1986) e Castro (1996), indicando o processo de ressurgência durante o verão e subsidência durante o inverno. Segundo Valentin et al. (1987), na região de Cabo Frio a área de superfície ocupada pelas águas frias da ressurgência é muito pequena, apenas de $5 \mathrm{~km}$ de largura numa faixa costeira. Já ao largo, as isotermas inclinam-se abruptamente, formando uma frente térmica praticamente vertical. No presente trabalho, durante o cruzeiro de verão, este padrão se repete, sendo somente mais larga a faixa costeira ocupada pelas águas frias.

Kampel (2003), analisando imagens de satélite da temperatura de superfície do mar, observou a presença de um meandramento ciclônico com cerca de $120 \mathrm{~km}$ de extensão no verão e de $100 \mathrm{~km}$ no inverno de 2001 . Campos et al. (1995) ofereceram uma explicação dinâmica para a formação do meandro em Cabo Frio, discutindo que, quando a costa muda de direção em torno de Cabo Frio, o fluxo da Corrente do Brasil, antes centrado em 1000 m, por inércia, atinge regiões mais profundas do talude continental. Como conseqüência há um estiramento da coluna de água e a corrente adquire vorticidade ciclônica. 
Segundo Castro \& Miranda (1998), a área de estudo não apresenta rios importantes, o que pode justificar a ausência de uma assinatura forte da AC durante o período de verão. Diferentemente, no inverno, a AC esteve presente sobre a plataforma continental. Segundo Campos (1995), no inverno de 1993, a presença de uma massa de água de densidade bastante baixa na parte mais rasa da plataforma continental possivelmente impediu uma maior penetração da ACAS. Essa massa, conforme Campos et al. (1996), provavelmente é originária de regiões ao sul da foz do Rio da Prata, na plataforma continental argentina. Piola et al., 2000, denominaram este fenômeno de frente subtropical de plataforma do Rio de La Plata e, em 2005, Piola e colaboradores mostraram que a influência da descarga do Rio de la Plata pode se estender por até $1300 \mathrm{~km}$ ao longo de uma faixa costeira. Outros trabalhos também reportam a presença de águas de baixa salinidade e temperatura durante o inverno que possivelmente provém, por advecção, da região sul (Campos, 1995; Gaeta, 1999). Kampel (2003) identificou águas com estas características alcançando a divisa entre os estados de São Paulo e Rio de Janeiro. Além disso, o autor observou um filamento com temperatura superficial de $22^{\circ} \mathrm{C}$ que parece ter sido advectado para o interior do meandramento ciclônico ao sul de Cabo Frio. Seriam interessantes futuros estudos que nos permitissem entender melhor a influência desta massa de água na costa sudeste, sobretudo em Cabo Frio.

Os índices termohalinos da Água Costeira, no presente estudo, apresentaram variações entre o inverno e verão. Amor (2005), em estudo da plataforma continental entre o Cabo de São Tomé e a llha de São Sebastião, apresentou índices termohalinos da AC expressando uma variação espacial e temporal exercida por efeitos atmosféricos e oceanográficos, como o 
escoamento continental, a radiação solar e a hidrodinâmica sobre as águas mais próximas da linha de costa, em cada estação do ano.

Baseado em dados de correntes obtidos com o perfilador acústico ADCP nos cruzeiros de mesoescala de verão e inverno de 2001, Leite (2005), resumidamente, apontou que durante o cruzeiro de verão, na região correspondente à quebra da plataforma continental, as correntes à meia água e de fundo apresentaram direção SE-E-NE, sugerindo que a atuação da Corrente do Brasil não tenha sido dominante. Ao longo da plataforma continental as correntes, em toda a coluna de água, apresentaram direções NW-W-SW, forçadas por ventos típicos desta época do ano. No inverno, com a passagem de frentes frias, as correntes apresentaram direção NE-E e, após a passagem, voltam a apresentar o padrão normal de correntes nesta área, ou seja, NW-W na plataforma continental e SW na quebra de plataforma.

Os valores de concentração de clorofila encontrados são semelhantes aos obtidos por Valentin (1984), na mesma área de estudo, quando os valores estiveram entre, aproximadamente, 0,5 e 2,0 $\mathrm{mg} \mathrm{m}^{-3}$ e o padrão de distribuição de clorofila foi caracterizado por uma intrusão em subsuperfície em direção ao mar aberto. Esta intrusão também foi observada neste trabalho, tanto no verão como no inverno. Os valores de clorofila a também coincidiram com os dados de Aidar et al. (1993) no litoral norte do Estado de São Paulo e Gaeta et al. (1993) para a região da Bacia de Campos.

Segundo Gonzalez-Rodrigues et al. (1992), no processo de ressurgência, após o afloramento de águas frias e ricas em nutrientes, ocorre uma fase produtiva caracterizada por um aumento de biomassa e produção primária. Sendo assim, em períodos de ressurgência, esperaríamos uma maior 
biomassa fitoplanctônica em comparação ao inverno. Porém, os resultados apresentados no presente estudo indicam que não houve diferença entre as concentrações de clorofila do verão e inverno. Kampel (2003) também obteve o mesmo resultado para a produção primária sobre a plataforma e atribuiu isso ao fato de que durante o cruzeiro de inverno, embora a influência da ACAS não chegue à superfície do mar, o aumento da concentração em sais nutrientes na base da zona eufótica também pode fortalecer a produção primária total. Além disso, no inverno, Kampel (2003) e Leite (2005) observaram plumas de águas frias à oeste de Cabo Frio, com cerca de $60 \mathrm{~km}$ de extensão, indicando um evento atípico de ressurgência. Segundo Valentin (1989) a Água Central do Atlântico Sul possui maior concentração de nutrientes do que a Água Tropical adjacente, fertilizando dessa forma a zona eufótica. Kampel, em 2003, analisando as imagens de concentração de clorofila na superfície do mar, durante o cruzeiro de verão deste estudo, verificou a presença de um meandramento ciclônico da $\mathrm{CB}$ ao sul de Cabo Frio com uma conseqüente intrusão de águas mais pobres sobre a plataforma, formando uma frente com intenso gradiente de biomassa e uma estrutura em forma de vórtice, a leste de Cabo Frio.

No presente trabalho, do mesmo modo que nas estações neríticas, não houve diferença significativa entre verão e inverno em relação à concentração de clorofila-a, porém Kampel obteve diferença da produção primária entre taludeverão e talude-inverno Essa diferença entre os resultados pode ter ocorrido devido ao fato do autor ter agrupado os dados dos cruzeiros de 2001 e 2002 nas duas estações de coleta (verão e inverno), sendo que em 2002 a área amostrada foi maior. Além disso, as estações neríticas e oceânicas neste 
trabalho foram definidas em relação à isóbata de 200 e Kampel (2003) utilizou a de 140 metros.

Os valores obtidos de clorofila-a foram menores aos geralmente encontrados em outras áreas de ocorrência de ressurgência costeira (Kampel, 2003). Segundo Falkowsky et al. (1991) nessas áreas e em feições de mesoescala indutoras de ressurgência a biomassa de clorofila-a pode chegar a valores maiores de $5 \mathrm{mg} \cdot \mathrm{m}^{-3}$. O relativo baixo nível de biomassa primária, pode ser, em parte, atribuído ao aumento na taxa de grazing pelo zooplâncton herbívoro, quando ocorrem máximos simultâneos de fito e zooplâncton (Valentin, 1984).

Os resultados deste trabalho indicam que os maiores valores de volume de plâncton foram encontrados nas estações neríticas. Valentin e Monteiro-Ribas (1993) encontraram o mesmo padrão nesta área e atribuíram à intrusão da ACAS sobre a plataforma a ocorrência do forte gradiente costa-oceano de volume de plâncton. O mesmo resultado foi encontrado por Katsuragawa et al. (1993) na região de Ubatuba, litoral norte do Estado de São Paulo, que sugeriram que as altas densidades observadas para o zooplâncton total estariam associadas à penetração da ACAS durante o verão.

Em relação aos valores encontrados, Nonaka (1999) registrou variações semelhantes durante o inverno e levemente menores durante o verão, na costa leste brasileira. Itagaki (1999) obteve valores muito maiores de volume de zooplâncton entre Cabo Frio e Cabo de Santa Marta Grande. Valentin (1984) encontrou abundância de zooplâncton, na mesma área de estudo do presente trabalho, semelhante a outras áreas de ressurgência importantes. Sabe-se que os padrões de flutuação das comunidades planctônicas sobre a plataforma 
continental, na região de Cabo Frio, são influenciados pela oscilação vertical da termoclina em função da ressurgência (Valentin et al.,1987), o que pode justificar a diferença de valores encontrados em diferentes trabalhos.

\section{2 - ICTIOPLÂNCTON}

Em relação à quantidade de ovos coletados por época do ano, o resultado coincidiu com Katsuragawa et al. (1993), que observaram que a desova da maioria das espécies foi mais intensa no verão. Na região entre Cabo Frio e Cabo de Santa Marta Grande, Itagaki (1999) observou, de um modo geral, que as maiores densidades ocorreram em profundidades menores de 75 metros e em regiões de ressurgência, principalmente em Cabo Frio, região do presente estudo. Outros trabalhos sugerem mudança temporal na atividade de desova dos peixes em relação à intrusão da ACAS, devido à variabilidade no total de abundância de ovos encontrada, como, por exemplo, Matsuura (1983). No trabalho de Franco (2003), na região sul da costa brasileira, a abundância de ovos variou entre 0,08 e 0,715 ovos $\cdot \mathrm{m}^{-3}$, durante o verão de 1997 , sendo que a média foi de 0,16 ovos $\cdot \mathrm{m}^{-3}$, relativamente menor que o valor encontrado durante o verão na região de Cabo Frio, se não considerarmos a amostra atípica com 1036 ovos $\cdot \mathrm{m}^{-3}$, que aumenta a média total.

Diferentemente dos resultados aqui encontrados, ou seja, maior abundância nas regiões neríticas, Franco (2003) encontrou maiores valores de densidade de ovos localizados em região de quebra de plataforma. Isso pode ter acontecido devido à divisão da área em somente dois ambientes (nerítico e oceânico). Sendo assim, não foi possível no presente trabalho a distinção entre as densidades na plataforma continental e quebra de plataforma, sendo tudo incluído nas estações neríticas. 
A baixa estratificação na distribuição vertical de ovos, principalmente no inverno, indica que nessa região a desova dos peixes ocorre em igual intensidade num espaço amplo da coluna de água, desde a superfície até pelo menos 100 metros de profundidade. Além dos processos de ressurgência e subsidência observados durante o estudo, outros fatores podem ter contribuído para a diferença de distribuição vertical entre os dois períodos. Deve-se considerar que o padrão de desova é diferente e depende da estratégia reprodutiva das espécies. Por exemplo, Matsuura \& Kitahara (1995) discutem a ocorrência de segregação para desova entre Sardinella brasiliensis e Engraulis anchoita. De acordo com os autores, a primeira espécie desova na camada superior de mistura, enquanto que a segunda prefere as camadas mais profundas e frias. Segundo Sherman et al. (1984) algumas espécies costeiras procuram manter alta abundância de ovos e larvas por um longo tempo e em uma área relativamente grande, aproveitando assim as condições favoráveis para o desenvolvimento larval. Outras espécies desenvolveram estratégias de desova no sentido de otimizar o encontro da presa, através de uma sincronia entre a época e local de desova e aumento do zooplâncton. A sincronia entre a ocorrência do ictioplâncton e demais componentes do zooplâncton, que representariam a fonte de alimento principal para as larvas de peixes, têm sido relatada em vários trabalhos (Katsuragawa et al., 1993, González-Quirós et al., 2003, entre outros).

Em uma próxima etapa, a identificação dos ovos coletados poderá revelar mais detalhes sobre os padrões de distribuição vertical dos ovos de diferentes espécies de peixes na área de estudo. 
A média de abundância de larvas obtida no verão de 2001, na região de Cabo Frio, foi muito maior em comparação com a média calculada para a região sul, em dezembro de 1997, quando a média foi 0,2 larvas $\cdot \mathrm{m}^{-3}$ (Franco, 2003).

Em relação ao número de famílias identificadas, 61 famílias ocorreram na região de Cabo Frio durante o verão e inverno de 2001. Nonaka (1999) identificou 77 famílias na região leste da costa brasileira. Itagaki (1999), na plataforma continental sudeste e Sinque \& Muelbert (1997), na região sul, identificaram 48 famílias. Esse padrão pode indicar um decréscimo na diversidade encontrada conforme o aumento da latitude. Maior diversidade na região leste foi atribuída à alta diversidade normalmente registrada em ecossistemas de recifes de coral, no caso o Banco de Abrolhos. Na região de Cabo Frio o aumento da diversidade pode ter ocorrido em função de ser uma área rica devido ao processo de ressurgência, mas também pelo fato deste estudo ter amostrado, além de regiões sobre a plataforma continental, também estações oceânicas.

Em relação à composição taxonômica as famílias que apresentaram maior abundância geralmente ocorrem como dominantes nos trabalhos realizados nas costas leste, sudeste e sul do Brasil. Engraulidae foi a família de maior densidade em todos os cruzeiros do presente estudo e de Itagaki (1999) entre Cabo Frio e Cabo de Santa Marta Grande. Myctophidae, que foi a segunda família com maior freqüência relativa nos cruzeiros de verão e inverno, foi a família dominante em três cruzeiros estudados por Nonaka (1999), sendo que Phosichthyidae, Sternoptychidae e Bregmacerotidae também foram bastante representativas. 
Quanto à variação sazonal Nonaka (1999) relatou que, dentre o grupo pelágico, famílias como Myctophidae, Sternopthychidae, Carangidae, Engraulidae, Gonostomatidae e Scombridae ocorreram principalmente no verão, enquanto que larvas de Phosichthyidae, Bregmacerotidae e Clupeidae apresentaram maiores densidades no inverno. No caso do presente trabalho, Engraulidae e Sternopthychidae não apresentaram diferença significativa entre verão e inverno (apesar de Engraulidae ter apresentado maior freqüência relativa durante o verão), enquanto Myctophidae, Carangidae e Scombridae também obtiveram maior representatividade no verão. Phosichthydae e Bregmacerotidae apresentaram o mesmo padrão, porém a família Clupeidae apresentou maiores freqüências (relativa e de ocorrência) durante o verão. A família Paralepididae, que não apresentou um padrão evidente na região leste da costa e no presente trabalho apesar de ocorrer em maior freqüência relativa durante o inverno, obteve maior freqüência de ocorrência no verão.

Itagaki (1999) encontrou 3 principais grupos de estações, denominados de Assembléias Costeira, Nerítica e Oceânica, além de grupos de transição, mas o autor considerou como estações oceânicas aquelas com profundidades maiores de 90 metros até as adjacências da isóbata de 100 metros, diferentemente deste trabalho no qual as estações consideradas oceânicas foram as com mais de 200 metros de profundidade. Nonaka (1999) também obteve Assembléia Costeira, Nerítica, e de transição, além de uma assembléia denominada "Banco de Abrolhos". No presente trabalho não foi possível detectar os mesmos grupos em função da distância da costa. A ausência de uma assembléia costeira ocorreu provavelmente devido à diferença de amostragem já que neste caso, exceto por duas estações com 40 metros de profundidade, 
todas as outras estavam além da isóbata de 100 metros. Em relação às assembléias nerítica e oceânica, a dificuldade de distinção neste trabalho devese, provavelmente, à coleta estratificada, visto que, por exemplo, as estações neríticas com presença de ACAS na superfície, vão se agrupar com arrastos profundos de estações oceânicas. O fato da coleta do presente trabalho ter sido feita em estações com profundidades até aproximadamente 2000 metros e, mesmo assim, não ter sido possível distinguir uma assembléia oceânica, reforça a hipótese dos grupos terem sido formados em relação à massa de água predominante e não em relação à profundidade local.

O agrupamento associado às massas de água foi considerado coerente visto que diversos grupos formados de famílias apresentaram as mesmas variáveis ambientais explicando seu padrão de distribuição na análise de regressão linear múltipla. Por exemplo, tanto Engraulidae como Ophidiidae, que foram agrupadas no verão, obtiveram relação significativa com a temperatura e porcentagem de AT. Outro exemplo é o da família Myctophidae que, tanto no verão como no inverno, na análise de agrupamento foi mais abundante no grupo de estações associado à AT.

\section{Engraulidae (Engraulis anchoita)}

As larvas de E. anchoita foram as mais representativas na área de estudo. Esse resultado corrobora estudos anteriores (e.g. Katsuragawa, 1985; Itagaki, 1999) que apontam a espécie como sendo uma das mais abundantes do ictioplâncton da costa sudeste do Brasil. Essa espécie apresentou índices relativamente altos, tanto em termos de ocorrência como de abundância, nos dois períodos, dando indícios de que a desova da $E$. anchoita está mais ligada às condições oceanográficas do que às épocas do ano, como discutido por 
Spach (1990). A presença de muitas larvas recém eclodidas de E. anchoita durante o verão indica que ocorreu desova desta espécie na região de estudo.

Em estudo na região do cabo de Santa Marta Grande (SC), Matsuura \& Kitahara (1995) encontraram larvas em pré-flexão e flexão na camada de mistura e a maioria das larvas em pós-flexão e metamorfose nas camadas mais profundas, próximas à base da termoclina. Sendo assim os autores concluíram que as larvas conseguem migrar mais profundamente conforme elas crescem e melhoram sua capacidade natatória. Ainda em relação à família Engraulidae, Brewer \& Kleppel (1986) também verificaram o mesmo padrão de distribuição de Engraulis mordax, uma espécie congênere que habita a costa da Califórnia (EUA). Larvas recém eclodidas são mais abundantes na superfície e nas profundidades médias da coluna de água (4, 8 ou 15 metros), enquanto larvas maiores do que $6 \mathrm{~mm}$ de comprimento ocorrem em maior abundância próximas ao fundo $(8,22$ ou 30 metros). Somente durante a noite as larvas maiores de 12 $\mathrm{mm}$ ocorrem na superfície, indicando também melhor capacidade natatória. $\mathrm{O}$ padrão encontrado no presente estudo corrobora, em partes, os resultados dos trabalhos acima, já que nos estratos superiores ocorreu alta freqüência relativa de larvas em pré-flexão e flexão, mas, porém, não ocorreram larvas de maiores tamanhos nas camadas mais profundas. A baixa freqüência de larvas em pósflexão pode ter ocorrido devido à maior capacidade natatória e melhor capacidade visual, que permitiriam a fuga da rede. Outro possível motivo é realmente não ter ocorrido, na época das coletas, larvas destas classes de comprimento, já que a desova parece estar relacionada à intrusão da ACAS sobre a plataforma, e não temos dados suficientes para dizer se ocorreu ressurgência em período anterior à coleta. 


\section{Myctophidae}

Devido ao tamanho das larvas de Myctophidae coletadas, e principalmente ao fato delas não terem ainda seus fotóforos formados, não foi possível a identificação em níveis de gênero e espécie.

Em um estudo realizado durante o verão, na Corrente de Kuroshio e na região de transição entre Kuroshio e Oyashio, Tsukamoto et al. (2001) descreveram a distribuição vertical de 4 espécies de Myctophidae, sendo que três delas apresentaram maior abundância nas camadas superiores a 100 metros. Myctophum asperum, por exemplo, foi coletada, durante o dia, nas camadas superiores a 30 metros com pico entre 50 e 75 metros, sendo que à noite a maioria foi coletada na superfície e entre 15 e 30 metros. No presente trabalho, no verão, as maiores abundâncias ocorreram entre 0 e 80 metros da coluna de água, porém a diversidade de espécies na costa sudeste do Brasil é muito alta, sendo difícil descrever um padrão para a família.

\section{Sternoptychidae (Maurolicus stehmanni)}

Segundo Weiss et al. (1988) na região sul brasileira, as áreas de desova de $M$. muelleri $(=M$. stehmanni) são próximas ao talude continental e em regiões oceânicas, principalmente no inverno e outono. As larvas também apresentaram maior abundância nestas estações, e menor no verão, diferentemente do presente estudo, no qual não houve diferença significativa entre o verão e 0 inverno. Comparando a distribuição de ovos e larvas, Weiss et al. (1988) encontraram uma tendência das larvas ocorrerem em estações mais neríticas, mesmo que uma pequena parte tenha sido encontrada em regiões oceânicas.

Em relação às classes de comprimento, o padrão encontrado no presente estudo, corrobora o encontrado por Weiss et al. (1988), visto que nos 
dois casos as larvas apresentaram menor comprimento médio no inverno, a diferença foi que os autores compararam com a primavera e aqui foi comparado ao verão. Conforme os autores, ovos em estágios iniciais do desenvolvimento foram mais freqüentes em estações com mais de 250 metros de profundidade; ovos em estágios mais desenvolvidos foram mais abundantes entre 200 e 250 metros de profundidade, além de apresentaram ocorrência ocasional em estações mais rasas do que 100 metros. Este padrão pode indicar um transporte em direção à costa conforme os estágios de desenvolvimento aumentam. Já as larvas de menor tamanho foram coletadas em estações com profundidade entre 200 e 250 metros, mas também em estações menos profundas (100 a 150 metros) sendo que as larvas maiores apresentaram maior freqüência nas estações entre 150 e 200 metros. Analisando os dados referentes às classes de comprimento em relação às estações neríticas (menos de 200 metros) e oceânicas, pode-se sugerir um padrão similar ao da região sul do país na região de cabo Frio.

Tsukamoto et al. (2001) descreveu a distribuição vertical de larvas de Maurolicus japonicus, sendo que as larvas foram coletadas nas camadas entre 15 e 150 metros de profundidade e foram mais abundantes entre 100 e 150 metros nas amostras diurnas e noturnas. No presente trabalho, os resultados indicam também a tendência de uma estratificação, sendo que no verão as maiores abundâncias foram encontradas entre 60 e 100 metros de profundidade e no inverno no estrato de 80 a 100 metros.

Maurolicus stehmanni foi extensivamente estudada por Ribeiro (1996), na região sudeste do Brasil. Uma das conclusões apresentadas pelo autor foi a de que a dinâmica das massas de água nessa região auxilia o transporte de 
ovos e larvas para áreas da plataforma interna pelos processos de penetração da ACAS. No entanto, Ribeiro (1996) trabalhou com dados coletados através de arrastos oblíquos com rede bongô, não tendo a possibilidade de analisar adequadamente a distribuição vertical. Observando os resultados do presente trabalho (Figs 30 e 31) podemos notar que as faixas de profundidade em que larvas da espécie ocorreram em maior abundância estão, pelo menos em parte localizadas na interface AT/ACAS ou dentro da ACAS, indicando a possibilidade de que parte das larvas de M. stehmanni poderia aproveitar o movimento de intrusão da ACAS para ampliar a área de ocorrência até regiões costeiras, como preconizado por Ribeiro (1996).

\section{Scombridae}

Os nossos resultados comprovam estudos anteriores na região, segundo os quais larvas de espécies da família Scombridae apresentariam ocorrência quase que restrita aos meses de primavera e verão (e.g. Matsuura \& Sato, 1981; Matsuura, 1983; Katsuragawa et al., 1993). Na área de cabo Frio os scombrídeos apresentaram uma das maiores taxas de ocorrência $(78,9 \%)$, enquanto que no inverno foram muito raros, restringindo-se a apenas um arrasto positivo (5,6\% de freqüência de ocorrência). Essa característica parece ser observado também em outras regiões do mundo, por exemplo, no Golfo de São Lourenço, no Canadá, de Lafontaine \& Gascon (1989) reportam dominância de Scomber scombrus nas assembléias de ictioplâncton nos meses de verão.

Quanto à distribuição vertical os resultados apontam que na região de cabo Frio a distribuição de larvas de Scombridae foi altamente estratificada, com maiores concentrações observadas nas camadas superficiais, principalmente nas camadas 0-20 m e 20-40 m. Não foi coletada nenhuma larva desta família 
no estrato de 80 a 100 metros nos dois cruzeiros. Tendências semelhantes de distribuição foram reportadas por vários autores em outras localidades. Boehlert \& Mundy (1994) estudando a distribuição de larvas de atuns da região de Hawaii (EUA) constataram que as larvas desse grupo são geralmente restritos à camada superior de mistura, sendo mais abundantes nos primeiros $20 \mathrm{~m}$ superficiais. De acordo com esses autores, dependendo da espécie, as larvas nunca são encontradas abaixo de 84 metros de profundidade. Coombs et al. (2001) também verificaram tendência semelhante no caso de larvas de Scomber scombrus na região da baía de Biscay (GB), as quais ocorreram predominantemente nos primeiros $50 \mathrm{~m}$ da coluna de água. Tsukamoto et al. (2001) reportam que as larvas de Scomber spp. podem ocorrer entre 0 e 150 metros de profundidade durante a noite, mas somente até 50 metros durante o dia, dando indícios de migração vertical diária.

\section{Bregmacerotidae (Bregmaceros atlanticus e B. cantori)}

Em um trabalho realizado na costa sudeste do Brasil, Matsuura et al. (1993), identificaram $99,2 \%$ de larvas de Bregmaceros cantori e $0,8 \%$ de $B$. atlanticus, sendo as duas espécies mais abundantes durante o inverno. No presente estudo, houve uma alternância entre o verão e inverno, sendo $B$. cantori também mais abundante no inverno $(64,3 \%)$, porém $B$. atlanticus mais abundante no verão (80\%). Castro (2006), durante o outono, inverno e primavera, encontrou na região da costa leste brasileira maior abundância de $B$. atlanticus do que de $B$. cantori, e atribuiu essa diferença ao fato da maioria das amostras terem sido coletadas na região oceânica, além da isóbata de 200 metros. 
Matsuura et al. (1993) encontraram maior abundância de B. cantori em estações neríticas (profundidades entre 60 e 135 metros) do que em oceânicas, sendo que neste trabalho a diferença não foi significativa estatisticamente, mesmo que, aparentemente, a ocorrência pareça maior nas neríticas (neste caso, até 200 metros de profundidade). No Golfo do México, Houde (1981) observou um padrão semelhante para a espécie, porém com maior ocorrência em estações entre 120 e 130 metros de profundidade.

Em relação à distribuição vertical de $B$. cantori, os resultados indicam densidade relativamente baixa de 0 a 20 metros e predominância nas camadas de 20 a 40 metros, porém esse padrão não foi confirmado pela estatística. Matsuura et al. (1993) encontrou larvas desta espécie até 90 metros, ou seja, a profundidade máxima amostrada, sendo somente $9 \%$ entre 0 e 30 metros.

Larvas de $B$. cantori em pré-flexão ocorreram com alta freqüência no estrato de 20 a 40 metros no cruzeiro de inverno, no qual, segundo Kampel (2003), a termoclina variou entre 21 e 46 metros de profundidade, com média igual a 33 metros. Sendo assim, mais uma vez os resultados aqui presentes coincidem com o de Matsuura et al. (1993), que encontrou predominância de larvas em pré-flexão associadas à termoclina. Segundo os autores, devido à forte estratificação da coluna de água durante o verão, adultos de B. cantori parecem estar associados à ACAS nas camadas mais profundas e desovar na termoclina ou abaixo dela, sendo que as larvas permanecem principalmente próximas à termoclina formada entre a ACAS e a AT ou AC. Na figura 51, notase que, realmente, os maiores valores de densidade de $B$. cantori estão associadas à estas zonas de mistura. 
No trabalho de Matsuura et al. (1993), larvas de B. atlanticus só ocorreram na região costeira de Ubatuba (litoral norte de São Paulo) e em Cabo Frio (RJ), sendo mais freqüentes nas isóbatas de 110 e 120 metros, porém estes autores só amostraram até 140 metros. O presente estudo mostra que as espécies $B$. atlanticus e $B$. cantori possuem uma maior distribuição, já que ocorreram em estações com até 1960 metros, apesar de serem mais abundantes sobre a plataforma.

\section{Phosichthyidae (Pollichthys mauli)}

A freqüência relativa das larvas da família Phosichthyidae foi maior no inverno em relação ao verão, porém essa diferença não foi significativa. Nonaka (1999) encontrou o mesmo padrão na região do Banco de Abrolhos e adjacências. Associada com maior freqüência às zonas de mistura entre a ACAS, AT e AC.

Quanto à espécie Pollichthys mauli, no verão a espécie apresentou maior freqüência dentre as larvas da família do que no inverno, sendo que em relação ao total de larvas de cada cruzeiro, a mesma porcentagem ocorreu no verão e no inverno. Queró et al. (1990) relatam que o pico de desova de $P$. mauli ocorre no verão.

Com base na figura de distribuição vertical de Pollichthys mauli durante o verão (Fig. 57), pode-se sugerir que as larvas desta espécie são associadas à ACAS já que, apesar de ocorrerem em maior densidade na AT a partir da radial 2, anteriormente ao afloramento da ACAS junto à costa a ocorrência da espécie na AT era baixa. Sendo assim o presente trabalho corrobora os trabalhos de Itagaki (1999) e Nonaka (1999). 
Em relação à distribuição vertical em função do horário do dia (Fig. 61), parece haver uma migração vertical, de larvas em flexão e pós-flexão, para as camadas superiores da coluna de água durante o período noturno. O mesmo padrão não pôde ser identificado no inverno devido ao baixo número de exemplares nesta estação do ano.

\section{Trichiuridae}

$\mathrm{Na}$ região de cabo Frio as larvas da família Trichiuridae foram preferencialmente costeiras, tanto no verão como no inverno, sendo que dentro da composição ictioplanctônica constituiu-se num grupo entre média a baixa abundância. Analisando a área como um todo, não se encontrou diferença significativa em termos de abundância, entre verão e inverno. Também em relação à distribuição vertical, não houve diferença entre verão e inverno. Em outras áreas da costa sudeste também tem sido observado o mesmo padrão de ocorrência e abundância, como no caso da região adjacente à ilha de São Sebastião (Katsuragawa et al., prelo). Talvez a baixa abundância se deva ao fato da coleta ter sido realizada fora do período, pois conforme Nakatani et al. (1980) a época de maior abundância de ovos e larvas de trichiurídeos e o outono.

\section{3 - RELAÇÃO ENTRE OS FATORES BIÓTICOS E ABIÓTICOS E O}

\section{ICTIOPLÂNCTON}

Sabe-se que os padrões de distribuição do ictioplâncton são influenciados pela interação de processos bióticos e abióticos. Os resultados da análise BIOENV comprovaram essa hipótese para o estudo em questão, visto que as variáveis que melhor explicam a variação dos dados foram as 
porcentagens de ACAS, de AC e a concentração de clorofila-a, tanto no verão como no inverno.

Pode-se dizer que os padrões de distribuição do ictioplâncton verificados neste trabalho apresentaram forte relação com os processos físicos, devido ao fato de muitos grupos de peixes estarem relacionados principalmente às zonas de mistura entre as massas de água. A intersecção das massas de água forma uma frente de gradientes intensos que servem como áreas de retenção. Além disso, o padrão encontrado de distribuição de clorofila-a, mostrando intrusões de alta biomassa fitoplanctônica em sub-superfície, coincidindo com as intersecções das massas de água, confirma a formação de tais zonas. No caso deste estudo, tanto a penetração da ACAS sobre a plataforma continental durante o verão como a intrusão de AT decorrente dos processos de subsidência no inverno formaram frentes térmicas na região. Geralmente, as áreas de retenção são consideradas importantes por aumentar a taxa de encontro entre as larvas de peixe e suas presas, mesmo onde a densidade das presas seja menor (por exemplo, Muelbert et al., 1994). Sendo assim, a distribuição vertical das larvas de peixes pode ser então uma estratégia para sua manutenção nestas áreas.

Devido à ocorrência de famílias de distribuição oceânica em estações costeiras, ou vice-versa, pode-se dizer que os resultados encontrados neste trabalho confirmam que, além de fatores biológicos, os fatores físicos influenciam na distribuição de larvas de peixes. Processos físicos como meandros e vórtices, por exemplo, podem ocasionar trocas entre águas costeiras e oceânicas (Mann \& Lazier, 1996), fazendo com que a composição da comunidade planctônica possa ser alterada. Além disso, estes vórtices podem induzir a ressurgência em quebra de plataforma. No presente estudo, o fato de ter sido observado um 
meandramento da Corrente do Brasil à leste do cabo Frio, pode justificar que algumas espécies de distribuição oceânica relacionadas à ACAS tenham sido encontradas em estações oceânicas, porém superficiais.

Os resultados encontrados no presente estudo indicam que a área do cabo Frio, durante os cruzeiros de verão e inverno de 2001, atende aos pressupostos da chamada "Teoria da Tríade Fundamental", proposta por Bakun (1996). Esta teoria estabelece três processos atuando em conjunto, para o sucesso do recrutamento de uma espécie: enriquecimento (causado pelo aporte de nutrientes na zona eufótica), concentração (causada pela formação de frentes devido à dinâmica das massas de água) e retenção (causada pelo comportamento migratório de larvas em conjunto com os processos físicos, a fim de que se mantenham num ambiente favorável ao seu desenvolvimento). 


\section{CONCLUSÕES}

1. Na região do cabo Frio, foi verificada a ocorrência de processos de ressurgência costeira no verão, e de subsidência, no inverno, o que não implicou numa variação significativa da biomassa fitoplanctônica entre os dois períodos.

2. Os maiores valores de concentração de clorofila-a encontrados em superfície na região nerítica e em uma faixa em subsuperfície em direção ao mar aberto, tanto no verão como no inverno, parecem estar relacionados com interseções entre as diferentes massas de água.

3. Não houve uma diferença significativa na composição taxonômica no verão e no inverno dentre os grupos mais abundantes (Engraulidae, Myctophidae, Sternoptychidae, Scombridae, Bregmacerotidae, Sternoptychidae e Phosichthyidae), no entanto, foi detectada variação entre a freqüência relativa desses grupos.

4. O acima mencionado sugere uma certa estabilidade na estrutura da comunidade ictioplanctônica e que os eventos de ressurgência e subsidência na região do cabo Frio estariam promovendo principalmente variações nas densidades relativas dos grupos.

5. De acordo com os resultados da análise de agrupamento, não foi possível diferenciar as estações neríticas das oceânicas em função da composição e densidade do ictioplâncton, em nenhum dos dois períodos, devido à amostragem ter sido estratificada. 
6. De um modo geral, existe uma tendência à estratificação vertical de ovos de peixes com maior abundância nas camadas superficiais e uma gradativa diminuição em direção ao fundo.

7. As larvas dos grupos analisados apresentam uma distribuição vertical diferenciada, sendo alguns de ocorrência nas camadas superficiais (por exemplo, Scombridae), outros em águas mais profundas (por exemplo, Maurolicus stehmanni) e ainda os que apresentaram uma distribuição homogênea na coluna de água.

8. De um modo geral não houve um padrão claro de distribuição vertical das larvas em função das classes de comprimento, salvo em alguns casos particulares.

9. De acordo com as análises multivariadas, é possível afirmar que o padrão de distribuição do ictioplâncton é determinado, em parte, pelas porcentagens de ACAS, de AC e a concentração de clorofila-a, tanto no verão como no inverno.

10. Com base nos resultados obtidos, foi possível demonstrar a influência direta dos processos físicos de mesoescala (i.e. ressurgência e subsidência) e dos padrões de distribuição de clorofila-a sobre a distribuição vertical do ictioplâncton na região do cabo Frio. 


\section{REFERÊNCIAS BIBLIOGRÁFICAS}

Ahlstrom, E. H. 1959. Vertical distribution of pelagic fish eggs and larvae off California and Baja California. U. S. Fish. Wild. Serv. Fish. Bull., 60: 107-146.

Ahlstrom, E. H. \& Ball, O. P. (1954). Description of eggs and larvae of jack mackerel (Trachurus symmetricus) and distribution and abundance of larvae in 1950 and 1951. Fish. Bull., 56: 207-245.

Aidar, E.; Gaeta, S. A.; Gianesella-Galvão, S. M. F.; Kutner, M. B. B. \& Teixeira, C. 1993. Ecossistema costeiro subtropical: nutrientes dissolvidos, fitoplâncton e clorofila-a e suas relações com as condições oceanográficas na região de Ubatuba, SP. Publção esp. Inst. Oceanogr., S Paulo, (10): 9-43. Allard, P. 1955. Anomalies dans le temperature de l'eau de la mer observees au Cabo Frio au Bresil. Bull. Inf. Com. Oceanogr. Etude Cotes, 7(2): 58-63.

Amor, C. 2004. Intrusões da Água Central do Atlântico Sul sobre a Plataforma Continental situada entre a llha de São Sebastião (SP) e o Cabo de São Tomé (RJ). Tese de Doutorado. Universidade de São Paulo, Inst. Oceanográfico. São Paulo, 254 p.

Bakun, A. 1996. Patterns in the ocean. Ocean Processes and Marine Population Dynamics. Centro de Investigaciones Biológicas del Noroeste, La Paz, BCS, México. 323 p.

Bjorkstedt, E. R.; Grantham, B. A.; Shkeady, Y.; Rosenfeld, L. \& Roughgarden, J. 1997. Ichthyoplankton distributions at coastal upwelling fronts off central California: implications for larval transport. In: Ichthyoplankton Ecology. Annual International Symposium. Fisheries Society of the British Isles. Julho, 1997. Resumos. University College Galway, República da Irlanda. 5 p. 
Boehlert, G. W. \& Mundy, B. C. 1994. Vertical and onshore-offshore distributional patterns of tuna larvae in relation to physical habitat features. Mar. Ecol. Prog. Ser., 107: 1-13.

Brewer, G. D. \& Kleppel, G. S. 1986. Diel vertical distribution of fish larvae and their prey in nearshore waters of southern California. Mar. Ecol. Prog. Ser., 27: 217-226.

Campos, E. J. D. 1995. Estudos da circulação oceânica no Atlântico Tropical e região oeste do Atlântico Subtropical Sul. Tese de Livre Docência. Inst. Oceanográfico da Universidade de São Paulo. São Paulo, 144 p.

Campos, E. J. D.; Gonçalves, J. E. \& Ikeda, Y. 1995. Water mass characteristics and geostrophic circulation in the South Brazil Bight-summer 1991. J. Geophys. Res., 100(9): 18537-18550.

Campos, E. J. D.; Lorenzzetti, J. A.;Stevenson, M. R.; Stech, J. L. \& De Souza, R. B. 1996. Penetration of Waters from the Brazil-Malvinas Confluence Region Along the South American Continental Shelf up tp $23^{\circ} \mathrm{S}$. An. Acad. Bras. Ci., 68: 49-58.

Castro, M. S. 2006. Variação espacial e temporal das larvas de peixes ao norte e ao sul do banco de Abrolhos e no entorno da cadeia Vitória-Trindade. Tese de Doutorado, Inst. de Biologia/Ecologia, Universidade Federal do Rio de Janeiro, Rio de Janeiro, $190 \mathrm{p}$.

Castro Filho, B. M. de.; de Miranda, L. B. \& Myao, S. Y. 1987. Condições hidrográficas na plataforma continental ao largo de Ubatuba: variações sazonais e em média escala. Bolm. Inst. oceanogr., S Paulo., 32(2): 135151. 
Castro Filho, B. M. de. 1996. Correntes e massas de água da plataforma norte de São Paulo. Tese de Livre Docência. Universidade de São Paulo, Inst. Oceanográfico. São Paulo, 248 p.

Castro Filho, B. M. de \& Miranda L. B. 1998. Physical oceanography of the western Atlantic continental shelf located between $4^{\circ} \mathrm{N}$ and $34^{\circ} \mathrm{S}$ coastal segment (4,W). In: Robinson, A. R. \& Brink, K. H., eds. The sea. Oxford, John Wiley \& Sons, pp: 209-251.

Clarke, K. R. \& Warwick, R. M. 1994. Change in marine communities: an approach to statistical analysis and interpretation. Plymouth Marine Laboratory, Plymouth, $144 \mathrm{p}$.

Coombs, S. H.; Giovanardi, O.; Halliday, N.; Manzueto, L. \& Hansell, R. 1997. Drift and mortality of eggs and larvae of anchovy (Engraulis encrasicolus) in relation to changes in wind mixing and freshwater discharge of the River Po. In: Ichthyoplankton Ecology. Annual International Symposium. Fisheries Society of the British Isles. Julho, 1997. Resumos. University College Galway, República da Irlanda. 8 p.

Coombs, S. H.; Morgans, D. \& Halliday, N. C. 2001. Seasonal and ontogenetic changes in the vertical distribution of eggs and larvae of mackerel (Scomber scombrus L.) and horse mackerel (Trachurus trachurus L.). Fish. Res., 50: $27-40$.

de Lafontaine, Y. \& Gascon, D. 1989. Ontogenetic variation in the vertical distribution of eggs and larvae of Atlantic mackerel (Scomber scombrus). Rapp. P.-v. Réun. Cons. int. Explor. Mer., 191: 137-145 
Denman, K. L. \& Powell, T. M. 1984. Effects of physical processes on planktonic ecosystems in the coastal ocean. Oceanogr. mar. Biol. Ann. Rev., 22: 125168.

Dias, J. F. 1995 Avaliação da condição nutricional das larvas de sardinhaverdadeira (Sardinella brasiliensis Steindachner, 1879) Clupeidae e da anchoíta (Engraulis anchoíta Hubbs \& Marini, 1935) Engraulididae, da costa sudeste do Brasil. Dissertação de mestrado. . Universidade de São Paulo, Inst. Oceanográfico. São Paulo, 191 p.

Emílsson, I. 1956. Relatório e resultados físico-químicos de três cruzeiros oceanográficos em 1956. Contr. Inst. oceanogr., Univ. S. Paulo, sér. Oceanogr. fís., 1: 1-70.

Emílsson, I. 1961. The shelf and coastal waters off southern Brazil. Bolm Inst. oceanogr., S Paulo, 11(2): 101-112.

Fahay, M. P. 1983. Guide to the early stages of marine fishes occurring in the Western North Atlantic Ocean, Cape Hateras to Southern Scotian Shelf. J. NE. Atlantic Fish. Sci., 4: 1-426.

Falkowski, P. G.; Ziemann, D.; Kolber, Z. \& Bienfang, P. K. 1991. Role of eddy pumping in enhancing primary production in the ocean. Nature, v.352, p.55.

Franco, B. F. \& Muelbert, J. H. 2003. Distribuição e composição do ictioplâncton na quebra de Plataforma do Sul do Brasil. Atlântica, Rio Grande, 25(1): 7586.

Franco, B. F.; Muelbert, J. H. \& Mata, M. M. 2006. Mesoscale physical processes and the distribution and composition of ichthyoplankton on the southern Brazilian shelf break. Fish. Oceanogr., 15 (1), 37-43. 
Freire, K. M. F. 1995. Alimentação de larvas de Engraulis anchoita (Teleostei: Engraulididae) na plataforma continental do Rio Grande do Sul, Brasil. Dissertação de Mestrado, Fundação Universidade do Rio Grande. Rio Grande, 74 p.

Gaeta, S. A. 1999. Produção Primária na Região Oeste do Atlântico Sul. Tese de Livre Docência. Inst. Oceanográfico da Universidade de São Paulo. São Paulo, $140 \mathrm{p}$.

Gaeta, S. A.; Metzler, P. M. \& Lopes, R. M. 1993. Plâncton e Produtividade Primária na plataforma da costa norte do Estado do Rio de JaneiroCampanha de Verão (dez/91-jan/92). Relatório do Projeto Monitoramento Oceânico da Bacia de Campos. FUNDESPA/GEOMAP-PETROBRAS.

González-Rodriguez, E.; Valentin, J. L.; André D. L. \& Jacob, S. A. 1992. Upwelling and downwelling at Cabo Frio (Brazil): comparison of biomass and primary production responses. J. Plankton Res., 14(2): 289-306.

González-Quirós R.; Cabal, J.; Álvarez-Marqués, F. \& Isla, A. 2003. Tchthyoplankton distribution and plankton production related to the shelf break at the Avilés Canyon. J. Mar Sci., 60: 198-210.

Gray, C. A. 1996. Do thermoclines explain the vertical distributions of larval fishes in the dynamic coastal waters of south-eastern Australia? Mar. Freshwater Res., 47: 183-190.

Grioche, A.; Harlay, X.; Koubbi, P. \& Lago, L. F., 2000. Vertical migrations of fish larvae: Eulerian and Lagrangian observations in the Eastern English Channel. J. Plankton Res., 22(10): 1813-1828

Guille A. 1970 Benthic bionomy of continental shelf of the French Catalane coast. II. Benthic communities of the macrofauna. Vie Milieu, 21 (8): 149-280. 
Haldorson, L.; Prichett, M.; Paul, A. J. \& Ziemann, D. 1993. Vertical distribution and migration of fish larvae in a Northeast Pacific bay. Mar. Ecol. Prog. Ser., 101: $67-80$.

Hempel, G.,1979. Early life history of marine fish. The egg stage. University of Washington. Washington Sea Grant Program, Seattle, 70 p.

Hill, M. O. 1979. TWINSPAN - A FORTRAN program for arranging multivariate data in a ordered two-way table by classification of the individuals and attributes. New York. Cornell University, Ithaca, 48 p.

Houde, E. D. 1981. Distribution and abundance of four types of codlet (Pisces: Bregmacerotidae) larvae from the eastern Gulf of Mexico. Biol. Oceanogr., 1:81-104.

Hunter, J. R. \& Sanchez, C. 1976. Diel changes in swim bladder inflation of the larvae of the northern anchovy, Engraulis mordax. Fish. Bull. U. S., 74: 847855.

Itagaki, M. K. 1999. Composição, Abundancia e Distribuição Horizontal das Assembléias de Larvas de Peixes Marinhos e sua Relação com os Fatores Hidrográficos na Costa Sudeste do Brasil. Dissertação de Mestrado. Inst. Oceanográfico da Universidade de São Paulo. São Paulo, 208 p.

Kampel, M. 2003. Estimativa da produção primária e biomassa fitoplanctônica através de sensoriamento remoto da cor do oceano e dados in situ na costa sudeste brasileira. Tese de doutorado. Inst. Oceanográfico da Universidade de São Paulo. São Paulo, 272 p.

Katsuragawa, M. 1985. Estudos sobre a variabilidade de amostragem, distribuição e abundância de larvas de peixes da região sudeste do Brasil. 
Dissertação de Mestrado. Inst. Oceanográfico da Universidade de São Paulo. São Paulo, 107 p. + tabs. + figs.

Katsuragawa, M. \& Matsuura, Y. 1990. Comparison of the diel and spatial distribution patterns of ichthyoplankton and ichthyoneuston in the Southeastern Brazilian Bight. Bolm Inst. oceanogr., S Paulo, 38(2): 133-146.

Katsuragawa, M. \& Matsuura, Y. 1992. Distribution and abundance of carangid larvae in the Southeastern Brazilian Bight during 1975-1981. Bolm Inst. oceanogr., S Paulo. 40(1/2): 55-78.

Katsuragawa, M.; Matsuura, Y.; Suzuki, K., Dias, J. F. \& Spach, H. L. 1993. O ictioplâncton ao largo de Ubatuba, SP: composição, distribuiçãoo e ocorrência sazonal (1985-1988). Publção esp. Inst. Oceanogr., S Paulo, (10): 85-121.

Katsuragawa, M.; Dias, J. F. \& Lopes, C. L. (no prelo) A Comunidade Ictioplanctônica. In.: Oceanografia de um Ecossistema Tropical Costeiro: Plataforma de São Sebastião. Pires-Vanin A. M. S. \& Furtado, V. V. eds.

Kendall, A. W. \& Naplin, N. A. 1981. Diel-depht distribution of summer ichthyoplankton in the middle Atlantic bight. Fishery Bulletin, 79 (4): 705-735.

Kramer, D.; Kalin, M. J.; Stevens, E. G.; Treikill, J. R. \& Zweifel, J. R. 1972. Collecting and processing data on fish eggs and larvae in the California current region. U.S. Dept. of Commerce. NOAA Tech. Rep. NMFS Circ., 370: 1-38.

Kurtz, F.W. 1999. Dinâmica larval de Sardinella brasiliensis (Steindachner, 1879) (Teleostei, Clupeidae) na região sudeste do Brasil e implicações no recrutamento. Tese de Doutorado, Instituto Oceanográfico, Universidade de São Paulo. São Paulo, 169 p. 
Leis, J. M. 1991. The pelagic stage of reef fishes: the larval biology of coral reef fishes. In: Sale, P. F. ed. The ecology of fishes on coral reefs. San Diego, Academic Press, 183-230.

Leis, J. M. \& Rennis, D. S. 1983. The larvae of Indo-Pacific coral reefs. Honolulu, Univ. Hawaii Press, 269 p.

Leis, J. M. \& Trnski, T. 1989. The larvae of Indo-Pacific shorefishes. Honolulu, Univ. Hawaii Press, 371 p.

Leite, J. R. B. 2005. Correntes na Plataforma Continental ao largo de Arraial do Cabo (RJ): medições com perfilador acústico (ADCP). Dissertação de Mestrado. Inst. Oceanográfico da Universidade de São Paulo. São Paulo, 167 p.

Mann, K. H. \& Lazier, J. R. N. 1996. Dynamics of Marine Ecosystems.

Biological-Physical Interactions in the Oceans. Second edition. Blackwell Science, USA, 394 p.

Mascarenhas, A. S.; Miranda, L. B. \& Rock, N. J. 1971. A study of the oceanographic conditions in the region of Cabo Frio. In: Costlow, J. D. org. The fertility of the sea. New York, Gordon \& Breach, p. 285-308.

Matsuura, Y. \& Sato, G. 1981. Distribution and abundance of Scombrid larvae in Southern Brazilian waters. Bull Mar. Sci., 31(4): 824-832.

Matsuura, Y. 1983. Estudo comparativo das fases iniciais do ciclo de vida da sardinha verdadeira, Sardinella brasiliensis e da sardinha cascuda, Harengula jaguana, (Pisces: Clupeidae) e nota sobre a dinâmica da população da sardinha verdadeira na região sudeste do Brasil. Tese de Livre-Docência. Universidade de São Paulo, Inst. Oceanográfico. São Paulo, 150p. + Tabs + Figs. 
Matsuura, Y. 1986. Contribuição ao estudo da estrutura oceanográfica da região sudeste entre o Cabo Frio (RJ) e o Cabo de Santa Marta Grande (SC). Ciência e Cultura, 38(8): 1439-1450.

Matsuura, Y. 1990. Synopsis on the reproductive biology and early life history of the Brazilian sardine, Sardinella brasiliensis and related environmental conditions. IOC Workshop Rep No. 65 Annex 8: 1-8.

Matsuura, Y.; Garcia, A. C. S.; Katsuragawa, M. \& Suzuki, K. 1993. Distribution and abundance of two species of codlet (Teleostei, Bregmacerotidae) larvae from the south-eastern Brazilian Bight. Fish. Oceanogr., 2(2): 82-90.

Matsuura, Y. \& Kitahara, E. M. 1995. Horizontal and vertical distribution of anchovy Engraulis anchoita eggs and larvae off Cape Santa Marta Grande in southern Brazil. Arch. Fish. Mar. Res., 42 (3):239-250.

Miranda, L. B. de. 1982. Análise de massas de água da plataforma continental e da região oceânica adjacente: Cabo de São Tomé (RJ) e a llha de São Sebastião (SP), Brasil. Tese de Livre Docência. Universidade de São Paulo, Instituto Oceanográfico. São Paulo, 123 p.

Moser, H. G. ed. 1996. The early stages of fishes in the California Current region. CalCOFI. Atlas, 33: 1-1505.

Moser, H. G. \& Ahlstrom, E. H. 1970. Development of laternfishes (family Myctophidae) in the California Current. Part. 1. Species with narrow-eyed larvae. Bull. Los Angeles Cty. Mus. Nat. Hist. 7: 1-145.

Muelbert, J. H.; Lewis, M. R. \& Kelley, D. E. 1994. The importance of small-scale turbulence in the feeding of herring larvae. J. Plankton Res., 16(8): 927-944. 
Muelbert, J. H. \& Sinque, C. 1996. Distribution of bluefish (Pomatomus saltatrix) larvae along the continental shelf off southern Brazil. Mar. Freshwater Res., 47: 311-314.

Nakatani, K. Matsuura, Y. \& Sato, G. 1980. Estudo do ciclo de vida do peixeespada Trichiurus lepturus. Bolm. Inst. Oceanogr., São Paulo, 29(2): 255259.

Neilson, J. D. \& Perry, R. I. 1990. Diel vertical migrations of marine fishes: an obligate or facultative process? Adv. mar. Biol., 26: 115-168.

Nelson, J. S.1994. Fishes of the world. $3^{\circ}$ ed. New York. John Wiley \& Sons, 600 p.

Nonaka, R. H. 1999. Distribuição e Abundância de Larvas de Peixes marinhos da região do Banco dos Abrolhos e Águas Adjacentes, e suas Relações com as Condições Oceanográficas. Dissertação de Mestrado. Inst. Oceanográfico da Universidade de São Paulo. São Paulo, 144 p.

Norcross, B. L. \& Shaw, R. F. 1984. Oceanic and estuarine transport of fish eggs and larvae: a review. Trans. Am. Fish. Soc., 113: 153-365.

Parrish, R. H.; Nelson, C. S. \& Bacon, A. 1981. Transport mechanisms and reproductive success of fishes in the California current. Biol. Oceanogr., 1: 175-203.

Peterson, W. T.; Miller, C. B. \& Hutchinson, A. 1979. Zonation and maintenance of copepod populations in the Oregon upwelling zone. Deep-sea Res, 26A: 467-494.

Piola, A. R.; Campos, E. J. D.; Möller, O. O.Jr.; Chao, M. \& Martinez, C. M. 2000. Subtropicla shelf front off eastern South América. J. Geophys. Res., 105: 6566-6578. 
Piola, A. R.; Matano, R. P; Palma, E. D. Möller, O. O. Jr. \& Campos, E. J. D. 2005. The influence of the Plata River discharge on the western South Atlantic shelf. Geophys. Res. Letters, 32: 1-4.

Power, J. H. 1984. Advection, diffusion, and drift migrations of larval fishes. In: McCleave, J. D.; Arnold, G. P.; Dodson, J. J. \& Neill, W. H. eds. Mechanisms of migration in fishes. NATO Conference Series. Series IV: Marine Science, 14: 27-38. Plenum Press, New York.

Quero, J. C. ; Njock, J. C. \& de la Hoz, M. M. 1990. Photichythyidae. In: Quéro, J. C.; Hureau, J. C.; Barrer, C.; Post, A. \& Saldanha, L. (eds.). Check-list of the fishes of the eastern tropical Atlantic (CLOFETA). JNICT, Lisbon; SEI, Paris; and UNESCO, Paris. Vol.1 pp: 343-348.

Ribeiro, M. R. 1996. Estudos sobre o desenvolvimento larval, abundância e distribuição de ovos e larvas da Maurolicus muelleri (Gmelin, 1789) (Teleostei: Sternoptychidae), e possíveis potencialidades ao largo da costa sudeste brasileira, compreendida entre $23^{\circ} \mathrm{S}$ (Cabo Frio-RJ) e $29^{\circ} \mathrm{S}$ (Cabo de Santa Marta Grande-SC). Dissertação de Mestrado. Inst. Oceanográfico da Universidade de São Paulo. São Paulo, 160 p.

Santos, A. M. P.; Peliz, A.; Dubert, J.; Oliveira, P. B.; Angélico M. M. \& Ré, P. 2004. Impact of a winter upwelling event on the distribution and transport of sardine (Sardina pilchardus) eggs and larvae off western Iberia: a retention mechanism. Cont. Shelf Res., 24: 149-165.

Sassa, C.; Kawaguchi, K; OOzeki, Y.; Kubota, H \& Sugisaki, H. 2004. Distribution patterns of larval myctophid fishes in the transition region of the western North Pacific. Mar. Biol., 144: 417-428. 
Sherman, K.; Smith, W.; Morse, W.; Berman, M.; Green, J. \& Ejsymont, L. 1984. Spawning strategies of fishes in relation to circulation, phytoplankton production, and pulses in zooplankton off the northeastern United States. Mar. Ecol. Prog. Ser., 18: 1-19.

Silva, P. de C. M. \& Rodrigues, R. F. 1966. Modificações na estrutura vertical das águas sobre a borda da plataforma continental, por influência do vento. Nota téc. Inst. Pesq. Mar., 35: 1-13.

Silveira, I. C. A. da; Schmidt, A. C. K.; Campos, E. J. D.; Godoy, S. S. de \& Ikeda, Y. 2000. A corrente do Brasil ao largo da costa leste brasileira. Rev. Bras. oceanogr., 48 (2): 171-183.

Sinque, C. \& Muelbert, J. H. 1997. Ichthyoplankton. In: Seeliger, U.; C. Odebrechr \& Castello, J. P. (eds.). Subtropical convergence environments. The coast and sea in the Southwestern Atlantic. Srpinger, berlin, pp: 51-56.

Smith, K. A. \& Suthers, I. M., 1999. Displacement of diverse ichthyoplankton assemblages by a coastal upwelling event on the Sidney shelf. Mar. Ecol. Prog. Ser., 176: 49-62.

Spach, H. L. 1990. Estudo comparativo da distribuição espaço-temporal e de padrões de agregação de ovos e larvas de Harengula jaguana, Sardinella brasiliensis (Clupeidae: Osteichthyes) e Engraulis anchoita (Engraulidae: Osteichthyes) na costa sudeste do Brasil. Tese de Doutorado. Universidade de São Paulo, Instituto Oceanográfico. São Paulo, 87 p. + 135 tabs + 90 figs. Stephenson, R. L. \& Power, M. J. 1989. Observations on herring larvae retained in the Bay of Fundy: variability in vertical movement and position of the patch edge. Rapp. P.-v. Réun. Cons. int. Explor. Mer, 191: 177-183. 
Tsukamoto, Y.; Zenitani, H., Kimura, R.; Watanabe, Y. \& Oozeki, Y. 2001. Vertical distribution of fish larvae in the Kuroshio and Kuroshio-Oyashio transition region in early summer. Bull. Natl. Res. Inst. Fish. Sci. , 16:39-56. Valentin, J. L. 1984. Analyse des parametres hydrobiologiques dans la remontée de Cabo Frio (Brésil). Mar. Biol., 82: 259-276.

Valentin, J. L.; André, D. L. \& Jacob, S. A. 1987. Hydrobiology in the Cabo Frio (Brazil) upwelling: two dimensional structure and variability during a wind cycle. Cont. Shelf Res., 7: 77-88.

Valentin J. L. 1989. A dinâmica do plâncton na ressurgência de Cabo Frio-RJ. In: III Encontro Brasileiro de Plâncton, Proceedings. Caiobá-PR, Fundação da Universidade Federal do Paraná, pp: 26-35.

Valentin, J. L. 2000. Ecologia numérica. Uma introdução à análise multivariada de dados ecológicos. Interciência. Rio de Janeiro, 117 p.

Valentin, J. L. \& Monteiro-Ribas, W. M. 1993. Zooplankton community structure on the east-southeast Brazilian continental shelf $\left(18-23^{\circ} S\right.$ latitude) Cont. Shelf Res., 13 (4): 407-424.

Weiss, G.; Hubold, G. \& Bonecker, A. C. 1988. Eggs and larvae of Maurolicus muelleri (Gmelin, 1789) (Teleostei, Sternoptychidae) in the southwest Atlantic. Meeresforsch, 32: 53-60.

Yoneda, N.T. 1987. Criação em laboratório de larvas da sardinha-verdadeira, Sardinella brasiliensis, e estudo dos incrementos diários nos otólitos. Dissertação de Mestrado, Universidade de São Paulo, Instituto Oceanográfico. São Paulo, 92 p.

Zar, J. H. 1996. Bioestatistical analysis. $3^{a}$. ed., Englewood Cliffis, Prentice-Hall, $661 \mathrm{p}$. 
Tabela 1. Valores de temperatura do cruzeiro de verão de 2001, na região do cabo Frio $(\mathrm{RJ})$. (prof. = faixa de profundidade; média = temperatura média; sd = desvio padrão; $\min =$ valor mínimo; $\max =$ valor máximo)

\begin{tabular}{|c|c|c|c|c|c|}
\hline \multirow{2}{*}{$\begin{array}{c}\mathrm{n}^{\circ} \mathrm{da} \\
\text { estação }\end{array}$} & \multirow{2}{*}{$\operatorname{prof}(m)$} & \multicolumn{4}{|c|}{ temperatura $\left({ }^{\circ} \mathrm{C}\right)$} \\
\hline & & média & $s d$ & $\min$ & $\max$ \\
\hline \multirow{5}{*}{84} & $0-20$ & 27,67 & 0,08 & 27,58 & 27,85 \\
\hline & $20-40$ & 27,44 & 0,11 & 27,14 & 27,57 \\
\hline & $40-60$ & 25,61 & 0,91 & 24,22 & 27,04 \\
\hline & $60-80$ & 23,28 & 0,40 & 22,84 & 24,09 \\
\hline & $80-100$ & 22,46 & 0,19 & 22,19 & 22,81 \\
\hline \multirow{5}{*}{85} & $0-20$ & 26,92 & 0,64 & 25,78 & 27,62 \\
\hline & $20-40$ & 24,78 & 0,40 & 24,36 & 25,64 \\
\hline & $40-60$ & 23,73 & 0,42 & 23,04 & 24,33 \\
\hline & $60-80$ & 22,20 & 0,47 & 21,55 & 22,97 \\
\hline & $80-100$ & 21,19 & 0,26 & 20,63 & 21,52 \\
\hline \multirow{5}{*}{86} & $0-20$ & 26,14 & 0,68 & 24,94 & 27,02 \\
\hline & $20-40$ & 23,62 & 0,75 & 22,36 & 24,81 \\
\hline & $40-60$ & 20,83 & 0,80 & 19,70 & 22,21 \\
\hline & $60-80$ & 18,63 & 0,61 & 17,75 & 19,60 \\
\hline & $80-100$ & 17,18 & 0,37 & 16,59 & 17,71 \\
\hline \multirow{5}{*}{87} & $0-20$ & 25,46 & $\overline{0,81}$ & 24,19 & 26,93 \\
\hline & $20-40$ & 23,10 & 0,43 & 22,57 & 24,01 \\
\hline & $40-60$ & 22,08 & 0,28 & 21,74 & 22,52 \\
\hline & $60-80$ & 20,41 & 0,68 & 19,57 & 21,68 \\
\hline & $80-100$ & 18,80 & 0,47 & 18,15 & 19,52 \\
\hline \multirow{5}{*}{88} & $0-20$ & 25,31 & 1,00 & 24,15 & 26,67 \\
\hline & $20-40$ & 23,07 & 0,50 & 22,36 & 24,04 \\
\hline & $40-60$ & 21,78 & 0,38 & 21,15 & 22,31 \\
\hline & $60-80$ & 19,91 & 0,77 & 18,67 & 21,07 \\
\hline & $80-100$ & 17,00 & 0,90 & 15,88 & 18,52 \\
\hline \multirow{2}{*}{89} & $0-20$ & 19,47 & 1,98 & 16,83 & 23,11 \\
\hline & $20-40$ & 15,51 & 0,47 & 15,17 & 16,55 \\
\hline \multirow{5}{*}{94} & $0-20$ & 24,85 & $\overline{0,91}$ & 23,29 & 25,66 \\
\hline & $20-40$ & 22,49 & 0,26 & 22,09 & 23,15 \\
\hline & $40-60$ & 21,40 & 0,31 & 20,96 & 22,01 \\
\hline & $60-80$ & 19,60 & 1,06 & 17,61 & 20,90 \\
\hline & $80-100$ & 15,51 & 0,73 & 14,59 & 17,21 \\
\hline \multirow{5}{*}{95} & $0-20$ & 24,96 & 1,03 & 23,04 & 25,80 \\
\hline & $20-40$ & 22,73 & 0,09 & 22,58 & 22,94 \\
\hline & $40-60$ & 21,83 & 0,61 & 20,66 & 22,56 \\
\hline & $60-80$ & 19,79 & 0,80 & 18,00 & 20,55 \\
\hline & $80-100$ & 16,99 & 0,36 & 16,70 & 17,83 \\
\hline \multirow{5}{*}{96} & $0-20$ & 25,18 & 0,47 & 24,21 & 25,55 \\
\hline & $20-40$ & 23,13 & 0,61 & 22,38 & 24,13 \\
\hline & $40-60$ & 21,70 & 0,45 & 20,97 & 22,31 \\
\hline & $60-80$ & 19,44 & 1,06 & 18,24 & 20,93 \\
\hline & $80-100$ & 17,99 & 0,17 & 17,62 & 18,20 \\
\hline
\end{tabular}

\begin{tabular}{|c|c|c|c|c|c|}
\hline \multirow{2}{*}{$\begin{array}{l}\mathrm{n}^{\circ} \text { da } \\
\text { estação }\end{array}$} & \multirow{2}{*}{ prof $(m)$} & \multicolumn{4}{|c|}{ temperatura $\left({ }^{\circ} \mathrm{C}\right)$} \\
\hline & & média & sd & $\min$ & $\max$ \\
\hline \multirow{5}{*}{97} & $0-20$ & 25,54 & 0,81 & 23,99 & 26,28 \\
\hline & $20-40$ & 22,98 & 0,45 & 22,39 & 23,84 \\
\hline & $40-60$ & 21,68 & 0,39 & 21,00 & 22,33 \\
\hline & $60-80$ & 19,87 & 0,64 & 18,75 & 20,90 \\
\hline & $80-100$ & 17,77 & 0,47 & 17,03 & 18,62 \\
\hline \multirow{5}{*}{01} & $0-20$ & 25,96 & 0,08 & 25,69 & 26,00 \\
\hline & $20-40$ & 24,10 & 0,85 & 22,95 & 25,57 \\
\hline & $40-60$ & 22,76 & 0,08 & 22,62 & 22,90 \\
\hline & $60-80$ & 22,36 & 0,29 & 21,64 & 22,62 \\
\hline & $80-100$ & 19,74 & 0,98 & 18,30 & 21,45 \\
\hline \multirow{5}{*}{02} & $0-20$ & 25,94 & 0,52 & 24,71 & 26,26 \\
\hline & $20-40$ & 23,58 & 0,76 & 22,58 & 24,61 \\
\hline & $40-60$ & 21,94 & 0,45 & 20,96 & 22,55 \\
\hline & $60-80$ & 19,49 & 0,55 & 18,50 & 20,71 \\
\hline & $80-100$ & 17,68 & 0,40 & 17,09 & 18,36 \\
\hline \multirow{5}{*}{03} & $0-20$ & 24,51 & $\overline{0,90}$ & 23,25 & 25,48 \\
\hline & $20-40$ & 22,70 & 0,28 & 22,40 & 23,22 \\
\hline & $40-60$ & 21,59 & 0,64 & 20,48 & 22,38 \\
\hline & $60-80$ & 19,41 & 0,51 & 18,61 & 20,38 \\
\hline & $80-100$ & 17,71 & 0,33 & 17,37 & 18,45 \\
\hline \multirow{5}{*}{04} & $0-20$ & 24,77 & 0,30 & 23,78 & 24,91 \\
\hline & $20-40$ & 22,02 & 0,78 & 21,03 & 23,42 \\
\hline & $40-60$ & 20,68 & 0,23 & 20,40 & 21,01 \\
\hline & $60-80$ & 20,00 & 0,60 & 18,35 & 20,40 \\
\hline & $80-100$ & 15,68 & 1,02 & 14,75 & 17,93 \\
\hline \multirow{5}{*}{06} & $0-20$ & 23,67 & 0,82 & 21,92 & 24,33 \\
\hline & $20-40$ & 21,24 & 0,40 & 20,70 & 21,80 \\
\hline & $40-60$ & 20,50 & 0,07 & 20,40 & 20,66 \\
\hline & $60-80$ & 17,73 & 2,09 & 14,42 & 20,37 \\
\hline & $80-100$ & 14,32 & 0,01 & 14,31 & 14,35 \\
\hline \multirow{2}{*}{09} & $0-20$ & 14,62 & 0,16 & 14,18 & 14,72 \\
\hline & $20-40$ & 13,87 & 0,12 & 13,72 & 14,08 \\
\hline \multirow{5}{*}{13} & $0-20$ & 24,61 & 0,40 & 23,42 & 24,83 \\
\hline & $20-40$ & 22,09 & 0,42 & 21,41 & 23,04 \\
\hline & $40-60$ & 20,82 & 0,27 & 20,49 & 21,35 \\
\hline & $60-80$ & 20,02 & 0,26 & 19,69 & 20,46 \\
\hline & $80-100$ & 17,27 & 1,77 & 14,97 & 19,65 \\
\hline \multirow{5}{*}{15} & $0-20$ & 24,07 & 0,56 & 22,48 & 24,39 \\
\hline & $20-40$ & 20,26 & 0,61 & 19,69 & 21,98 \\
\hline & $40-60$ & 18,19 & 0,84 & 16,87 & 19,60 \\
\hline & $60-80$ & 15,14 & 0,96 & 14,28 & 16,75 \\
\hline & $80-100$ & 14,27 & 0,00 & 14,27 & 14,28 \\
\hline \multirow{2}{*}{18} & $0-20$ & 16,16 & 0,67 & 15,16 & 17,06 \\
\hline & $20-40$ & 14,90 & 0,17 & 14,63 & 15,13 \\
\hline
\end{tabular}


Tabela 2. Valores de temperatura do cruzeiro de inverno de 2001, na região do cabo Frio (RJ). (prof. = faixa de profundidade; média = temperatura média; sd = desvio padrão; $\min =$ valor mínimo; $\max =$ valor máximo)

\begin{tabular}{|c|c|c|c|c|c|}
\hline \multirow{2}{*}{$\begin{array}{l}\mathrm{n}^{\circ} \text { da } \\
\text { estação }\end{array}$} & \multirow{2}{*}{ prof. (m) } & \multicolumn{4}{|c|}{ temperatura $\left({ }^{\circ} \mathrm{C}\right)$} \\
\hline & & média & sd & $\min$ & $\max$ \\
\hline \multirow{4}{*}{50} & $0-20$ & 22,65 & 0,01 & 22,63 & 22,66 \\
\hline & $20-40$ & 22,79 & 0,16 & 22,65 & 23,19 \\
\hline & $40-60$ & 22,60 & 0,74 & 21,50 & 23,40 \\
\hline & $60-80$ & 20,17 & 0,91 & 18,27 & 21,42 \\
\hline \multirow{5}{*}{51} & $0-20$ & 23,02 & 0,04 & 23,00 & 23,13 \\
\hline & $20-40$ & 23,64 & 0,27 & 23,18 & 24,09 \\
\hline & $40-60$ & 23,94 & 0,21 & 23,49 & 24,20 \\
\hline & $60-80$ & 22,37 & 0,57 & 21,38 & 23,37 \\
\hline & $80-100$ & 20,22 & 0,57 & 19,17 & 21,23 \\
\hline \multirow{5}{*}{52} & $0-20$ & 23,05 & 0,00 & 23,04 & 23,05 \\
\hline & $20-40$ & 23,16 & 0,09 & 23,05 & 23,28 \\
\hline & $40-60$ & 22,75 & 0,57 & 21,51 & 23,28 \\
\hline & $60-80$ & 19,76 & 0,82 & 18,48 & 21,29 \\
\hline & $80-100$ & 17,40 & 0,43 & 16,83 & 18,32 \\
\hline \multirow{5}{*}{53} & $0-20$ & 24,72 & 0,00 & 24,71 & 24,72 \\
\hline & $20-40$ & 24,69 & 0,03 & 24,63 & 24,71 \\
\hline & $40-60$ & 24,49 & 0,08 & 24,39 & 24,62 \\
\hline & $60-80$ & 24,36 & 0,01 & 24,35 & 24,38 \\
\hline & $80-100$ & 24,33 & 0,05 & 24,21 & 24,36 \\
\hline \multirow{5}{*}{54} & $0-20$ & 23,94 & 0,04 & 23,87 & 23,99 \\
\hline & $20-40$ & 23,79 & 0,05 & 23,72 & 23,87 \\
\hline & $40-60$ & 23,69 & 0,02 & 23,67 & 23,74 \\
\hline & $60-80$ & 23,77 & 0,02 & 23,74 & 23,79 \\
\hline & $80-100$ & 23,01 & 0,48 & 22,28 & 23,72 \\
\hline \multirow{5}{*}{55} & $0-20$ & 22,98 & 0,00 & 22,97 & 22,98 \\
\hline & $20-40$ & 23,06 & 0,12 & 22,98 & 23,34 \\
\hline & $40-60$ & 22,38 & 0,66 & 21,45 & 23,35 \\
\hline & $60-80$ & 20,20 & 0,73 & 19,11 & 21,35 \\
\hline & $80-100$ & 18,05 & 0,72 & 16,72 & 19,03 \\
\hline \multirow{5}{*}{56} & $0-20$ & 23,10 & 0,00 & 23,10 & 23,10 \\
\hline & $20-40$ & 23,15 & 0,09 & 23,10 & 23,42 \\
\hline & $40-60$ & 23,66 & 0,42 & 22,91 & 24,14 \\
\hline & $60-80$ & 22,26 & 0,67 & 20,77 & 22,87 \\
\hline & $80-100$ & 19,94 & 0,61 & 18,54 & 20,66 \\
\hline \multirow{4}{*}{57} & $0-20$ & 22,30 & 0,01 & 22,30 & 22,32 \\
\hline & $20-40$ & 22,32 & 0,05 & 22,21 & 22,37 \\
\hline & $40-60$ & 22,14 & 0,53 & 21,10 & 22,79 \\
\hline & $60-80$ & 19,05 & 1,36 & 16,79 & 20,95 \\
\hline
\end{tabular}

\begin{tabular}{|c|c|c|c|c|c|}
\hline \multirow{2}{*}{$\begin{array}{l}\mathrm{n}^{\circ} \text { da } \\
\text { estação }\end{array}$} & \multirow{2}{*}{ prof. (m) } & \multicolumn{4}{|c|}{ temperatura $\left({ }^{\circ} \mathrm{C}\right)$} \\
\hline & & média & sd & $\min$ & $\max$ \\
\hline \multirow{4}{*}{58} & $0-20$ & 22,27 & 0,00 & 22,27 & 22,27 \\
\hline & $20-40$ & 22,37 & 0,10 & 22,27 & 22,51 \\
\hline & $40-60$ & 22,07 & 0,64 & 20,71 & 22,75 \\
\hline & $60-80$ & 19,93 & 0,68 & 18,58 & 20,69 \\
\hline \multirow{5}{*}{60} & $0-20$ & 23,05 & 0,00 & 23,05 & 23,05 \\
\hline & $20-40$ & 23,05 & 0,00 & 23,05 & 23,05 \\
\hline & $40-60$ & 22,95 & 0,08 & 22,85 & 23,05 \\
\hline & $60-80$ & 21,65 & 1,02 & 19,68 & 22,84 \\
\hline & $80-100$ & 18,54 & 0,60 & 17,55 & 19,50 \\
\hline \multirow{5}{*}{61} & $0-20$ & 23,07 & 0,07 & 23,02 & 23,21 \\
\hline & $20-40$ & 23,26 & 0,01 & 23,23 & 23,28 \\
\hline & $40-60$ & 23,14 & 0,33 & 22,27 & 23,36 \\
\hline & $60-80$ & 21,33 & 0,45 & 20,54 & 22,09 \\
\hline & $80-100$ & 19,42 & 0,69 & 18,15 & 20,45 \\
\hline \multirow{4}{*}{62} & $0-20$ & 22,31 & 0,09 & 22,16 & 22,38 \\
\hline & $20-40$ & 21,76 & 0,51 & 20,63 & 22,16 \\
\hline & $40-60$ & 18,76 & 1,09 & 17,21 & 20,48 \\
\hline & $60-80$ & 16,12 & 0,47 & 15,62 & 17,11 \\
\hline \multirow{4}{*}{63} & $0-20$ & 22,36 & 0,00 & 22,36 & 22,37 \\
\hline & $20-40$ & 22,44 & 0,04 & 22,39 & 22,50 \\
\hline & $40-60$ & 21,26 & 1,08 & 19,53 & 22,52 \\
\hline & $60-80$ & 17,79 & 0,66 & 17,05 & 19,30 \\
\hline \multirow{4}{*}{71} & $0-20$ & 22,46 & 0,03 & 22,42 & 22,50 \\
\hline & $20-40$ & 21,43 & 0,69 & 20,62 & 22,42 \\
\hline & $40-60$ & 18,96 & 0,75 & 18,00 & 20,58 \\
\hline & $60-80$ & 15,87 & 1,03 & 14,89 & 17,90 \\
\hline \multirow{5}{*}{72} & $0-20$ & 22,65 & 0,06 & 22,57 & 22,71 \\
\hline & $20-40$ & 22,54 & 0,05 & 22,40 & 22,57 \\
\hline & $40-60$ & 21,27 & 0,55 & 20,66 & 22,32 \\
\hline & $60-80$ & 19,45 & 1,46 & 16,49 & 20,65 \\
\hline & $80-100$ & 15,50 & 0,47 & 14,78 & 16,30 \\
\hline \multirow{5}{*}{73} & $0-20$ & 23,11 & 0,02 & 23,09 & 23,14 \\
\hline & $20-40$ & 23,12 & 0,04 & 22,99 & 23,15 \\
\hline & $40-60$ & 22,45 & 0,47 & 21,45 & 22,96 \\
\hline & $60-80$ & 19,63 & 0,92 & 18,17 & 21,26 \\
\hline & $80-100$ & 16,57 & 1,07 & 15,02 & 18,08 \\
\hline \multirow{5}{*}{74} & $0-20$ & 22,60 & 0,04 & 22,54 & 22,64 \\
\hline & $20-40$ & 23,09 & 0,42 & 22,65 & 24,05 \\
\hline & $40-60$ & 23,91 & 0,47 & 22,73 & 24,28 \\
\hline & $60-80$ & 20,68 & 0,88 & 19,49 & 22,49 \\
\hline & $80-100$ & 18,96 & 0,34 & 18,29 & 19,39 \\
\hline
\end{tabular}


Tabela 3. Valores de salinidade do cruzeiro de verão de 2001, na região do cabo Frio $(\mathrm{RJ})$. (prof. = faixa de profundidade; média = temperatura média; sd = desvio padrão; $\min =$ valor mínimo; $\max =$ valor máximo)

\begin{tabular}{|c|c|c|c|c|c|}
\hline \multirow{2}{*}{$\begin{array}{l}\mathrm{n}^{\circ} \text { da } \\
\text { estação }\end{array}$} & \multirow{2}{*}{ prof $(m)$} & \multicolumn{4}{|c|}{ salinidade } \\
\hline & & média & sd & $\min$ & $\max$ \\
\hline \multirow{5}{*}{84} & $0-20$ & 37,24 & 0,00 & 37,24 & 37,24 \\
\hline & $20-40$ & 37,23 & 0,01 & 37,21 & 37,24 \\
\hline & $40-60$ & 37,18 & 0,04 & 37,11 & 37,21 \\
\hline & $60-80$ & 37,08 & 0,02 & 37,05 & 37,10 \\
\hline & $80-100$ & 37,03 & 0,03 & 36,99 & 37,09 \\
\hline \multirow{5}{*}{85} & $0-20$ & 36,72 & 0,06 & 36,67 & 36,84 \\
\hline & $20-40$ & 36,98 & 0,08 & 36,86 & 37,10 \\
\hline & $40-60$ & 37,09 & 0,02 & 37,06 & 37,11 \\
\hline & $60-80$ & 36,90 & 0,08 & 36,80 & 37,05 \\
\hline & $80-100$ & 36,73 & 0,06 & 36,60 & 36,80 \\
\hline \multirow{5}{*}{86} & $0-20$ & 37,02 & 0,13 & 36,82 & 37,17 \\
\hline & $20-40$ & 37,08 & 0,07 & 36,92 & 37,17 \\
\hline & $40-60$ & 36,64 & 0,15 & 36,41 & 36,89 \\
\hline & $60-80$ & 36,19 & 0,12 & 36,04 & 36,39 \\
\hline & $80-100$ & 35,92 & 0,08 & 35,81 & 36,03 \\
\hline \multirow{5}{*}{87} & $0-20$ & 37,02 & 0,16 & 36,80 & 37,23 \\
\hline & $20-40$ & 37,04 & 0,02 & 37,01 & 37,09 \\
\hline & $40-60$ & 36,93 & 0,05 & 36,86 & 37,01 \\
\hline & $60-80$ & 36,52 & 0,16 & 36,35 & 36,84 \\
\hline & $80-100$ & 36,22 & 0,07 & 36,14 & 36,34 \\
\hline \multirow{5}{*}{88} & $0-20$ & 36,77 & 0,18 & 36,60 & 37,05 \\
\hline & $20-40$ & 37,03 & 0,02 & 36,99 & 37,05 \\
\hline & $40-60$ & 36,86 & 0,09 & 36,72 & 36,98 \\
\hline & $60-80$ & 36,45 & 0,17 & 36,19 & 36,70 \\
\hline & $80-100$ & 35,91 & 0,15 & 35,73 & 36,16 \\
\hline \multirow{2}{*}{89} & $0-20$ & 35,85 & 0,26 & 35,53 & 36,27 \\
\hline & $20-40$ & 35,53 & 0,07 & 35,48 & 35,69 \\
\hline \multirow{5}{*}{94} & $0-20$ & 36,43 & 0,10 & 36,33 & 36,62 \\
\hline & $20-40$ & 36,90 & 0,14 & 36,65 & 37,02 \\
\hline & $40-60$ & 36,82 & 0,07 & 36,73 & 36,95 \\
\hline & $60-80$ & 36,47 & 0,20 & 36,07 & 36,72 \\
\hline & $80-100$ & 35,71 & 0,12 & 35,56 & 35,99 \\
\hline \multirow{5}{*}{95} & $0-20$ & 36,59 & 0,07 & 36,53 & 36,75 \\
\hline & $20-40$ & 36,97 & 0,10 & 36,77 & 37,04 \\
\hline & $40-60$ & 36,85 & 0,15 & 36,58 & 37,03 \\
\hline & $60-80$ & 36,43 & 0,15 & 36,08 & 36,56 \\
\hline & $80-100$ & 35,92 & 0,05 & 35,87 & 36,05 \\
\hline \multirow{5}{*}{96} & $0-20$ & 36,85 & 0,16 & 36,70 & 37,08 \\
\hline & $20-40$ & 37,02 & 0,04 & 36,96 & 37,08 \\
\hline & $40-60$ & 36,83 & 0,09 & 36,69 & 36,95 \\
\hline & $60-80$ & 36,32 & 0,23 & 36,10 & 36,68 \\
\hline & $80-100$ & 36,08 & 0,03 & 36,02 & 36,11 \\
\hline
\end{tabular}

\begin{tabular}{|c|c|c|c|c|c|}
\hline \multirow{2}{*}{$\begin{array}{c}\mathrm{n}^{\circ} \text { da } \\
\text { estação }\end{array}$} & \multirow{2}{*}{ prof $(m)$} & \multicolumn{4}{|c|}{ salinidade } \\
\hline & & média & $s d$ & $\min$ & $\max$ \\
\hline \multirow{5}{*}{97} & $0-20$ & 36,83 & 0,06 & 36,79 & 36,97 \\
\hline & $20-40$ & 36,98 & 0,03 & 36,94 & 37,02 \\
\hline & $40-60$ & 36,80 & 0,07 & 36,67 & 36,92 \\
\hline & $60-80$ & 36,45 & 0,12 & 36,23 & 36,65 \\
\hline & $80-100$ & 36,05 & 0,09 & 35,91 & 36,21 \\
\hline \multirow{5}{*}{01} & $0-20$ & 36,81 & 0,01 & 36,80 & 36,82 \\
\hline & $20-40$ & 36,88 & 0,04 & 36,80 & 36,93 \\
\hline & $40-60$ & 37,00 & 0,04 & 36,91 & 37,03 \\
\hline & $60-80$ & 36,97 & 0,08 & 36,77 & 37,02 \\
\hline & $80-100$ & 36,39 & 0,19 & 36,10 & 36,73 \\
\hline \multirow{5}{*}{02} & $0-20$ & 36,83 & 0,03 & 36,81 & 36,92 \\
\hline & $20-40$ & 37,00 & 0,03 & 36,95 & 37,04 \\
\hline & $40-60$ & 36,80 & 0,11 & 36,57 & 36,96 \\
\hline & $60-80$ & 36,29 & 0,10 & 36,09 & 36,51 \\
\hline & $80-100$ & 35,95 & 0,07 & 35,84 & 36,07 \\
\hline \multirow{5}{*}{03} & $0-20$ & 36,63 & 0,17 & 36,45 & 36,87 \\
\hline & $20-40$ & 36,92 & 0,02 & 36,87 & 36,94 \\
\hline & $40-60$ & 36,74 & 0,14 & 36,50 & 36,92 \\
\hline & $60-80$ & 36,28 & 0,11 & 36,10 & 36,48 \\
\hline & $80-100$ & 35,94 & 0,06 & 35,87 & 36,07 \\
\hline \multirow{5}{*}{04} & $0-20$ & 36,35 & 0,06 & 36,32 & 36,54 \\
\hline & $20-40$ & 36,64 & 0,08 & 36,53 & 36,75 \\
\hline & $40-60$ & 36,51 & 0,04 & 36,47 & 36,58 \\
\hline & $60-80$ & 36,39 & 0,13 & 36,05 & 36,47 \\
\hline & $80-100$ & 35,63 & 0,17 & 35,48 & 35,99 \\
\hline \multirow{5}{*}{06} & $0-20$ & 36,18 & 0,18 & 36,04 & 36,58 \\
\hline & $20-40$ & 36,59 & 0,06 & 36,51 & 36,67 \\
\hline & $40-60$ & 36,50 & 0,01 & 36,49 & 36,51 \\
\hline & $60-80$ & 35,96 & 0,38 & 35,41 & 36,48 \\
\hline & $80-100$ & 35,41 & 0,00 & 35,41 & 35,42 \\
\hline \multirow{2}{*}{09} & $0-20$ & 35,36 & 0,01 & 35,35 & 35,37 \\
\hline & $20-40$ & 35,33 & 0,01 & 35,32 & 35,34 \\
\hline \multirow{5}{*}{13} & $0-20$ & 36,45 & 0,06 & 36,40 & 36,54 \\
\hline & $20-40$ & 36,68 & 0,05 & 36,55 & 36,75 \\
\hline & $40-60$ & 36,56 & 0,04 & 36,52 & 36,65 \\
\hline & $60-80$ & 36,45 & 0,05 & 36,40 & 36,53 \\
\hline & $80-100$ & 35,94 & 0,32 & 35,55 & 36,40 \\
\hline \multirow{5}{*}{15} & $0-20$ & 36,02 & 0,05 & 35,99 & 36,17 \\
\hline & $20-40$ & 36,33 & 0,05 & 36,21 & 36,39 \\
\hline & $40-60$ & 35,97 & 0,13 & 35,83 & 36,24 \\
\hline & $60-80$ & 35,56 & 0,14 & 35,44 & 35,82 \\
\hline & $80-100$ & 35,43 & 0,00 & 35,43 & 35,44 \\
\hline \multirow{2}{*}{18} & $0-20$ & 35,49 & 0,06 & 35,42 & 35,58 \\
\hline & $20-40$ & 35,41 & 0,01 & 35,39 & 35,42 \\
\hline
\end{tabular}


Tabela 4. Valores de salinidade do cruzeiro deinverno de 2001, na região do cabo Frio $(\mathrm{RJ})$. (prof. = faixa de profundidade; média = temperatura média; sd = desvio padrão; $\min$ = valor mínimo; $\max =$ valor máximo)

\begin{tabular}{|c|c|c|c|c|c|}
\hline \multirow{2}{*}{$\begin{array}{c}\mathrm{n}^{\circ} \text { da } \\
\text { estação }\end{array}$} & \multirow{2}{*}{ prof (m) } & \multicolumn{4}{|c|}{ salinidade } \\
\hline & & média & $\mathrm{sd}$ & $\min$ & $\max$ \\
\hline \multirow{4}{*}{50} & $0-20$ & 35,83 & 0,01 & 35,82 & 35,85 \\
\hline & $20-40$ & 36,00 & 0,15 & 35,86 & 36,37 \\
\hline & $40-60$ & 36,61 & 0,08 & 36,43 & 36,73 \\
\hline & $60-80$ & 36,37 & 0,15 & 36,05 & 36,56 \\
\hline \multirow{5}{*}{51} & $0-20$ & 36,32 & 0,02 & 36,31 & 36,39 \\
\hline & $20-40$ & 36,71 & 0,18 & 36,42 & 37,03 \\
\hline & $40-60$ & 37,09 & 0,03 & 37,03 & 37,12 \\
\hline & $60-80$ & 36,86 & 0,09 & 36,68 & 37,01 \\
\hline & $80-100$ & 36,46 & 0,11 & 36,26 & 36,65 \\
\hline \multirow{5}{*}{52} & $0-20$ & 36,39 & 0,00 & 36,38 & 36,39 \\
\hline & $20-40$ & 36,53 & 0,12 & 36,39 & 36,72 \\
\hline & $40-60$ & 36,69 & 0,07 & 36,55 & 36,75 \\
\hline & $60-80$ & 36,33 & 0,12 & 36,12 & 36,52 \\
\hline & $80-100$ & 35,93 & 0,07 & 35,83 & 36,09 \\
\hline \multirow{5}{*}{53} & $0-20$ & 37,14 & 0,01 & 37,13 & 37,15 \\
\hline & $20-40$ & 37,16 & 0,00 & 37,15 & 37,16 \\
\hline & $40-60$ & 37,16 & 0,00 & 37,15 & 37,16 \\
\hline & $60-80$ & 37,15 & 0,01 & 37,15 & 37,16 \\
\hline & $80-100$ & 37,16 & 0,01 & 37,13 & 37,17 \\
\hline \multirow{5}{*}{54} & $0-20$ & 37,05 & 0,01 & 37,03 & 37,07 \\
\hline & $20-40$ & 37,01 & 0,01 & 36,99 & 37,03 \\
\hline & $40-60$ & 37,01 & 0,02 & 36,99 & 37,04 \\
\hline & $60-80$ & 37,06 & 0,01 & 37,04 & 37,07 \\
\hline & $80-100$ & 36,88 & 0,11 & 36,74 & 37,06 \\
\hline \multirow{5}{*}{55} & $0-20$ & 36,35 & 0,00 & 36,34 & 36,36 \\
\hline & $20-40$ & 36,44 & 0,12 & 36,36 & 36,72 \\
\hline & $40-60$ & 36,66 & 0,07 & 36,56 & 36,76 \\
\hline & $60-80$ & 36,42 & 0,10 & 36,25 & 36,55 \\
\hline & $80-100$ & 36,05 & 0,13 & 35,81 & 36,23 \\
\hline \multirow{5}{*}{56} & $0-20$ & 36,35 & 0,00 & 36,34 & 36,35 \\
\hline & $20-40$ & 36,40 & 0,06 & 36,35 & 36,58 \\
\hline & $40-60$ & 36,94 & 0,11 & 36,65 & 37,06 \\
\hline & $60-80$ & 36,78 & 0,13 & 36,50 & 36,89 \\
\hline & $80-100$ & 36,34 & 0,13 & 36,04 & 36,49 \\
\hline \multirow{4}{*}{57} & $0-20$ & 35,83 & 0,00 & 35,82 & 35,83 \\
\hline & $20-40$ & 35,87 & 0,04 & 35,83 & 35,96 \\
\hline & $40-60$ & 36,33 & 0,18 & 35,99 & 36,51 \\
\hline & $60-80$ & 36,12 & 0,23 & 35,74 & 36,42 \\
\hline
\end{tabular}

\begin{tabular}{|c|c|c|c|c|c|}
\hline \multirow{2}{*}{$\begin{array}{c}\mathrm{n}^{\circ} \text { da } \\
\text { estação }\end{array}$} & \multirow{2}{*}{ prof (m) } & \multicolumn{4}{|c|}{ salinidade } \\
\hline & & média & $s d$ & $\min$ & $\max$ \\
\hline \multirow{4}{*}{58} & $0-20$ & 35,36 & 0,00 & 35,35 & 35,36 \\
\hline & $20-40$ & 35,69 & 0,24 & 35,36 & 36,04 \\
\hline & $40-60$ & 36,41 & 0,18 & 36,07 & 36,60 \\
\hline & $60-80$ & 36,26 & 0,11 & 36,04 & 36,38 \\
\hline \multirow{5}{*}{60} & $0-20$ & 36,39 & 0,00 & 36,39 & 36,39 \\
\hline & $20-40$ & 36,39 & 0,00 & 36,39 & 36,39 \\
\hline & $40-60$ & 36,46 & 0,06 & 36,39 & 36,56 \\
\hline & $60-80$ & 36,46 & 0,11 & 36,21 & 36,56 \\
\hline & $80-100$ & 36,05 & 0,09 & 35,90 & 36,19 \\
\hline \multirow{5}{*}{61} & $0-20$ & 36,35 & 0,05 & 36,31 & 36,46 \\
\hline & $20-40$ & 36,49 & 0,01 & 36,47 & 36,51 \\
\hline & $40-60$ & 36,57 & 0,04 & 36,52 & 36,63 \\
\hline & $60-80$ & 36,53 & 0,04 & 36,44 & 36,56 \\
\hline & $80-100$ & 36,23 & 0,13 & 35,98 & 36,42 \\
\hline \multirow{4}{*}{62} & $0-20$ & 35,85 & 0,04 & 35,82 & 35,92 \\
\hline & $20-40$ & 36,03 & 0,11 & 35,92 & 36,19 \\
\hline & $40-60$ & 36,02 & 0,12 & 35,83 & 36,18 \\
\hline & $60-80$ & 35,65 & 0,07 & 35,58 & 35,81 \\
\hline \multirow{4}{*}{63} & $0-20$ & 35,53 & 0,01 & 35,52 & 35,57 \\
\hline & $20-40$ & 35,97 & 0,10 & 35,65 & 36,03 \\
\hline & $40-60$ & 36,26 & 0,10 & 36,03 & 36,41 \\
\hline & $60-80$ & 35,93 & 0,11 & 35,81 & 36,18 \\
\hline \multirow{4}{*}{71} & $0-20$ & 36,05 & 0,01 & 36,05 & 36,07 \\
\hline & $20-40$ & 36,10 & 0,02 & 36,06 & 36,14 \\
\hline & $40-60$ & 36,07 & 0,05 & 35,98 & 36,16 \\
\hline & $60-80$ & 35,62 & 0,16 & 35,48 & 35,96 \\
\hline \multirow{5}{*}{72} & $0-20$ & 36,08 & 0,03 & 36,05 & 36,13 \\
\hline & $20-40$ & 36,15 & 0,01 & 36,13 & 36,17 \\
\hline & $40-60$ & 36,28 & 0,07 & 36,16 & 36,34 \\
\hline & $60-80$ & 36,16 & 0,23 & 35,71 & 36,35 \\
\hline & $80-100$ & 35,57 & 0,08 & 35,45 & 35,69 \\
\hline \multirow{5}{*}{73} & $0-20$ & 36,35 & 0,09 & 36,23 & 36,47 \\
\hline & $20-40$ & 36,54 & 0,08 & 36,47 & 36,67 \\
\hline & $40-60$ & 36,62 & 0,05 & 36,51 & 36,67 \\
\hline & $60-80$ & 36,24 & 0,15 & 35,99 & 36,49 \\
\hline & $80-100$ & 35,72 & 0,17 & 35,47 & 35,98 \\
\hline \multirow{5}{*}{74} & $0-20$ & 36,04 & 0,04 & 36,01 & 36,13 \\
\hline & $20-40$ & 36,43 & 0,25 & 36,15 & 36,97 \\
\hline & $40-60$ & 36,99 & 0,09 & 36,76 & 37,06 \\
\hline & $60-80$ & 36,31 & 0,17 & 36,17 & 36,70 \\
\hline & $80-100$ & 36,11 & 0,05 & 36,01 & 36,16 \\
\hline
\end{tabular}


Tabela 5. Estimativa do volume de plâncton dos diferentes estratos amostrados com a rede Multinet durante o cruzeiro de verão de 2001, na região do cabo Frio (RJ).

\begin{tabular}{|c|c|c|c|c|c|}
\hline \multirow{2}{*}{$\begin{array}{c}\mathrm{n}^{\circ} \text { da } \\
\text { estação }\end{array}$} & \multicolumn{5}{|c|}{ Volume de plâncton $\left(\mathrm{ml}^{\left.-\mathrm{m}^{-3}\right)}\right.$} \\
\hline & 0 a $20 \mathrm{~m}$ & 20 a $40 \mathrm{~m}$ & 40 a $60 \mathrm{~m}$ & 60 a $80 \mathrm{~m}$ & 80 a $100 \mathrm{~m}$ \\
\hline 84 & 0,29 & 0,24 & 0,07 & 0,08 & 0,04 \\
\hline 85 & 0,04 & 0,17 & 0,13 & 0,14 & 0,12 \\
\hline 86 & 0,09 & 0,11 & 0,05 & 0,02 & 0,02 \\
\hline 87 & 1,65 & 1,50 & 0,35 & 0,28 & 0,18 \\
\hline 88 & 0,73 & 1,11 & 3,37 & 2,69 & 0,16 \\
\hline 89 & 1,06 & 0,24 & - & - & - \\
\hline 94 & 0,24 & 0,29 & 0,21 & 0,20 & 0,04 \\
\hline 95 & 0,14 & 0,13 & 0,22 & 0,25 & 0,19 \\
\hline 96 & 0,31 & 0,17 & 0,14 & 0,14 & 0,08 \\
\hline 97 & 0,15 & 0,09 & 0,17 & 0,17 & 0,03 \\
\hline 01 & 0,14 & 0,10 & 0,11 & 0,11 & 0,19 \\
\hline 02 & 0,08 & 0,07 & 0,15 & 0,08 & 0,02 \\
\hline 03 & 0,27 & 0,41 & 0,49 & 0,32 & 0,07 \\
\hline 04 & 0,63 & 0,93 & 0,60 & 0,19 & 0,11 \\
\hline 06 & 0,81 & 3,81 & 1,08 & 0,23 & 0,26 \\
\hline 09 & 0,29 & 0,56 & - & - & - \\
\hline 13 & 0,43 & 0,91 & 1,52 & 1,63 & 0,28 \\
\hline 15 & 1,74 & 2,05 & 2,07 & 1,63 & 0,73 \\
\hline 18 & 0,05 & 0,04 & - & - & - \\
\hline média & 0,48 & 0,68 & 0,67 & 0,51 & 0,16 \\
\hline d.p. & 0,51 & 0,94 & 0,93 & 0,77 & 0,17 \\
\hline mínimo & 0,04 & 0,04 & 0,05 & 0,02 & 0,02 \\
\hline máximo & 1,74 & 3,81 & 3,37 & 2,69 & 0,73 \\
\hline
\end{tabular}

Tabela 6. Estimativa do volume de plâncton dos diferentes estratos amostrados com a rede Multinet durante o cruzeiro de inverno de 2001, na região do cabo Frio $(\mathrm{RJ})$.

\begin{tabular}{|c|c|c|c|c|c|}
\hline \multirow{2}{*}{$\begin{array}{c}\mathrm{n}^{\circ} \mathrm{da} \\
\text { estação }\end{array}$} & \multicolumn{5}{|c|}{ Volume de plâncton $\left(\mathrm{ml}^{\mathrm{m}} \mathrm{m}^{-3}\right)$} \\
\hline & 0 a $20 \mathrm{~m}$ & 20 a $40 \mathrm{~m}$ & 40 a $60 \mathrm{~m}$ & 60 a $80 \mathrm{~m}$ & 80 a $100 \mathrm{~m}$ \\
\hline 50 & 0,44 & 0,10 & 0,13 & 0,08 & - \\
\hline 51 & 0,06 & 0,15 & 0,04 & 0,03 & 0,04 \\
\hline 52 & 0,06 & 0,08 & 0,01 & 0,01 & 0,01 \\
\hline 53 & 0,05 & 0,06 & 0,02 & 0,02 & 0,00 \\
\hline 54 & 0,08 & 0,09 & 0,17 & 0,02 & 0,01 \\
\hline 55 & 0,12 & 0,13 & 0,01 & 0,03 & 0,00 \\
\hline 56 & 0,11 & 0,07 & 0,06 & 0,01 & 0,01 \\
\hline 57 & 0,38 & 0,35 & 0,04 & 0,06 & - \\
\hline 58 & 1,32 & 0,40 & 0,14 & 0,06 & - \\
\hline 60 & 0,10 & 0,08 & 0,07 & 0,03 & 0,00 \\
\hline 61 & 0,10 & 0,13 & 0,03 & 0,02 & 0,02 \\
\hline 62 & 0,56 & 0,39 & 0,13 & 0,05 & - \\
\hline 63 & 1,19 & 0,25 & 0,12 & 0,03 & - \\
\hline 71 & 0,56 & 0,30 & 0,14 & 0,08 & - \\
\hline 72 & 0,21 & 0,13 & 0,10 & 0,08 & 0,08 \\
\hline 73 & 0,13 & 0,28 & 0,07 & 0,02 & 0,02 \\
\hline 74 & 0,51 & 0,10 & 0,09 & 0,05 & 0,05 \\
\hline média & 0,35 & 0,18 & 0,08 & 0,04 & 0,02 \\
\hline d.p. & 0,39 & 0,12 & 0,05 & 0,02 & 0,03 \\
\hline mínimo & 0,05 & 0,06 & 0,01 & 0,01 & 0,00 \\
\hline máximo & 1,32 & 0,40 & 0,17 & 0,08 & 0,08 \\
\hline
\end{tabular}


Tabela 7. Estimativa da densidade de ovos de peixes ( $\mathrm{n}^{\circ}$ de ovos. $\mathrm{m}^{-3}$ ) dos diferentes estratos amostrados com a rede Multinet durante o cruzeiro de verão de 2001 , na região do cabo Frio (RJ).

\begin{tabular}{|c|c|c|c|c|c|}
\hline \multirow{2}{*}{$\begin{array}{c}\mathrm{n}^{\circ} \text { da } \\
\text { estação }\end{array}$} & \multicolumn{5}{|c|}{$\mathrm{N}^{\circ}$ de ovos. $\mathrm{m}^{-3}$} \\
\hline & 0 a $20 \mathrm{~m}$ & 20 a $40 \mathrm{~m}$ & 40 a $60 \mathrm{~m}$ & 60 a $80 \mathrm{~m}$ & 80 a $100 \mathrm{~m}$ \\
\hline 84 & 0,02 & 0,03 & 0,00 & 0,06 & 0,04 \\
\hline 85 & 0,02 & 0,00 & 0,08 & 0,30 & 0,15 \\
\hline 86 & 0,07 & 0,08 & 0,08 & 0,18 & 0,14 \\
\hline 87 & 1,07 & 1036,37 & 0,55 & 0,48 & 0,04 \\
\hline 88 & 0,48 & 0,76 & 0,16 & 0,57 & 0,20 \\
\hline 89 & 8,85 & 0,16 & - & - & - \\
\hline 94 & 0,59 & 0,69 & 0,50 & 0,47 & 0,36 \\
\hline 95 & 1,52 & 0,52 & 0,19 & 0,00 & 0,43 \\
\hline 96 & 1,18 & 0,82 & 1,16 & 0,45 & 0,08 \\
\hline 97 & 0,58 & 0,27 & 0,12 & 0,07 & 0,14 \\
\hline 01 & 0,48 & 0,23 & 0,07 & 0,07 & 0,19 \\
\hline 02 & 0,63 & 0,34 & 0,00 & 0,14 & 0,09 \\
\hline 03 & 0,32 & 0,18 & 0,41 & 0,29 & 0,07 \\
\hline 04 & 0,34 & 0,41 & 0,13 & 0,38 & 0,32 \\
\hline 06 & 0,16 & 0,00 & 0,09 & 0,00 & 0,00 \\
\hline 09 & 0,31 & 0,06 & - & - & - \\
\hline 13 & 0,29 & 0,41 & 0,09 & 0,09 & 0,56 \\
\hline 15 & 0,13 & 0,09 & 0,00 & 0,03 & 0,00 \\
\hline 18 & 0,47 & 0,59 & - & - & - \\
\hline média & 0,92 & 54,84 & 0,23 & 0,22 & 0,18 \\
\hline d.p. & 1,96 & 237,69 & 0,30 & 0,20 & 0,16 \\
\hline mínimo & 0,02 & 0,00 & 0,00 & 0,00 & 0,00 \\
\hline máximo & 8,85 & 1036,37 & 1,16 & 0,57 & 0,56 \\
\hline
\end{tabular}

Tabela 8. Estimativa da densidade de ovos de peixes $\left(\mathrm{n}^{\circ}\right.$ de ovos. $\left.\mathrm{m}^{-3}\right)$ dos diferentes estratos amostrados com a rede Multinet durante o cruzeiro de inverno de 2001, na região do cabo Frio (RJ).

\begin{tabular}{|c|c|c|c|c|c|}
\hline \multirow{2}{*}{$\begin{array}{c}\mathrm{n}^{\circ} \mathrm{da} \\
\text { estação }\end{array}$} & \multicolumn{5}{|c|}{$\mathrm{N}^{\circ}$ de ovos. $\mathrm{m}^{-3}$} \\
\hline & 0 a $20 \mathrm{~m}$ & 20 a $40 \mathrm{~m}$ & 40 a $60 \mathrm{~m}$ & 60 a $80 \mathrm{~m}$ & 80 a $100 \mathrm{~m}$ \\
\hline 50 & 0,80 & 0,21 & 0,35 & 0,40 & - \\
\hline 51 & 0,19 & 0,18 & 0,30 & 0,24 & 0,04 \\
\hline 52 & 4,36 & 3,54 & 0,42 & 0,75 & 0,08 \\
\hline 53 & 0,03 & 0,00 & 0,07 & 0,00 & 0,00 \\
\hline 54 & 0,04 & 0,00 & 0,11 & 0,06 & 0,05 \\
\hline 55 & 0,22 & 0,77 & 0,55 & 0,12 & 0,00 \\
\hline 56 & 0,18 & 0,00 & 0,69 & 0,10 & 0,22 \\
\hline 57 & 0,51 & 0,23 & 0,09 & 0,19 & - \\
\hline 58 & 0,50 & 0,28 & 0,00 & 0,00 & - \\
\hline 60 & 0,29 & 0,20 & 0,27 & 0,22 & 0,03 \\
\hline 61 & 0,25 & 0,92 & 0,30 & 0,56 & 1,57 \\
\hline 62 & 0,44 & 0,26 & 0,58 & 0,32 & - \\
\hline 63 & 0,11 & 0,15 & 0,12 & 0,16 & - \\
\hline 71 & 1,13 & 0,29 & 0,12 & 0,23 & - \\
\hline 72 & 0,11 & 0,27 & 0,58 & 0,35 & 0,48 \\
\hline 73 & 0,32 & 0,45 & 0,13 & 0,14 & 0,04 \\
\hline 74 & 0,22 & 0,93 & 0,15 & 0,05 & 0,04 \\
\hline média & 0,57 & 0,51 & 0,29 & 0,23 & 0,23 \\
\hline d.p. & 1,02 & 0,83 & 0,21 & 0,20 & 0,47 \\
\hline mínimo & 0,03 & 0,00 & 0,00 & 0,00 & 0,00 \\
\hline máximo & 4,36 & 3,54 & 0,69 & 0,75 & 1,57 \\
\hline
\end{tabular}


Tabela 9. Estimativa da densidade de larvas de peixes $\left(n^{\circ}\right.$ de larvas. $\mathrm{m}^{-3}$ ) dos diferentes estratos amostrados com a rede Multinet durante o cruzeiro de verão de 2001, na região do cabo Frio (RJ).

\begin{tabular}{cccccc}
\hline $\mathrm{n}^{\circ}$ da & \multicolumn{5}{c}{$\mathrm{N}^{\circ}$ de larvas. $\mathrm{m}^{-3}$} \\
\cline { 2 - 6 } estação & 0 a $20 \mathrm{~m}$ & $20 \mathrm{a} 40 \mathrm{~m}$ & $40 \mathrm{a} 60 \mathrm{~m}$ & $60 \mathrm{a} 80 \mathrm{~m}$ & $80 \mathrm{a} 100 \mathrm{~m}$ \\
\hline 84 & 3,40 & 4,06 & 0,73 & 0,47 & 0,08 \\
85 & 0,60 & 0,44 & 0,31 & 0,19 & 0,30 \\
86 & 0,48 & 0,59 & 0,34 & 0,32 & 0,46 \\
87 & 0,14 & 1,00 & 0,17 & 0,28 & 0,47 \\
88 & 2,39 & 0,62 & 0,26 & 0,29 & 0,08 \\
89 & 0,16 & 0,00 & - & - & - \\
94 & 1,69 & 1,61 & 1,43 & 0,77 & 0,04 \\
95 & 0,98 & 0,95 & 1,16 & 0,71 & 0,43 \\
96 & 0,30 & 0,37 & 0,14 & 0,20 & 0,06 \\
97 & 0,64 & 0,67 & 0,38 & 0,42 & 0,20 \\
01 & 0,32 & 0,23 & 0,31 & 0,34 & 0,26 \\
02 & 0,55 & 0,17 & 0,40 & 0,42 & 0,21 \\
03 & 0,59 & 0,38 & 0,57 & 0,19 & 0,14 \\
04 & 1,21 & 1,71 & 1,07 & 0,48 & 0,95 \\
06 & 1,11 & 0,59 & 0,91 & 0,44 & 0,09 \\
09 & 0,13 & 0,31 & - & - & - \\
13 & 0,74 & 0,46 & 0,91 & 0,63 & 1,34 \\
15 & 22,73 & 17,63 & 5,08 & 0,77 & 0,46 \\
18 & 0,23 & 0,20 & - & - & - \\
\hline média & 2,02 & 1,68 & 0,89 & 0,43 & 0,35 \\
d.p. & 5,08 & 3,97 & 1,18 & 0,20 & 0,35 \\
mínimo & 0,13 & 0,00 & 0,14 & 0,19 & 0,04 \\
máximo & 22,73 & 17,63 & 5,08 & 0,77 & 1,34 \\
\hline & & & &
\end{tabular}

Tabela 10. Estimativa da densidade de larvas de peixes ( $n^{\circ}$ de larvas. $m^{-3}$ ) dos diferentes estratos amostrados com a rede Multinet durante o cruzeiro de inverno de 2001, na região do cabo Frio (RJ).

\begin{tabular}{cccccc}
\hline $\mathrm{n}^{\circ}$ da & \multicolumn{5}{c}{$\mathrm{N}^{\circ}$ de larvas. $\mathrm{m}^{-3}$} \\
\cline { 2 - 6 } estação & 0 a $20 \mathrm{~m}$ & $20 \mathrm{a} 40 \mathrm{~m}$ & $40 \mathrm{a} 60 \mathrm{~m}$ & $60 \mathrm{a} 80 \mathrm{~m}$ & $80 \mathrm{a} 100 \mathrm{~m}$ \\
\hline 50 & 0,58 & 1,50 & 0,35 & 0,19 & - \\
51 & 1,06 & 3,38 & 1,04 & 0,86 & 0,04 \\
52 & 0,54 & 0,87 & 0,14 & 0,19 & 0,00 \\
53 & 0,67 & 0,35 & 0,22 & 0,14 & 0,10 \\
54 & 0,39 & 1,05 & 0,89 & 0,43 & 0,36 \\
55 & 0,50 & 0,39 & 0,37 & 0,18 & 0,16 \\
56 & 0,33 & 0,93 & 0,42 & 0,05 & 0,09 \\
57 & 0,07 & 1,25 & 0,32 & 0,37 & - \\
58 & 1,24 & 2,61 & 0,74 & 0,07 & - \\
60 & 0,27 & 0,25 & 0,15 & 0,43 & 0,08 \\
61 & 0,25 & 0,41 & 0,23 & 0,00 & 0,16 \\
62 & 1,18 & 1,10 & 0,46 & 0,00 & - \\
63 & 1,68 & 1,52 & 0,47 & 0,04 & - \\
71 & 1,13 & 0,50 & 0,18 & 0,15 & - \\
72 & 2,07 & 1,79 & 0,39 & 0,29 & 0,03 \\
73 & 0,49 & 0,90 & 0,38 & 0,29 & 0,54 \\
74 & 3,49 & 1,76 & 0,72 & 0,55 & 0,25 \\
\hline média & 0,94 & 1,21 & 0,44 & 0,25 & 0,16 \\
d.p. & 0,85 & 0,84 & 0,26 & 0,23 & 0,16 \\
mínimo & 0,07 & 0,25 & 0,14 & 0,00 & 0,00 \\
máximo & 3,49 & 3,38 & 1,04 & 0,86 & 0,54 \\
\hline
\end{tabular}


Tabela 11. Freqüência relativa e freqüência de ocorrência das famílias identificadas nos cruzeiros de verão e inverno de 2001, na região do cabo Frio (RJ).

\begin{tabular}{|c|c|c|c|c|}
\hline & & rão & $\operatorname{inv}$ & erno \\
\hline & freq rel (\%) & freq ocor (\%) & freq rel (\%) & freq ocor (\%) \\
\hline Acanthuridae & - & - & 0,05 & 5,6 \\
\hline Acropomatidae & - & - & 1,09 & 16,7 \\
\hline Anguilliformes & 0,50 & 52,6 & 1,64 & 61,1 \\
\hline Argentinidae & 0,04 & 5,3 & 0,04 & 5,6 \\
\hline Balistidae & 0,17 & 21,1 & - & - \\
\hline Blenniidae & 0,30 & 15,8 & 0,34 & 16,7 \\
\hline Bothidae & 1,58 & 73,7 & 0,29 & 5,6 \\
\hline Bregmacerotidae & 1,59 & 57,9 & 11,75 & 83,3 \\
\hline Callionymidae & 0,19 & 26,3 & 0,21 & 5,6 \\
\hline Carangidae & 0,83 & 47,4 & 0,04 & 5,6 \\
\hline Carapidae & 0,05 & 5,3 & - & - \\
\hline Chaetodonthidae & - & - & 0,05 & 5,6 \\
\hline Clupeidae & 2,72 & 47,4 & 0,13 & 11,1 \\
\hline Cynoglosidae & 0,45 & 5,3 & 3,91 & 38,9 \\
\hline Dactylopteridae & 0,15 & 26,3 & - & - \\
\hline Echeneidae & 0,05 & 10,5 & - & - \\
\hline Engraulidae & 35,67 & 42,1 & 18,82 & 50,0 \\
\hline Fistularidae & 0,02 & 5,3 & - & - \\
\hline Gempylidae & 0,03 & 5,3 & - & - \\
\hline Gerreidae & 0,05 & 10,5 & - & - \\
\hline Gobidae & 0,17 & 15,8 & 0,18 & 11,1 \\
\hline Gononostomatidae & 0,47 & 26,3 & 0,26 & 5,6 \\
\hline Hemiramphidae & - & - & 0,05 & 5,6 \\
\hline Holocentridae & 0,14 & 21,1 & - & - \\
\hline Labridae & 0,14 & 26,3 & 0,06 & 5,6 \\
\hline Lophidae & 0,05 & 10,5 & 0,05 & 5,6 \\
\hline Lutjanidae & 0,02 & 5,3 & - & - \\
\hline Macrouridae & - & - & 0,11 & 5,6 \\
\hline Malacanthidae & 0,17 & 15,8 & - & - \\
\hline Melamphaidae & 0,03 & 5,3 & 0,11 & 11,1 \\
\hline Monacanthidae & 0,06 & 10,5 & - & - \\
\hline Moridae & 0,03 & 5,3 & - & - \\
\hline Mugilidae & - & - & 0,11 & 5,6 \\
\hline Mullidae & 0,08 & 21,1 & 1,86 & 61,1 \\
\hline Myctophidae & 14,33 & 78,9 & 12,91 & 88,9 \\
\hline Nomeidae & - & - & 0,05 & 5,6 \\
\hline Notosudidae & - & - & 0,35 & 11,1 \\
\hline Ophididae & 0,61 & 31,6 & 0,08 & 5,6 \\
\hline Ostracidae & 0,01 & 5,3 & - & - \\
\hline Paralepididae & 0,46 & 31,6 & 0,98 & 16,7 \\
\hline Paralichthydae & 0,60 & 36,8 & 0,41 & 22,2 \\
\hline Phosichthydae & 2,19 & 73,7 & 3,95 & 72,2 \\
\hline
\end{tabular}


Tabela 11 (continuação). Freqüência relativa e freqüência de ocorrência das famílias identificadas nos cruzeiros de verão e inverno de 2001, na região do cabo Frio (RJ).

\begin{tabular}{lcccc}
\hline & \multicolumn{2}{c}{ verão } & \multicolumn{2}{c}{ inverno } \\
\cline { 2 - 5 } & freq rel (\%) & freq ocor (\%) & freq rel (\%) & freq ocor (\%) \\
\hline Phycidae & - & - & 2,03 & 38,9 \\
Pinguipedidae & 0,32 & 10,5 & - & - \\
Pleuronectiformes & 0,95 & 26,3 & 2,72 & 33,3 \\
Pomacanthidae & 0,01 & 5,3 & 0,04 & 5,6 \\
Priacanthidae & 0,22 & 26,3 & - & - \\
Scaridae & 0,68 & 57,9 & 0,29 & 11,1 \\
Scianidae & 0,20 & 15,8 & 1,06 & 27,8 \\
Scombridae & 4,45 & 78,9 & 0,08 & 5,6 \\
Scopelarchidae & 0,08 & 5,3 & 0,34 & 16,7 \\
Scorpaenidae & 0,20 & 26,3 & 0,35 & 16,7 \\
Serranidae & 0,18 & 36,8 & 0,22 & 11,1 \\
Sparidae & 0,04 & 5,3 & - & - \\
Sternopthycidae & 8,33 & 78,9 & 8,86 & 83,3 \\
Stomiidae & 0,10 & 15,8 & 0,37 & 11,1 \\
Stromateidae & 0,16 & 10,5 & - & - \\
Syngnathidae & - & - & 0,07 & 5,6 \\
Synodontidae & 0,15 & 21,1 & 1,19 & 33,3 \\
Tetraodontidae & 0,03 & 5,3 & 0,05 & 5,6 \\
Trichiuridae & 0,61 & 36,8 & 4,62 & 66,7 \\
Triglidae & 0,11 & 15,8 & 0,30 & 16,7 \\
Uranoscopidae & 0,03 & 5,3 & - & - \\
não identificados & 19,19 & - & 17,54 & - \\
\hline total & 100,00 & - & 100,00 & - \\
\hline
\end{tabular}


Tabela 12 . Resultados da Análise de Regressão Múltipla entre a densidade (larvas. $\mathrm{m}^{-3}$ ) dos grupos cuja freqüencia de ocorrência foi superior a $30 \%$ e as variáveis ambientais para o cruzeiro de verão de 2001, na região do Cabo Frio (RJ). Valores de $b$ em negrito foram significativamente diferentes de zero. (prof - profundidade; temp - temperatura; sal - salinidade; ACAS - Água Central do Atlântico Sul; AT - Água Tropical; AC - Água Costeira)

\begin{tabular}{|c|c|c|c|c|c|c|c|c|c|c|}
\hline \multirow{2}{*}{ Grupos } & \multirow{2}{*}{ (p) } & \multirow{2}{*}{$\mathrm{R}$} & \multirow{2}{*}{$\mathrm{R} 2$} & \multicolumn{7}{|c|}{$\mathrm{b}$} \\
\hline & & & & prof & temp & sal & $\% A C A S$ & $\%$ AT & $\% A C$ & Clorofila a \\
\hline Anguilliformes & 0,7287 & - & - & - & - & - & - & - & - & - \\
\hline Bregmacerotidae & 0,0064 & 0,470 & 0,220 & 0,0001 & $-0,0239$ & 0,1872 & 0,0013 & 0,0008 & 0,0058 & 0,0104 \\
\hline Carangidae & 0,0019 & 0,506 & 0,256 & 0,0001 & 0,0318 & $-0,0764$ & $-0,0004$ & $-0,0023$ & $-0,0047$ & 0,0177 \\
\hline Clupeidae & 0,0003 & 0,555 & 0,308 & 0,0001 & 0,1170 & $-0,7758$ & $-0,0026$ & 0,0005 & $-0,0233$ & $-0,0052$ \\
\hline Ophidiidae & 0,0016 & 0,511 & 0,261 & 0,0001 & 0,0236 & 0,0550 & $-0,0005$ & $-0,0045$ & $-0,0036$ & 0,0061 \\
\hline Paralepididae & 0,0019 & 0,506 & 0,256 & 0,0001 & $-0,0099$ & 0,0336 & $-0,0018$ & $-0,0013$ & 0,0015 & 0,0011 \\
\hline Paralichthyidae & 0,0553 & 0,401 & 0,161 & 0,0001 & 0,0139 & $-0,0716$ & $-0,0002$ & $-0,0001$ & $-0,0032$ & 0,0179 \\
\hline Phosichthyidae & 0,3304 & - & - & - & - & - & - & - & - & - \\
\hline Scaridae & 0,0169 & 0,442 & 0,196 & 0,0001 & 0,0124 & $-0,0721$ & 0,0001 & 0,0002 & $-0,0002$ & $-0,0034$ \\
\hline Trichiuridae & 0,1260 & - & - & - & - & - & - & - & - & - \\
\hline Maurolicus stehmanni & 0,0001 & 0,610 & 0,380 & 0,0001 & 0,1071 & 0,3470 & $-0,0001$ & $-0,0219$ & $-0,0197$ & $-0,0747$ \\
\hline Pollichthys mauli & 0,1718 & - & - & - & - & - & - & - & - & - \\
\hline Engraulis anchoita & 0,0012 & 0,510 & 0,260 & 0,0001 & 2,0046 & 5,2646 & $-0,0907$ & $-0,4339$ & $-0,3096$ & 0,2074 \\
\hline Bregmaceros atlanticus & 0,0133 & 0,440 & 0,200 & 0,0001 & $-0,0185$ & 0,1392 & 0,0007 & 0,0005 & 0,0041 & 0,0061 \\
\hline Bregmaceros cantori & 0,5285 & - & - & - & - & - & - & - & - & - \\
\hline
\end{tabular}


Tabela 13. Resultados da Análise de Regressão Múltipla entre a densidade (larvas. $\mathrm{m}^{-3}$ ) dos grupos cuja freqüencia de ocorrência foi superior a $30 \%$ e espécies identificadas e as variáveis ambientais para o cruzeiro de inverno de 2001, na região do Cabo Frio (RJ). Valores de b em negrito foram significativamente diferentes de zero. (prof - profundidade; temp temperatura; sal - salinidade; ACAS - Água Central do Atlântico Sul; AT - Água Tropical; AC - Água Costeira)

\begin{tabular}{|c|c|c|c|c|c|c|c|c|c|c|}
\hline \multirow{2}{*}{ Grupos } & \multirow{2}{*}{ (p) } & \multirow{2}{*}{$\mathrm{R}$} & \multirow{2}{*}{$\mathrm{R} 2$} & \multicolumn{7}{|c|}{$\mathrm{b}$} \\
\hline & & & & prof & temp & sal & $\% A C A S$ & $\%$ AT & $\% A C$ & Clorofila a \\
\hline Anguilliformes & 0,1224 & - & - & - & - & - & - & - & - & - \\
\hline Cynoglossidae & 0,3399 & - & - & - & - & - & - & - & - & - \\
\hline Engraulidae & 0,0002 & 0,610 & 0,370 & 0,0001 & 0,0545 & $-0,9709$ & $-0,0163$ & $-0,0066$ & $-0,0136$ & 0,0843 \\
\hline Mullidae & 0,0461 & 0,450 & 0,200 & 0,0001 & 0,0711 & $-0,3296$ & 0,0004 & $-0,0010$ & $-0,0059$ & $-0,0372$ \\
\hline Ophidiidae & 0,4144 & - & - & - & - & - & - & - & - & - \\
\hline Paralepididae & 0,8053 & - & - & - & - & - & - & - & - & - \\
\hline Paralichthyidae & 0,3070 & - & - & - & - & - & - & - & - & - \\
\hline Sternoptychidae & 0,0186 & 0,480 & 0,230 & 0,0001 & 0,0899 & 1,0568 & 0,0178 & $-0,0164$ & 0,0089 & $-0,0065$ \\
\hline Synodontidae & 0,0886 & - & - & - & - & - & - & - & - & - \\
\hline Engraulis anchoita & 0,5270 & - & - & - & - & - & - & - & - & - \\
\hline Bregmaceros atlanticus & 0,6773 & - & - & - & - & - & - & - & - & - \\
\hline Bregmaceros cantori & 0,8762 & - & - & - & - & - & - & - & - & - \\
\hline
\end{tabular}


Tabela 14. Estimativa da densidade de larvas de Engraulis anchoita ( $\mathrm{n}^{\circ}$ de larvas. $100 \mathrm{~m}^{-3}$ ) dos diferentes estratos amostrados com a rede Multinet durante o cruzeiro de verão de 2001, na região do cabo Frio (RJ).

\begin{tabular}{|c|c|c|c|c|c|}
\hline \multirow{2}{*}{$\begin{array}{c}\mathrm{n}^{\circ} \mathrm{da} \\
\text { estação }\end{array}$} & \multicolumn{5}{|c|}{$\mathrm{N}^{\circ}$ de larvas. $100 \mathrm{~m}^{-3}$} \\
\hline & 0 a $20 \mathrm{~m}$ & 20 a $40 \mathrm{~m}$ & 40 a $60 \mathrm{~m}$ & 60 a $80 \mathrm{~m}$ & 80 a $100 m$ \\
\hline 84 & 0,00 & 0,00 & 0,00 & 0,00 & 0,00 \\
\hline 85 & 0,00 & 0,00 & 0,00 & 0,00 & 0,00 \\
\hline 86 & 0,00 & 0,00 & 0,00 & 0,00 & 0,00 \\
\hline 87 & 0,00 & 0,00 & 0,00 & 0,00 & 0,00 \\
\hline 88 & 2,08 & 0,00 & 0,00 & 0,00 & 0,00 \\
\hline 89 & 3,98 & 0,00 & - & - & - \\
\hline 94 & 0,00 & 0,00 & 0,00 & 0,00 & 0,00 \\
\hline 95 & 0,00 & 0,00 & 0,00 & 0,00 & 0,00 \\
\hline 96 & 0,00 & 0,00 & 0,00 & 0,00 & 0,00 \\
\hline 97 & 0,00 & 0,00 & 0,00 & 0,00 & 0,00 \\
\hline 01 & 0,00 & 2,54 & 0,00 & 0,00 & 0,00 \\
\hline 02 & 0,00 & 0,00 & 0,00 & 0,00 & 0,00 \\
\hline 03 & 0,00 & 0,00 & 0,00 & 0,00 & 0,00 \\
\hline 04 & 0,00 & 3,72 & 0,00 & 3,20 & 0,00 \\
\hline 06 & 2,71 & 8,47 & 0,00 & 0,00 & 0,00 \\
\hline 09 & 1,28 & 5,57 & - & - & - \\
\hline 13 & 0,00 & 0,00 & 0,00 & 0,00 & 0,00 \\
\hline 15 & 1473,86 & 1505,44 & 383,60 & 26,69 & 0,00 \\
\hline 18 & 20,87 & 16,96 & - & - & - \\
\hline média & 79,20 & 81,19 & 23,97 & 1,87 & - \\
\hline d.p. & 337,77 & 344,92 & 95,90 & 6,67 & - \\
\hline mínimo & 0,00 & 0,00 & 0,00 & 0,00 & - \\
\hline máximo & 1473,86 & 1505,44 & 383,60 & 26,69 & - \\
\hline
\end{tabular}

Tabela 15. Estimativa da densidade de larvas de Engraulis anchoita $\left(\mathrm{n}^{\circ}\right.$ de larvas. $100 \mathrm{~m}^{-3}$ ) dos diferentes estratos amostrados com a rede Multinet durante o cruzeiro de inverno de 2001, na região do cabo Frio (RJ).

\begin{tabular}{cccccc}
\hline $\mathrm{n}^{\circ}$ da & \multicolumn{5}{c}{$\mathrm{N}^{\circ}$ de larvas.100m } \\
estação & 0 a $20 \mathrm{~m}$ & 20 a $40 \mathrm{~m}$ & $40 \mathrm{a} 60 \mathrm{~m}$ & $60 \mathrm{a} 80 \mathrm{~m}$ & $80 \mathrm{a} 100 \mathrm{~m}$ \\
\cline { 2 - 6 } 50 & 4,84 & 15,57 & 0,00 & 0,00 & - \\
51 & 0,00 & 0,00 & 0,00 & 0,00 & 0,00 \\
52 & 0,00 & 0,00 & 0,00 & 0,00 & 0,00 \\
53 & 0,00 & 0,00 & 0,00 & 0,00 & 0,00 \\
54 & 0,00 & 0,00 & 0,00 & 0,00 & 0,00 \\
55 & 0,00 & 0,00 & 0,00 & 0,00 & 0,00 \\
56 & 0,00 & 0,00 & 0,00 & 0,00 & 0,00 \\
57 & 3,61 & 9,23 & 0,00 & 0,00 & - \\
58 & 82,71 & 136,53 & 16,40 & 3,65 & - \\
60 & 0,00 & 0,00 & 0,00 & 0,00 & 0,00 \\
61 & 0,00 & 0,00 & 0,00 & 0,00 & 0,00 \\
62 & 34,29 & 6,44 & 0,00 & 0,00 & - \\
63 & 112,74 & 96,00 & 5,00 & 0,00 & - \\
71 & 46,14 & 7,20 & 4,11 & 0,00 & - \\
72 & 91,59 & 40,36 & 0,00 & 9,66 & 0,00 \\
73 & 2,90 & 0,00 & 0,00 & 0,00 & 0,00 \\
74 & 207,98 & 41,41 & 0,00 & 5,00 & 0,00 \\
\hline média & 34,52 & 20,75 & 1,50 & 1,08 & - \\
d.p. & 58,25 & 38,97 & 4,13 & 2,65 & - \\
mínimo & 0,00 & 0,00 & 0,00 & 0,00 & - \\
máximo & 207,98 & 136,53 & 16,40 & 9,66 & - \\
\hline & & & &
\end{tabular}


Tabela 16. Estimativa da densidade de larvas de Myctophidae $\left(\mathrm{n}^{\circ}\right.$ de larvas. $100 \mathrm{~m}^{-3}$ ) dos diferentes estratos amostrados com a rede Multinet durante o cruzeiro de verão de 2001, na região do cabo Frio (RJ).

\begin{tabular}{|c|c|c|c|c|c|}
\hline \multirow{2}{*}{$\begin{array}{c}n^{\circ} \text { da } \\
\text { estação }\end{array}$} & \multicolumn{5}{|c|}{$\mathrm{N}^{\circ}$ de larvas. $100 \mathrm{~m}^{-3}$} \\
\hline & 0 a $20 \mathrm{~m}$ & 20 a $40 \mathrm{~m}$ & 40 a $60 \mathrm{~m}$ & 60 a $80 \mathrm{~m}$ & 80 a $100 \mathrm{~m}$ \\
\hline 84 & 206,84 & 234,01 & 17,49 & 27,66 & 8,09 \\
\hline 85 & 2,22 & 6,75 & 7,77 & 4,65 & 11,74 \\
\hline 86 & 14,98 & 26,86 & 13,08 & 9,06 & 4,64 \\
\hline 87 & 0,00 & 80,17 & 10,37 & 2,80 & 0,00 \\
\hline 88 & 18,70 & 17,79 & 20,73 & 3,59 & 0,00 \\
\hline 89 & 0,00 & 0,00 & & - & - \\
\hline 94 & 5,93 & 45,91 & 80,05 & 17,36 & 0,00 \\
\hline 95 & 7,03 & 26,24 & 53,80 & 22,73 & 0,00 \\
\hline 96 & 2,34 & 8,48 & 8,26 & 0,00 & 0,00 \\
\hline 97 & 3,03 & 40,32 & 19,03 & 3,49 & 5,57 \\
\hline 01 & 0,00 & 10,14 & 8,87 & 6,73 & 10,81 \\
\hline 02 & 7,87 & 12,23 & 29,94 & 2,79 & 0,00 \\
\hline 03 & 6,75 & 2,95 & 4,06 & 0,00 & 0,00 \\
\hline 04 & 4,19 & 37,21 & 42,81 & 0,00 & 0,00 \\
\hline 06 & 2,71 & 12,70 & 13,00 & 2,94 & 0,00 \\
\hline 09 & 0,00 & 0,00 & & - & - \\
\hline 13 & 1,90 & 4,96 & 39,80 & 25,40 & 0,00 \\
\hline 15 & 0,00 & 0,00 & 0,00 & 0,00 & 0,00 \\
\hline 18 & 0,00 & 0,00 & & - & - \\
\hline média & 14,97 & 29,83 & 23,07 & 8,07 & 2,55 \\
\hline d.p. & 46,75 & 53,59 & 21,40 & 9,60 & 4,23 \\
\hline mínimo & 0,00 & 0,00 & 0,00 & 0,00 & 0,00 \\
\hline máximo & 206,84 & 234,01 & 80,05 & 27,66 & 11,74 \\
\hline
\end{tabular}

Tabela 17. Estimativa da densidade de larvas de Myctophidae $\left(\mathrm{n}^{\circ}\right.$ de larvas. $100 \mathrm{~m}^{-3}$ ) dos diferentes estratos amostrados com a rede Multinet durante o cruzeiro de inverno de 2001, na região do cabo Frio (RJ).

\begin{tabular}{|c|c|c|c|c|c|}
\hline \multirow{2}{*}{$\begin{array}{c}\mathrm{n}^{\circ} \mathrm{da} \\
\text { estação }\end{array}$} & \multicolumn{5}{|c|}{$\mathrm{N}^{\circ}$ de larvas. $100 \mathrm{~m}^{-3}$} \\
\hline & 0 a $20 \mathrm{~m}$ & 20 a $40 \mathrm{~m}$ & 40 a $60 \mathrm{~m}$ & 60 a $80 \mathrm{~m}$ & 80 a $100 \mathrm{~m}$ \\
\hline 50 & 2,42 & 10,38 & 15,04 & 0,00 & - \\
\hline 51 & 15,18 & 36,22 & 0,00 & 6,11 & 0,00 \\
\hline 52 & 21,22 & 31,79 & 4,68 & 0,00 & 0,00 \\
\hline 53 & 13,43 & 11,74 & 7,27 & 6,79 & 0,00 \\
\hline 54 & 9,83 & 52,65 & 44,72 & 31,02 & 13,57 \\
\hline 55 & 14,85 & 17,18 & 6,17 & 5,92 & 0,00 \\
\hline 56 & 0,00 & 16,90 & 6,93 & 0,00 & 0,00 \\
\hline 57 & 0,00 & 23,08 & 0,00 & 14,93 & - \\
\hline 58 & 0,00 & 8,03 & 8,20 & 0,00 & - \\
\hline 60 & 0,00 & 5,00 & 0,00 & 0,00 & 0,00 \\
\hline 61 & 0,00 & 10,26 & 7,54 & 0,00 & 0,00 \\
\hline 62 & 0,00 & 6,44 & 0,00 & 0,00 & - \\
\hline 63 & 0,00 & 2,53 & 2,50 & 0,00 & - \\
\hline 71 & 0,00 & 0,00 & 0,00 & 0,00 & - \\
\hline 72 & 0,00 & 0,00 & 0,00 & 0,00 & 0,00 \\
\hline 73 & 2,90 & 5,65 & 0,00 & 0,00 & 0,00 \\
\hline 74 & 16,00 & 27,61 & 15,11 & 0,00 & 0,00 \\
\hline média & 5,64 & 15,62 & 6,95 & 3,81 & 1,23 \\
\hline d.p. & 7,53 & 14,46 & 10,97 & 8,13 & 4,09 \\
\hline mínimo & 0,00 & 0,00 & 0,00 & 0,00 & 0,00 \\
\hline máximo & 21,22 & 52,65 & 44,72 & 31,02 & 13,57 \\
\hline
\end{tabular}


Tabela 18. Estimativa da densidade de larvas de Sternopthychidae $\left(n^{\circ}\right.$ de larvas. $100 \mathrm{~m}^{-3}$ ) dos diferentes estratos amostrados com a rede Multinet durante o cruzeiro de verão de 2001, na região do cabo Frio (RJ).

\begin{tabular}{|c|c|c|c|c|c|}
\hline \multirow{2}{*}{$\begin{array}{c}\mathrm{n}^{\circ} \text { da } \\
\text { estação }\end{array}$} & \multicolumn{5}{|c|}{$\mathrm{N}^{\circ}$ de larvas. $100 \mathrm{~m}^{-3}$} \\
\hline & 0 a $20 \mathrm{~m}$ & 20 a $40 \mathrm{~m}$ & 40 a 60 m & 60 a $80 \mathrm{~m}$ & 80 a $100 \mathrm{~m}$ \\
\hline 84 & 0,00 & 0,00 & 0,00 & 0,00 & 0,00 \\
\hline 85 & 0,00 & 0,00 & 0,00 & 0,00 & 11,74 \\
\hline 86 & 0,00 & 0,00 & 10,46 & 11,32 & 34,83 \\
\hline 87 & 1,37 & 0,00 & 3,46 & 25,21 & 42,57 \\
\hline 88 & 0,00 & 0,00 & 0,00 & 7,18 & 0,00 \\
\hline 89 & 0,00 & 0,00 & - & - & - \\
\hline 94 & 2,96 & 0,00 & 0,00 & 14,88 & 0,00 \\
\hline 95 & 2,34 & 0,00 & 2,69 & 37,88 & 37,51 \\
\hline 96 & 0,00 & 0,00 & 5,51 & 5,61 & 5,55 \\
\hline 97 & 0,00 & 0,00 & 7,14 & 17,46 & 8,36 \\
\hline 01 & 0,00 & 0,00 & 0,00 & 0,00 & 4,33 \\
\hline 02 & 2,62 & 0,00 & 0,00 & 11,15 & 0,00 \\
\hline 03 & 0,00 & 2,95 & 48,76 & 9,70 & 3,59 \\
\hline 04 & 0,00 & 0,00 & 8,56 & 9,60 & 73,58 \\
\hline 06 & 2,71 & 0,00 & 73,69 & 35,25 & 4,38 \\
\hline 09 & 0,00 & 0,00 & - & - & - \\
\hline 13 & 0,00 & 0,00 & 0,00 & 14,51 & 97,15 \\
\hline 15 & 0,00 & 0,00 & 33,12 & 34,70 & 41,57 \\
\hline 18 & 0,00 & 0,00 & - & - & - \\
\hline média & 0,63 & 0,16 & 12,09 & 14,65 & 22,82 \\
\hline d.p. & 1,12 & 0,68 & 21,37 & 12,49 & 29,40 \\
\hline mínimo & 0,00 & 0,00 & 0,00 & 0,00 & 0,00 \\
\hline máximo & 2,96 & 2,95 & 73,69 & 37,88 & 97,15 \\
\hline
\end{tabular}

Tabela 19. Estimativa da densidade de larvas de Sternopthychidae $\left(n^{\circ}\right.$ de larvas. $100 \mathrm{~m}^{-3}$ ) dos diferentes estratos amostrados com a rede Multinet durante o cruzeiro de inverno de 2001, na região do cabo Frio (RJ).

\begin{tabular}{|c|c|c|c|c|c|}
\hline \multirow{2}{*}{$\begin{array}{c}\mathrm{n}^{\circ} \mathrm{da} \\
\text { estação }\end{array}$} & \multicolumn{5}{|c|}{$\mathrm{N}^{\circ}$ de larvas. $100 \mathrm{~m}^{-3}$} \\
\hline & 0 a $20 \mathrm{~m}$ & 20 a $40 \mathrm{~m}$ & 40 a $60 \mathrm{~m}$ & 60 a $80 \mathrm{~m}$ & 80 a $100 \mathrm{~m}$ \\
\hline 50 & 0,00 & 0,00 & 15,04 & 2,69 & - \\
\hline 51 & 0,00 & 6,04 & 4,34 & 42,76 & 4,37 \\
\hline 52 & 14,15 & 23,85 & 9,35 & 12,46 & 0,00 \\
\hline 53 & 23,50 & 0,00 & 0,00 & 0,00 & 9,81 \\
\hline 54 & 3,93 & 0,00 & 0,00 & 0,00 & 0,00 \\
\hline 55 & 0,00 & 0,00 & 6,17 & 5,92 & 11,75 \\
\hline 56 & 0,00 & 0,00 & 0,00 & 0,00 & 3,13 \\
\hline 57 & 0,00 & 0,00 & 27,17 & 0,00 & - \\
\hline 58 & 0,00 & 0,00 & 0,00 & 0,00 & - \\
\hline 60 & 7,33 & 0,00 & 6,07 & 32,33 & 2,63 \\
\hline 61 & 0,00 & 0,00 & 0,00 & 0,00 & 0,00 \\
\hline 62 & 0,00 & 0,00 & 5,80 & 0,00 & - \\
\hline 63 & 0,00 & 0,00 & 5,00 & 3,89 & - \\
\hline 71 & 0,00 & 0,00 & 4,11 & 10,63 & - \\
\hline 72 & 0,00 & 0,00 & 0,00 & 0,00 & 2,66 \\
\hline 73 & 0,00 & 16,96 & 4,26 & 10,70 & 47,07 \\
\hline 74 & 0,00 & 0,00 & 22,67 & 29,98 & 24,78 \\
\hline média & 2,88 & 2,76 & 6,47 & 8,90 & 9,66 \\
\hline d.p. & 6,52 & 6,91 & 8,07 & 13,38 & 14,43 \\
\hline mínimo & 0,00 & 0,00 & 0,00 & 0,00 & 0,00 \\
\hline máximo & 23,50 & 23,85 & 27,17 & 42,76 & 47,07 \\
\hline
\end{tabular}


Tabela 20. Estimativa da densidade de larvas de Maurolicus stehmanni $\left(\mathrm{n}^{\circ}\right.$ de larvas. $100 \mathrm{~m}^{-3}$ ) dos diferentes estratos amostrados com a rede Multinet durante o cruzeiro de verão de 2001, na região do cabo Frio (RJ).

\begin{tabular}{|c|c|c|c|c|c|}
\hline \multirow{2}{*}{$\begin{array}{c}\mathrm{n}^{\circ} \mathrm{da} \\
\text { estação }\end{array}$} & \multicolumn{5}{|c|}{$\mathrm{N}^{\circ}$ de larvas. $100 \mathrm{~m}^{-3}$} \\
\hline & 0 a $20 \mathrm{~m}$ & 20 a $40 \mathrm{~m}$ & 40 a $60 \mathrm{~m}$ & 60 a $80 \mathrm{~m}$ & 80 a $100 \mathrm{~m}$ \\
\hline 84 & 0,00 & 0,00 & 0,00 & 0,00 & 0,00 \\
\hline 85 & 0,00 & 0,00 & 0,00 & 0,00 & 11,74 \\
\hline 86 & 0,00 & 0,00 & 5,23 & 6,79 & 34,83 \\
\hline 87 & 0,00 & 0,00 & 1,73 & 19,61 & 35,85 \\
\hline 88 & 0,00 & 0,00 & 0,00 & 0,00 & 0,00 \\
\hline 89 & 0,00 & 0,00 & - & - & - \\
\hline 94 & 0,00 & 0,00 & 0,00 & 9,92 & 0,00 \\
\hline 95 & 2,34 & 0,00 & 2,69 & 37,88 & 37,51 \\
\hline 96 & 0,00 & 0,00 & 5,51 & 5,61 & 2,78 \\
\hline 97 & 0,00 & 0,00 & 2,38 & 17,46 & 8,36 \\
\hline 01 & 0,00 & 0,00 & 0,00 & 0,00 & 4,33 \\
\hline 02 & 2,62 & 0,00 & 0,00 & 0,00 & 0,00 \\
\hline 03 & 0,00 & 2,95 & 32,50 & 9,70 & 3,59 \\
\hline 04 & 0,00 & 0,00 & 4,28 & 3,20 & 64,92 \\
\hline 06 & 2,71 & 0,00 & 65,02 & 35,25 & 4,38 \\
\hline 09 & 0,00 & 0,00 & - & - & - \\
\hline 13 & 0,00 & 0,00 & 0,00 & 10,88 & 60,14 \\
\hline 15 & 0,00 & 0,00 & 33,12 & 32,03 & 39,13 \\
\hline 18 & 0,00 & 0,00 & - & - & - \\
\hline média & 0,40 & 0,16 & 9,53 & 11,77 & 19,22 \\
\hline d.p. & 0,96 & 0,68 & 18,29 & 13,10 & 22,54 \\
\hline mínimo & 0,00 & 0,00 & 0,00 & 0,00 & 0,00 \\
\hline máximo & 2,71 & 2,95 & 65,02 & 37,88 & 64,92 \\
\hline
\end{tabular}

Tabela 21. Estimativa da densidade de larvas de Maurolicus stehmanni $\left(\mathrm{n}^{\circ}\right.$ de larvas. $100 \mathrm{~m}^{-3}$ ) dos diferentes estratos amostrados com a rede Multinet durante o cruzeiro de inverno de 2001, na região do cabo Frio (RJ).

\begin{tabular}{|c|c|c|c|c|c|}
\hline \multirow{2}{*}{$\begin{array}{c}\mathrm{n}^{\circ} \mathrm{da} \\
\text { estação }\end{array}$} & \multicolumn{5}{|c|}{$\mathrm{N}^{\circ}$ de larvas. $100 \mathrm{~m}^{-3}$} \\
\hline & 0 a $20 \mathrm{~m}$ & 20 a 40 m & 40 a $60 \mathrm{~m}$ & 60 a $80 \mathrm{~m}$ & 80 a $100 \mathrm{~m}$ \\
\hline 50 & 0,00 & 0,00 & 15,04 & 2,69 & - \\
\hline 51 & 0,00 & 0,00 & 0,00 & 36,65 & 4,37 \\
\hline 52 & 0,00 & 0,00 & 4,68 & 12,46 & 0,00 \\
\hline 53 & 6,71 & 0,00 & 0,00 & 0,00 & 9,81 \\
\hline 54 & 0,00 & 0,00 & 0,00 & 0,00 & 0,00 \\
\hline 55 & 0,00 & 0,00 & 6,17 & 5,92 & 11,75 \\
\hline 56 & 0,00 & 0,00 & 0,00 & 0,00 & 3,13 \\
\hline 57 & 0,00 & 0,00 & 22,64 & 0,00 & - \\
\hline 58 & 0,00 & 0,00 & 0,00 & 0,00 & - \\
\hline 60 & 4,89 & 0,00 & 6,07 & 13,47 & 2,63 \\
\hline 61 & 0,00 & 0,00 & 0,00 & 0,00 & 0,00 \\
\hline 62 & 0,00 & 0,00 & 5,80 & 0,00 & - \\
\hline 63 & 0,00 & 0,00 & 2,50 & 1,95 & - \\
\hline 71 & 0,00 & 0,00 & 4,11 & 10,63 & - \\
\hline 72 & 0,00 & 0,00 & 0,00 & 0,00 & 2,66 \\
\hline 73 & 0,00 & 0,00 & 0,00 & 3,57 & 36,21 \\
\hline 74 & 0,00 & 0,00 & 22,67 & 29,98 & 24,78 \\
\hline média & 0,68 & 0,00 & 5,27 & 6,90 & 8,67 \\
\hline d.p. & 1,95 & 0,00 & 7,64 & 11,01 & 11,73 \\
\hline mínimo & 0,00 & 0,00 & 0,00 & 0,00 & 0,00 \\
\hline máximo & 6,71 & 0,00 & 22,67 & 36,65 & 36,21 \\
\hline
\end{tabular}


Tabela 22. Estimativa da densidade de larvas de Scombridae $\left(\mathrm{n}^{\circ}\right.$ de larvas. $100 \mathrm{~m}^{-3}$ ) dos diferentes estratos amostrados com a rede Multinet durante o cruzeiro de verão de 2001, na região do cabo Frio (RJ).

\begin{tabular}{cccccc}
\hline $\mathrm{n}^{\circ}$ da \\
estação & 0 a $20 \mathrm{~m}$ & $20 \mathrm{a} 40 \mathrm{~m}$ & $40 \mathrm{a} 60 \mathrm{~m}$ & $60 \mathrm{a} 80 \mathrm{~m}$ & $80 \mathrm{a} 100 \mathrm{~m}$ \\
\cline { 2 - 6 } 84 & 15,46 & 10,32 & 0,00 & 0,00 & 0,00 \\
85 & 8,88 & 10,13 & 0,00 & 0,00 & 0,00 \\
86 & 10,30 & 0,00 & 0,00 & 0,00 & 0,00 \\
87 & 1,37 & 0,00 & 0,00 & 0,00 & 0,00 \\
88 & 39,47 & 17,79 & 5,18 & 0,00 & 0,00 \\
89 & 0,00 & 0,00 & - & - & - \\
94 & 35,58 & 0,00 & 5,72 & 4,96 & 0,00 \\
95 & 21,09 & 6,56 & 2,69 & 0,00 & 0,00 \\
96 & 3,91 & 5,66 & 0,00 & 0,00 & 0,00 \\
97 & 12,11 & 0,00 & 0,00 & 0,00 & 0,00 \\
01 & 4,61 & 2,54 & 0,00 & 0,00 & 0,00 \\
02 & 2,62 & 0,00 & 0,00 & 0,00 & 0,00 \\
03 & 11,26 & 0,00 & 0,00 & 0,00 & 0,00 \\
04 & 67,03 & 59,54 & 17,12 & 0,00 & 0,00 \\
06 & 2,71 & 0,00 & 0,00 & 0,00 & 0,00 \\
09 & 0,00 & 0,00 & - & - & - \\
13 & 9,48 & 3,31 & 28,43 & 5,44 & 0,00 \\
15 & 0,00 & 0,00 & 0,00 & 0,00 & 0,00 \\
18 & 0,00 & 0,00 & - & - & - \\
\hline média & 12,94 & 6,10 & 3,70 & 0,65 & 0,00 \\
d.p. & 17,35 & 13,86 & 7,96 & 1,78 & 0,00 \\
mínimo & 0,00 & 0,00 & 0,00 & 0,00 & 0,00 \\
máximo & 67,03 & 59,54 & 28,43 & 5,44 & 0,00 \\
\hline & & & & \\
\hline
\end{tabular}

Tabela 23. Estimativa da densidade de larvas de Scombridade $\left(\mathrm{n}^{\circ}\right.$ de larvas. $100 \mathrm{~m}^{-3}$ ) dos diferentes estratos amostrados com a rede Multinet durante o cruzeiro de inverno de 2001, na região do cabo Frio (RJ).

\begin{tabular}{cccccc}
\hline $\mathrm{n}^{\circ}$ da & \multicolumn{5}{c}{$\mathrm{N}^{\circ}$ de larvas.100m } \\
\cline { 2 - 6 } & 0 a $20 \mathrm{~m}$ & 20 a $40 \mathrm{~m}$ & $40 \mathrm{a} 60 \mathrm{~m}$ & 60 a $80 \mathrm{~m}$ & 80 a $100 \mathrm{~m}$ \\
\hline 50 & 0,00 & 0,00 & 0,00 & 0,00 & - \\
51 & 0,00 & 0,00 & 4,34 & 0,00 & 0,00 \\
52 & 0,00 & 0,00 & 0,00 & 0,00 & 0,00 \\
53 & 0,00 & 0,00 & 0,00 & 0,00 & 0,00 \\
54 & 0,00 & 0,00 & 0,00 & 0,00 & 0,00 \\
55 & 0,00 & 0,00 & 0,00 & 0,00 & 0,00 \\
56 & 0,00 & 0,00 & 0,00 & 0,00 & 0,00 \\
57 & 0,00 & 0,00 & 0,00 & 0,00 & - \\
58 & 0,00 & 0,00 & 0,00 & 0,00 & - \\
60 & 0,00 & 0,00 & 0,00 & 0,00 & 0,00 \\
61 & 0,00 & 0,00 & 0,00 & 0,00 & 0,00 \\
62 & 0,00 & 0,00 & 0,00 & 0,00 & - \\
63 & 0,00 & 0,00 & 0,00 & 0,00 & - \\
71 & 0,00 & 0,00 & 0,00 & 0,00 & - \\
72 & 0,00 & 0,00 & 0,00 & 0,00 & 0,00 \\
73 & 0,00 & 0,00 & 0,00 & 0,00 & 0,00 \\
74 & 0,00 & 0,00 & 0,00 & 0,00 & 0,00 \\
\hline média & - & - & 0,26 & - & - \\
d.p. & - & - & 1,05 & - & - \\
mínimo & - & - & 0,00 & - & - \\
máximo & - & - & 4,34 & - & \\
\hline & & & & & - \\
\hline
\end{tabular}


Tabela 24. Estimativa da densidade de larvas de Bregmacerotidae $\left(\mathrm{n}^{\circ}\right.$ de larvas. $100 \mathrm{~m}^{-3}$ ) dos diferentes estratos amostrados com a rede Multinet durante o cruzeiro de verão de 2001, na região do cabo Frio (RJ).

\begin{tabular}{cccccc}
\hline $\mathrm{n}^{\circ}$ da \\
estação & 0 a $20 \mathrm{~m}$ & 20 a $40 \mathrm{~m}$ & 40 a $60 \mathrm{~m}$ & 60 a $80 \mathrm{~m}$ & 80 a $100 \mathrm{~m}$ \\
\cline { 2 - 6 } 84 & 0,00 & 0,00 & 0,00 & 0,00 & 0,00 \\
85 & 0,00 & 0,00 & 0,00 & 4,65 & 1,24 \\
86 & 0,00 & 10,74 & 5,23 & 0,00 & 0,00 \\
87 & 0,00 & 0,00 & 3,46 & 0,00 & 0,00 \\
88 & 0,00 & 0,00 & 0,00 & 0,00 & 0,00 \\
89 & 0,00 & 0,00 & - & - & - \\
94 & 0,00 & 11,48 & 15,25 & 12,40 & 0,00 \\
95 & 2,34 & 9,84 & 16,14 & 5,05 & 0,00 \\
96 & 0,00 & 2,83 & 0,00 & 0,00 & 0,00 \\
97 & 0,00 & 0,00 & 0,00 & 0,00 & 0,00 \\
01 & 0,00 & 0,00 & 0,00 & 4,49 & 0,00 \\
02 & 0,00 & 0,00 & 7,48 & 2,79 & 2,35 \\
03 & 0,00 & 23,61 & 0,00 & 0,00 & 0,00 \\
04 & 0,00 & 0,00 & 8,56 & 3,20 & 0,00 \\
06 & 0,00 & 0,00 & 0,00 & 0,00 & 0,00 \\
09 & 0,00 & 0,00 & - & - & - \\
13 & 0,95 & 0,00 & 0,00 & 0,00 & 0,00 \\
15 & 0,00 & 0,00 & 0,00 & 0,00 & 0,00 \\
18 & 0,00 & 0,00 & - & - & - \\
\hline média & 0,17 & 3,08 & 3,51 & 2,04 & 0,22 \\
d.p. & 0,57 & 6,36 & 5,57 & 3,39 & 0,65 \\
mínimo & 0,00 & 0,00 & 0,00 & 0,00 & 0,00 \\
máximo & 2,34 & 23,61 & 16,14 & 12,40 & 2,35 \\
\hline & & & & \\
\hline
\end{tabular}

Tabela 25. Estimativa da densidade de larvas de Bregmacerotidae $\left(n^{\circ}\right.$ de larvas. $100 \mathrm{~m}^{-3}$ ) dos diferentes estratos amostrados com a rede Multinet durante o cruzeiro de inverno de 2001, na região do cabo Frio (RJ).

\begin{tabular}{|c|c|c|c|c|c|}
\hline \multirow{2}{*}{$\begin{array}{c}\mathrm{n}^{\circ} \text { da } \\
\text { estação }\end{array}$} & \multicolumn{5}{|c|}{$\mathrm{N}^{\circ}$ de larvas. $100 \mathrm{~m}^{-3}$} \\
\hline & 0 a $20 \mathrm{~m}$ & 20 a $40 \mathrm{~m}$ & 40 a $60 \mathrm{~m}$ & 60 a $80 \mathrm{~m}$ & 80 a $100 \mathrm{~m}$ \\
\hline 50 & 14,53 & 80,43 & 0,00 & 5,37 & - \\
\hline 51 & 7,59 & 120,74 & 34,70 & 6,11 & 0,00 \\
\hline 52 & 0,00 & 11,92 & 0,00 & 0,00 & 0,00 \\
\hline 53 & 0,00 & 0,00 & 0,00 & 0,00 & 0,00 \\
\hline 54 & 0,00 & 0,00 & 5,59 & 0,00 & 0,00 \\
\hline 55 & 0,00 & 0,00 & 6,17 & 0,00 & 0,00 \\
\hline 56 & 3,66 & 8,45 & 6,93 & 0,00 & 0,00 \\
\hline 57 & 0,00 & 50,77 & 0,00 & 11,20 & - \\
\hline 58 & 4,14 & 48,19 & 4,10 & 0,00 & - \\
\hline 60 & 0,00 & 0,00 & 0,00 & 0,00 & 0,00 \\
\hline 61 & 4,24 & 0,00 & 0,00 & 0,00 & 0,00 \\
\hline 62 & 14,70 & 19,33 & 5,80 & 0,00 & - \\
\hline 63 & 2,21 & 15,16 & 0,00 & 0,00 & - \\
\hline 71 & 0,00 & 7,20 & 0,00 & 0,00 & - \\
\hline 72 & 8,72 & 22,42 & 11,68 & 0,00 & 0,00 \\
\hline 73 & 0,00 & 5,65 & 0,00 & 0,00 & 0,00 \\
\hline 74 & 41,60 & 17,26 & 7,56 & 0,00 & 0,00 \\
\hline média & 5,96 & 23,97 & 4,85 & 1,33 & - \\
\hline d.p. & 10,43 & 33,43 & 8,53 & 3,18 & - \\
\hline mínimo & 0,00 & 0,00 & 0,00 & 0,00 & - \\
\hline máximo & 41,60 & 120,74 & 34,70 & 11,20 & - \\
\hline
\end{tabular}


Tabela 26. Estimativa da densidade de larvas de Bregmaceros atlanticus ( $\mathrm{n}^{\circ}$ de larvas. $100 \mathrm{~m}^{-3}$ ) dos diferentes estratos amostrados com a rede Multinet durante o cruzeiro de verão de 2001, na região do cabo Frio (RJ).

\begin{tabular}{cccccc}
\hline $\mathrm{n}^{\circ}$ da \\
estação & 0 a $20 \mathrm{~m}$ & 20 a $40 \mathrm{~m}$ & $40 \mathrm{a} 60 \mathrm{~m}$ & 60 a $80 \mathrm{~m}$ & $80 \mathrm{a} 100 \mathrm{~m}$ \\
\cline { 2 - 6 } 8 & 0,00 & 0,00 & 0,00 & 0,00 & 0,00 \\
85 & 0,00 & 0,00 & 0,00 & 0,00 & 0,62 \\
86 & 0,00 & 10,74 & 5,23 & 0,00 & 0,00 \\
87 & 0,00 & 0,00 & 3,46 & 0,00 & 0,00 \\
88 & 0,00 & 0,00 & 0,00 & 0,00 & 0,00 \\
89 & 0,00 & 0,00 & - & - & - \\
94 & 0,00 & 5,74 & 7,62 & 7,44 & 0,00 \\
95 & 2,34 & 9,84 & 16,14 & 5,05 & 0,00 \\
96 & 0,00 & 2,83 & 0,00 & 0,00 & 0,00 \\
97 & 0,00 & 0,00 & 0,00 & 0,00 & 0,00 \\
01 & 0,00 & 0,00 & 0,00 & 4,49 & 0,00 \\
02 & 0,00 & 0,00 & 7,48 & 0,00 & 2,35 \\
03 & 0,00 & 20,66 & 0,00 & 0,00 & 0,00 \\
04 & 0,00 & 0,00 & 8,56 & 3,20 & 0,00 \\
06 & 0,00 & 0,00 & 0,00 & 0,00 & 0,00 \\
09 & 0,00 & 0,00 & - & - & - \\
13 & 0,95 & 0,00 & 0,00 & 0,00 & 0,00 \\
15 & 0,00 & 0,00 & 0,00 & 0,00 & 0,00 \\
18 & 0,00 & 0,00 & - & - & - \\
\hline média & 0,17 & 2,62 & 3,03 & 1,26 & 0,19 \\
d.p. & 0,57 & 5,52 & 4,76 & 2,39 & 0,60 \\
mínimo & 0,00 & 0,00 & 0,00 & 0,00 & 0,00 \\
máximo & 2,34 & 20,66 & 16,14 & 7,44 & 2,35 \\
\hline
\end{tabular}

Tabela 27. Estimativa da densidade de larvas de Bregmaceros atlanticus $\left(\mathrm{n}^{\circ}\right.$ de larvas. $100 \mathrm{~m}^{-3}$ ) dos diferentes estratos amostrados com a rede Multinet durante o cruzeiro de inverno de 2001, na região do cabo Frio (RJ).

\begin{tabular}{|c|c|c|c|c|c|}
\hline \multirow{2}{*}{$\begin{array}{c}\mathrm{n}^{\circ} \text { da } \\
\text { estação }\end{array}$} & \multicolumn{5}{|c|}{$\mathrm{N}^{\circ}$ de larvas. $100 \mathrm{~m}^{-3}$} \\
\hline & 0 a $20 \mathrm{~m}$ & 20 a $40 \mathrm{~m}$ & 40 a $60 \mathrm{~m}$ & 60 a $80 m$ & 80 a 100 m \\
\hline 50 & 0,00 & 0,00 & 0,00 & 0,00 & - \\
\hline 51 & 0,00 & 6,04 & 0,00 & 0,00 & 0,00 \\
\hline 52 & 0,00 & 3,97 & 0,00 & 0,00 & 0,00 \\
\hline 53 & 0,00 & 0,00 & 0,00 & 0,00 & 0,00 \\
\hline 54 & 0,00 & 0,00 & 0,00 & 0,00 & 0,00 \\
\hline 55 & 0,00 & 0,00 & 0,00 & 0,00 & 0,00 \\
\hline 56 & 0,00 & 0,00 & 0,00 & 0,00 & 0,00 \\
\hline 57 & 0,00 & 9,23 & 0,00 & 0,00 & - \\
\hline 58 & 4,14 & 0,00 & 0,00 & 0,00 & - \\
\hline 60 & 0,00 & 0,00 & 0,00 & 0,00 & 0,00 \\
\hline 61 & 4,24 & 0,00 & 0,00 & 0,00 & 0,00 \\
\hline 62 & 0,00 & 0,00 & 0,00 & 0,00 & - \\
\hline 63 & 0,00 & 0,00 & 0,00 & 0,00 & - \\
\hline 71 & 0,00 & 0,00 & 0,00 & 0,00 & - \\
\hline 72 & 8,72 & 4,48 & 0,00 & 0,00 & 0,00 \\
\hline 73 & 0,00 & 0,00 & 0,00 & 0,00 & 0,00 \\
\hline 74 & 0,00 & 0,00 & 3,78 & 0,00 & 0,00 \\
\hline média & 1,01 & 1,40 & 0,22 & - & - \\
\hline d.p. & 2,42 & 2,79 & 0,92 & - & - \\
\hline mínimo & 0,00 & 0,00 & 0,00 & - & - \\
\hline máximo & 8,72 & 9,23 & 3,78 & - & - \\
\hline
\end{tabular}


Tabela 28. Estimativa da densidade de larvas de Bregmaceros cantori $\left(\mathrm{n}^{\circ}\right.$ de larvas. $100 \mathrm{~m}^{-3}$ ) dos diferentes estratos amostrados com a rede Multinet durante o cruzeiro de verão de 2001, na região do cabo Frio (RJ).

\begin{tabular}{cccccc}
\hline $\mathrm{n}^{\circ}$ da & \multicolumn{5}{c}{$\mathrm{N}^{\circ}$ de larvas.100m } \\
estação & 0 a $20 \mathrm{~m}$ & 20 a $40 \mathrm{~m}$ & $40 \mathrm{a} 60 \mathrm{~m}$ & $60 \mathrm{a} 80 \mathrm{~m}$ & $80 \mathrm{a} 100 \mathrm{~m}$ \\
\cline { 2 - 6 } 84 & 0,00 & 0,00 & 0,00 & 0,00 & 0,00 \\
85 & 0,00 & 0,00 & 0,00 & 0,00 & 0,62 \\
86 & 0,00 & 0,00 & 0,00 & 0,00 & 0,00 \\
87 & 0,00 & 0,00 & 0,00 & 0,00 & 0,00 \\
88 & 0,00 & 0,00 & 0,00 & 0,00 & 0,00 \\
89 & 0,00 & 0,00 & - & - & - \\
94 & 0,00 & 0,00 & 0,00 & 0,00 & 0,00 \\
95 & 0,00 & 0,00 & 0,00 & 0,00 & 0,00 \\
96 & 0,00 & 0,00 & 0,00 & 0,00 & 0,00 \\
97 & 0,00 & 0,00 & 0,00 & 0,00 & 0,00 \\
01 & 0,00 & 0,00 & 0,00 & 0,00 & 0,00 \\
02 & 0,00 & 0,00 & 0,00 & 0,00 & 0,00 \\
03 & 0,00 & 0,00 & 0,00 & 0,00 & 0,00 \\
04 & 0,00 & 0,00 & 0,00 & 0,00 & 0,00 \\
06 & 0,00 & 0,00 & 0,00 & 0,00 & 0,00 \\
09 & 0,00 & 0,00 & - & - & - \\
13 & 0,00 & 0,00 & 0,00 & 0,00 & 0,00 \\
15 & 0,00 & 0,00 & 0,00 & 0,00 & 0,00 \\
18 & 0,00 & 0,00 & - & - & - \\
\hline média & - & - & - & - & 0,04 \\
d.p. & - & - & - & - & 0,15 \\
mínimo & - & - & - & - & 0,00 \\
máximo & - & - & -62 \\
\hline
\end{tabular}

Tabela 29. Estimativa da densidade de larvas de Bregmaceros cantori $\left(\mathrm{n}^{\circ}\right.$ de larvas. $100 \mathrm{~m}^{-3}$ ) dos diferentes estratos amostrados com a rede Multinet durante o cruzeiro de inverno de 2001, na região do cabo Frio (RJ).

\begin{tabular}{|c|c|c|c|c|c|}
\hline \multirow{2}{*}{$\begin{array}{c}\mathrm{n}^{\circ} \text { da } \\
\text { estação }\end{array}$} & \multicolumn{5}{|c|}{$\mathrm{N}^{\circ}$ de larvas. $100 \mathrm{~m}^{-3}$} \\
\hline & 0 a $20 \mathrm{~m}$ & 20 a $40 \mathrm{~m}$ & 40 a $60 \mathrm{~m}$ & 60 a $80 \mathrm{~m}$ & 80 a $100 \mathrm{~m}$ \\
\hline 50 & 14,53 & 80,43 & 0,00 & 2,69 & - \\
\hline 51 & 7,59 & 90,55 & 21,69 & 0,00 & 0,00 \\
\hline 52 & 0,00 & 7,95 & 0,00 & 0,00 & 0,00 \\
\hline 53 & 0,00 & 0,00 & 0,00 & 0,00 & 0,00 \\
\hline 54 & 0,00 & 0,00 & 0,00 & 0,00 & 0,00 \\
\hline 55 & 0,00 & 0,00 & 0,00 & 0,00 & 0,00 \\
\hline 56 & 3,66 & 0,00 & 0,00 & 0,00 & 0,00 \\
\hline 57 & 0,00 & 0,00 & 0,00 & 11,20 & - \\
\hline 58 & 0,00 & 28,11 & 4,10 & 0,00 & - \\
\hline 60 & 0,00 & 0,00 & 0,00 & 0,00 & 0,00 \\
\hline 61 & 0,00 & 0,00 & 0,00 & 0,00 & 0,00 \\
\hline 62 & 14,70 & 19,33 & 5,80 & 0,00 & - \\
\hline 63 & 2,21 & 15,16 & 0,00 & 0,00 & - \\
\hline 71 & 0,00 & 2,40 & 0,00 & 0,00 & - \\
\hline 72 & 0,00 & 4,48 & 0,00 & 0,00 & 0,00 \\
\hline 73 & 0,00 & 0,00 & 0,00 & 0,00 & 0,00 \\
\hline 74 & 35,20 & 0,00 & 0,00 & 0,00 & 0,00 \\
\hline média & 4,58 & 14,61 & 1,86 & 0,82 & - \\
\hline d.p. & 9,30 & 27,97 & 5,37 & 2,75 & - \\
\hline mínimo & 0,00 & 0,00 & 0,00 & 0,00 & - \\
\hline máximo & 35,20 & 90,55 & 21,69 & 11,20 & - \\
\hline
\end{tabular}


Tabela 30. Estimativa da densidade de larvas de Phosichthyidae $\left(\mathrm{n}^{\circ}\right.$ de larvas. $100 \mathrm{~m}^{-3}$ ) dos diferentes estratos amostrados com a rede Multinet durante o cruzeiro de verão de 2001, na região do cabo Frio (RJ).

\begin{tabular}{|c|c|c|c|c|c|}
\hline \multirow{2}{*}{$\begin{array}{l}\mathrm{n}^{\circ} \text { da } \\
\text { estação }\end{array}$} & \multicolumn{5}{|c|}{$\mathrm{N}^{\circ}$ de larvas. $100 \mathrm{~m}^{-3}$} \\
\hline & 0 a $20 \mathrm{~m}$ & 20 a $40 \mathrm{~m}$ & 40 a $60 \mathrm{~m}$ & 60 a $80 \mathrm{~m}$ & 80 a $100 \mathrm{~m}$ \\
\hline 84 & 1,93 & 3,44 & 24,49 & 2,77 & 0,00 \\
\hline 85 & 0,00 & 0,00 & 2,59 & 2,32 & 0,00 \\
\hline 86 & 0,00 & 2,69 & 0,00 & 0,00 & 2,32 \\
\hline 87 & 0,00 & 0,00 & 0,00 & 0,00 & 0,00 \\
\hline 88 & 2,08 & 4,45 & 0,00 & 0,00 & 0,00 \\
\hline 89 & 0,00 & 0,00 & - & - & - \\
\hline 94 & 11,86 & 28,70 & 3,81 & 4,96 & 0,00 \\
\hline 95 & 4,69 & 13,12 & 2,69 & 0,00 & 2,68 \\
\hline 96 & 0,78 & 0,00 & 0,00 & 0,00 & 0,00 \\
\hline 97 & 0,00 & 0,00 & 4,76 & 3,49 & 0,00 \\
\hline 01 & 0,00 & 0,00 & 6,66 & 2,24 & 2,16 \\
\hline 02 & 0,00 & 0,00 & 0,00 & 13,94 & 7,06 \\
\hline 03 & 2,25 & 0,00 & 0,00 & 0,00 & 0,00 \\
\hline 04 & 2,09 & 7,44 & 0,00 & 6,40 & 0,00 \\
\hline 06 & 8,12 & 8,47 & 0,00 & 0,00 & 0,00 \\
\hline 09 & 0,00 & 0,00 & - & - & - \\
\hline 13 & 2,84 & 9,93 & 1,90 & 0,00 & 0,00 \\
\hline 15 & 0,00 & 0,00 & 0,00 & 0,00 & 0,00 \\
\hline 18 & 0,00 & 0,00 & - & - & - \\
\hline média & 1,93 & 4,12 & 2,93 & 2,26 & 0,89 \\
\hline d.p. & 3,20 & 7,22 & 6,12 & 3,73 & 1,90 \\
\hline mínimo & 0,00 & 0,00 & 0,00 & 0,00 & 0,00 \\
\hline máximo & 11,86 & 28,70 & 24,49 & 13,94 & 7,06 \\
\hline
\end{tabular}

Tabela 31. Estimativa da densidade de larvas de Phosichthyidae $\left(\mathrm{n}^{\circ}\right.$ de larvas. $100 \mathrm{~m}^{-3}$ ) dos diferentes estratos amostrados com a rede Multinet durante o cruzeiro de inverno de 2001, na região do cabo Frio (RJ).

\begin{tabular}{|c|c|c|c|c|c|}
\hline \multirow{2}{*}{$\begin{array}{c}\mathrm{n}^{\circ} \text { da } \\
\text { estação }\end{array}$} & \multicolumn{5}{|c|}{$\mathrm{N}^{\circ}$ de larvas. $100 \mathrm{~m}^{-3}$} \\
\hline & 0 a $20 \mathrm{~m}$ & 20 a $40 \mathrm{~m}$ & 40 a $60 \mathrm{~m}$ & 60 a $80 \mathrm{~m}$ & 80 a $100 \mathrm{~m}$ \\
\hline 50 & 0,00 & 0,00 & 0,00 & 0,00 & - \\
\hline 51 & 3,80 & 0,00 & 0,00 & 0,00 & 0,00 \\
\hline 52 & 2,36 & 7,95 & 0,00 & 0,00 & 0,00 \\
\hline 53 & 0,00 & 0,00 & 0,00 & 6,79 & 0,00 \\
\hline 54 & 9,83 & 29,25 & 16,77 & 6,20 & 0,00 \\
\hline 55 & 2,48 & 0,00 & 6,17 & 0,00 & 0,00 \\
\hline 56 & 0,00 & 0,00 & 0,00 & 0,00 & 0,00 \\
\hline 57 & 0,00 & 0,00 & 0,00 & 0,00 & - \\
\hline 58 & 0,00 & 0,00 & 4,10 & 3,65 & - \\
\hline 60 & 0,00 & 5,00 & 3,03 & 0,00 & 2,63 \\
\hline 61 & 0,00 & 0,00 & 0,00 & 0,00 & 0,00 \\
\hline 62 & 4,90 & 0,00 & 0,00 & 0,00 & - \\
\hline 63 & 0,00 & 0,00 & 2,50 & 0,00 & - \\
\hline 71 & 0,00 & 0,00 & 0,00 & 0,00 & - \\
\hline 72 & 2,18 & 0,00 & 0,00 & 0,00 & 0,00 \\
\hline 73 & 0,00 & 11,31 & 4,26 & 0,00 & 0,00 \\
\hline 74 & 0,00 & 13,80 & 15,11 & 9,99 & 0,00 \\
\hline média & 1,50 & 3,96 & 3,06 & 1,57 & 0,24 \\
\hline d.p. & 2,66 & 7,89 & 5,24 & 3,12 & 0,79 \\
\hline mínimo & 0,00 & 0,00 & 0,00 & 0,00 & 0,00 \\
\hline máximo & 9,83 & 29,25 & 16,77 & 9,99 & 2,63 \\
\hline
\end{tabular}


Tabela 32. Estimativa da densidade de larvas de Pollichthys mauli ( $\mathrm{n}^{\circ}$ de larvas. $100 \mathrm{~m}^{-3}$ ) dos diferentes estratos amostrados com a rede Multinet durante o cruzeiro de verão de 2001, na região do cabo Frio (RJ).

\begin{tabular}{|c|c|c|c|c|c|}
\hline \multirow{2}{*}{$\begin{array}{c}\mathrm{n}^{\circ} \text { da } \\
\text { estação }\end{array}$} & \multicolumn{5}{|c|}{$\mathrm{N}^{\circ}$ de larvas. $100 \mathrm{~m}^{-3}$} \\
\hline & 0 a $20 \mathrm{~m}$ & 20 a $40 \mathrm{~m}$ & 40 a $60 \mathrm{~m}$ & 60 a $80 \mathrm{~m}$ & 80 a $100 \mathrm{~m}$ \\
\hline 84 & 0,00 & 0,00 & 0,00 & 2,77 & 0,00 \\
\hline 85 & 0,00 & 0,00 & 0,00 & 0,00 & 0,00 \\
\hline 86 & 0,00 & 0,00 & 0,00 & 0,00 & 2,32 \\
\hline 87 & 0,00 & 0,00 & 0,00 & 0,00 & 0,00 \\
\hline 88 & 2,08 & 4,45 & 0,00 & 0,00 & 0,00 \\
\hline 89 & 0,00 & 0,00 & - & - & - \\
\hline 94 & 11,86 & 22,96 & 0,00 & 4,96 & 0,00 \\
\hline 95 & 4,69 & 13,12 & 2,69 & 0,00 & 0,00 \\
\hline 96 & 0,78 & 0,00 & 0,00 & 0,00 & 0,00 \\
\hline 97 & 0,00 & 0,00 & 4,76 & 3,49 & 0,00 \\
\hline 01 & 0,00 & 0,00 & 4,44 & 2,24 & 0,00 \\
\hline 02 & 0,00 & 0,00 & 0,00 & 11,15 & 7,06 \\
\hline 03 & 2,25 & 0,00 & 0,00 & 0,00 & 0,00 \\
\hline 04 & 2,09 & 7,44 & 0,00 & 6,40 & 0,00 \\
\hline 06 & 8,12 & 8,47 & 0,00 & 0,00 & 0,00 \\
\hline 09 & 0,00 & 0,00 & - & - & - \\
\hline 13 & 1,90 & 4,96 & 1,90 & 0,00 & 0,00 \\
\hline 15 & 0,00 & 0,00 & 0,00 & 0,00 & 0,00 \\
\hline 18 & 0,00 & 0,00 & - & - & - \\
\hline média & 1,78 & 3,23 & 0,86 & 1,94 & 0,59 \\
\hline d.p. & 3,22 & 6,11 & 1,66 & 3,21 & 1,82 \\
\hline mínimo & 0,00 & 0,00 & 0,00 & 0,00 & 0,00 \\
\hline máximo & 11,86 & 22,96 & 4,76 & 11,15 & 7,06 \\
\hline
\end{tabular}

Tabela 33. Estimativa da densidade de larvas de Pollichthys mauli $\left(\mathrm{n}^{\circ}\right.$ de larvas. $100 \mathrm{~m}^{-3}$ ) dos diferentes estratos amostrados com a rede Multinet durante o cruzeiro de inverno de 2001, na região do cabo Frio (RJ).

\begin{tabular}{cccccc}
\hline $\mathrm{n}^{\circ}$ da & \multicolumn{5}{c}{$\mathrm{N}^{\circ}$ de larvas. $100 \mathrm{~m}^{-3}$} \\
\cline { 2 - 6 } estação & 0 a $20 \mathrm{~m}$ & $20 \mathrm{a} 40 \mathrm{~m}$ & $40 \mathrm{a} 60 \mathrm{~m}$ & $60 \mathrm{a} 80 \mathrm{~m}$ & $80 \mathrm{a} 100 \mathrm{~m}$ \\
\hline 50 & 0,00 & 0,00 & 0,00 & 0,00 & - \\
51 & 3,80 & 0,00 & 0,00 & 0,00 & 0,00 \\
52 & 0,00 & 3,97 & 0,00 & 0,00 & 0,00 \\
53 & 0,00 & 0,00 & 0,00 & 6,79 & 0,00 \\
54 & 0,00 & 0,00 & 0,00 & 0,00 & 0,00 \\
55 & 0,00 & 0,00 & 0,00 & 0,00 & 0,00 \\
56 & 0,00 & 0,00 & 0,00 & 0,00 & 0,00 \\
57 & 0,00 & 0,00 & 0,00 & 0,00 & - \\
58 & 0,00 & 0,00 & 4,10 & 3,65 & - \\
60 & 0,00 & 5,00 & 0,00 & 0,00 & 2,63 \\
61 & 0,00 & 0,00 & 0,00 & 0,00 & 0,00 \\
62 & 4,90 & 0,00 & 0,00 & 0,00 & - \\
63 & 0,00 & 0,00 & 0,00 & 0,00 & - \\
71 & 0,00 & 0,00 & 0,00 & 0,00 & - \\
72 & 2,18 & 0,00 & 0,00 & 0,00 & 0,00 \\
73 & 0,00 & 0,00 & 0,00 & 0,00 & 0,00 \\
74 & 0,00 & 10,35 & 11,33 & 5,00 & 0,00 \\
\hline média & 0,64 & 1,14 & 0,91 & 0,91 & 0,24 \\
d.p. & 1,50 & 2,81 & 2,86 & 2,10 & 0,79 \\
mínimo & 0,00 & 0,00 & 0,00 & 0,00 & 0,00 \\
máximo & 4,90 & 10,35 & 11,33 & 6,79 & 2,63 \\
\hline
\end{tabular}


Tabela 34. Estimativa da densidade de larvas de Trichiuridae $\left(\mathrm{n}^{\circ}\right.$ de larvas. $100 \mathrm{~m}^{-3}$ ) dos diferentes estratos amostrados com a rede Multinet durante o cruzeiro de verão de 2001, na região do cabo Frio (RJ).

\begin{tabular}{|c|c|c|c|c|c|}
\hline \multirow{2}{*}{$\begin{array}{c}\mathrm{n}^{\circ} \text { da } \\
\text { estação }\end{array}$} & \multicolumn{5}{|c|}{$\mathrm{N}^{\circ}$ de larvas. $100 \mathrm{~m}^{-3}$} \\
\hline & 0 a $20 \mathrm{~m}$ & 20 a $40 \mathrm{~m}$ & 40 a $60 \mathrm{~m}$ & 60 a $80 \mathrm{~m}$ & 80 a $100 \mathrm{~m}$ \\
\hline 84 & 0,00 & 0,00 & 0,00 & 0,00 & 0,00 \\
\hline 85 & 0,00 & 0,00 & 0,00 & 0,00 & 0,00 \\
\hline 86 & 0,00 & 0,00 & 0,00 & 0,00 & 0,00 \\
\hline 87 & 0,00 & 0,00 & 0,00 & 0,00 & 0,00 \\
\hline 88 & 0,00 & 4,45 & 0,00 & 0,00 & 0,00 \\
\hline 89 & 0,00 & 0,00 & - & - & - \\
\hline 94 & 0,00 & 5,74 & 7,62 & 0,00 & 0,00 \\
\hline 95 & 0,00 & 0,00 & 5,38 & 0,00 & 0,00 \\
\hline 96 & 0,00 & 0,00 & 0,00 & 0,00 & 0,00 \\
\hline 97 & 0,00 & 0,00 & 0,00 & 0,00 & 0,00 \\
\hline 01 & 0,00 & 0,00 & 0,00 & 0,00 & 2,16 \\
\hline 02 & 0,00 & 0,00 & 0,00 & 2,79 & 0,00 \\
\hline 03 & 0,00 & 0,00 & 0,00 & 0,00 & 0,00 \\
\hline 04 & 4,19 & 7,44 & 4,28 & 0,00 & 2,16 \\
\hline 06 & 0,00 & 0,00 & 0,00 & 0,00 & 0,00 \\
\hline 09 & 0,00 & 0,00 & - & - & - \\
\hline 13 & 3,79 & 3,31 & 5,69 & 0,00 & 0,00 \\
\hline 15 & 0,00 & 0,00 & 0,00 & 0,00 & 0,00 \\
\hline 18 & 0,00 & 0,00 & - & - & - \\
\hline média & 0,42 & 1,10 & 1,44 & 0,17 & 0,27 \\
\hline d.p. & 1,26 & 2,31 & 2,64 & 0,70 & 0,74 \\
\hline mínimo & 0,00 & 0,00 & 0,00 & 0,00 & 0,00 \\
\hline máximo & 4,19 & 7,44 & 7,62 & 2,79 & 2,16 \\
\hline
\end{tabular}

Tabela 35. Estimativa da densidade de larvas de Trichiuridae $\left(\mathrm{n}^{0}\right.$ de larvas. $100 \mathrm{~m}^{-3}$ ) dos diferentes estratos amostrados com a rede Multinet durante o cruzeiro de inverno de 2001, na região do cabo Frio (RJ).

\begin{tabular}{|c|c|c|c|c|c|}
\hline \multirow{2}{*}{$\begin{array}{c}\mathrm{n}^{\circ} \text { da } \\
\text { estação }\end{array}$} & \multicolumn{5}{|c|}{$\mathrm{N}^{\circ}$ de larvas. $100 \mathrm{~m}^{-3}$} \\
\hline & 0 a $20 \mathrm{~m}$ & 20 a $40 \mathrm{~m}$ & 40 a $60 \mathrm{~m}$ & 60 a $80 \mathrm{~m}$ & 80 a $100 \mathrm{~m}$ \\
\hline 50 & 0,00 & 10,38 & 0,00 & 0,00 & \\
\hline 51 & 0,00 & 12,07 & 26,03 & 0,00 & 0,00 \\
\hline 52 & 2,36 & 0,00 & 0,00 & 0,00 & 0,00 \\
\hline 53 & 0,00 & 0,00 & 0,00 & 0,00 & 0,00 \\
\hline 54 & 0,00 & 0,00 & 0,00 & 0,00 & 0,00 \\
\hline 55 & 0,00 & 0,00 & 6,17 & 0,00 & 0,00 \\
\hline 56 & 0,00 & 0,00 & 0,00 & 0,00 & 0,00 \\
\hline 57 & 0,00 & 23,08 & 0,00 & 7,47 & - \\
\hline 58 & 0,00 & 4,02 & 20,49 & 0,00 & - \\
\hline 60 & 0,00 & 0,00 & 0,00 & 0,00 & 0,00 \\
\hline 61 & 0,00 & 0,00 & 0,00 & 0,00 & 0,00 \\
\hline 62 & 9,80 & 32,22 & 0,00 & 0,00 & - \\
\hline 63 & 0,00 & 12,63 & 2,50 & 0,00 & - \\
\hline 71 & 17,94 & 19,19 & 0,00 & 0,00 & - \\
\hline 72 & 0,00 & 8,97 & 7,79 & 3,22 & 0,00 \\
\hline 73 & 0,00 & 0,00 & 8,51 & 0,00 & 0,00 \\
\hline 74 & 6,40 & 0,00 & 0,00 & 0,00 & 0,00 \\
\hline média & 2,15 & 7,21 & 4,21 & 0,63 & - \\
\hline d.p. & 4,91 & 9,89 & 7,80 & 1,93 & - \\
\hline mínimo & 0,00 & 0,00 & 0,00 & 0,00 & - \\
\hline máximo & 17,94 & 32,22 & 26,03 & 7,47 & - \\
\hline
\end{tabular}


Tabela 36. Estimativa da densidade de larvas de Anguiliformes ( $n^{\circ}$ de larvas. $100 \mathrm{~m}^{-3}$ ) dos diferentes estratos amostrados com a rede Multinet durante o cruzeiro de verão de 2001, na região do cabo Frio (RJ).

\begin{tabular}{cccccc}
\hline $\mathrm{n}^{\circ}$ da \\
estação & 0 a $20 \mathrm{~m}$ & $20 \mathrm{a} 40 \mathrm{~m}$ & $40 \mathrm{a} 60 \mathrm{~m}$ & $60 \mathrm{a} 80 \mathrm{~m}$ & $80 \mathrm{a} 100 \mathrm{~m}$ \\
\cline { 2 - 6 } 84 & 0,00 & 0,00 & 0,00 & 0,00 & 0,00 \\
85 & 0,00 & 0,00 & 0,00 & 2,32 & 1,24 \\
86 & 0,00 & 0,00 & 0,00 & 0,00 & 0,00 \\
87 & 0,00 & 0,00 & 0,00 & 0,00 & 0,00 \\
88 & 2,08 & 4,45 & 0,00 & 0,00 & 0,00 \\
89 & 0,00 & 0,00 & - & - & - \\
94 & 2,96 & 0,00 & 0,00 & 0,00 & 0,00 \\
95 & 0,00 & 0,00 & 5,38 & 0,00 & 0,00 \\
96 & 0,00 & 2,83 & 0,00 & 0,00 & 0,00 \\
97 & 0,00 & 0,00 & 0,00 & 3,49 & 0,00 \\
01 & 0,00 & 0,00 & 0,00 & 2,24 & 0,00 \\
02 & 0,00 & 0,00 & 0,00 & 0,00 & 0,00 \\
03 & 0,00 & 0,00 & 0,00 & 0,00 & 0,00 \\
04 & 2,09 & 0,00 & 0,00 & 0,00 & 0,00 \\
06 & 2,71 & 0,00 & 0,00 & 0,00 & 0,00 \\
09 & 0,00 & 0,00 & - & - & - \\
13 & 0,95 & 1,65 & 0,00 & 0,00 & 13,88 \\
15 & 0,00 & 0,00 & 0,00 & 0,00 & 0,00 \\
18 & 0,00 & 0,00 & - & - & - \\
\hline média & 0,57 & 0,47 & 0,34 & 0,50 & 0,94 \\
d.p. & 1,04 & 1,21 & 1,34 & 1,11 & 3,46 \\
mínimo & 0,00 & 0,00 & 0,00 & 0,00 & 0,00 \\
máximo & 2,96 & 4,45 & 5,38 & 3,49 & \\
\hline & & & & \\
\hline
\end{tabular}

Tabela 37. Estimativa da densidade de larvas de Anguiliformes $\left(n^{\circ}\right.$ de larvas. $100 \mathrm{~m}^{-3}$ ) dos diferentes estratos amostrados com a rede Multinet durante o cruzeiro de inverno de 2001, na região do cabo Frio (RJ).

\begin{tabular}{cccccc}
\hline $\mathrm{n}^{\circ}$ da \\
estação & 0 a $20 \mathrm{~m}$ & $20 \mathrm{a} 40 \mathrm{~m}$ & $40 \mathrm{a} 60 \mathrm{~m}$ & $60 \mathrm{a} 80 \mathrm{~m}$ & $80 \mathrm{a} 100 \mathrm{~m}$ \\
\cline { 2 - 6 } 50 & 0,00 & 2,59 & 0,00 & 0,00 & - \\
51 & 7,59 & 0,00 & 8,68 & 0,00 & 0,00 \\
52 & 0,00 & 0,00 & 0,00 & 0,00 & 0,00 \\
53 & 0,00 & 0,00 & 0,00 & 0,00 & 0,00 \\
54 & 0,00 & 0,00 & 0,00 & 0,00 & 0,00 \\
55 & 0,00 & 0,00 & 0,00 & 0,00 & 0,00 \\
56 & 0,00 & 0,00 & 0,00 & 0,00 & 0,00 \\
57 & 0,00 & 9,23 & 0,00 & 0,00 & - \\
58 & 0,00 & 4,02 & 0,00 & 0,00 & - \\
60 & 2,44 & 0,00 & 0,00 & 0,00 & 0,00 \\
61 & 0,00 & 0,00 & 0,00 & 0,00 & 0,00 \\
62 & 0,00 & 12,89 & 0,00 & 0,00 & - \\
63 & 0,00 & 0,00 & 12,50 & 0,00 & - \\
71 & 0,00 & 0,00 & 2,05 & 0,00 & - \\
72 & 0,00 & 0,00 & 3,89 & 0,00 & 0,00 \\
73 & 0,00 & 5,65 & 4,26 & 0,00 & 0,00 \\
74 & 6,40 & 3,45 & 0,00 & 0,00 & 0,00 \\
\hline média & 0,97 & 2,23 & 1,85 & - & - \\
d.p. & 2,35 & 3,82 & 3,63 & - & - \\
mínimo & 0,00 & 0,00 & 0,00 & - & - \\
máximo & 7,59 & 12,89 & 12,50 & - & \\
\hline
\end{tabular}


Tabela 38. Estimativa da densidade de larvas de Bothidae $\left(\mathrm{n}^{\circ}\right.$ de larvas. $100 \mathrm{~m}^{-3}$ ) dos diferentes estratos amostrados com a rede Multinet durante o cruzeiro de verão de 2001, na região do cabo Frio (RJ).

\begin{tabular}{cccccc}
\hline $\mathrm{n}^{\circ}$ da & \multicolumn{5}{c}{$\mathrm{N}^{\circ}$ de larvas.100m } \\
estação & 0 a $20 \mathrm{~m}$ & $20 \mathrm{a} 40 \mathrm{~m}$ & $40 \mathrm{a} 60 \mathrm{~m}$ & $60 \mathrm{a} 80 \mathrm{~m}$ & $80 \mathrm{a} 100 \mathrm{~m}$ \\
\cline { 2 - 6 } 84 & 0,00 & 0,00 & 0,00 & 0,00 & 0,00 \\
85 & 22,20 & 3,38 & 5,18 & 0,00 & 0,00 \\
86 & 1,87 & 0,00 & 0,00 & 0,00 & 0,00 \\
87 & 5,50 & 0,00 & 0,00 & 0,00 & 0,00 \\
88 & 18,70 & 0,00 & 0,00 & 0,00 & 0,00 \\
89 & 0,00 & 0,00 & - & - & - \\
94 & 0,00 & 5,74 & 0,00 & 0,00 & 0,00 \\
95 & 11,72 & 0,00 & 2,69 & 0,00 & 0,00 \\
96 & 9,38 & 0,00 & 0,00 & 2,81 & 0,00 \\
97 & 15,14 & 13,44 & 0,00 & 0,00 & 0,00 \\
01 & 0,00 & 2,54 & 2,22 & 0,00 & 0,00 \\
02 & 0,00 & 2,45 & 0,00 & 0,00 & 0,00 \\
03 & 9,01 & 0,00 & 0,00 & 0,00 & 0,00 \\
04 & 0,00 & 0,00 & 0,00 & 0,00 & 0,00 \\
06 & 2,71 & 0,00 & 0,00 & 0,00 & 0,00 \\
09 & 0,00 & 0,00 & - & - & - \\
13 & 3,79 & 1,65 & 0,00 & 0,00 & 0,00 \\
15 & 10,85 & 0,00 & 0,00 & 0,00 & 0,00 \\
18 & 0,00 & 0,00 & - & - & - \\
\hline média & 5,83 & 1,54 & 0,63 & 0,18 & - \\
d.p. & 7,09 & 3,29 & 1,48 & 0,70 & - \\
mínimo & 0,00 & 0,00 & 0,00 & 0,00 & - \\
máximo & 22,20 & 13,44 & 5,18 & 2,81 & - \\
\hline & & & & \\
\hline
\end{tabular}

Tabela 39. Estimativa da densidade de larvas de Carangidae $\left(\mathrm{n}^{\circ}\right.$ de larvas. $100 \mathrm{~m}^{-3}$ ) dos diferentes estratos amostrados com a rede Multinet durante o cruzeiro de verão de 2001, na região do cabo Frio (RJ).

\begin{tabular}{|c|c|c|c|c|c|}
\hline \multirow{2}{*}{$\begin{array}{c}\mathrm{n}^{\circ} \text { da } \\
\text { estação }\end{array}$} & \multicolumn{5}{|c|}{$\mathrm{N}^{\circ}$ de larvas. $100 \mathrm{~m}^{-3}$} \\
\hline & 0 a $20 \mathrm{~m}$ & 20 a $40 \mathrm{~m}$ & 40 a $60 \mathrm{~m}$ & 60 a $80 \mathrm{~m}$ & 80 a $100 \mathrm{~m}$ \\
\hline 84 & 0,00 & 3,44 & 0,00 & 0,00 & 0,00 \\
\hline 85 & 0,00 & 0,00 & 0,00 & 0,00 & 0,00 \\
\hline 86 & 8,43 & 2,69 & 0,00 & 0,00 & 0,00 \\
\hline 87 & 0,00 & 0,00 & 0,00 & 0,00 & 0,00 \\
\hline 88 & 6,23 & 0,00 & 0,00 & 0,00 & 0,00 \\
\hline 89 & 0,00 & 0,00 & - & - & - \\
\hline 94 & 0,00 & 0,00 & 0,00 & 0,00 & 0,00 \\
\hline 95 & 0,00 & 0,00 & 0,00 & 0,00 & 0,00 \\
\hline 96 & 0,00 & 2,83 & 0,00 & 0,00 & 0,00 \\
\hline 97 & 0,00 & 0,00 & 0,00 & 0,00 & 0,00 \\
\hline 01 & 4,61 & 2,54 & 0,00 & 0,00 & 0,00 \\
\hline 02 & 0,00 & 0,00 & 0,00 & 0,00 & 0,00 \\
\hline 03 & 0,00 & 0,00 & 0,00 & 0,00 & 0,00 \\
\hline 04 & 0,00 & 7,44 & 4,28 & 0,00 & 0,00 \\
\hline 06 & 2,71 & 0,00 & 0,00 & 0,00 & 0,00 \\
\hline 09 & 0,00 & 0,00 & - & - & - \\
\hline 13 & 0,00 & 0,00 & 0,00 & 1,81 & 0,00 \\
\hline 15 & 30,39 & 2,92 & 0,00 & 0,00 & 0,00 \\
\hline 18 & 0,00 & 0,00 & - & - & - \\
\hline média & 2,76 & 1,15 & 0,27 & 0,11 & - \\
\hline d.p. & 7,14 & 2,00 & 1,07 & 0,45 & - \\
\hline mínimo & 0,00 & 0,00 & 0,00 & 0,00 & - \\
\hline máximo & 30,39 & 7,44 & 4,28 & 1,81 & - \\
\hline
\end{tabular}


Tabela 40. Estimativa da densidade de larvas de Clupeidae $\left(\mathrm{n}^{\circ}\right.$ de larvas. $100 \mathrm{~m}^{-3}$ ) dos diferentes estratos amostrados com a rede Multinet durante o cruzeiro de verão de 2001, na região do cabo Frio (RJ).

\begin{tabular}{|c|c|c|c|c|c|}
\hline \multirow{2}{*}{$\begin{array}{l}\mathrm{n}^{\circ} \text { da } \\
\text { estação }\end{array}$} & \multicolumn{5}{|c|}{$\mathrm{N}^{\circ}$ de larvas. $100 \mathrm{~m}^{-3}$} \\
\hline & 0 a $20 \mathrm{~m}$ & 20 a $40 \mathrm{~m}$ & 40 a $60 \mathrm{~m}$ & 60 a $80 \mathrm{~m}$ & 80 a $100 \mathrm{~m}$ \\
\hline 84 & 0,00 & 0,00 & 0,00 & 0,00 & 0,00 \\
\hline 85 & 0,00 & 0,00 & 0,00 & 0,00 & 0,00 \\
\hline 86 & 0,00 & 0,00 & 0,00 & 0,00 & 0,00 \\
\hline 87 & 0,00 & 10,02 & 0,00 & 0,00 & 0,00 \\
\hline 88 & 91,41 & 0,00 & 0,00 & 3,59 & 0,00 \\
\hline 89 & 0,00 & 0,00 & - & - & - \\
\hline 94 & 62,26 & 0,00 & 0,00 & 0,00 & 0,00 \\
\hline 95 & 0,00 & 0,00 & 0,00 & 0,00 & 0,00 \\
\hline 96 & 1,56 & 0,00 & 0,00 & 0,00 & 0,00 \\
\hline 97 & 0,00 & 0,00 & 0,00 & 0,00 & 0,00 \\
\hline 01 & 0,00 & 0,00 & 0,00 & 0,00 & 0,00 \\
\hline 02 & 0,00 & 0,00 & 0,00 & 0,00 & 0,00 \\
\hline 03 & 2,25 & 0,00 & 0,00 & 0,00 & 0,00 \\
\hline 04 & 8,38 & 0,00 & 0,00 & 0,00 & 0,00 \\
\hline 06 & 16,24 & 0,00 & 0,00 & 0,00 & 0,00 \\
\hline 09 & 0,00 & 0,00 & - & - & - \\
\hline 13 & 5,69 & 0,00 & 0,00 & 0,00 & 0,00 \\
\hline 15 & 62,95 & 0,00 & 0,00 & 0,00 & 0,00 \\
\hline 18 & 0,00 & 0,00 & - & - & - \\
\hline média & 13,20 & 0,53 & - & 0,22 & - \\
\hline d.p. & 27,14 & 2,30 & - & 0,90 & - \\
\hline mínimo & 0,00 & 0,00 & - & 0,00 & - \\
\hline máximo & 91,41 & 10,02 & - & 3,59 & - \\
\hline
\end{tabular}

Tabela 41. Estimativa da densidade de larvas de Cynoglossidae $\left(\mathrm{n}^{\circ}\right.$ de larvas. $100 \mathrm{~m}^{-3}$ ) dos diferentes estratos amostrados com a rede Multinet durante o cruzeiro de inverno de 2001, na região do cabo Frio (RJ).

\begin{tabular}{cccccc}
\hline $\mathrm{n}^{\circ}$ da & \multicolumn{5}{c}{$\mathrm{N}^{\circ}$ de larvas. $100 \mathrm{~m}^{-3}$} \\
\cline { 2 - 6 } estação & 0 a $20 \mathrm{~m}$ & 20 a $40 \mathrm{~m}$ & $40 \mathrm{a} 60 \mathrm{~m}$ & 60 a $80 \mathrm{~m}$ & 80 a $100 \mathrm{~m}$ \\
\hline 50 & 0,00 & 0,00 & 0,00 & 0,00 & - \\
51 & 0,00 & 60,37 & 0,00 & 0,00 & 0,00 \\
52 & 0,00 & 0,00 & 0,00 & 0,00 & 0,00 \\
53 & 0,00 & 0,00 & 0,00 & 0,00 & 0,00 \\
54 & 0,00 & 0,00 & 0,00 & 0,00 & 0,00 \\
55 & 0,00 & 0,00 & 0,00 & 0,00 & 0,00 \\
56 & 0,00 & 42,24 & 0,00 & 0,00 & 0,00 \\
57 & 0,00 & 0,00 & 0,00 & 0,00 & - \\
58 & 12,41 & 24,09 & 4,10 & 0,00 & - \\
60 & 0,00 & 0,00 & 0,00 & 0,00 & 0,00 \\
61 & 0,00 & 0,00 & 0,00 & 0,00 & 0,00 \\
62 & 29,39 & 0,00 & 0,00 & 0,00 & - \\
63 & 13,26 & 2,53 & 0,00 & 0,00 & - \\
71 & 0,00 & 0,00 & 0,00 & 0,00 & - \\
72 & 0,00 & 0,00 & 0,00 & 0,00 & 0,00 \\
73 & 2,90 & 0,00 & 0,00 & 0,00 & 0,00 \\
74 & 12,80 & 0,00 & 0,00 & 0,00 & 0,00 \\
\hline média & 4,16 & 7,60 & 0,24 & - & - \\
d.p. & 8,18 & 17,74 & 0,99 & - & - \\
mínimo & 0,00 & 0,00 & 0,00 & - & - \\
máximo & 29,39 & 60,37 & 4,10 & - & \\
\hline & & & & - \\
\hline
\end{tabular}


Tabela 42. Estimativa da densidade de larvas de Mullidae $\left(n^{\circ}\right.$ de larvas. $100 \mathrm{~m}^{-3}$ ) dos diferentes estratos amostrados com a rede Multinet durante o cruzeiro de inverno de 2001, na região do cabo Frio (RJ).

\begin{tabular}{cccccc}
\hline $\mathrm{n}^{\circ}$ da \\
estação & 0 a $20 \mathrm{~m}$ & 20 a $40 \mathrm{~m}$ & 40 a $60 \mathrm{~m}$ & $60 \mathrm{a} 80 \mathrm{~m}$ & $80 \mathrm{a} 100 \mathrm{~m}$ \\
\cline { 2 - 6 } 50 & 4,84 & 0,00 & 0,00 & 0,00 & - \\
51 & 3,80 & 0,00 & 0,00 & 0,00 & 0,00 \\
52 & 0,00 & 0,00 & 0,00 & 0,00 & 0,00 \\
53 & 0,00 & 0,00 & 0,00 & 0,00 & 0,00 \\
54 & 0,00 & 0,00 & 0,00 & 0,00 & 0,00 \\
55 & 14,85 & 0,00 & 0,00 & 0,00 & 0,00 \\
56 & 18,29 & 0,00 & 0,00 & 0,00 & 0,00 \\
57 & 3,61 & 0,00 & 0,00 & 0,00 & - \\
58 & 0,00 & 0,00 & 0,00 & 0,00 & - \\
60 & 4,89 & 0,00 & 0,00 & 0,00 & 0,00 \\
61 & 4,24 & 0,00 & 0,00 & 0,00 & 0,00 \\
62 & 14,70 & 0,00 & 0,00 & 0,00 & - \\
63 & 0,00 & 0,00 & 0,00 & 0,00 & - \\
71 & 0,00 & 0,00 & 0,00 & 0,00 & - \\
72 & 15,27 & 0,00 & 0,00 & 0,00 & 0,00 \\
73 & 2,90 & 0,00 & 0,00 & 0,00 & 0,00 \\
74 & 9,60 & 0,00 & 0,00 & 0,00 & 0,00 \\
\hline média & 5,70 & - & - & - & - \\
d.p. & 6,34 & - & - & - & - \\
mínimo & 0,00 & - & - & - & - \\
máximo & 18,29 & - & - & & - \\
\hline & & & & - & - \\
\hline
\end{tabular}

Tabela 43. Estimativa da densidade de larvas de Ophidiidae $\left(\mathrm{n}^{0}\right.$ de larvas. $100 \mathrm{~m}^{-3}$ ) dos diferentes estratos amostrados com a rede Multinet durante o cruzeiro de verão de 2001, na região do cabo Frio (RJ).

\begin{tabular}{|c|c|c|c|c|c|}
\hline \multirow{2}{*}{$\begin{array}{c}\mathrm{n}^{\circ} \text { da } \\
\text { estação }\end{array}$} & \multicolumn{5}{|c|}{$\mathrm{N}^{\circ}$ de larvas. $100 \mathrm{~m}^{-3}$} \\
\hline & 0 a $20 \mathrm{~m}$ & 20 a $40 \mathrm{~m}$ & 40 a $60 \mathrm{~m}$ & 60 a $80 \mathrm{~m}$ & 80 a $100 \mathrm{~m}$ \\
\hline 84 & 0,00 & 0,00 & 0,00 & 0,00 & 0,00 \\
\hline 85 & 0,00 & 0,00 & 0,00 & 0,00 & 0,00 \\
\hline 86 & 0,00 & 0,00 & 0,00 & 0,00 & 0,00 \\
\hline 87 & 0,00 & 0,00 & 0,00 & 0,00 & 0,00 \\
\hline 88 & 0,00 & 0,00 & 0,00 & 0,00 & 0,00 \\
\hline 89 & 3,98 & 0,00 & - & - & - \\
\hline 94 & 0,00 & 0,00 & 0,00 & 2,48 & 0,00 \\
\hline 95 & 0,00 & 0,00 & 0,00 & 0,00 & 0,00 \\
\hline 96 & 0,00 & 0,00 & 0,00 & 0,00 & 0,00 \\
\hline 97 & 0,00 & 0,00 & 0,00 & 0,00 & 0,00 \\
\hline 01 & 0,00 & 0,00 & 0,00 & 0,00 & 0,00 \\
\hline 02 & 0,00 & 0,00 & 0,00 & 0,00 & 0,00 \\
\hline 03 & 0,00 & 0,00 & 0,00 & 0,00 & 0,00 \\
\hline 04 & 0,00 & 0,00 & 0,00 & 0,00 & 0,00 \\
\hline 06 & 0,00 & 0,00 & 0,00 & 0,00 & 0,00 \\
\hline 09 & 1,28 & 5,57 & - & - & - \\
\hline 13 & 0,00 & 0,00 & 5,69 & 0,00 & 0,00 \\
\hline 15 & 8,68 & 20,46 & 8,28 & 0,00 & 0,00 \\
\hline 18 & 0,00 & 2,83 & - & - & - \\
\hline média & 0,73 & 1,52 & 0,87 & 0,15 & - \\
\hline d.p. & 2,14 & 4,80 & 2,43 & 0,62 & - \\
\hline mínimo & 0,00 & 0,00 & 0,00 & 0,00 & - \\
\hline máximo & 8,68 & 20,46 & 8,28 & 2,48 & - \\
\hline
\end{tabular}


Tabela 44. Estimativa da densidade de larvas de Paralepididae $\left(\mathrm{n}^{\circ}\right.$ de larvas. $100 \mathrm{~m}^{-3}$ ) dos diferentes estratos amostrados com a rede Multinet durante o cruzeiro de verão de 2001, na região do cabo Frio (RJ).

\begin{tabular}{|c|c|c|c|c|c|}
\hline \multirow{2}{*}{$\begin{array}{l}\mathrm{n}^{\circ} \text { da } \\
\text { estação }\end{array}$} & \multicolumn{5}{|c|}{$\mathrm{N}^{\circ}$ de larvas. $100 \mathrm{~m}^{-3}$} \\
\hline & 0 a $20 \mathrm{~m}$ & 20 a $40 \mathrm{~m}$ & 40 a $60 \mathrm{~m}$ & 60 a $80 \mathrm{~m}$ & 80 a $100 \mathrm{~m}$ \\
\hline 84 & 0,00 & 0,00 & 0,00 & 0,00 & 0,00 \\
\hline 85 & 0,00 & 0,00 & 0,00 & 0,00 & 0,00 \\
\hline 86 & 0,00 & 0,00 & 0,00 & 0,00 & 0,00 \\
\hline 87 & 0,00 & 0,00 & 0,00 & 0,00 & 0,00 \\
\hline 88 & 6,23 & 0,00 & 0,00 & 0,00 & 0,00 \\
\hline 89 & 0,00 & 0,00 & - & - & - \\
\hline 94 & 5,93 & 0,00 & 0,00 & 2,48 & 0,00 \\
\hline 95 & 4,69 & 0,00 & 0,00 & 0,00 & 0,00 \\
\hline 96 & 0,00 & 2,83 & 0,00 & 0,00 & 0,00 \\
\hline 97 & 0,00 & 0,00 & 0,00 & 0,00 & 0,00 \\
\hline 01 & 0,00 & 0,00 & 0,00 & 0,00 & 0,00 \\
\hline 02 & 0,00 & 0,00 & 0,00 & 0,00 & 0,00 \\
\hline 03 & 0,00 & 0,00 & 0,00 & 0,00 & 0,00 \\
\hline 04 & 14,66 & 3,72 & 0,00 & 3,20 & 0,00 \\
\hline 06 & 0,00 & 0,00 & 0,00 & 0,00 & 0,00 \\
\hline 09 & 0,00 & 0,00 & - & - & - \\
\hline 13 & 0,95 & 0,00 & 0,00 & 0,00 & 0,00 \\
\hline 15 & 0,00 & 0,00 & 0,00 & 0,00 & 0,00 \\
\hline 18 & 0,00 & 0,00 & - & - & - \\
\hline média & 1,71 & 0,34 & - & 0,35 & - \\
\hline d.p. & 3,77 & 1,04 & - & 0,98 & - \\
\hline mínimo & 0,00 & 0,00 & - & 0,00 & - \\
\hline máximo & 14,66 & 3,72 & - & 3,20 & - \\
\hline
\end{tabular}

Tabela 45. Estimativa da densidade de larvas de Paralichthyidae $\left(\mathrm{n}^{\circ}\right.$ de larvas. $100 \mathrm{~m}^{-3}$ ) dos diferentes estratos amostrados com a rede Multinet durante o cruzeiro de verão de 2001, na região do cabo Frio (RJ).

\begin{tabular}{|c|c|c|c|c|c|}
\hline \multirow{2}{*}{$\begin{array}{c}\mathrm{n}^{\circ} \text { da } \\
\text { estação }\end{array}$} & \multicolumn{5}{|c|}{$\mathrm{N}^{\circ}$ de larvas. $100 \mathrm{~m}^{-3}$} \\
\hline & 0 a $20 \mathrm{~m}$ & 20 a $40 \mathrm{~m}$ & 40 a $60 \mathrm{~m}$ & 60 a $80 \mathrm{~m}$ & 80 a $100 \mathrm{~m}$ \\
\hline 84 & 0,00 & 0,00 & 0,00 & 0,00 & 0,00 \\
\hline 85 & 0,00 & 0,00 & 0,00 & 0,00 & 0,00 \\
\hline 86 & 0,00 & 0,00 & 0,00 & 0,00 & 0,00 \\
\hline 87 & 0,00 & 0,00 & 0,00 & 0,00 & 0,00 \\
\hline 88 & 0,00 & 0,00 & 0,00 & 0,00 & 0,00 \\
\hline 89 & 2,66 & 0,00 & - & - & - \\
\hline 94 & 2,96 & 5,74 & 1,91 & 0,00 & 0,00 \\
\hline 95 & 2,34 & 0,00 & 2,69 & 0,00 & 0,00 \\
\hline 96 & 0,78 & 0,00 & 0,00 & 0,00 & 0,00 \\
\hline 97 & 0,00 & 0,00 & 0,00 & 0,00 & 0,00 \\
\hline 01 & 0,00 & 0,00 & 0,00 & 0,00 & 0,00 \\
\hline 02 & 0,00 & 0,00 & 0,00 & 0,00 & 0,00 \\
\hline 03 & 0,00 & 0,00 & 0,00 & 0,00 & 0,00 \\
\hline 04 & 2,09 & 14,88 & 0,00 & 3,20 & 0,00 \\
\hline 06 & 0,00 & 12,70 & 0,00 & 0,00 & 0,00 \\
\hline 09 & 0,00 & 0,00 & - & - & - \\
\hline 13 & 0,00 & 1,65 & 0,00 & 0,00 & 0,00 \\
\hline 15 & 4,34 & 0,00 & 0,00 & 0,00 & 0,00 \\
\hline 18 & 0,00 & 0,00 & - & - & - \\
\hline média & 0,80 & 1,84 & 0,29 & 0,20 & - \\
\hline d.p. & 1,35 & 4,44 & 0,80 & 0,80 & - \\
\hline mínimo & 0,00 & 0,00 & 0,00 & 0,00 & - \\
\hline máximo & 4,34 & 14,88 & 2,69 & 3,20 & - \\
\hline
\end{tabular}


Tabela 46. Estimativa da densidade de larvas de Phycidae $\left(\mathrm{n}^{\circ}\right.$ de larvas. $100 \mathrm{~m}^{-3}$ ) dos diferentes estratos amostrados com a rede Multinet durante o cruzeiro de inverno de 2001, na região do cabo Frio (RJ).

\begin{tabular}{|c|c|c|c|c|c|}
\hline \multirow{2}{*}{$\begin{array}{l}\mathrm{n}^{\circ} \text { da } \\
\text { estação }\end{array}$} & \multicolumn{5}{|c|}{$\mathrm{N}^{\circ}$ de larvas. $100 \mathrm{~m}^{-3}$} \\
\hline & 0 a $20 \mathrm{~m}$ & 20 a $40 \mathrm{~m}$ & 40 a $60 \mathrm{~m}$ & 60 a $80 \mathrm{~m}$ & 80 a $100 \mathrm{~m}$ \\
\hline 50 & 0,00 & 0,00 & 0,00 & 0,00 & - \\
\hline 51 & 0,00 & 0,00 & 0,00 & 0,00 & 0,00 \\
\hline 52 & 0,00 & 0,00 & 0,00 & 0,00 & 0,00 \\
\hline 53 & 0,00 & 0,00 & 0,00 & 0,00 & 0,00 \\
\hline 54 & 0,00 & 0,00 & 0,00 & 0,00 & 0,00 \\
\hline 55 & 7,43 & 12,89 & 0,00 & 0,00 & 0,00 \\
\hline 56 & 0,00 & 16,90 & 13,85 & 0,00 & 0,00 \\
\hline 57 & 0,00 & 9,23 & 0,00 & 3,73 & - \\
\hline 58 & 0,00 & 0,00 & 0,00 & 0,00 & - \\
\hline 60 & 4,89 & 0,00 & 0,00 & 0,00 & 0,00 \\
\hline 61 & 4,24 & 0,00 & 0,00 & 0,00 & 0,00 \\
\hline 62 & 0,00 & 0,00 & 0,00 & 0,00 & - \\
\hline 63 & 0,00 & 0,00 & 0,00 & 0,00 & - \\
\hline 71 & 2,56 & 0,00 & 0,00 & 0,00 & - \\
\hline 72 & 2,18 & 0,00 & 0,00 & 0,00 & 0,00 \\
\hline 73 & 17,40 & 0,00 & 0,00 & 10,70 & 0,00 \\
\hline 74 & 0,00 & 0,00 & 0,00 & 0,00 & 0,00 \\
\hline média & 2,28 & 2,30 & 0,81 & 0,85 & - \\
\hline d.p. & 4,49 & 5,29 & 3,36 & 2,69 & - \\
\hline mínimo & 0,00 & 0,00 & 0,00 & 0,00 & - \\
\hline máximo & 17,40 & 16,90 & 13,85 & 10,70 & - \\
\hline
\end{tabular}

Tabela 47. Estimativa da densidade de larvas de Pleuronectiformes $\left(n^{\circ}\right.$ de larvas. $100 \mathrm{~m}^{-3}$ ) dos diferentes estratos amostrados com a rede Multinet durante o cruzeiro de inverno de 2001, na região do cabo Frio (RJ).

\begin{tabular}{|c|c|c|c|c|c|}
\hline \multirow{2}{*}{$\begin{array}{c}\mathrm{n}^{\circ} \mathrm{da} \\
\text { estação }\end{array}$} & \multicolumn{5}{|c|}{$\mathrm{N}^{\circ}$ de larvas. $100 \mathrm{~m}^{-3}$} \\
\hline & 0 a $20 \mathrm{~m}$ & 20 a $40 \mathrm{~m}$ & 40 a $60 \mathrm{~m}$ & 60 a $80 \mathrm{~m}$ & 80 a $100 \mathrm{~m}$ \\
\hline 50 & 0,00 & 0,00 & 0,00 & 0,00 & - \\
\hline 51 & 0,00 & 0,00 & 0,00 & 0,00 & 0,00 \\
\hline 52 & 0,00 & 0,00 & 0,00 & 0,00 & 0,00 \\
\hline 53 & 0,00 & 0,00 & 0,00 & 0,00 & 0,00 \\
\hline 54 & 0,00 & 0,00 & 0,00 & 0,00 & 0,00 \\
\hline 55 & 0,00 & 0,00 & 0,00 & 0,00 & 0,00 \\
\hline 56 & 0,00 & 0,00 & 0,00 & 0,00 & 0,00 \\
\hline 57 & 0,00 & 0,00 & 0,00 & 0,00 & - \\
\hline 58 & 0,00 & 0,00 & 4,10 & 0,00 & - \\
\hline 60 & 0,00 & 0,00 & 0,00 & 0,00 & 0,00 \\
\hline 61 & 0,00 & 0,00 & 0,00 & 0,00 & 0,00 \\
\hline 62 & 0,00 & 6,44 & 0,00 & 0,00 & - \\
\hline 63 & 0,00 & 7,58 & 0,00 & 0,00 & - \\
\hline 71 & 10,25 & 0,00 & 0,00 & 0,00 & - \\
\hline 72 & 23,99 & 58,29 & 3,89 & 3,22 & 0,00 \\
\hline 73 & 0,00 & 11,31 & 0,00 & 0,00 & 0,00 \\
\hline 74 & 6,40 & 6,90 & 0,00 & 0,00 & 0,00 \\
\hline média & 2,39 & 5,33 & 0,47 & 0,19 & - \\
\hline d.p. & 6,25 & 14,12 & 1,33 & 0,78 & - \\
\hline mínimo & 0,00 & 0,00 & 0,00 & 0,00 & - \\
\hline máximo & 23,99 & 58,29 & 4,10 & 3,22 & - \\
\hline
\end{tabular}


Tabela 48. Estimativa da densidade de larvas de Scaridae $\left(\mathrm{n}^{\circ}\right.$ de larvas. $100 \mathrm{~m}^{-3}$ ) dos diferentes estratos amostrados com a rede Multinet durante o cruzeiro de verão de 2001, na região do cabo Frio (RJ).

\begin{tabular}{cccccc}
\hline $\mathrm{n}^{\circ}$ da & \multicolumn{5}{c}{$\mathrm{N}^{\circ}$ de larvas.100m ${ }^{-3}$} \\
\cline { 2 - 6 } estação & 0 a $20 \mathrm{~m}$ & 20 a $40 \mathrm{~m}$ & 40 a $60 \mathrm{~m}$ & $60 \mathrm{a} 80 \mathrm{~m}$ & $80 \mathrm{a} 100 \mathrm{~m}$ \\
\hline 84 & 0,00 & 6,88 & 0,00 & 0,00 & 0,00 \\
85 & 0,00 & 6,75 & 2,59 & 0,00 & 0,00 \\
86 & 0,00 & 0,00 & 0,00 & 0,00 & 0,00 \\
87 & 0,00 & 0,00 & 0,00 & 0,00 & 0,00 \\
88 & 8,31 & 0,00 & 0,00 & 0,00 & 0,00 \\
89 & 0,00 & 0,00 & - & - & - \\
94 & 2,96 & 5,74 & 0,00 & 0,00 & 0,00 \\
95 & 0,00 & 0,00 & 0,00 & 0,00 & 0,00 \\
96 & 0,78 & 0,00 & 0,00 & 0,00 & 0,00 \\
97 & 6,05 & 0,00 & 0,00 & 0,00 & 0,00 \\
01 & 0,00 & 0,00 & 4,44 & 0,00 & 0,00 \\
02 & 0,00 & 0,00 & 0,00 & 0,00 & 0,00 \\
03 & 2,25 & 0,00 & 0,00 & 0,00 & 0,00 \\
04 & 0,00 & 0,00 & 4,28 & 0,00 & 0,00 \\
06 & 0,00 & 0,00 & 0,00 & 0,00 & 0,00 \\
09 & 0,00 & 0,00 & - & - & - \\
13 & 2,84 & 3,31 & 0,00 & 0,00 & 0,00 \\
15 & 6,51 & 0,00 & 0,00 & 2,67 & 0,00 \\
18 & 0,00 & 0,00 & - & - & - \\
\hline média & 1,56 & 1,19 & 0,71 & 0,17 & - \\
d.p. & 2,63 & 2,47 & 1,56 & 0,67 & - \\
mínimo & 0,00 & 0,00 & 0,00 & 0,00 & - \\
máximo & 8,31 & 6,88 & 4,44 & 2,67 & \\
\hline & & & & & \\
\hline
\end{tabular}

Tabela 49. Estimativa da densidade de larvas de Serranidae $\left(\mathrm{n}^{\circ}\right.$ de larvas. $100 \mathrm{~m}^{-3}$ ) dos diferentes estratos amostrados com a rede Multinet durante o cruzeiro de verão de 2001, na região do cabo Frio (RJ).

\begin{tabular}{|c|c|c|c|c|c|}
\hline \multirow{2}{*}{$\begin{array}{c}\mathrm{n}^{\circ} \mathrm{da} \\
\text { estação }\end{array}$} & \multicolumn{5}{|c|}{$\mathrm{N}^{\circ}$ de larvas. $100 \mathrm{~m}^{-3}$} \\
\hline & 0 a $20 \mathrm{~m}$ & 20 a $40 \mathrm{~m}$ & 40 a $60 \mathrm{~m}$ & 60 a $80 \mathrm{~m}$ & 80 a $100 \mathrm{~m}$ \\
\hline 84 & 0,00 & 0,00 & 0,00 & 0,00 & 0,00 \\
\hline 85 & 0,00 & 0,00 & 0,00 & 0,00 & 0,00 \\
\hline 86 & 1,87 & 0,00 & 0,00 & 0,00 & 0,00 \\
\hline 87 & 0,00 & 0,00 & 0,00 & 0,00 & 0,00 \\
\hline 88 & 2,08 & 0,00 & 0,00 & 0,00 & 0,00 \\
\hline 89 & 0,00 & 0,00 & - & - & - \\
\hline 94 & 0,00 & 0,00 & 0,00 & 0,00 & 0,00 \\
\hline 95 & 0,00 & 0,00 & 0,00 & 0,00 & 0,00 \\
\hline 96 & 0,00 & 0,00 & 0,00 & 0,00 & 0,00 \\
\hline 97 & 0,00 & 0,00 & 0,00 & 0,00 & 0,00 \\
\hline 01 & 0,00 & 0,00 & 0,00 & 0,00 & 0,00 \\
\hline 02 & 0,00 & 0,00 & 0,00 & 0,00 & 0,00 \\
\hline 03 & 0,00 & 0,00 & 0,00 & 0,00 & 0,00 \\
\hline 04 & 0,00 & 0,00 & 0,00 & 0,00 & 0,00 \\
\hline 06 & 8,12 & 0,00 & 0,00 & 0,00 & 0,00 \\
\hline 09 & 1,28 & 0,00 & - & - & - \\
\hline 13 & 0,95 & 0,00 & 0,00 & 0,00 & 0,00 \\
\hline 15 & 2,17 & 0,00 & 0,00 & 0,00 & 0,00 \\
\hline 18 & 1,30 & 0,00 & - & - & - \\
\hline média & 0,94 & - & - & - & - \\
\hline d.p. & 1,92 & - & - & - & - \\
\hline mínimo & 0,00 & - & - & - & - \\
\hline máximo & 8,12 & - & - & - & - \\
\hline
\end{tabular}


Tabela 50. Estimativa da densidade de larvas de Synodontidae $\left(\mathrm{n}^{\circ}\right.$ de larvas. $100 \mathrm{~m}^{-3}$ ) dos diferentes estratos amostrados com a rede Multinet durante o cruzeiro de inverno de 2001, na região do cabo Frio (RJ).

\begin{tabular}{|c|c|c|c|c|c|}
\hline \multirow{2}{*}{$\begin{array}{c}\mathrm{n}^{\circ} \mathrm{da} \\
\text { estação }\end{array}$} & \multicolumn{5}{|c|}{$\mathrm{N}^{\circ}$ de larvas. $100 \mathrm{~m}^{-3}$} \\
\hline & 0 a $20 \mathrm{~m}$ & 20 a $40 \mathrm{~m}$ & 40 a $60 \mathrm{~m}$ & 60 a $80 \mathrm{~m}$ & 80 a 100 m \\
\hline 50 & 0,00 & 2,59 & 0,00 & 2,69 & - \\
\hline 51 & 0,00 & 6,04 & 0,00 & 0,00 & 0,00 \\
\hline 52 & 0,00 & 3,97 & 0,00 & 0,00 & 0,00 \\
\hline 53 & 0,00 & 0,00 & 0,00 & 0,00 & 0,00 \\
\hline 54 & 0,00 & 0,00 & 0,00 & 0,00 & 0,00 \\
\hline 55 & 0,00 & 0,00 & 0,00 & 0,00 & 0,00 \\
\hline 56 & 0,00 & 0,00 & 0,00 & 0,00 & 0,00 \\
\hline 57 & 0,00 & 0,00 & 0,00 & 0,00 & - \\
\hline 58 & 8,27 & 12,05 & 4,10 & 0,00 & - \\
\hline 60 & 0,00 & 0,00 & 0,00 & 0,00 & 0,00 \\
\hline 61 & 0,00 & 0,00 & 0,00 & 0,00 & 0,00 \\
\hline 62 & 0,00 & 0,00 & 0,00 & 0,00 & - \\
\hline 63 & 2,21 & 2,53 & 2,50 & 0,00 & - \\
\hline 71 & 0,00 & 0,00 & 0,00 & 0,00 & - \\
\hline 72 & 0,00 & 0,00 & 0,00 & 0,00 & 0,00 \\
\hline 73 & 0,00 & 0,00 & 0,00 & 0,00 & 0,00 \\
\hline 74 & 6,40 & 0,00 & 3,78 & 5,00 & 0,00 \\
\hline média & 0,99 & 1,60 & 0,61 & 0,45 & - \\
\hline d.p. & 2,47 & 3,23 & 1,39 & 1,34 & - \\
\hline mínimo & 0,00 & 0,00 & 0,00 & 0,00 & - \\
\hline máximo & 8,27 & 12,05 & 4,10 & 5,00 & - \\
\hline
\end{tabular}


Tabela 51. Resultados da Análise de Componentes Principais realizada com as variáveis ambientais obtidas no cruzeiro de verão de 2001, na região do cabo Frio $(R J)$.

\begin{tabular}{lcc}
\hline & Eixo 1 & Eixo 2 \\
\hline Autovalores & 4.397 & 1.082 \\
Porcentagem & 62.809 & 15.453 \\
Porcentagem acumulada & 62.809 & 78.262 \\
& & \\
variáveis & & \\
profundidade & 0,253 & $-0,379$ \\
temperatura & 0,463 & 0,186 \\
salinidade & 0,439 & $-0,305$ \\
porcentagem ACAS & $-0,467$ & $\mathbf{- 0 , 0 8 5}$ \\
porcentagem AT & 0,459 & $-0,173$ \\
porcentagem AC & 0,203 & 0,829 \\
clorofila & $-0,241$ & $\mathbf{- 0 , 0 6 4}$ \\
\hline
\end{tabular}

Tabela 52. Resultados da Análise de Componentes Principais realizada com as variáveis ambientais obtidas no cruzeiro de inverno de 2001, na região do cabo Frio (RJ).

\begin{tabular}{lcc}
\hline & Eixo 1 & Eixo 2 \\
\hline Autovalores & 3,572 & 2,349 \\
Porcentagem & 51,023 & 33,561 \\
Porcentagem acumulada & 51,023 & 84,584 \\
& & \\
variáveis & & \\
profundidade & 0,396 & $-0,157$ \\
temperatura & 0,401 & 0,417 \\
salinidade & 0,507 & $-0,110$ \\
porcentagem ACAS & $-0,301$ & $-0,524$ \\
porcentagem AT & 0,519 & $-\mathbf{0 , 0 5 6}$ \\
porcentagem AC & $-0,232$ & 0,551 \\
clorofila & $-0,109$ & 0,457 \\
\hline
\end{tabular}




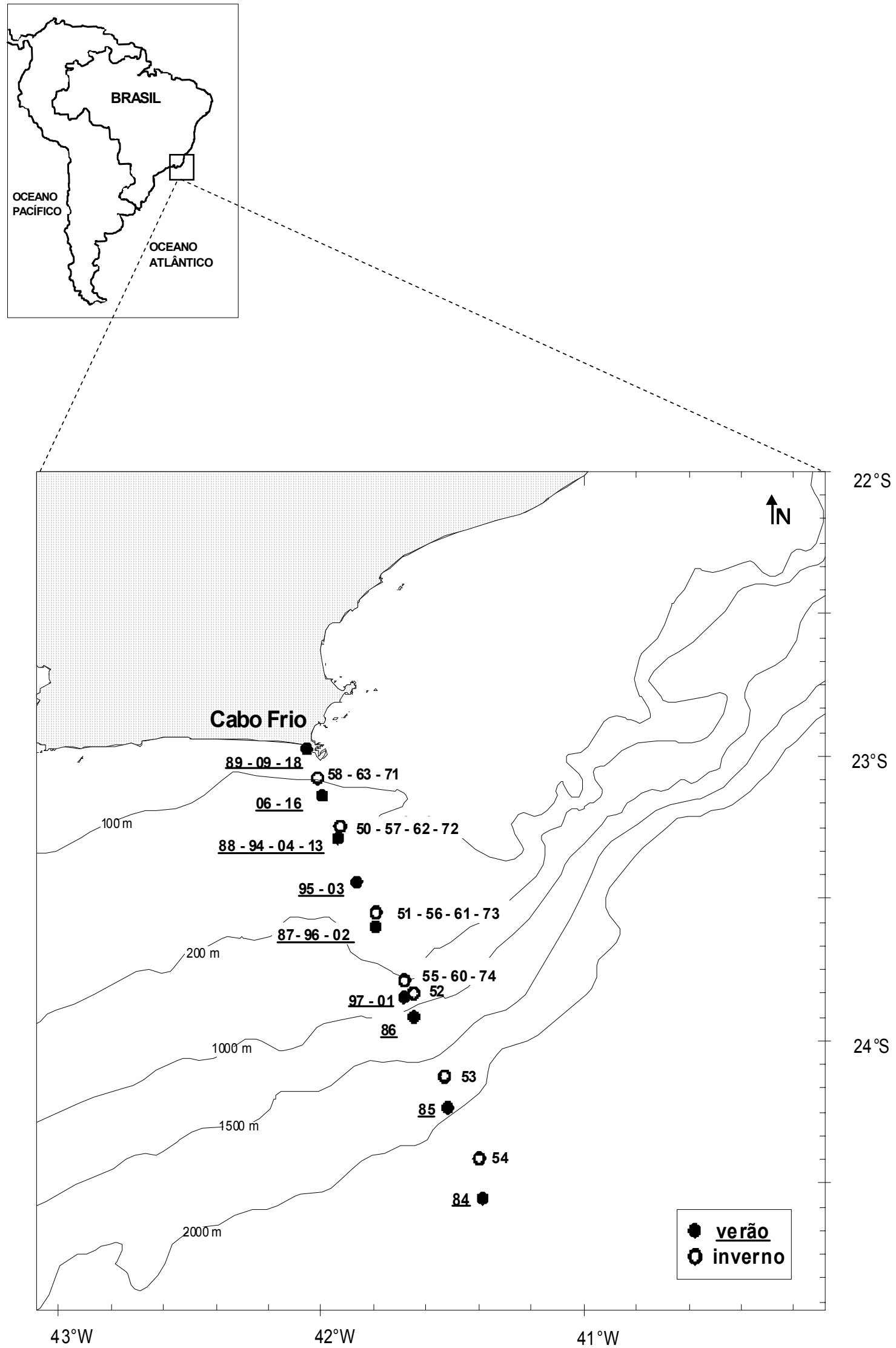

Figura 1. Área de estudo com a localização das estações de coleta dos cruzeiros realizados no verão e inverno de 2001 na reqião do cabo Frio (RJ) 

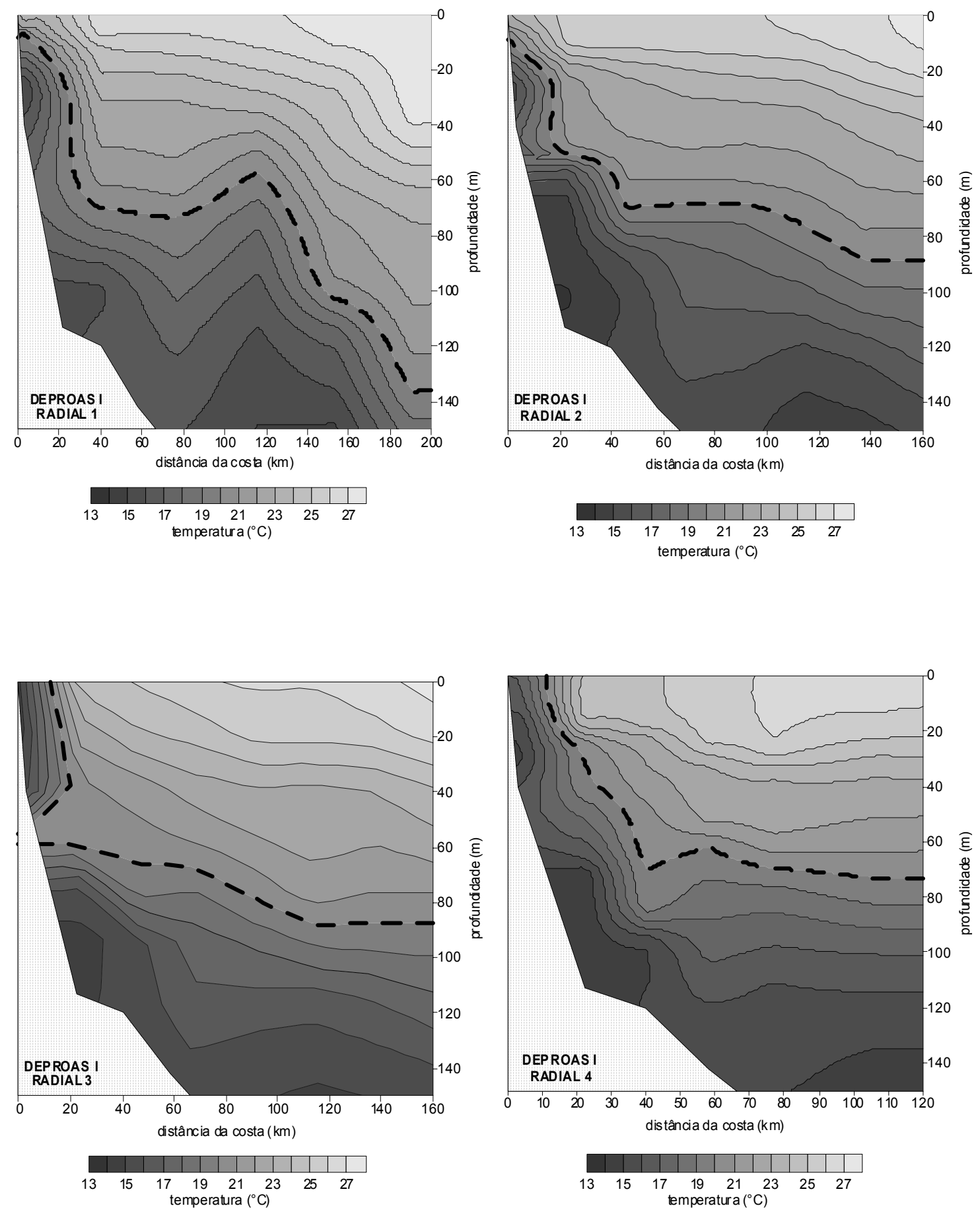

Figura 2. Perfis verticais de temperatura $\left({ }^{\circ} \mathrm{C}\right)$ das radiais realizadas durante o cruzeiro de verão de 2001 , na região do cabo Frio (RJ). A linha pontilha representa a isoterma de $20^{\circ} \mathrm{C}$. 

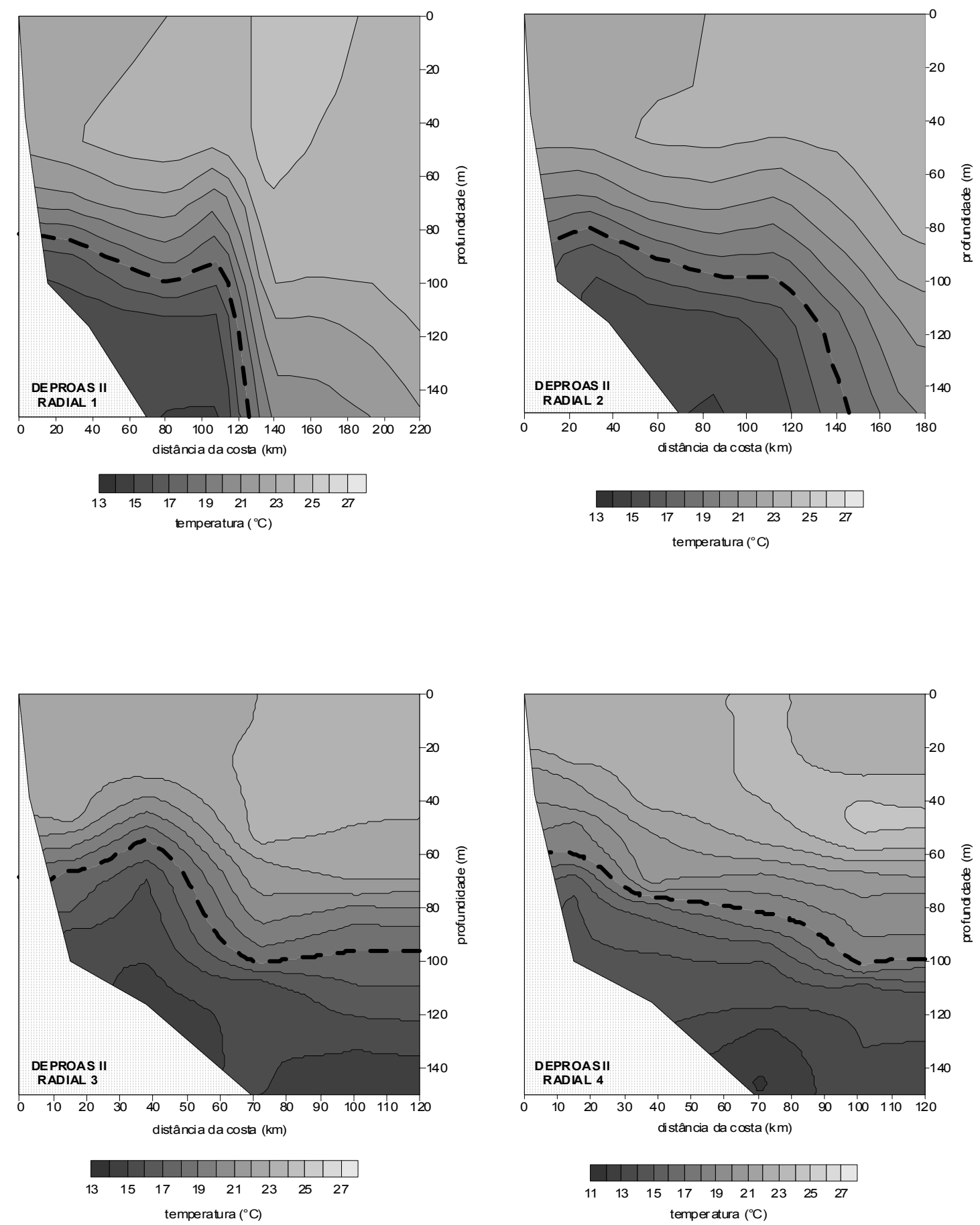

Figura 3. Perfis verticais de temperatura $\left({ }^{\circ} \mathrm{C}\right)$ das radiais realizadas durante o cruzeiro de inverno de 2001 , na região do cabo Frio (RJ). A linha pontilha representa a isoterma de $20^{\circ} \mathrm{C}$. 

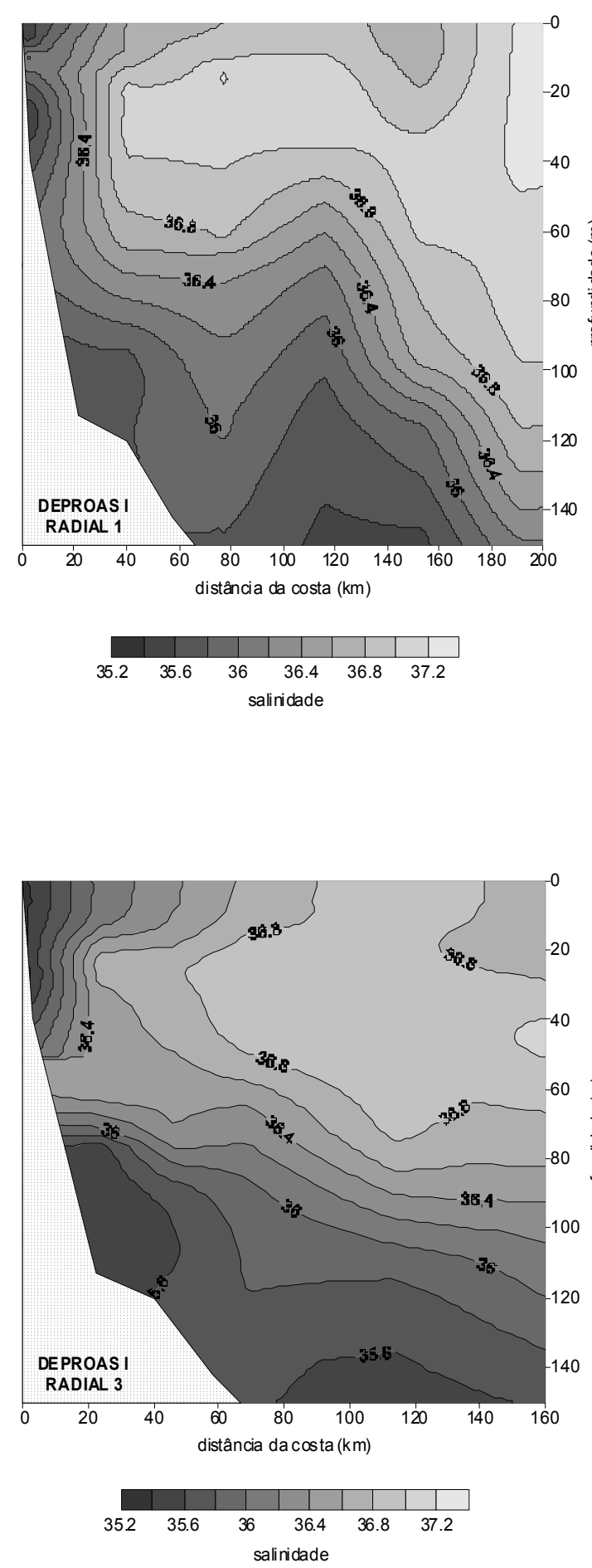
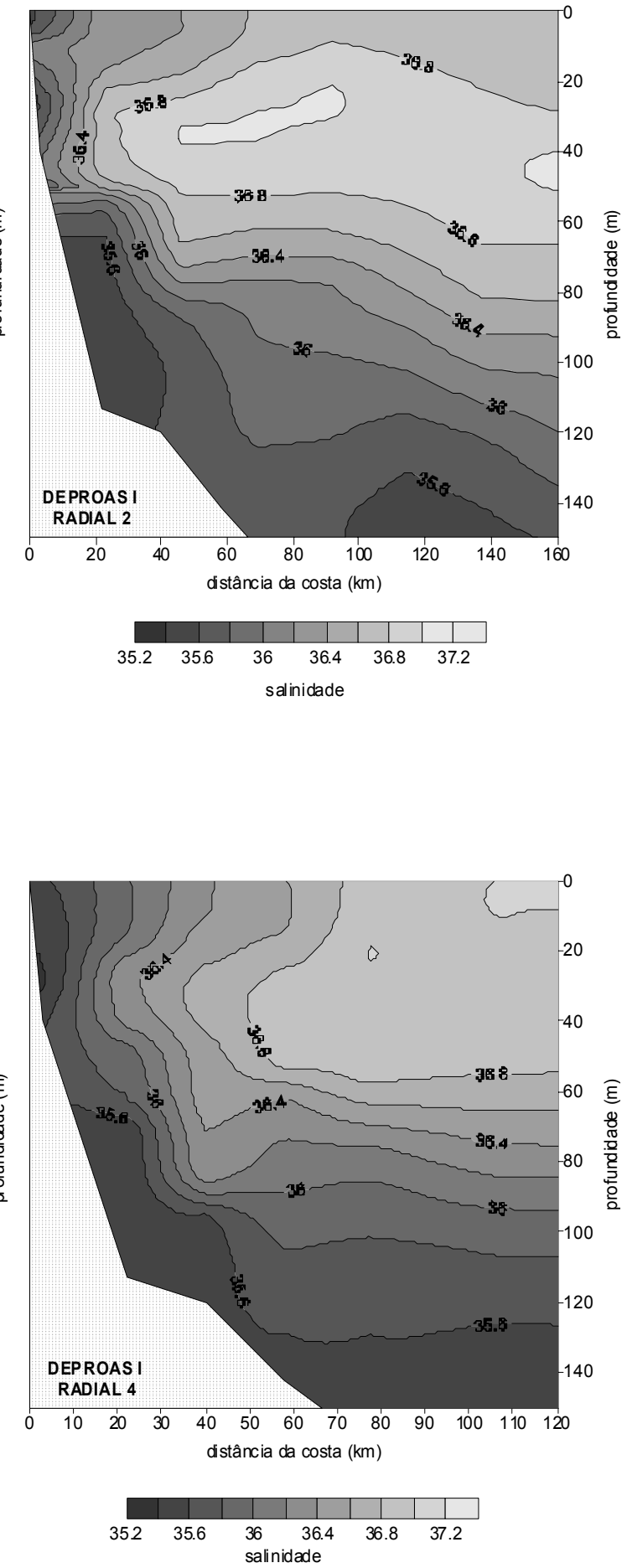

Figura 4. Perfis verticais de salinidade das radiais realizadas durante 0 cruzeiro de verão de 2001, na região do cabo Frio (RJ). 

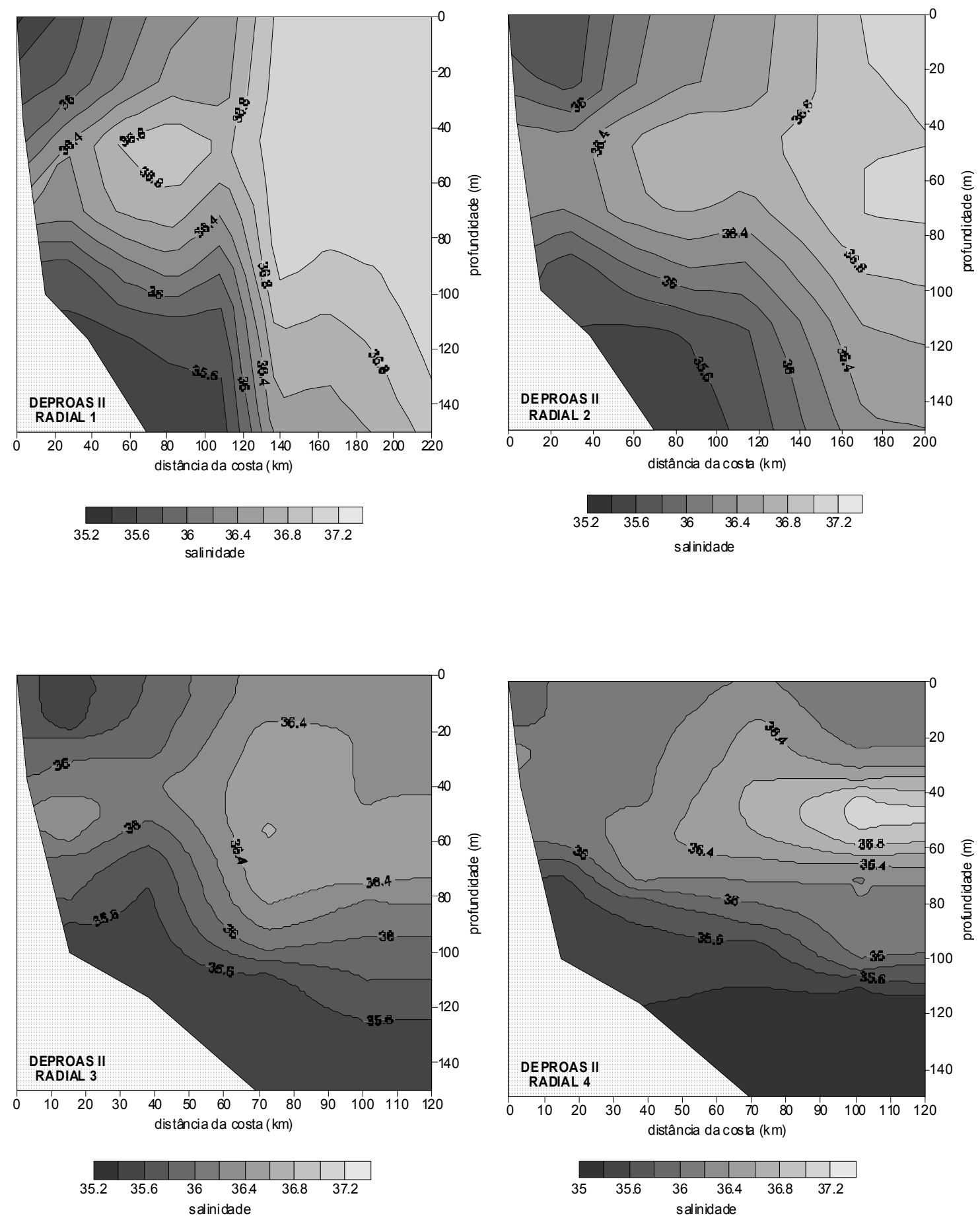

Figura 5. Perfis verticais de salinidade das radiais realizadas durante o cruzeiro de inverno de 2001, na região do cabo Frio (RJ). 
a)

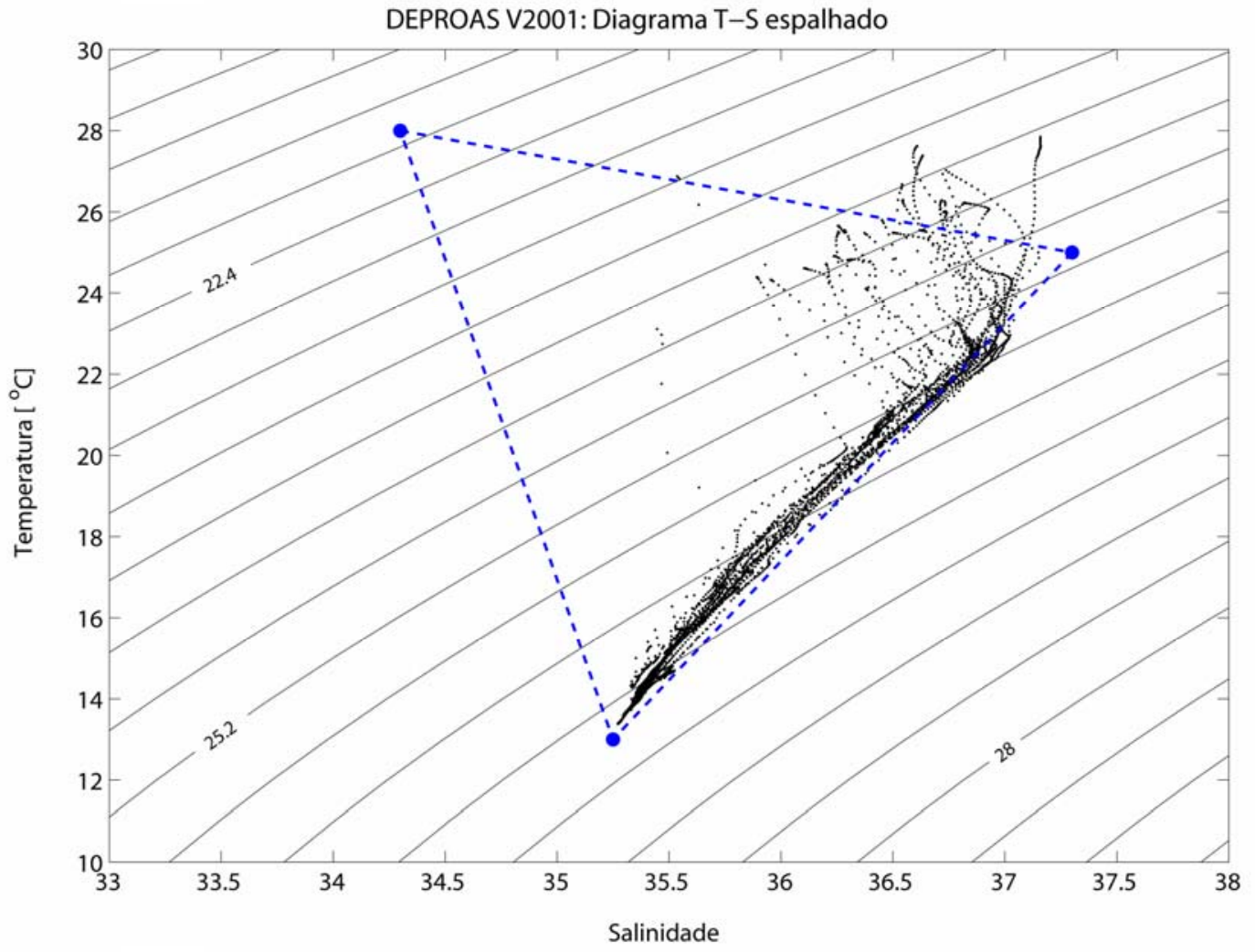

b)

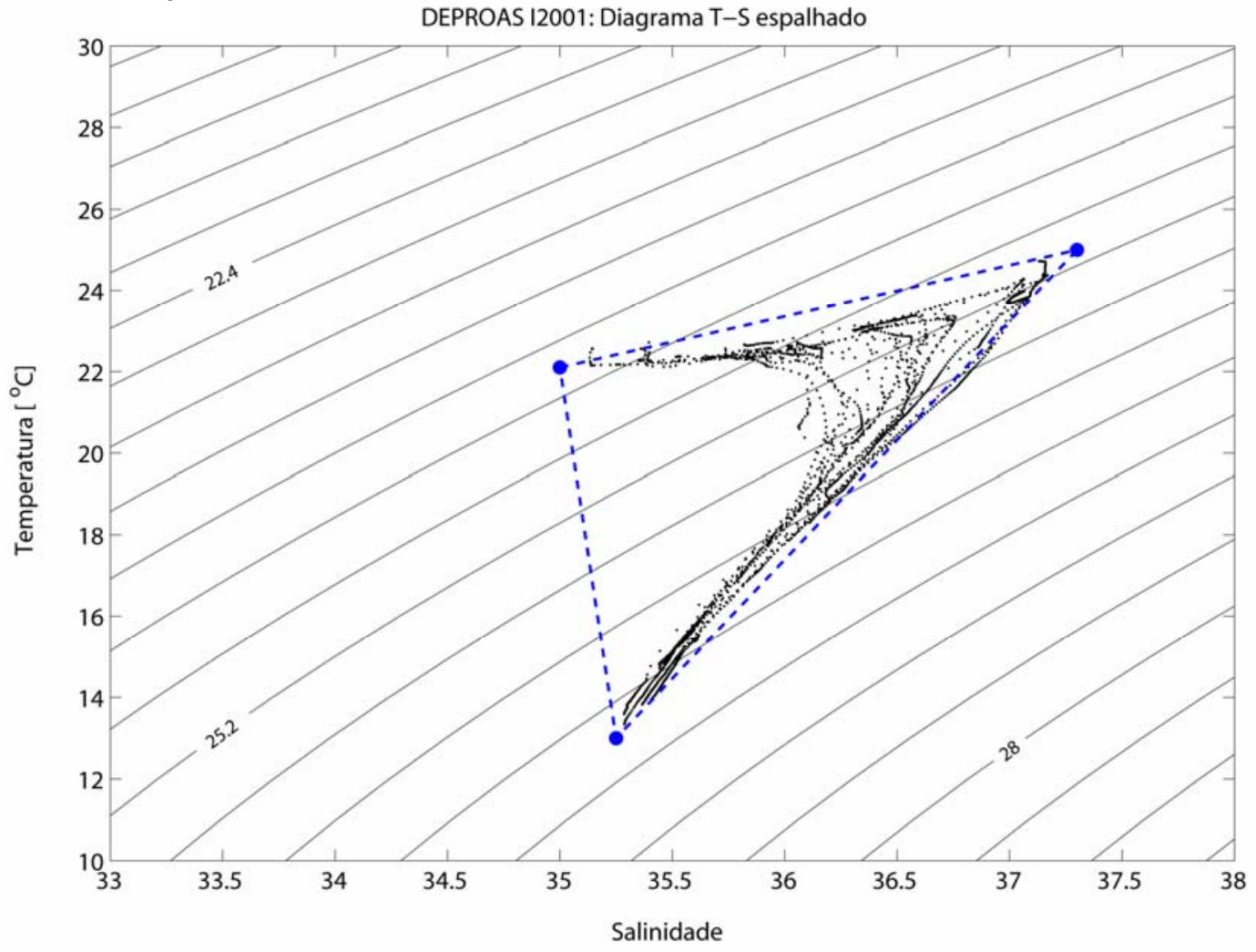

Figura 6. Diagramas TS produzidos com os parâmetros obtidos durante os cruzeiros de (a) verão e (b) inverno de 2001, na região do cabo Frio. 

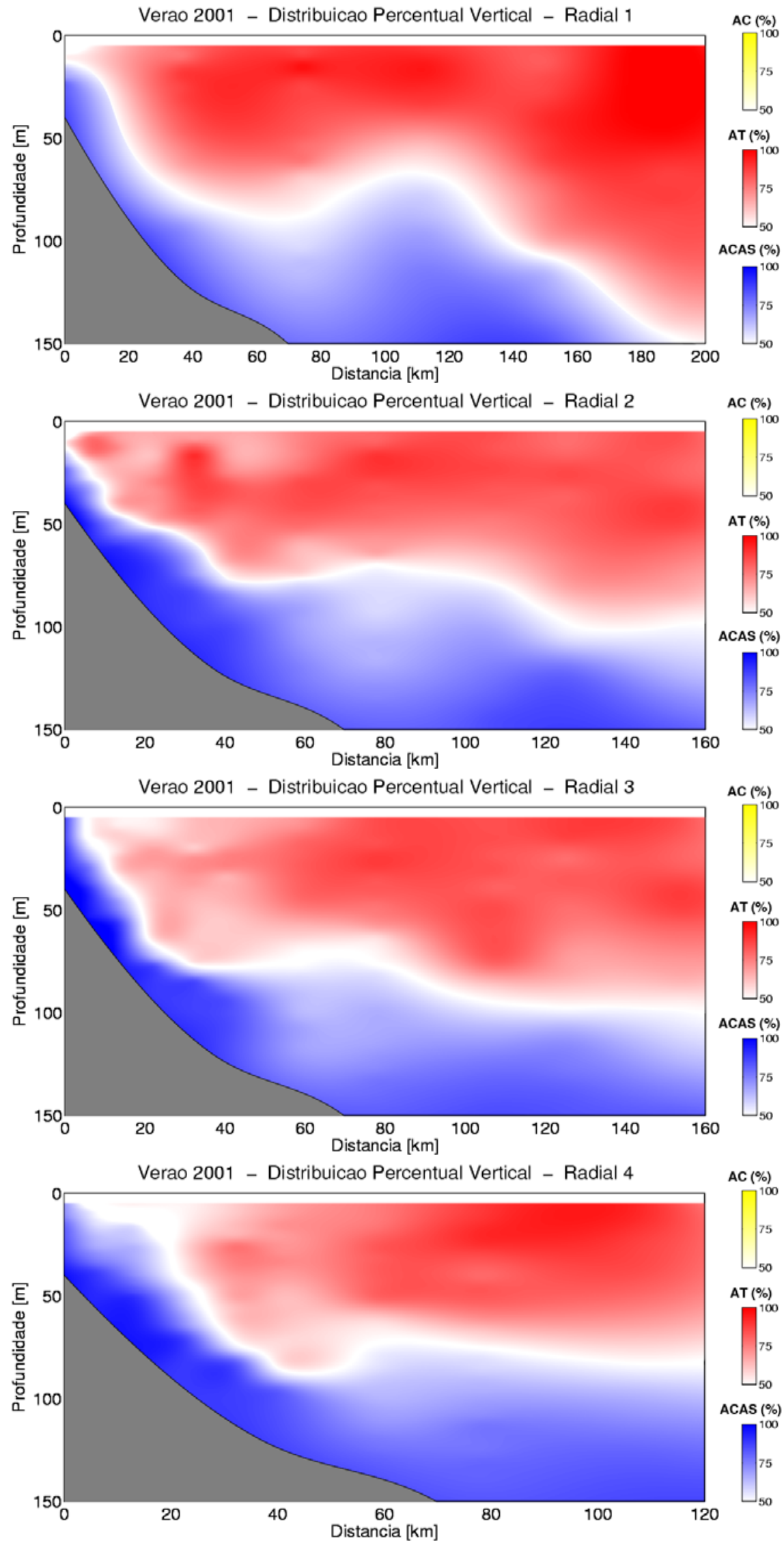

Figura 7. Distribuição percentual de massas de água durante cruzeiro realizado no verão de 2001, na região do cabo Frio (RJ). 

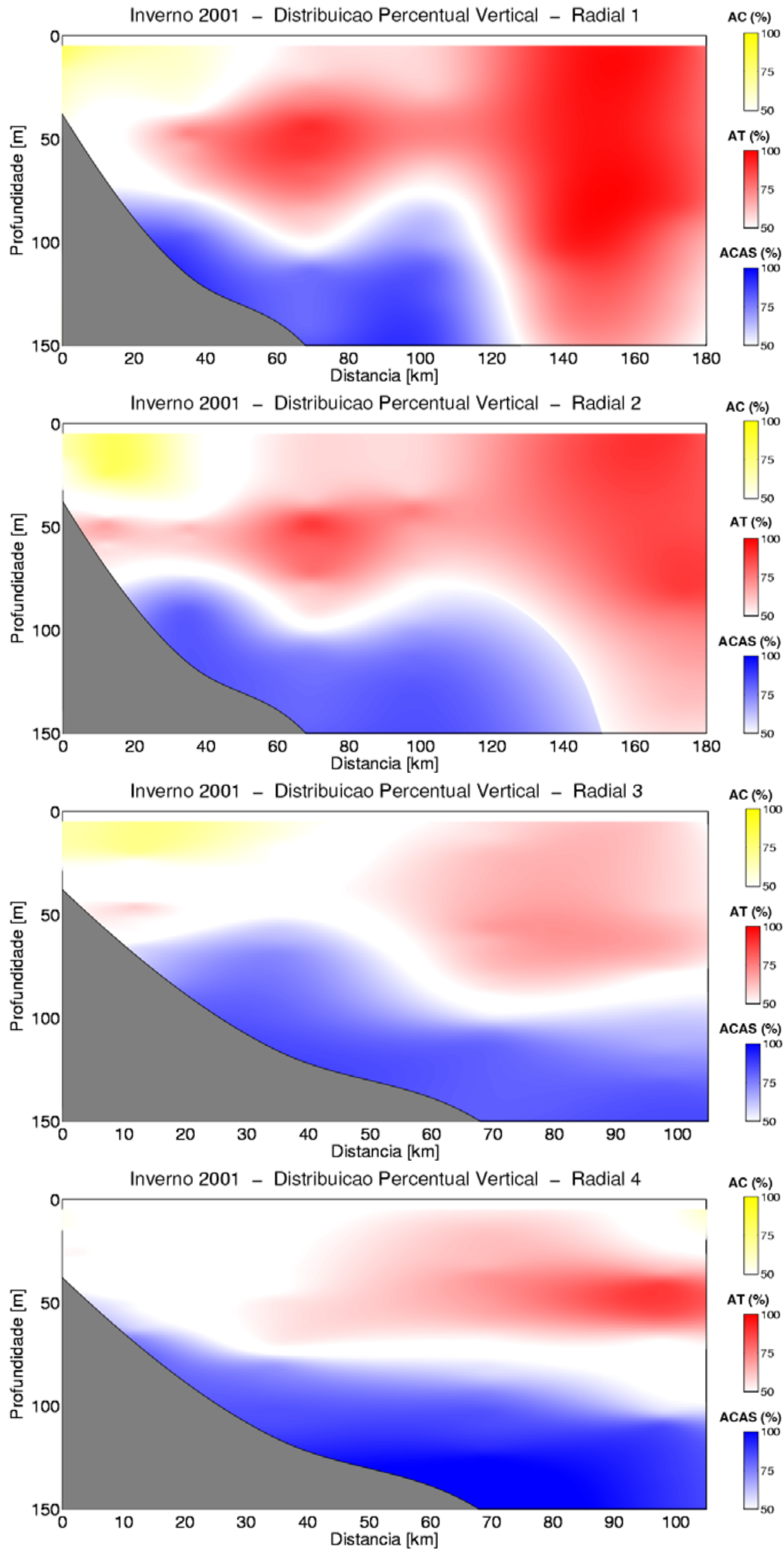

Figura 8. Distribuição percentual de massas de água durante cruzeiro realizado no inverno de 2001, na região do cabo Frio (RJ). 

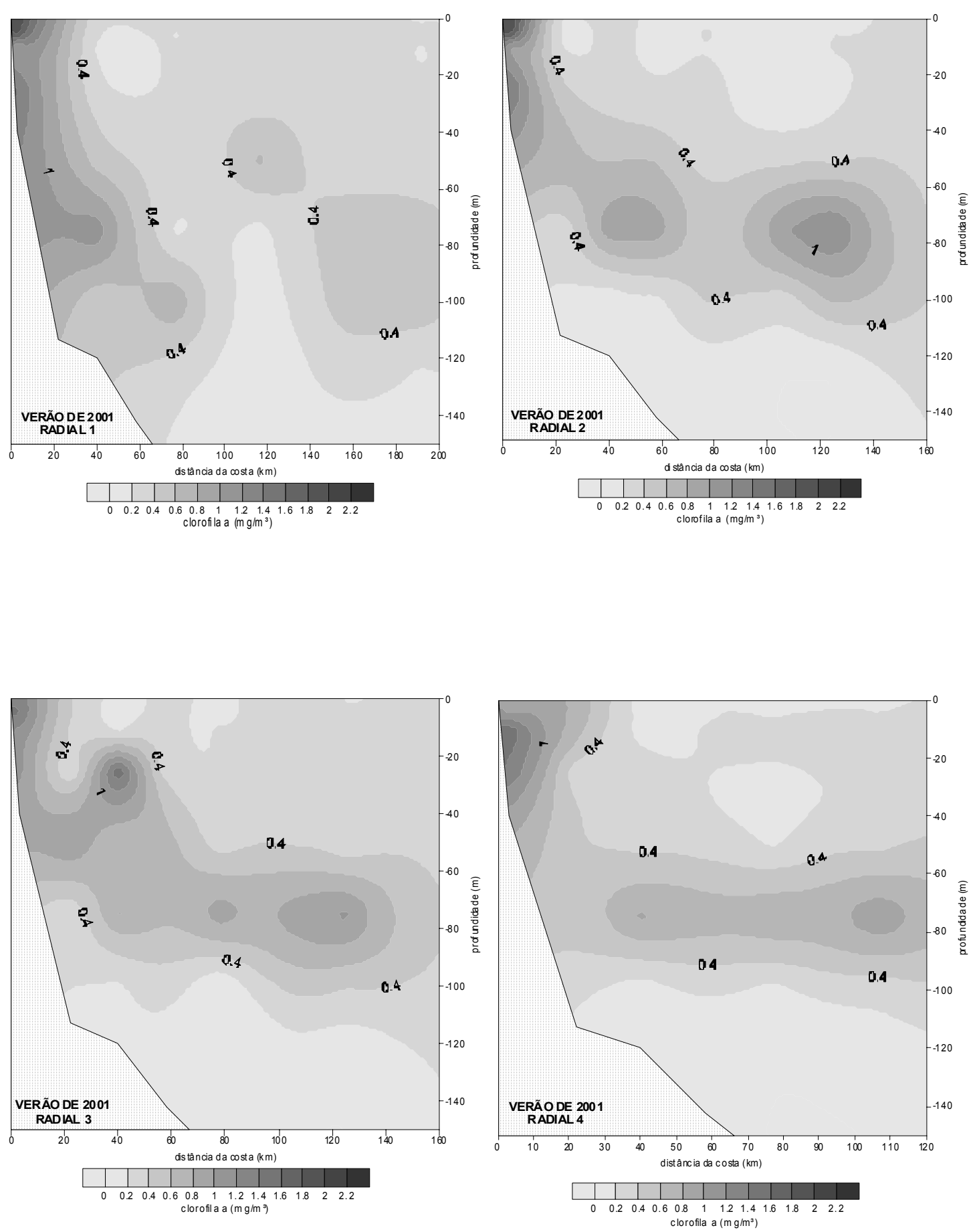

Figura 9. Perfis de concentração de clorofila a $\left(\mathrm{mg} \cdot \mathrm{m}^{-3}\right)$ das radiais realizadas durante o cruzeiro de verão de 2001, na região do cabo Frio (RJ). 

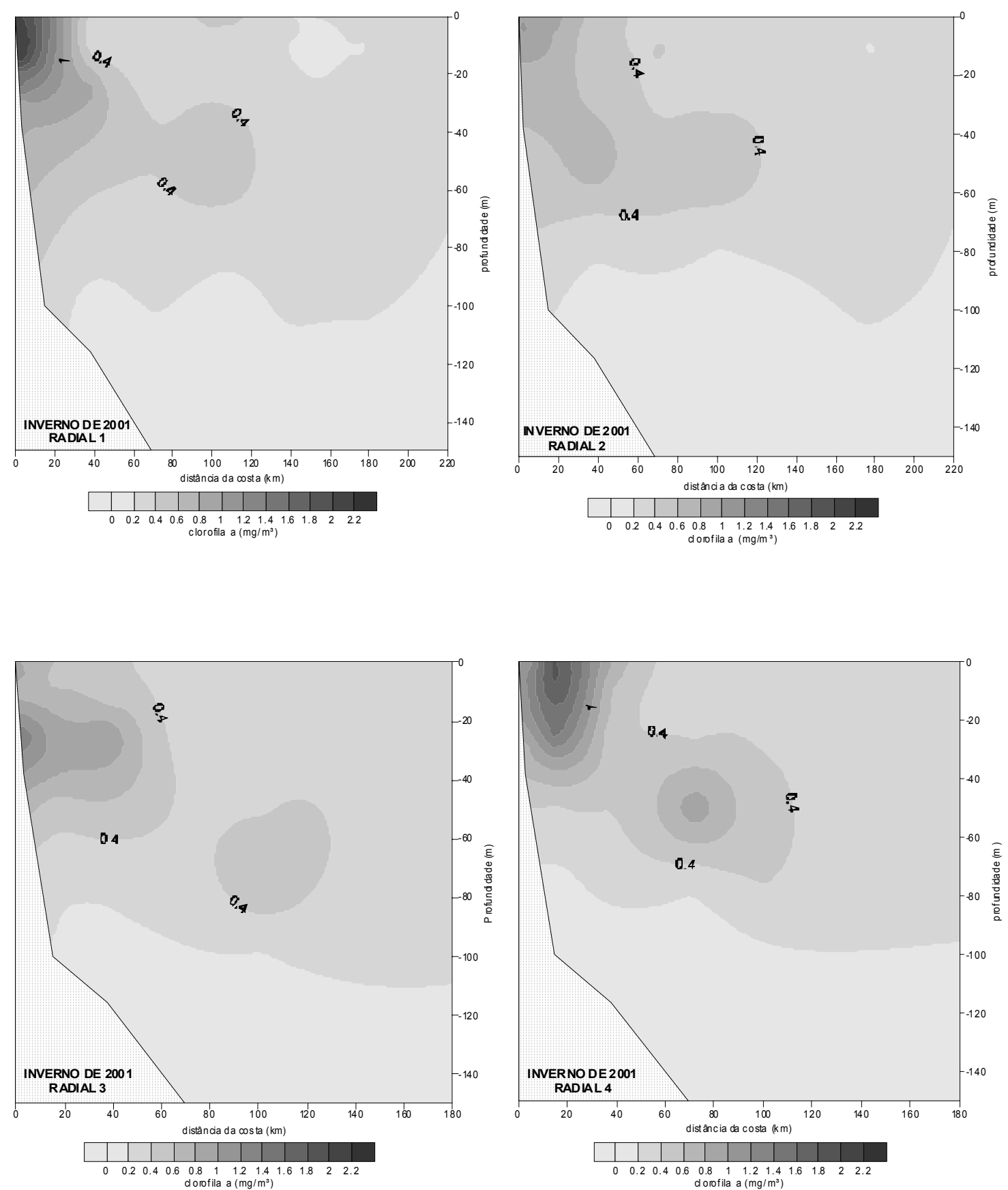

Figura 10. Perfis de concentração de clorofila a $\left(\mathrm{mg} \cdot \mathrm{m}^{-3}\right)$ das radiais realizadas durante o cruzeiro de inverno de 2001, na região do cabo Frio (RJ). 

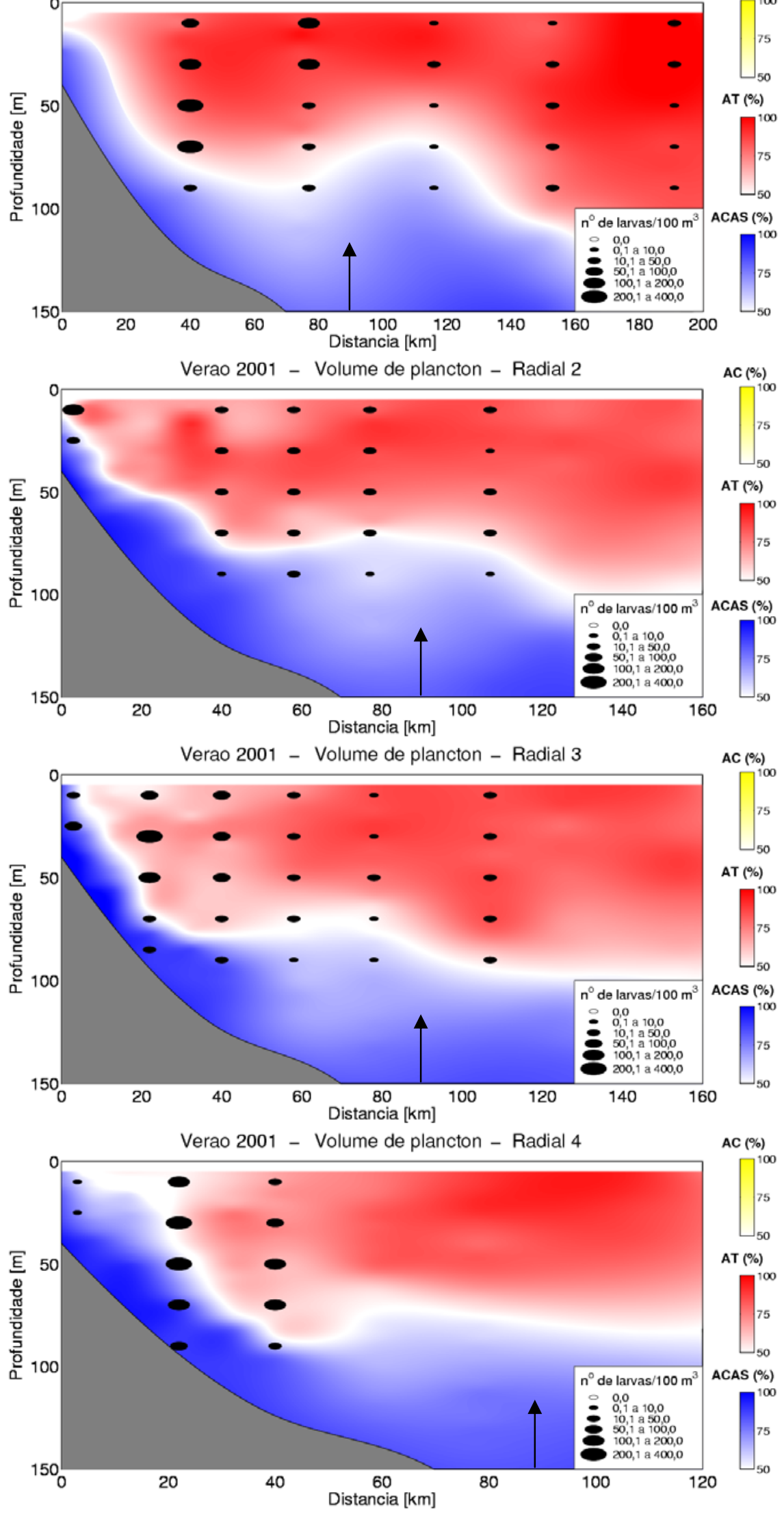

Figura 11. Distribuição espacial de volume de plâncton coletado no verão de 2001, na região do cabo Frio (RJ). A seta no eixo inferior separa as 

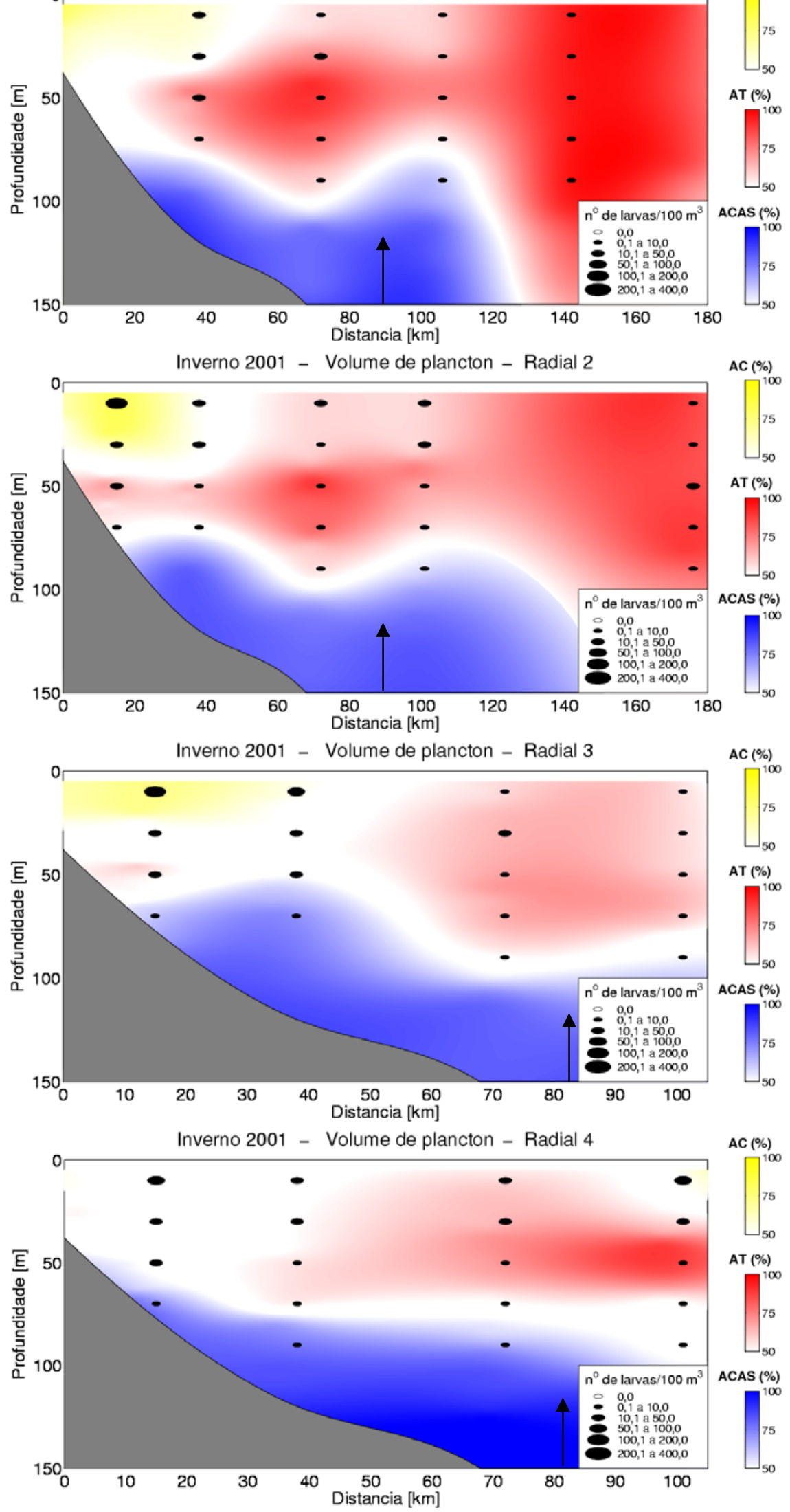

Figura 12. Distribuição espacial de volume de plâncton coletado no inverno de 2001, na região do cabo Frio (RJ). A seta no eixo inferior separa as 

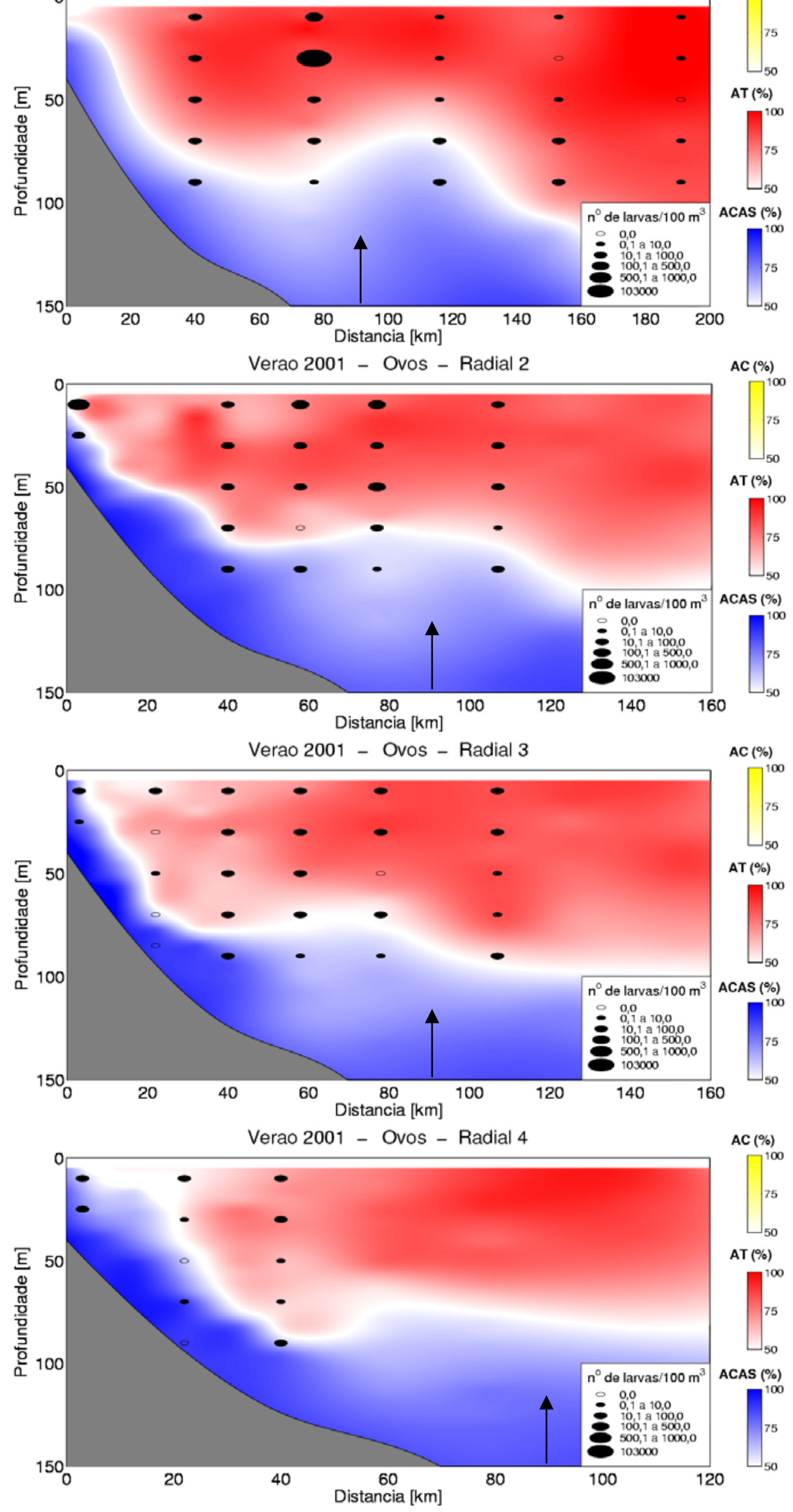

Figura 13. Distribuição espacial da densidade de ovos de peixes coletados no verão de 2001, na região do cabo Frio (RJ). A seta no eixo inferior separa 

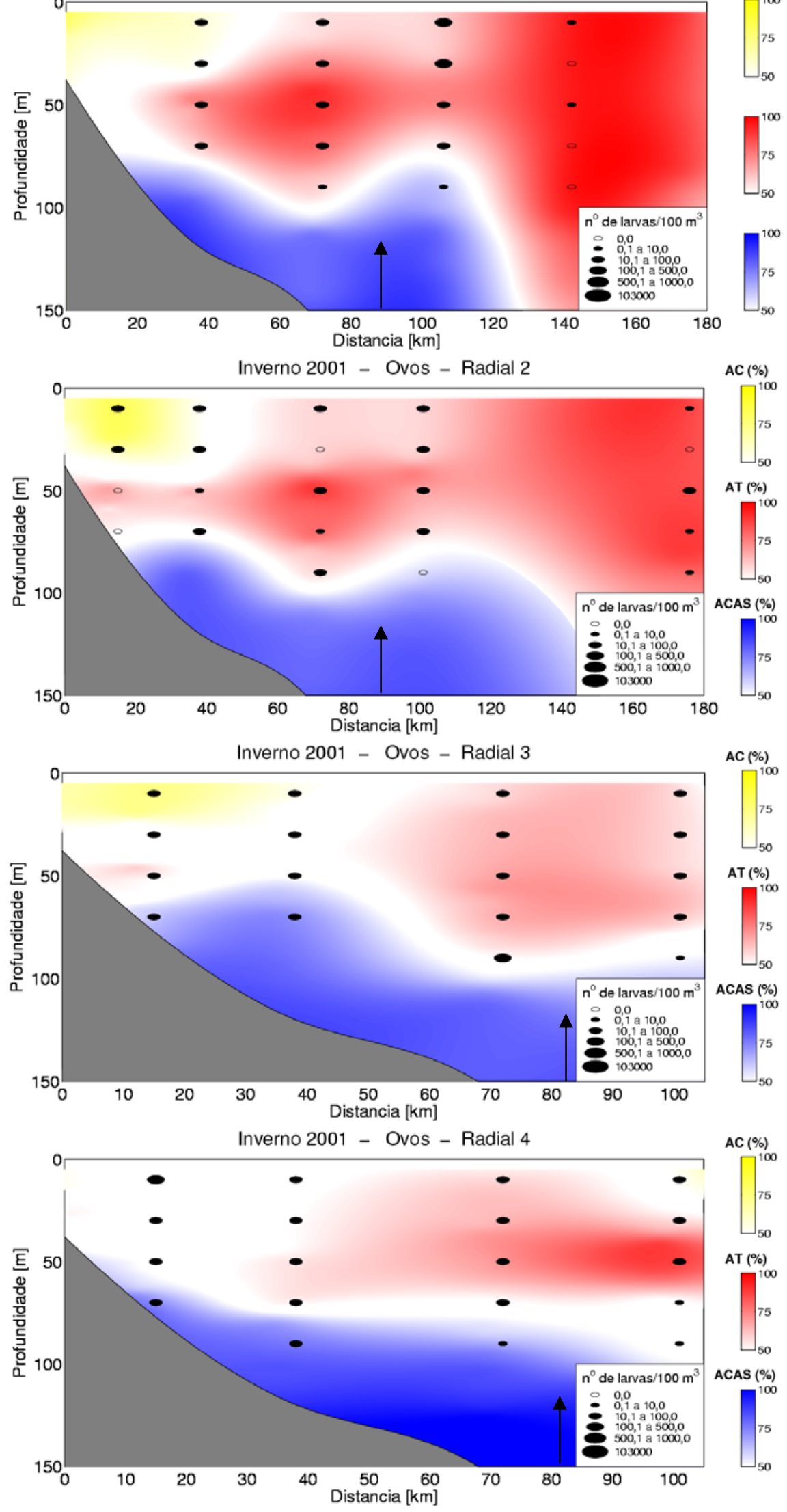

Figura 14. Distribuição espacial da densidade de ovos de peixes coletados no inverno de 2001 , na região do cabo Frio $(\mathrm{RJ})$. A seta no eixo inferior 

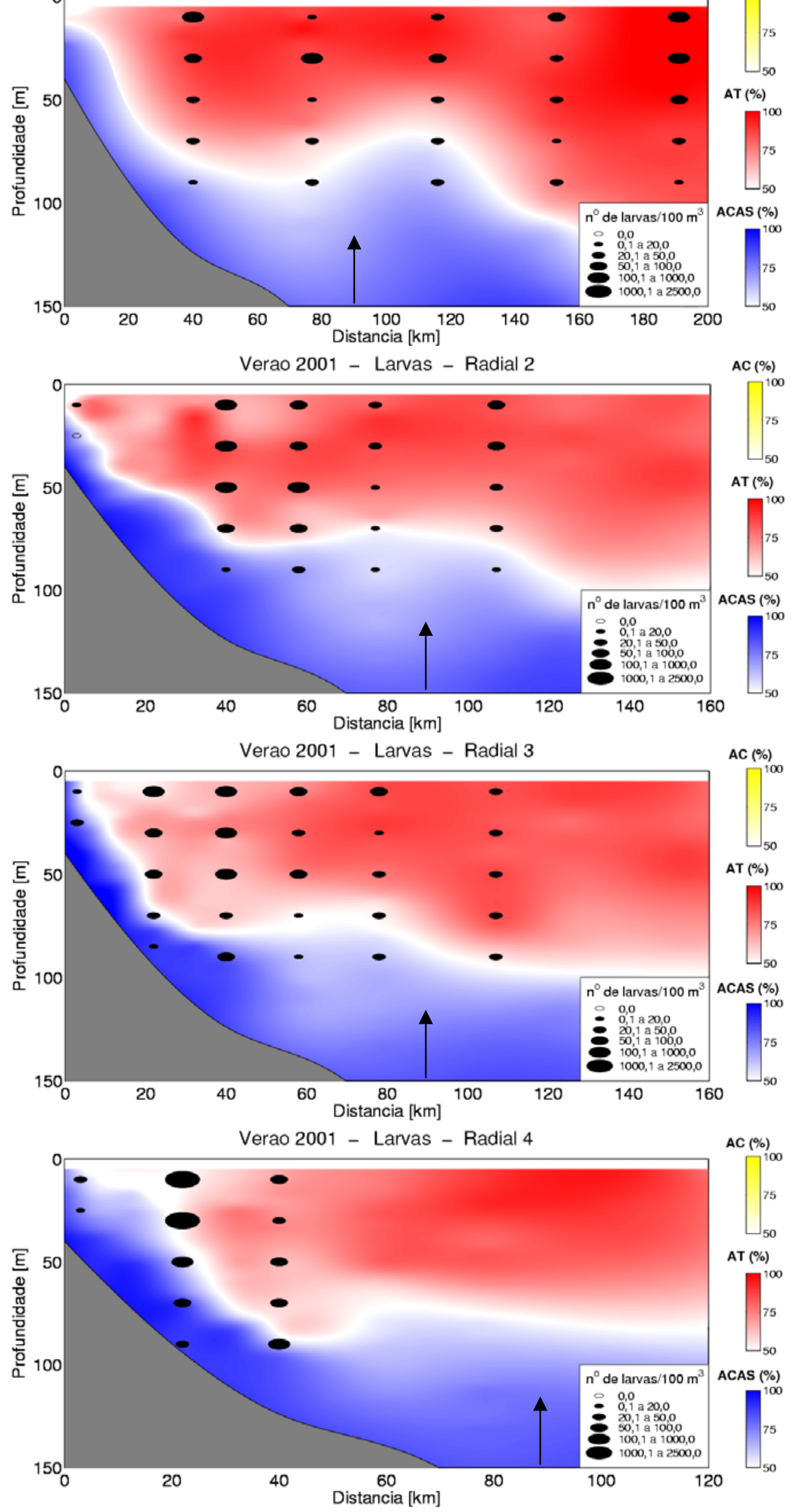

Figura 15. Distribuição espacial de larvas de peixes coletadas no verão de 2001, na região do cabo Frio (RJ). A seta no eixo inferior separa as estações 

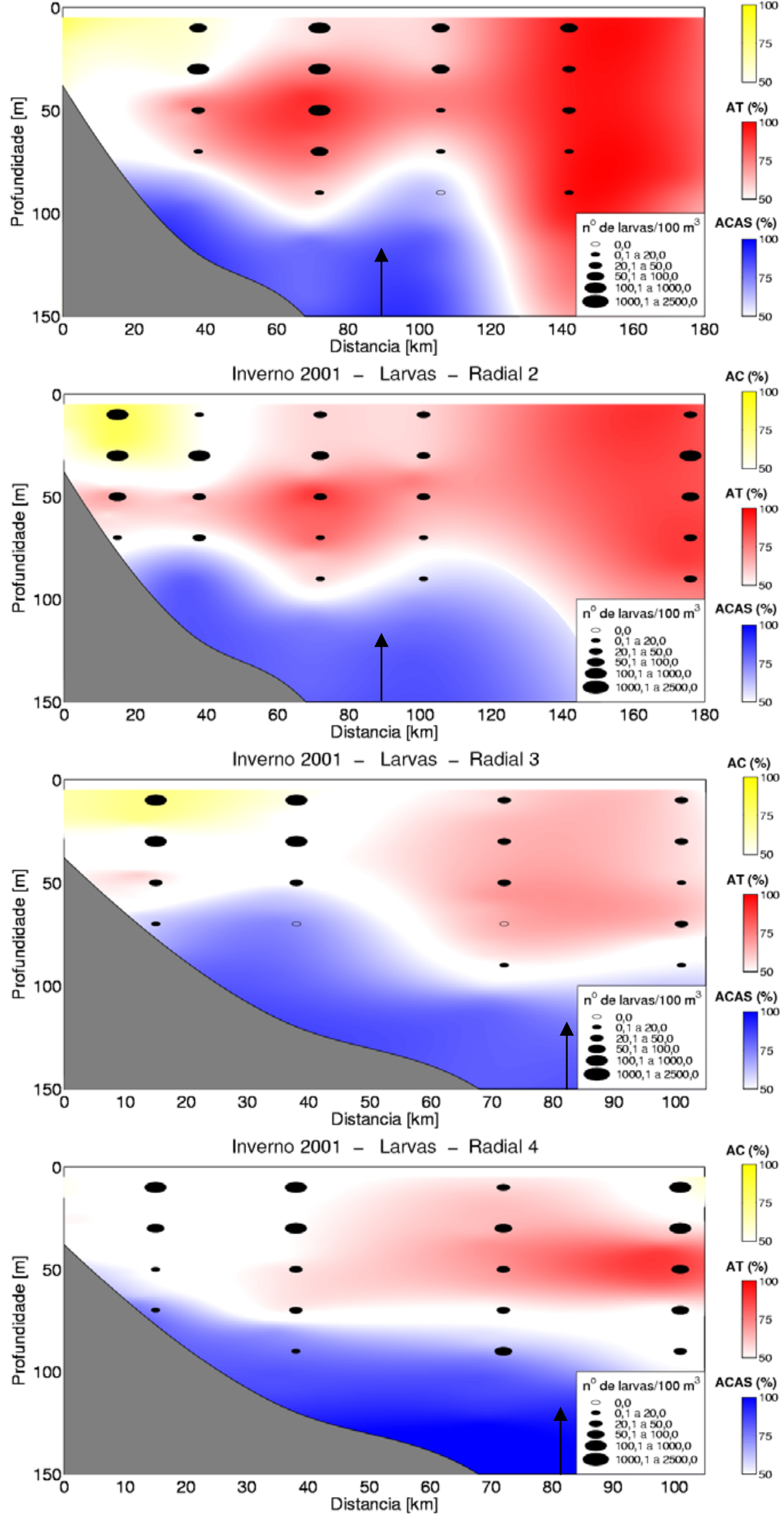

Figura 16. Distribuição espacial de larvas de peixes coletadas no inverno de 2001, na região do cabo Frio (RJ). A seta no eixo inferior separa as estações 


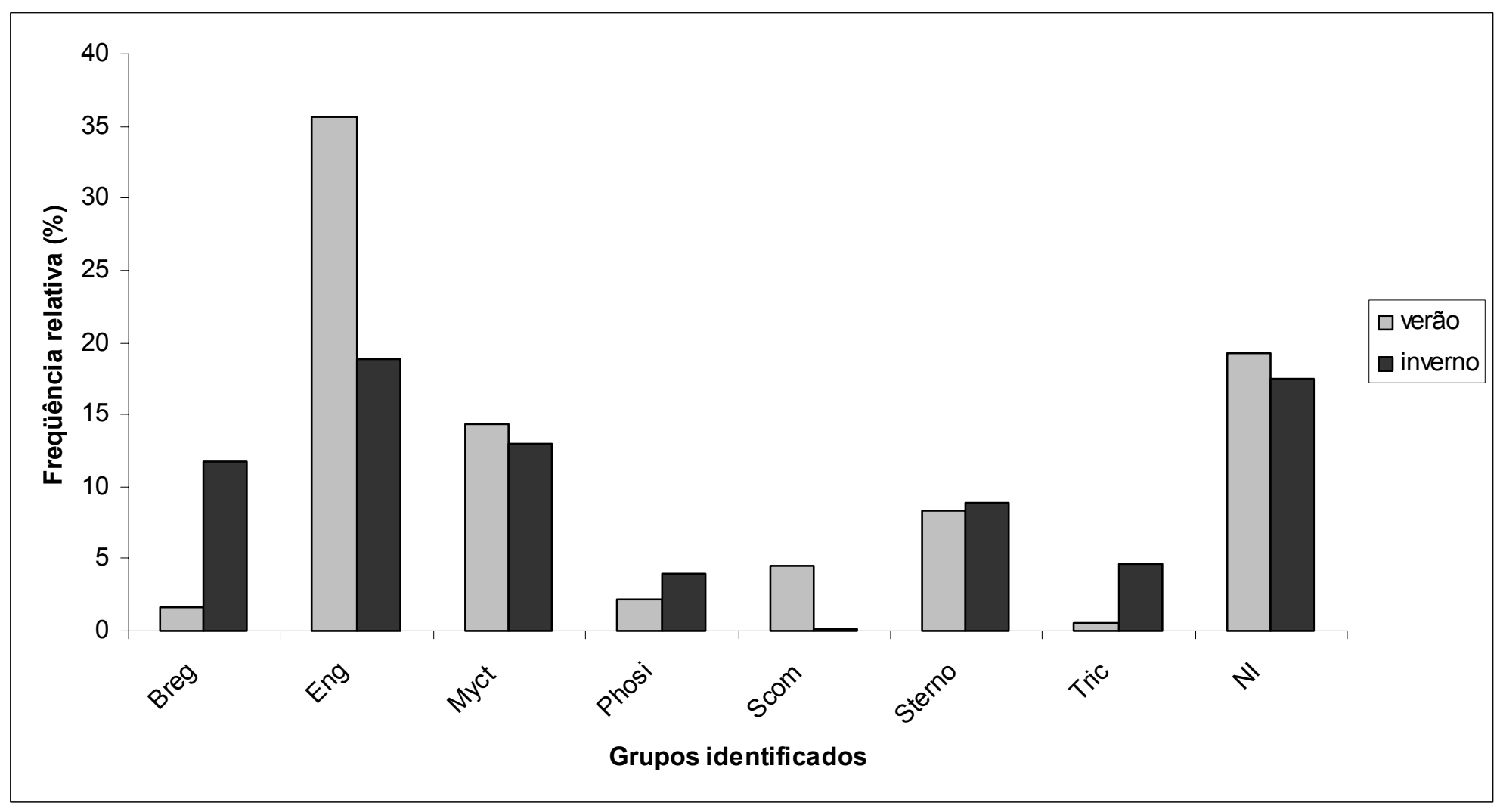

Figura 17. Freqüência relativa dos grupos de larvas de peixes com freqüência de ocorrência igual ou maior de $50 \%$ e freqüência relativa igual ou maior de $3 \%$ em pelo menos um dos cruzeiros, verão ou inverno, realizados em 2001, na região do cabo Frio (RJ) (Breg = Bregmacerotidae; Eng = Engraulidae; Myct = Myctophidae; Phosi = Phosichthyidae; Scom = Scombridae; Sterno = Sternopthychidae; Tric = Trichiuridae; $\mathrm{NI}=$ não identificadas $)$. 

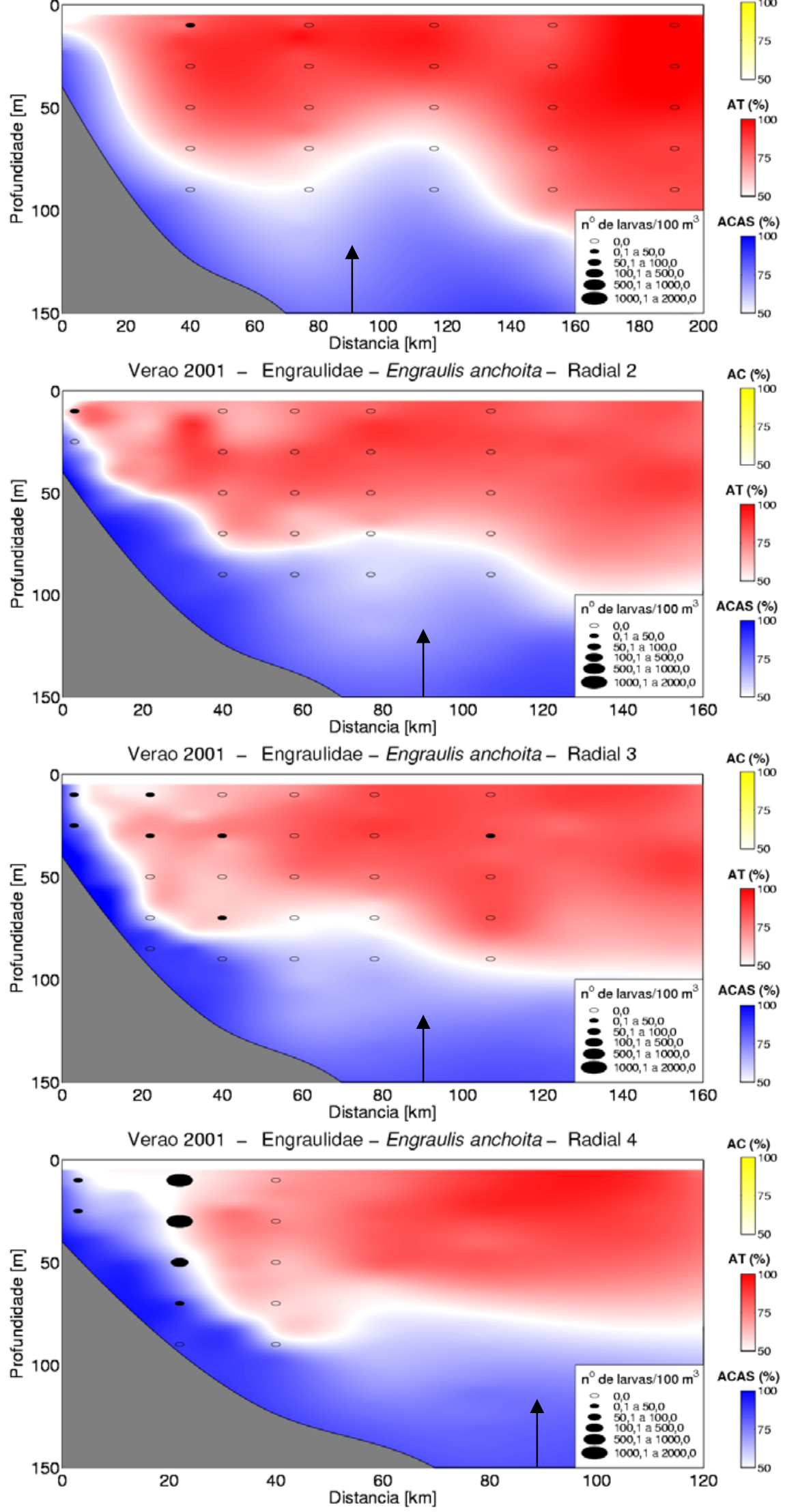

Figura 18. Distribuição espacial de larvas de Engraulis anchoita coletadas no verão de 2001 , na região do cabo Frio (RJ). A seta no eixo inferior separa 


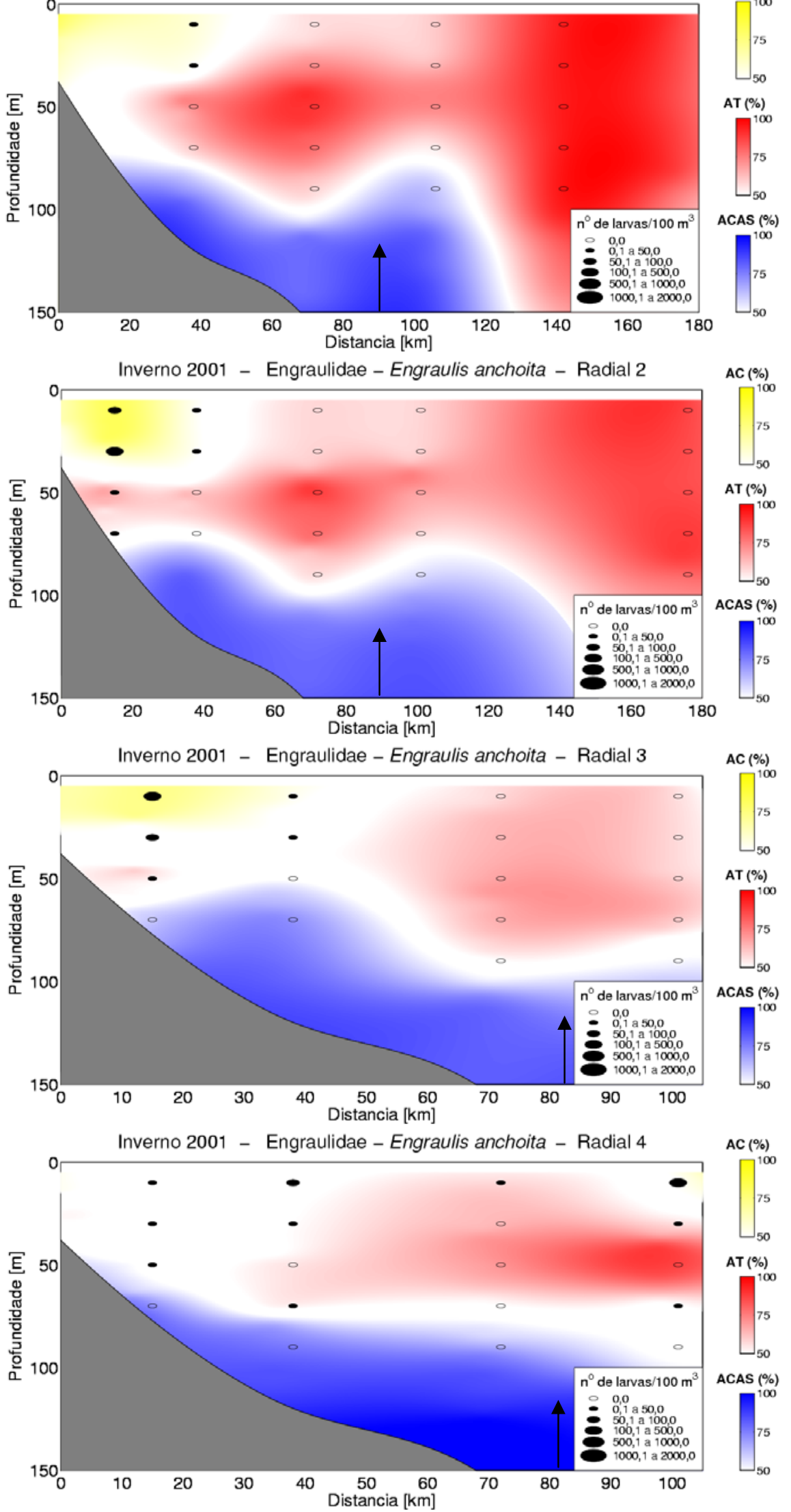

Figura 19. Distribuição espacial de larvas de Engraulis anchoita coletadas no inverno de 2001 , na região do cabo Frio $(\mathrm{RJ})$. A seta no eixo inferior 
$(n=1041)$
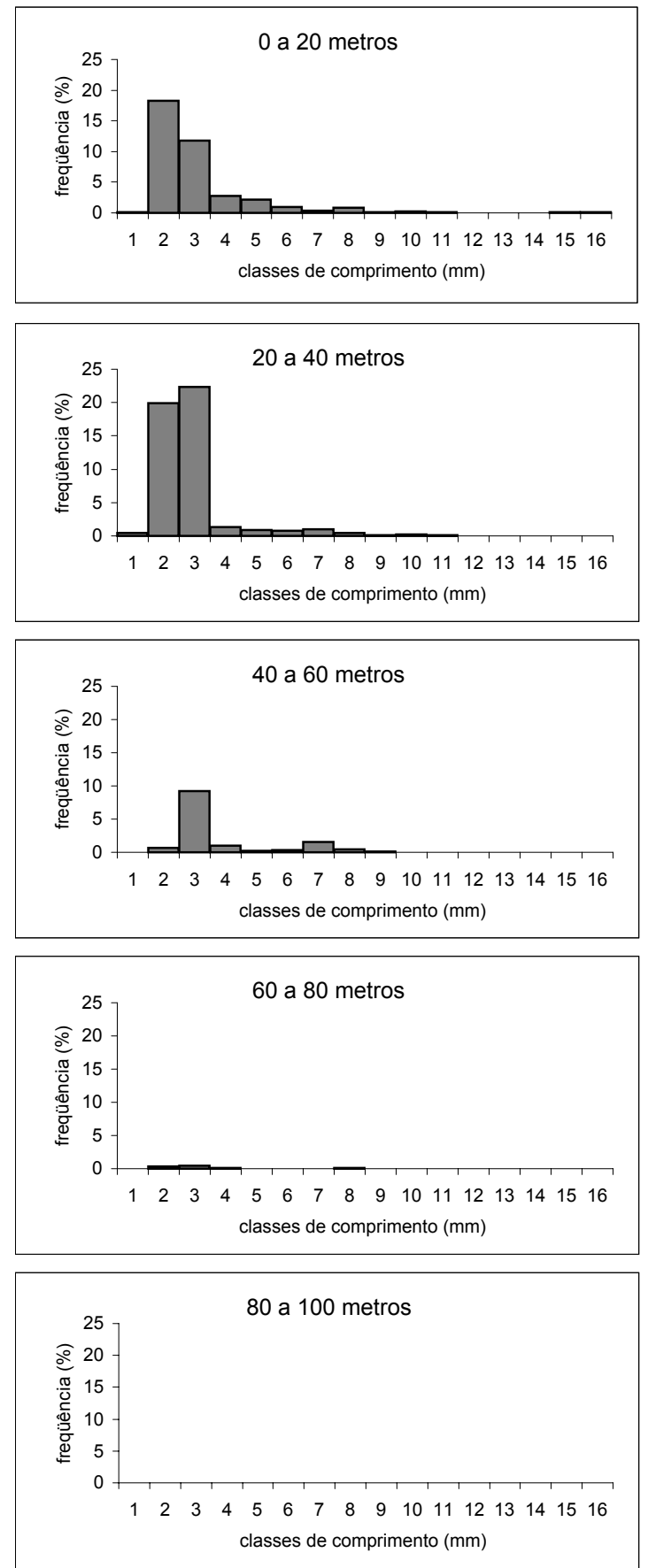

Figura 20. Engraulis anchoita: distribuição da freqüência relativa total de larvas por classe de comprimento nos estratos amostrados no verão de 2001 , na região do cabo Frio (RJ). 
estações neríticas $(n=1040)$
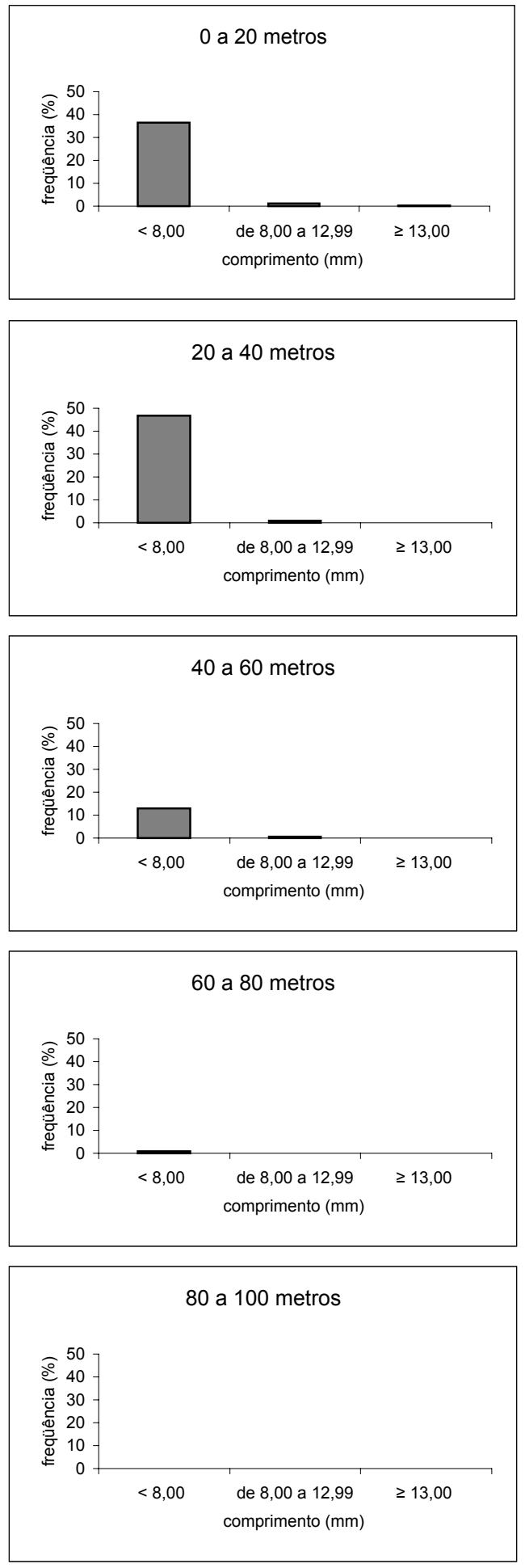

Figura 21. Engraulis anchoita: distribuição da freqüência relativa nerítica de larvas por classe de comprimento nos estratos amostrados no verão de 2001, na região do cabo Frio (RJ) ( $\leq$ 8mm: pré-flexão; 8,00 a 12,99mm: flexão; $\geq 13,00$ : pós-flexão (Moser \& Ahlstron, 1970)). 
estações diurnas $(n=25)$
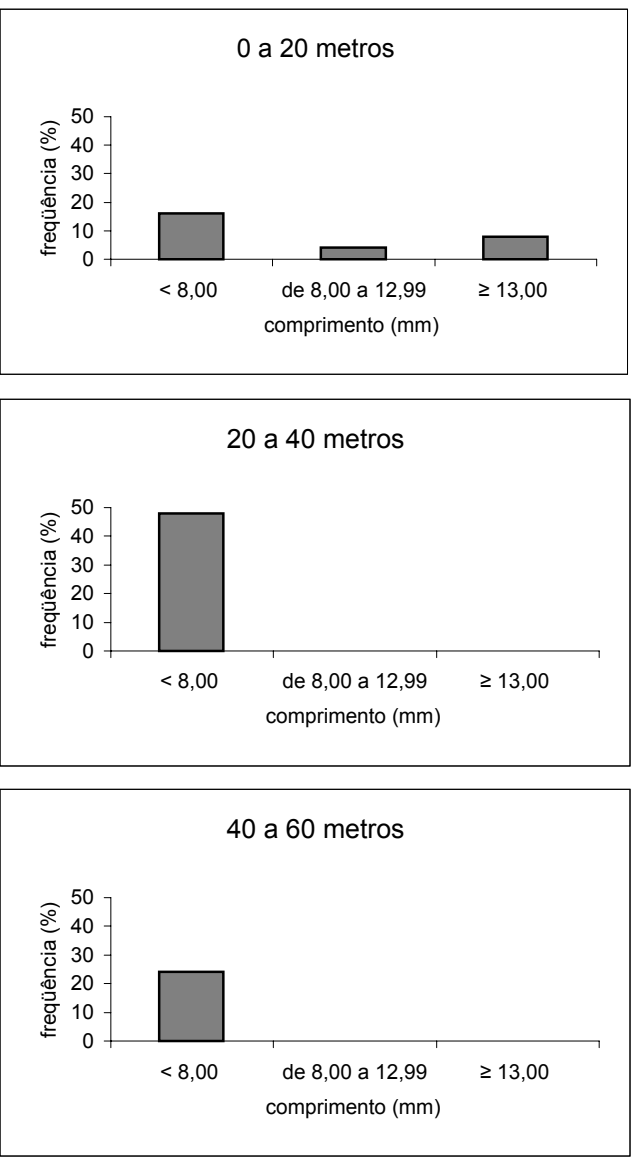

60 a 80 metros
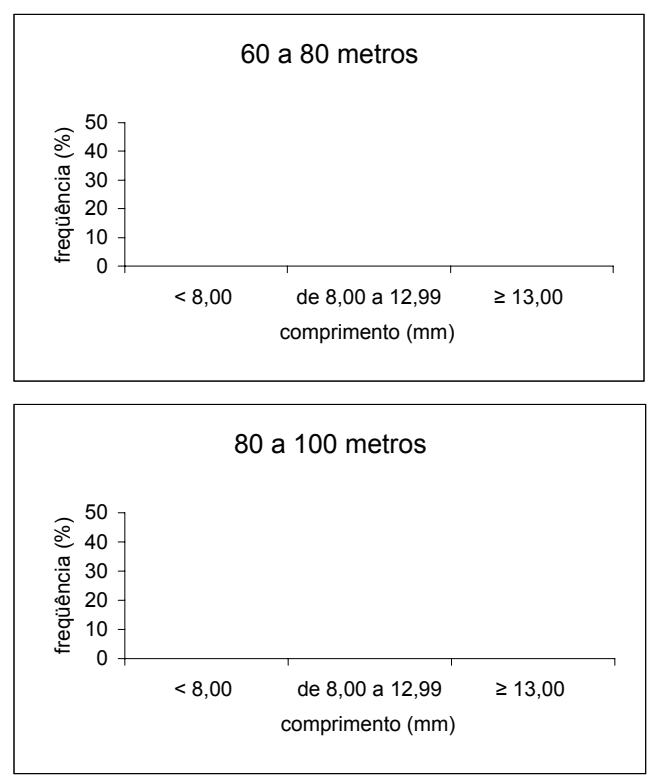

estações noturnas $(n=1016)$
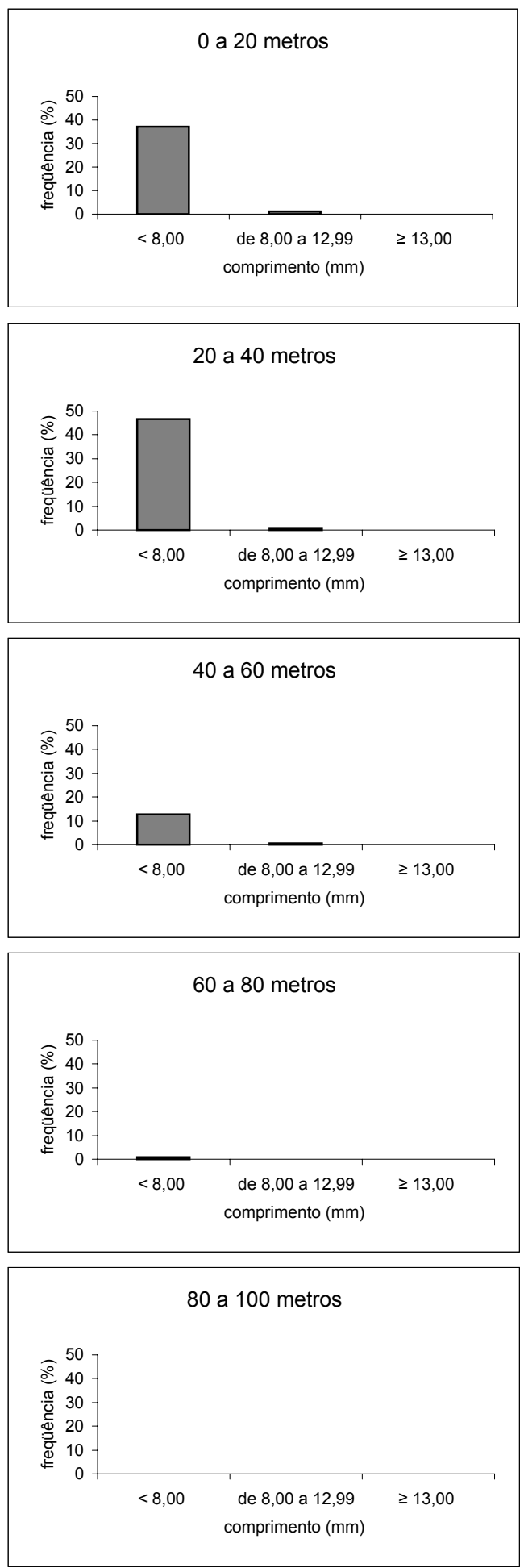

Figura 22. Engraulis anchoita: distribuição da freqüência relativa diurna e noturna de larvas por classe de comprimento nos estratos amostrados no verão de 2001, na região do cabo Frio $(\mathrm{RJ})$ ( $\leq$ 8mm: pré-flexão; 8,00 a 12,99mm: flexão; $\geq 13,00$ : pós-flexão (Moser \& Ahlstron, 1970I) 
( $n=291)$
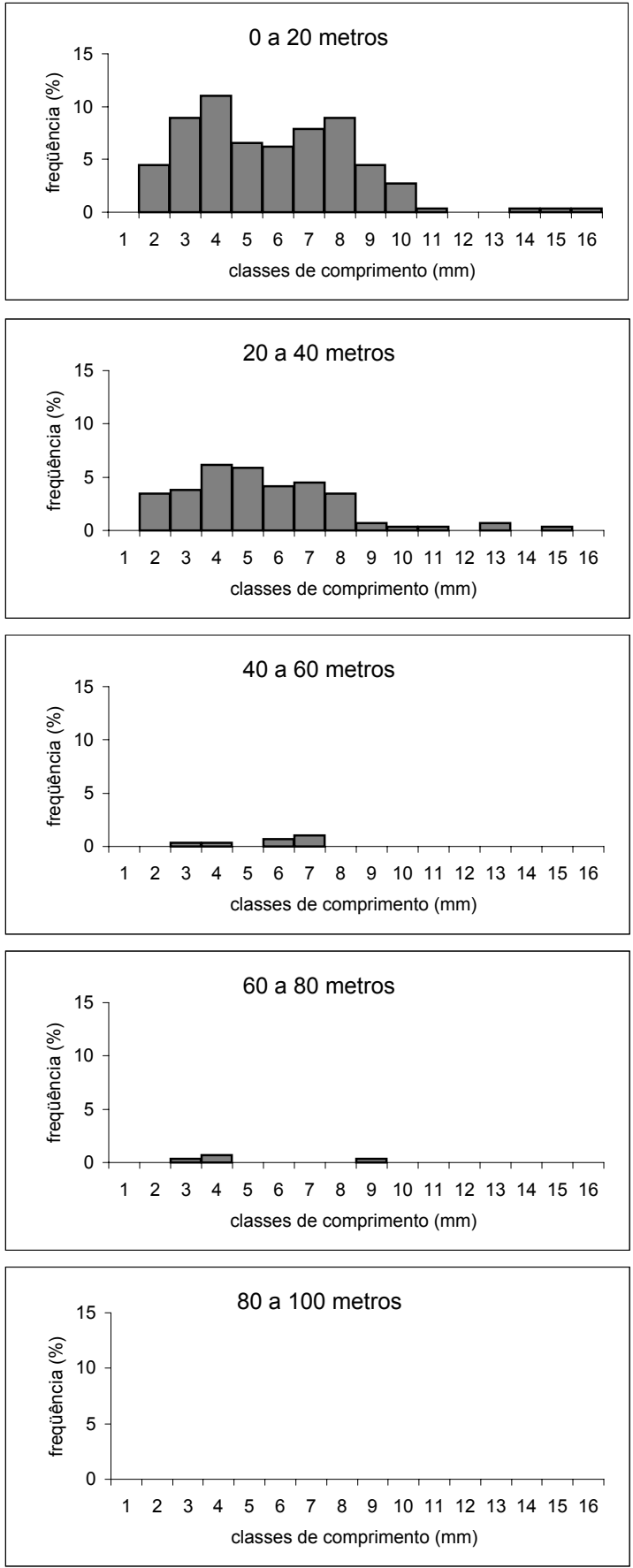

Figura 23. Engraulis anchoita: distribuição da freqüência relativa total de larvas por classe de comprimento nos estratos amostrados no inverno de 2001, na região do cabo Frio (RJ). 
estações neríticas $(n=215)$
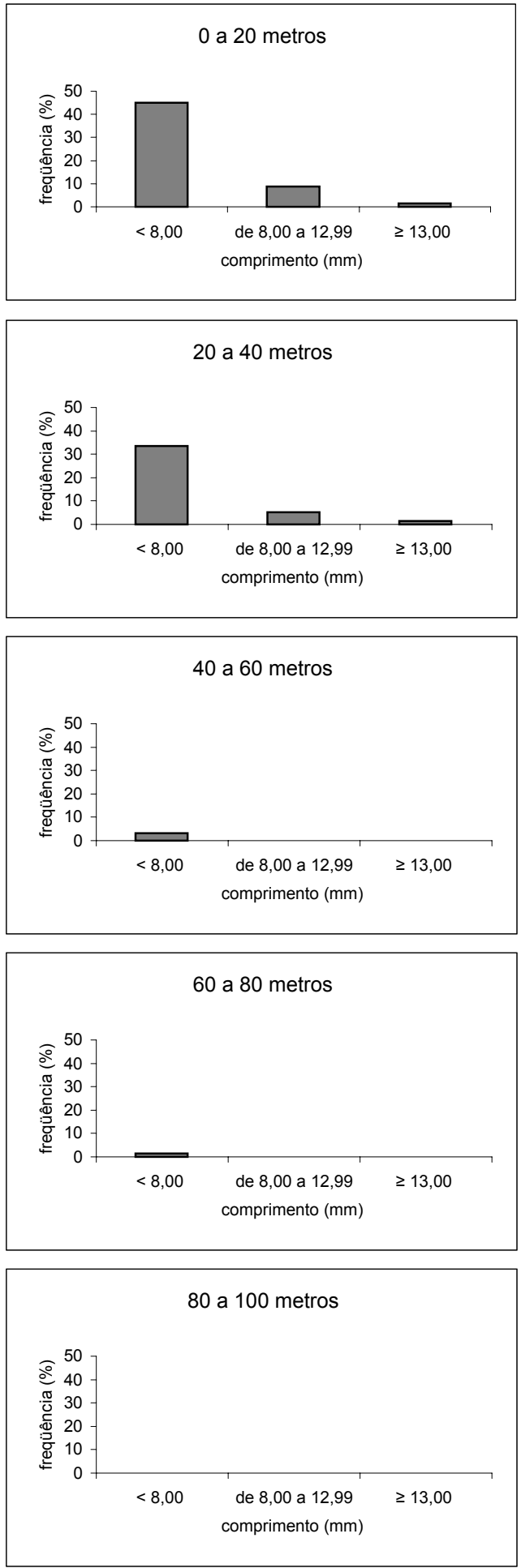

estações oceânicas (n=76)
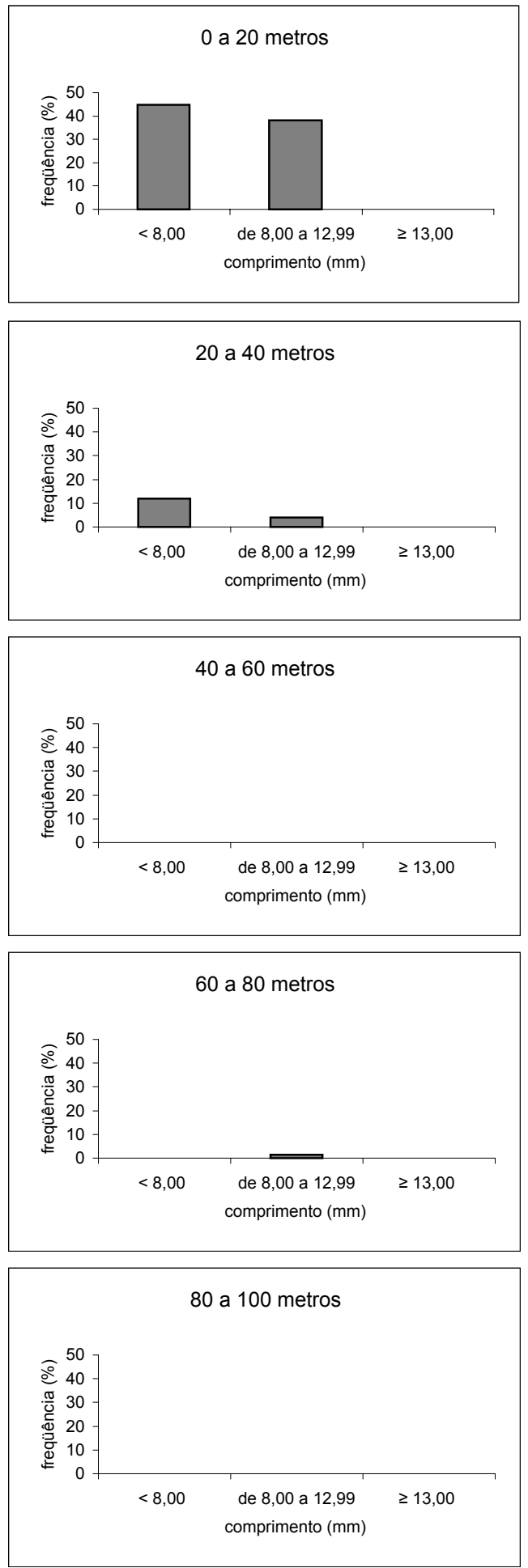

Figura 24. Engraulis anchoita: distribuição da freqüência relativa nerítica e oceânica de larvas por classe de comprimento nos estratos amostrados no inverno de 2001, na região do cabo Frio (RJ) ( $\leq 8 \mathrm{~mm}$ : pré-flexão; 8,00 a 12,99mm: flexão; $\geq 13,00$ : pós-flexão (Moser \& Ahlstron, 1970I) 
estações diurnas $(n=71)$
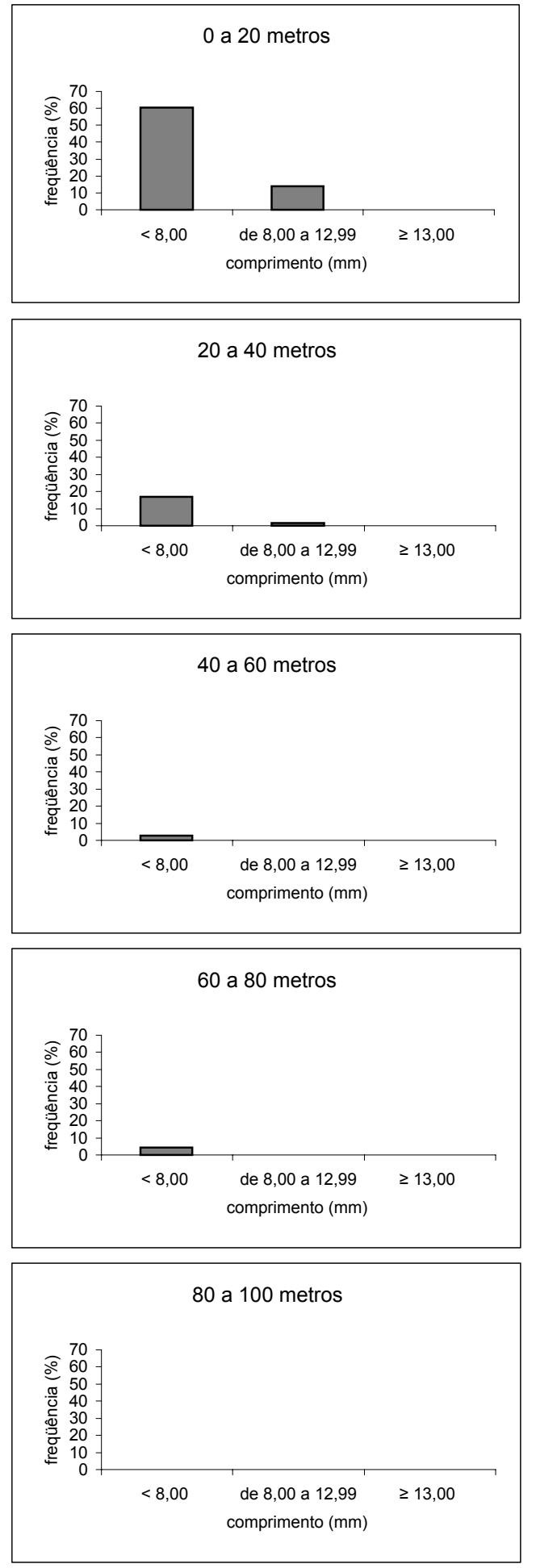

estações noturnas $(n=220)$
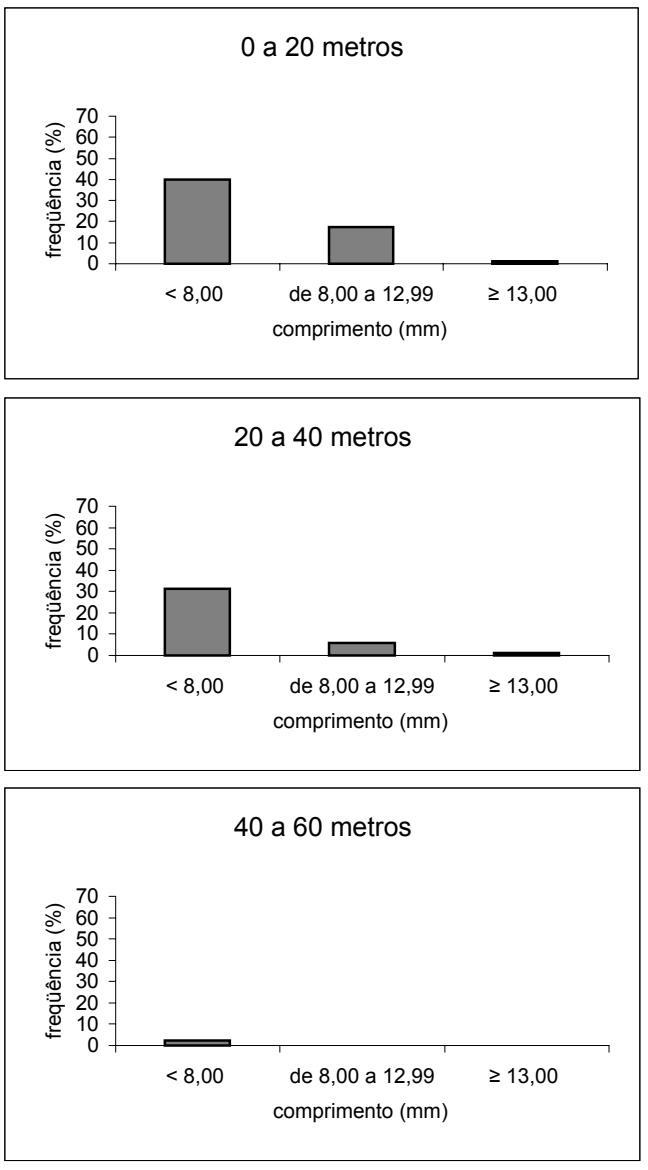

60 a 80 metros

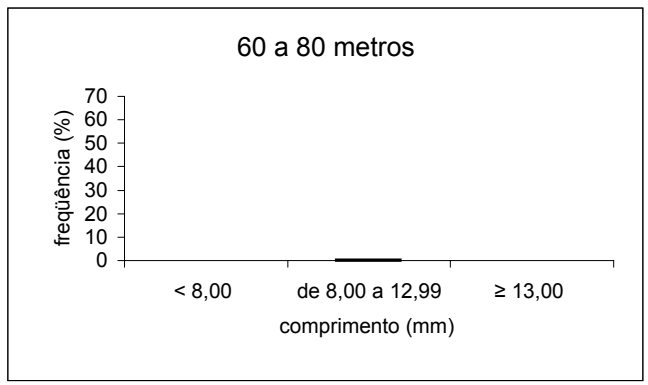

80 a 100 metros

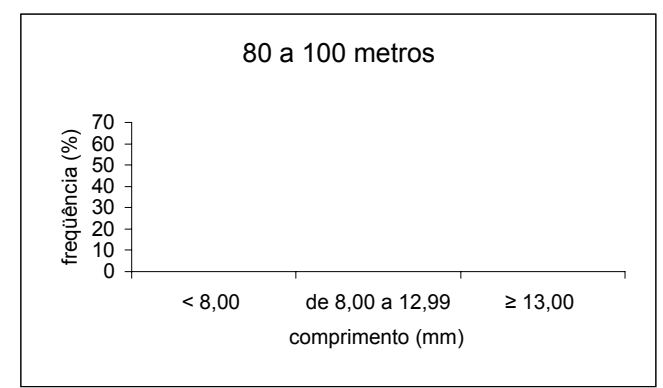

Figura 25. Engraulis anchoita: distribuição da freqüência relativa diurna e noturna de larvas por classe de comprimento nos estratos amostrados no inverno de 2001, na região do cabo Frio $(\mathrm{RJ})(\leq 8 \mathrm{~mm}$ : pré-flexão; 8,00 a 12,99mm: flexão; $\geq 13,00$ : pós-flexão (Moser \& Ahlstron, 197011 

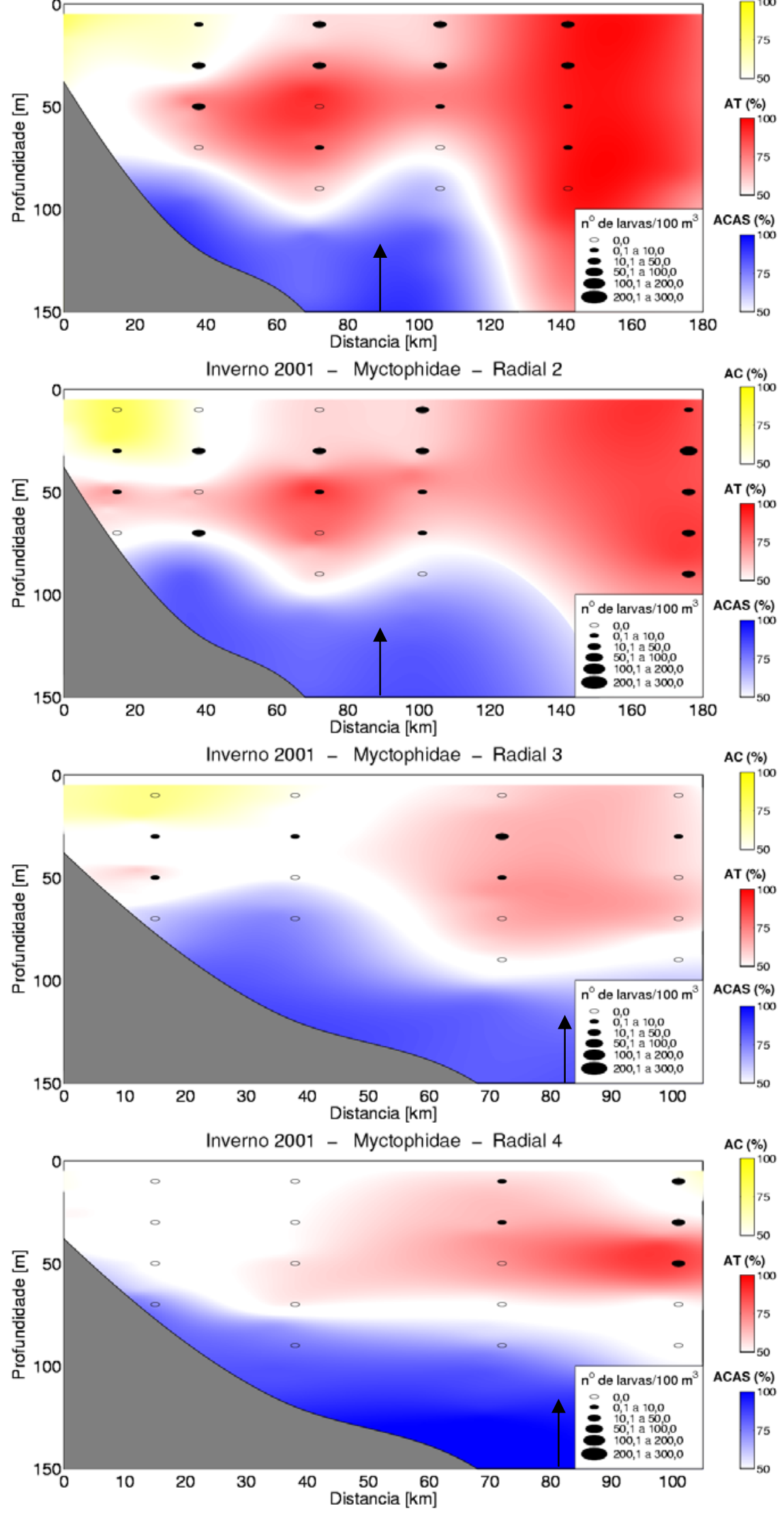

Figura 27. Distribuição espacial de larvas de Myctophidae coletadas no inverno de 2001 , na região do cabo Frio $(\mathrm{RJ})$. A seta no eixo inferior separa 

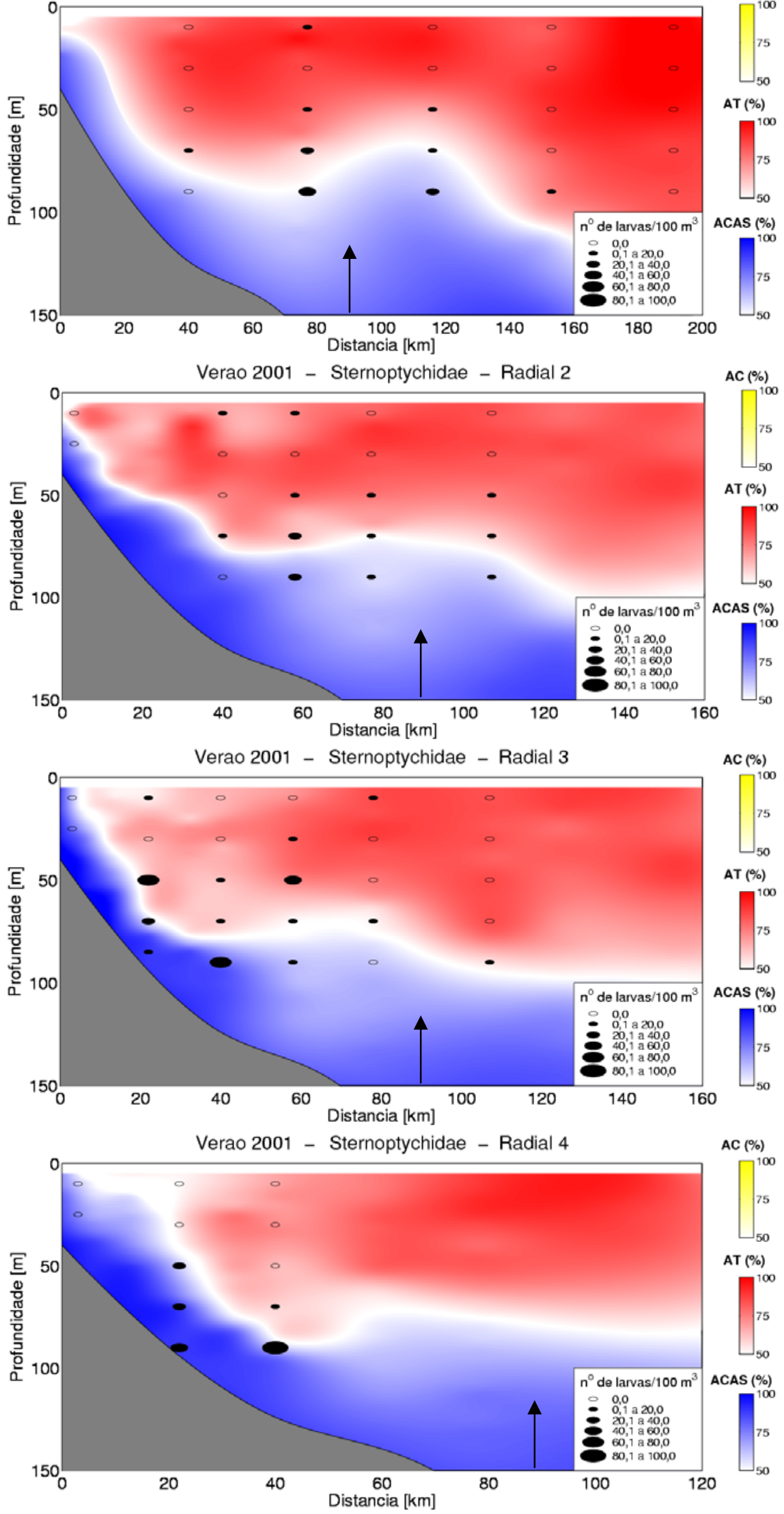

Figura 28. Distribuição espacial de larvas de Sternoptychidae coletadas no verão de 2001 , na região do cabo Frio $(\mathrm{RJ})$. A seta no eixo inferior separa 
( $n=247)$
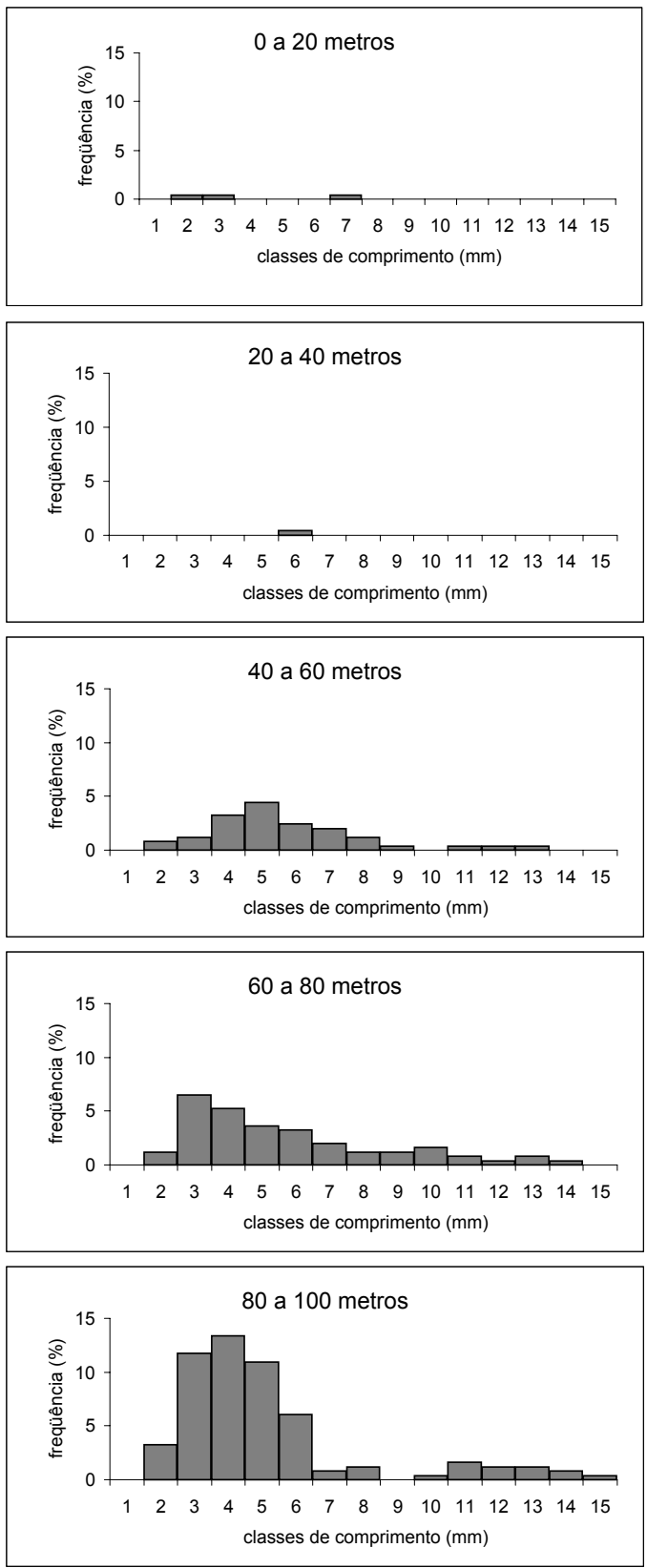

Figura 32. Maurolicus stehmanni: distribuição da freqüência relativa total de larvas por classe de comprimento nos estratos amostrados no verão de 2001, na região do cabo Frio (RJ). 
estações neríticas $(n=197)$
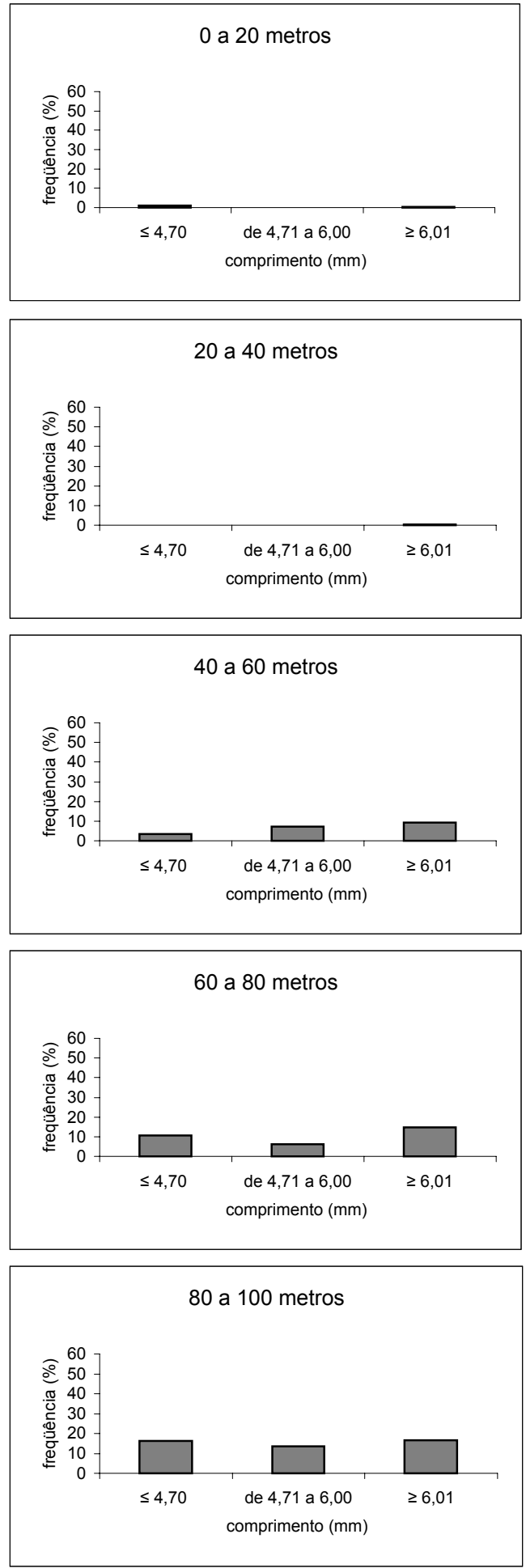

estações oceânicas $(n=50)$
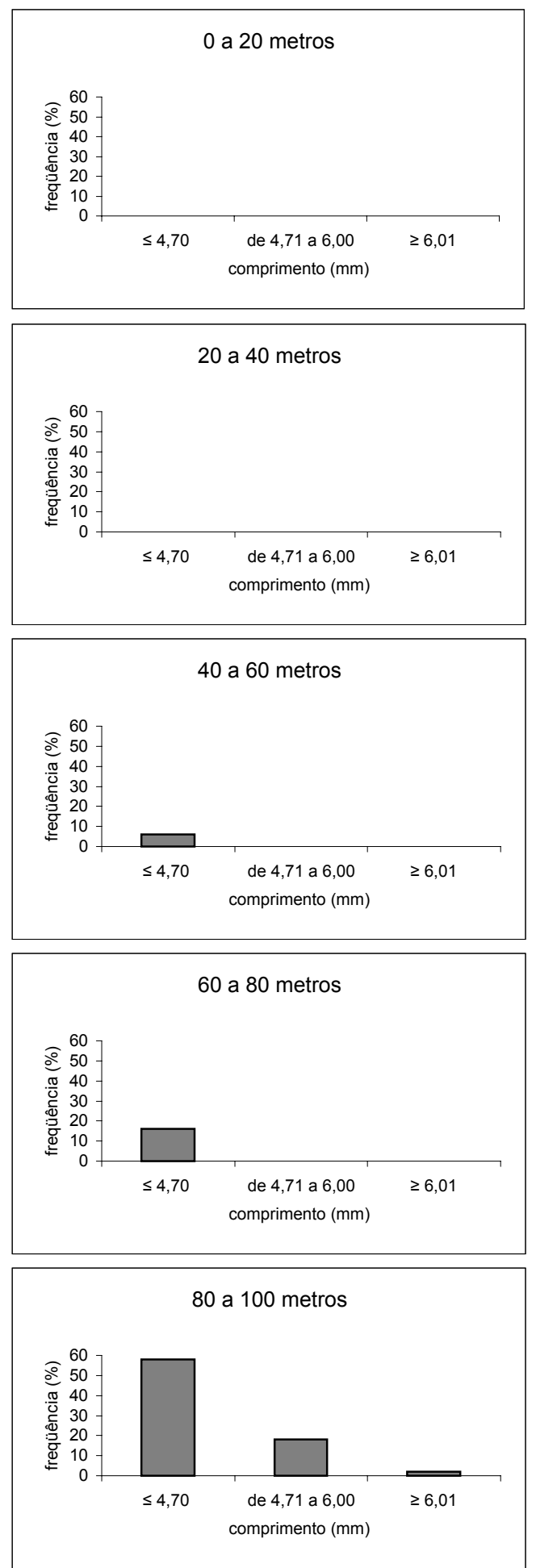

Figura 33. Maurolicus stehmanni: distribuição da freqüência relativa nerítica e oceânica de larvas por classe de comprimento nos estratos amostrados no verão de 2001, na região do cabo Frio (RJ) ( $\leq 4,70 \mathrm{~mm}$ : pré-flexão; 4,71 a 6,00mm: flexão; $\geq 6,01$ : pós-flexão (Ribeiro, 1996)l 
estações diurnas $(n=51)$
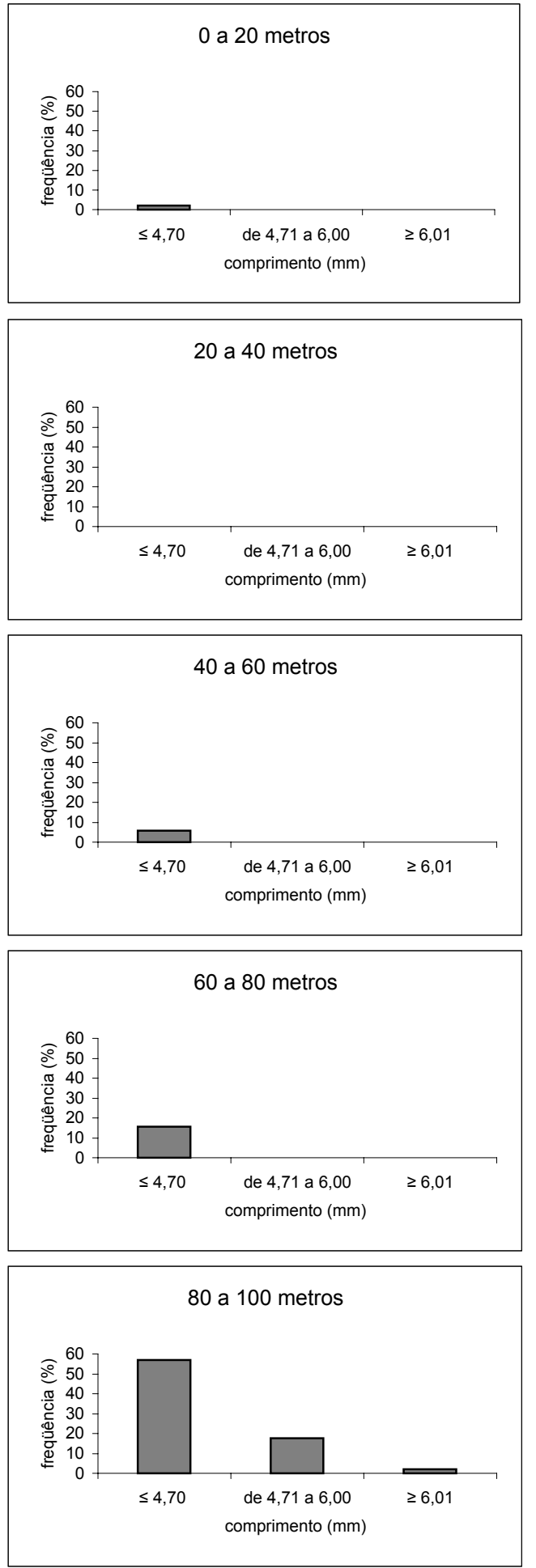

estações noturnas $(n=196)$
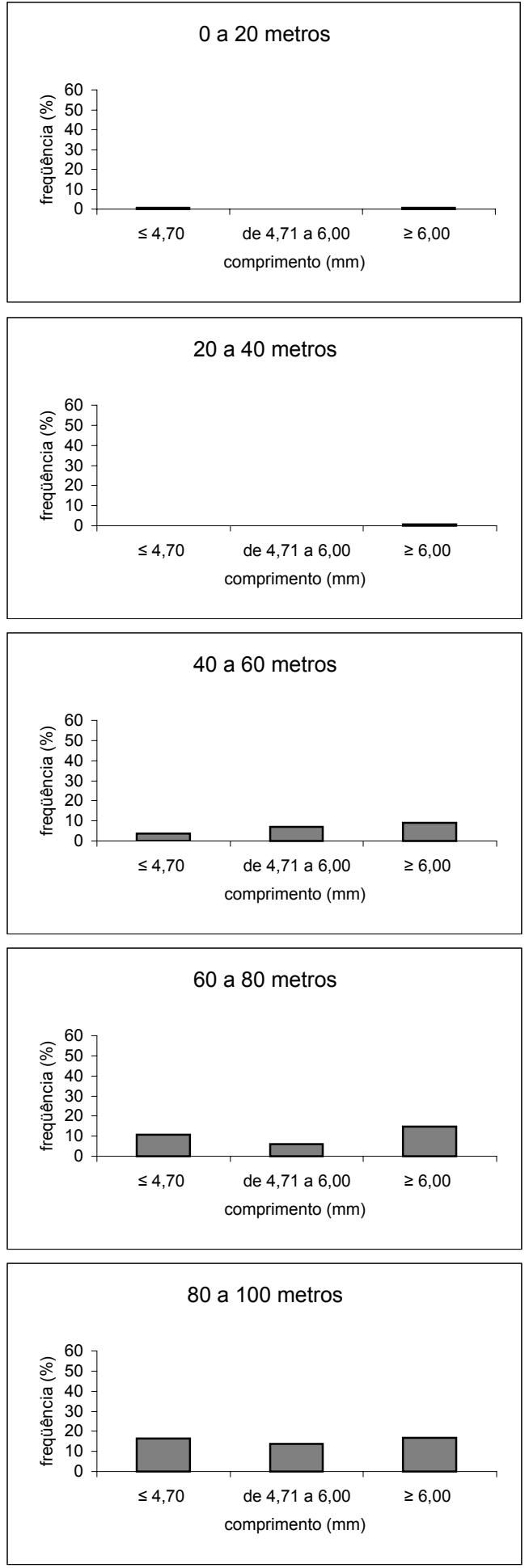

Figura 34. Maurolicus stehmanni: distribuição da freqüência relativa diurna e noturna de larvas por classe de comprimento nos estratos amostrados no verão de 2001 , na região do cabo Frio (RJ) ( $\leq 4,70 \mathrm{~mm}$ : pré-flexão; 4,71 a 6,00mm: flexão; $\geq 6,01$ : pós-flexão (Ribeiro, 1996)). 
(n=80)
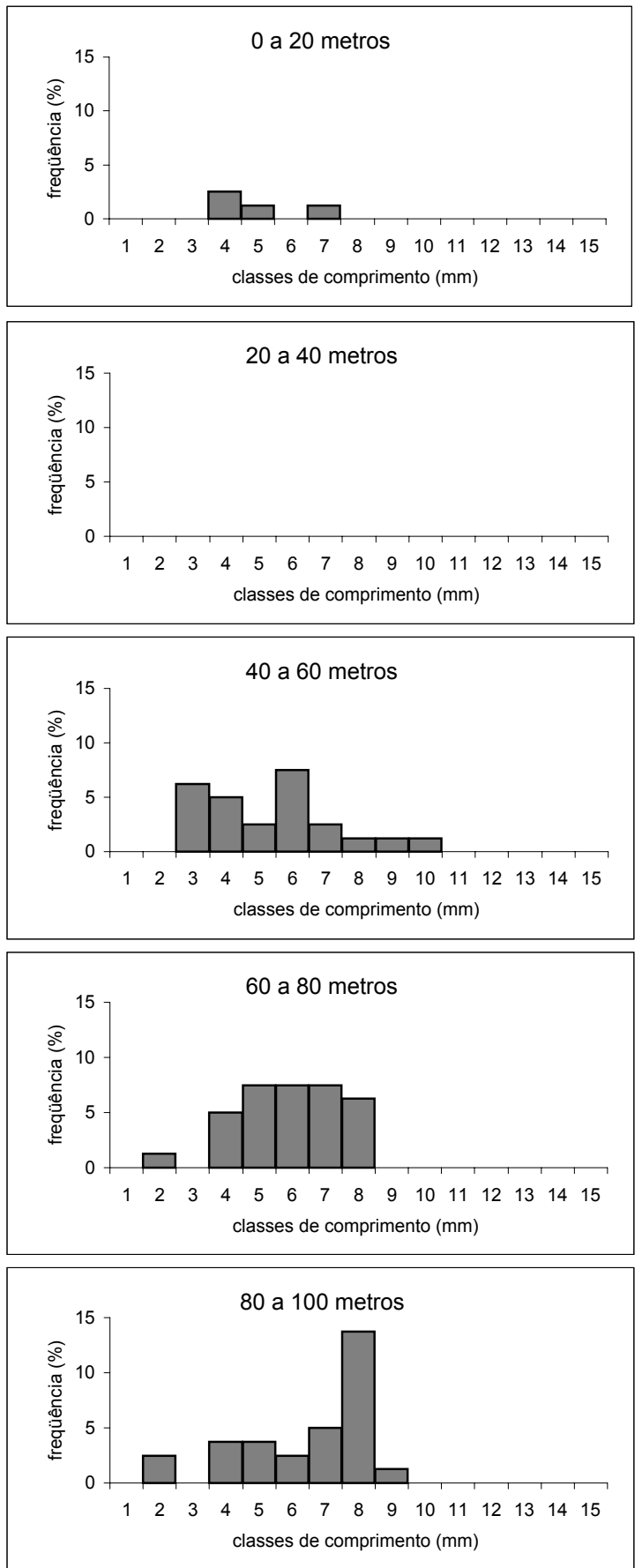

Figura 35. Maurolicus stehmanni: distribuição da freqüência relativa total de larvas por classe de comprimento nos estratos amostrados no inverno de 2001, na região do cabo Frio (RJ). 
estações neríticas $(n=39)$
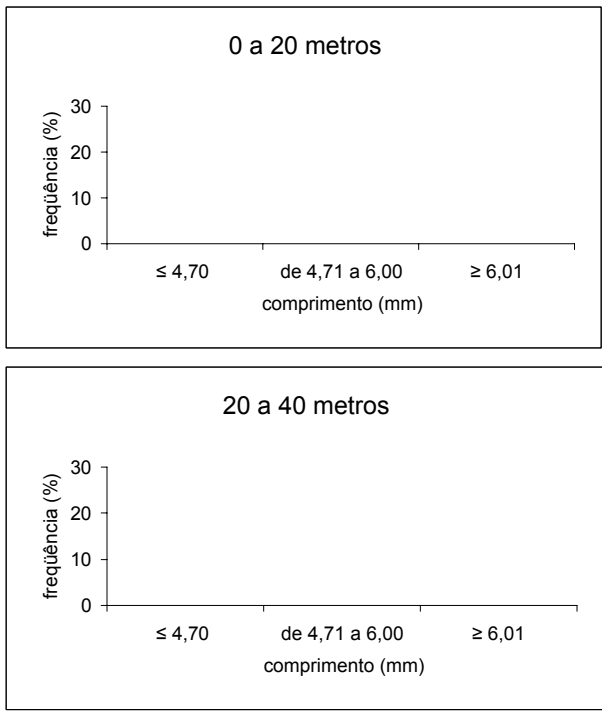

40 a 60 metros

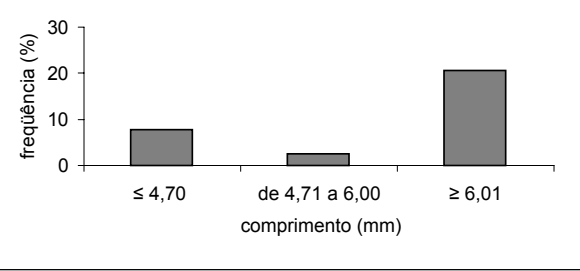

60 a 80 metros

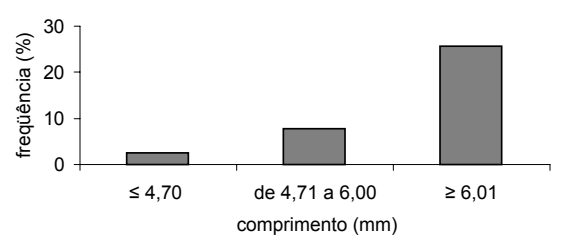

80 a 100 metros

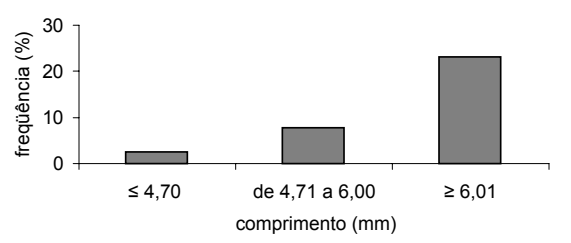

estações oceânicas $(n=41)$

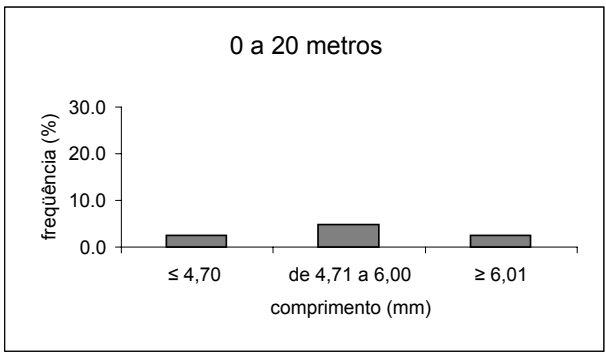

20 a 40 metros

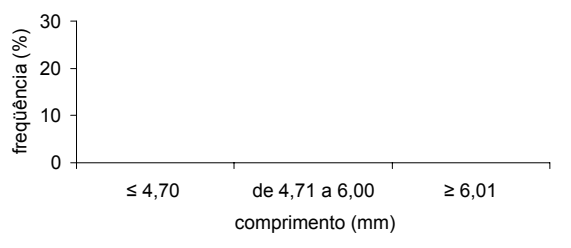

40 a 60 metros

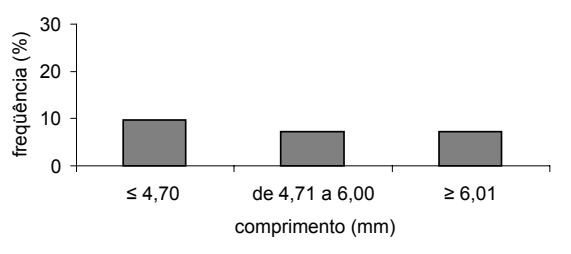

60 a 80 metros

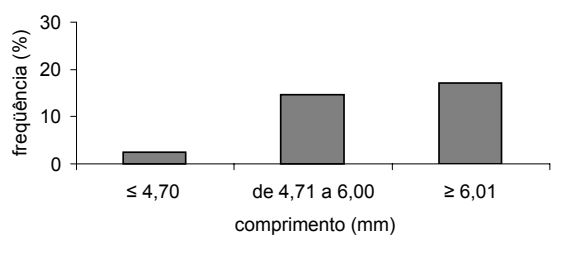

80 a 100 metros

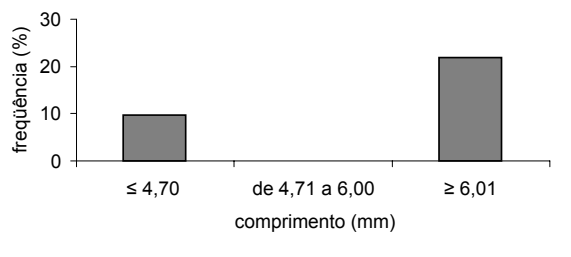

Figura 36. Maurolicus stehmanni: distribuição da freqüência relativa nerítica e oceânica de larvas por classe de comprimento nos estratos amostrados no inverno de 2001, na região do cabo Frio (RJ) ( 4 4,70mm: pré-flexão; 4,71 a 6,00mm: flexão; $\geq 6,01$ : pós-flexão (Ribeiro, 1996)). 
estações diurnas $(n=48)$
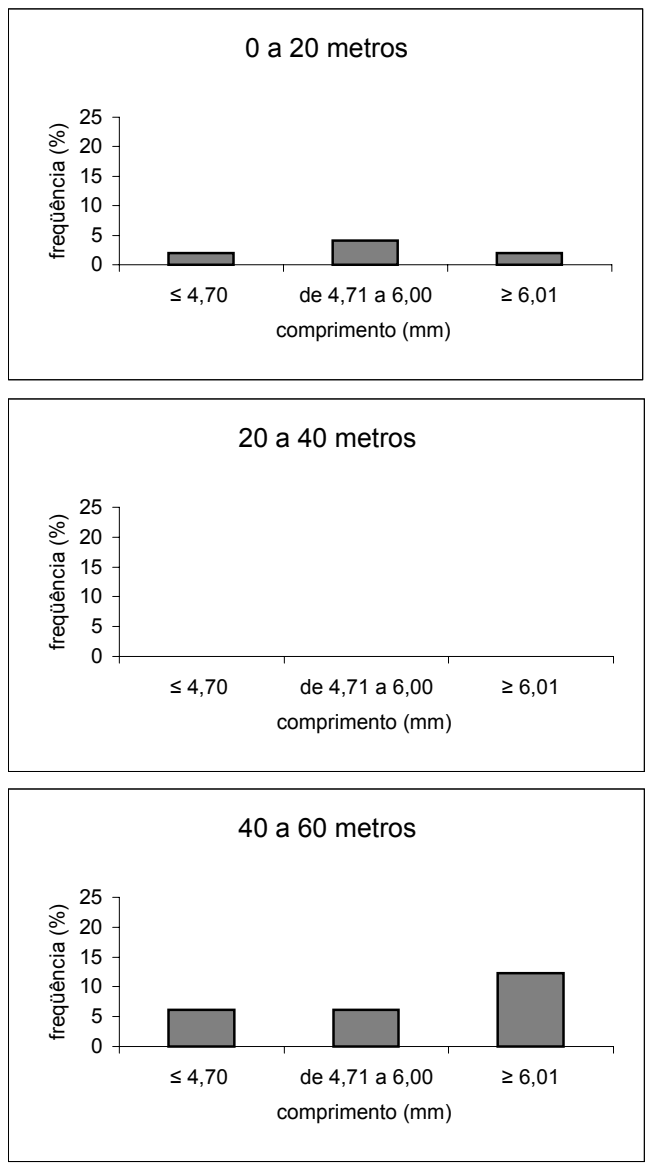

60 a 80 metros

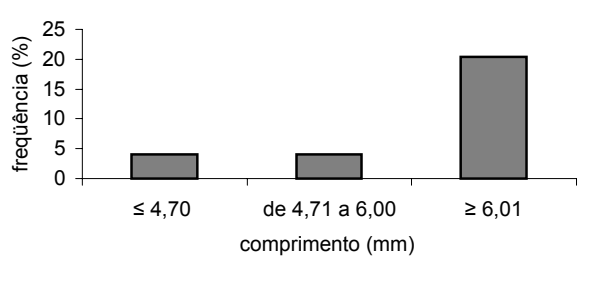

80 a 100 metros

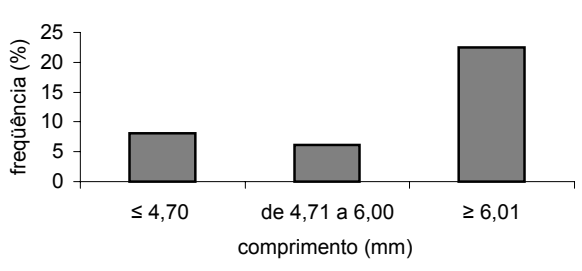

Figura 37. Maurolicus stehmanni: distribuição da freqüência relativa diurna e noturna de larvas por classe de comprimento nos estratos amostrados no inverno de 2001, na região do cabo Frio (RJ) ( $\leq 4,70 \mathrm{~mm}$ : pré-flexão; 4,71 a 6,00mm: flexão; $\geq 6,01$ : pós-flexão (Ribeiro, 1996)).
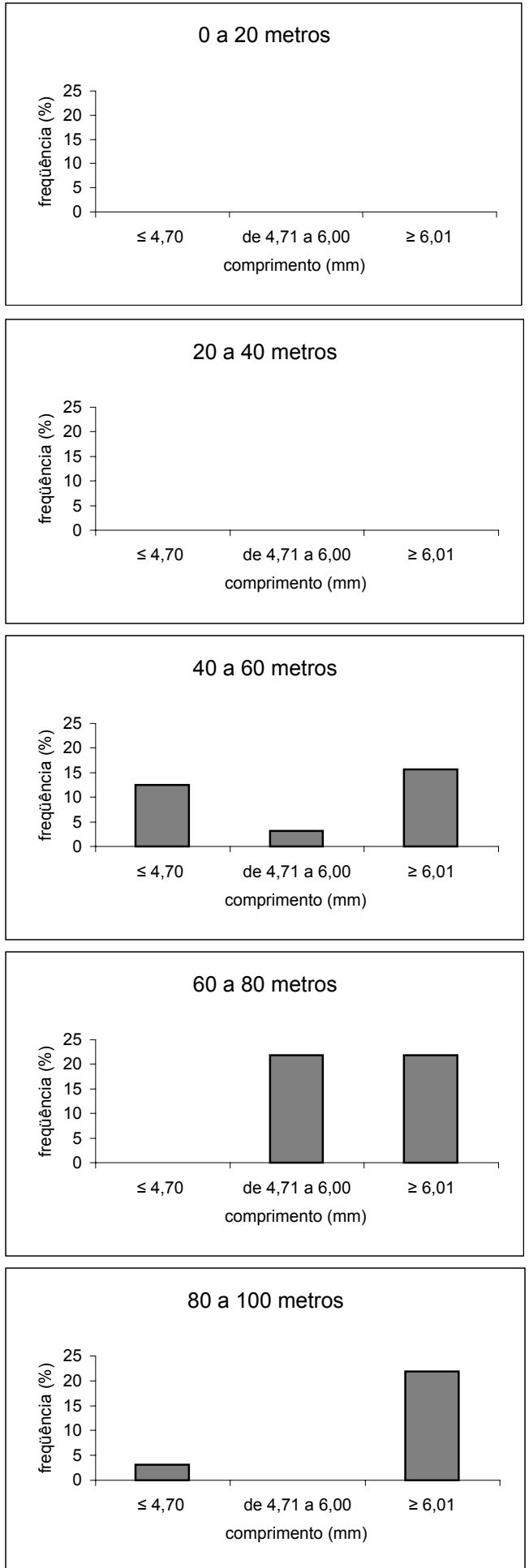

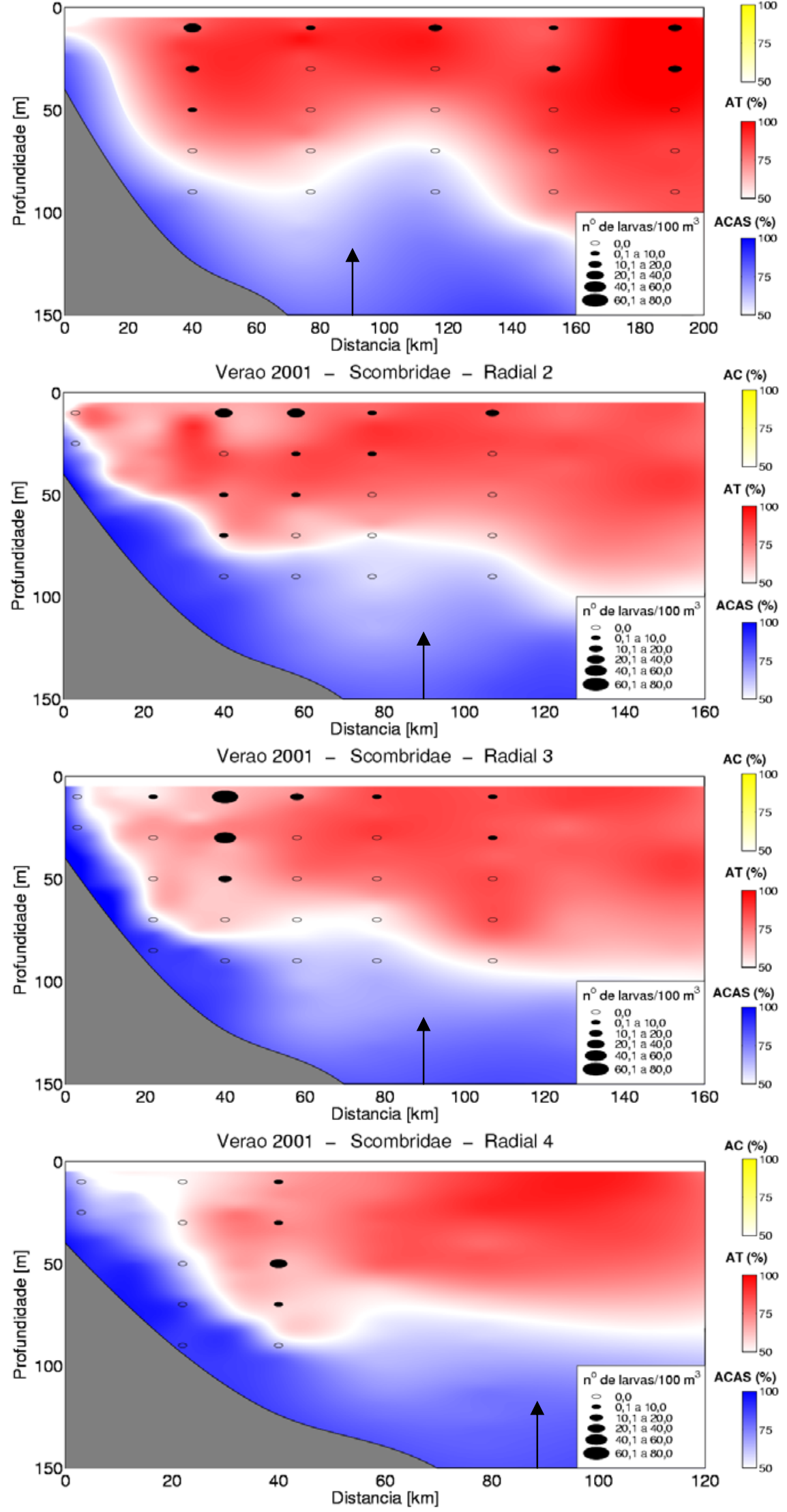

Figura 38. Distribuição espacial de larvas de Scombridae coletadas no verão de 2001, na região do cabo Frio (RJ). A seta no eixo inferior separa as 

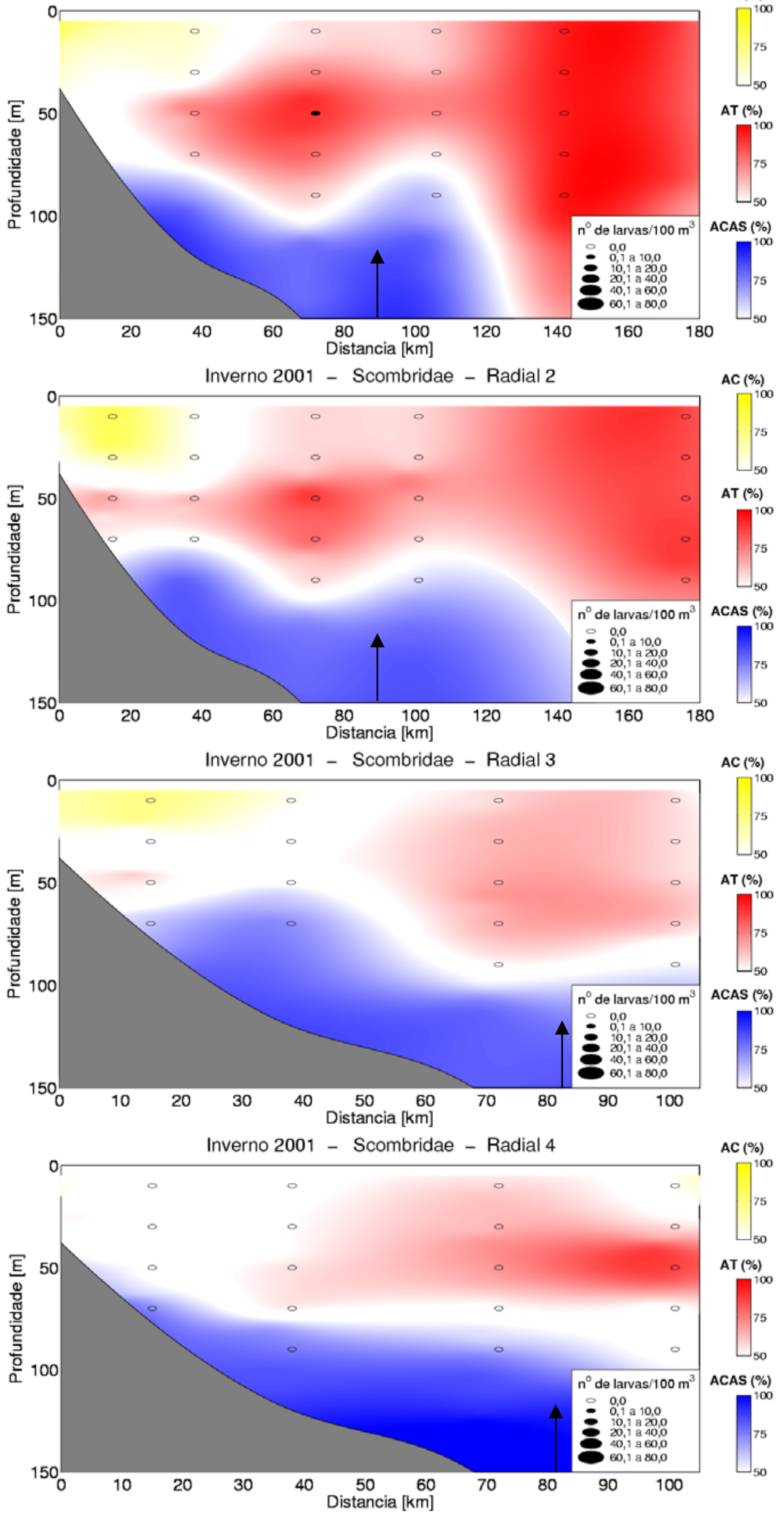

Figura 39. Distribuição espacial de larvas de Scombridae coletadas no inverno de 2001 , na região do cabo Frio $(\mathrm{RJ})$. A seta no eixo inferior separa 

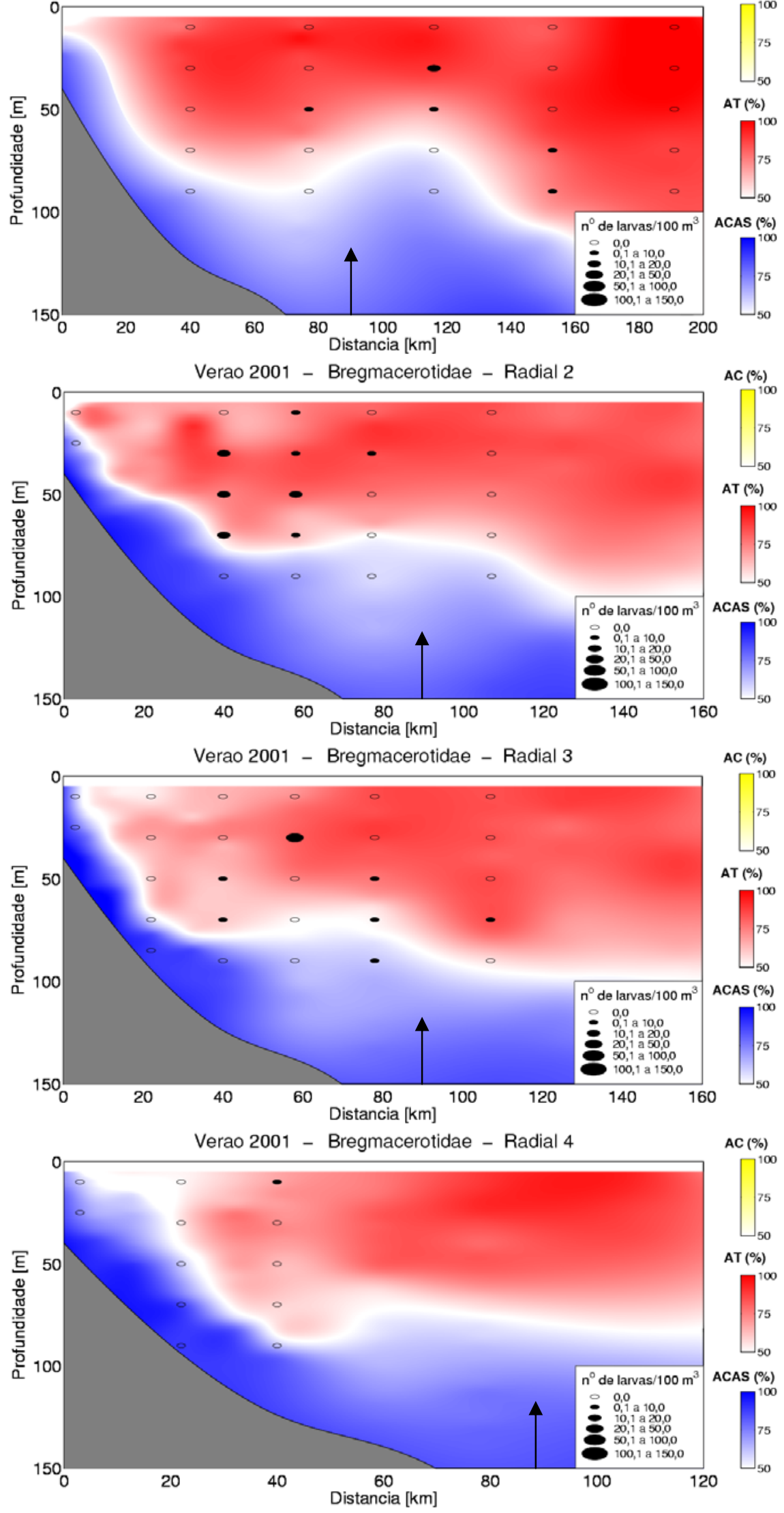

Figura 40. Distribuição espacial de larvas de Bregmacerotidae coletadas no verão de 2001 , na região do cabo Frio $(\mathrm{RJ})$. A seta no eixo inferior separa 

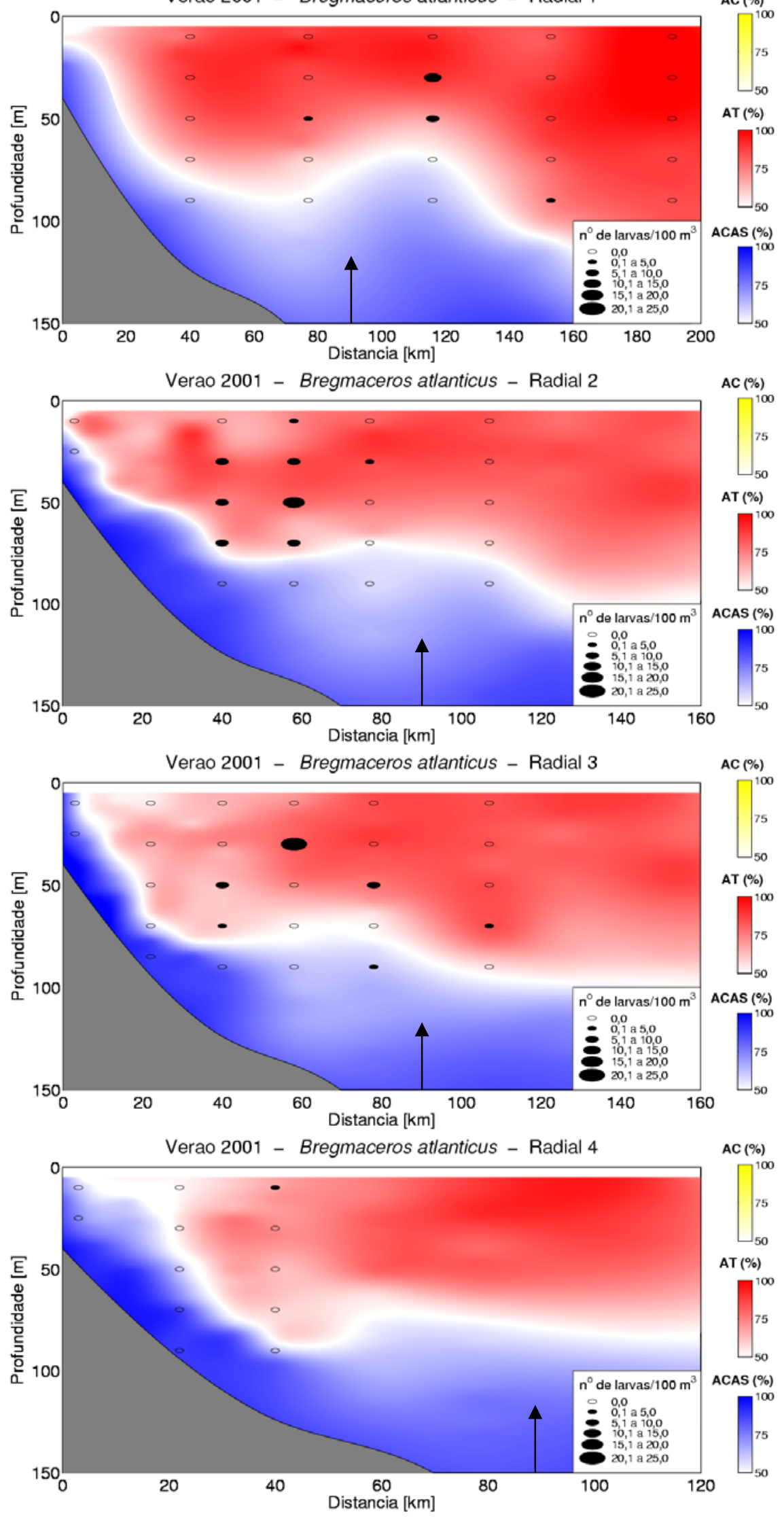

Figura 42. Distribuição espacial de larvas de Bregmaceros atlanticus coletadas no cruzeiro realizado no verão de 2001 , na reqião do cabo Frio 
$(n=46)$
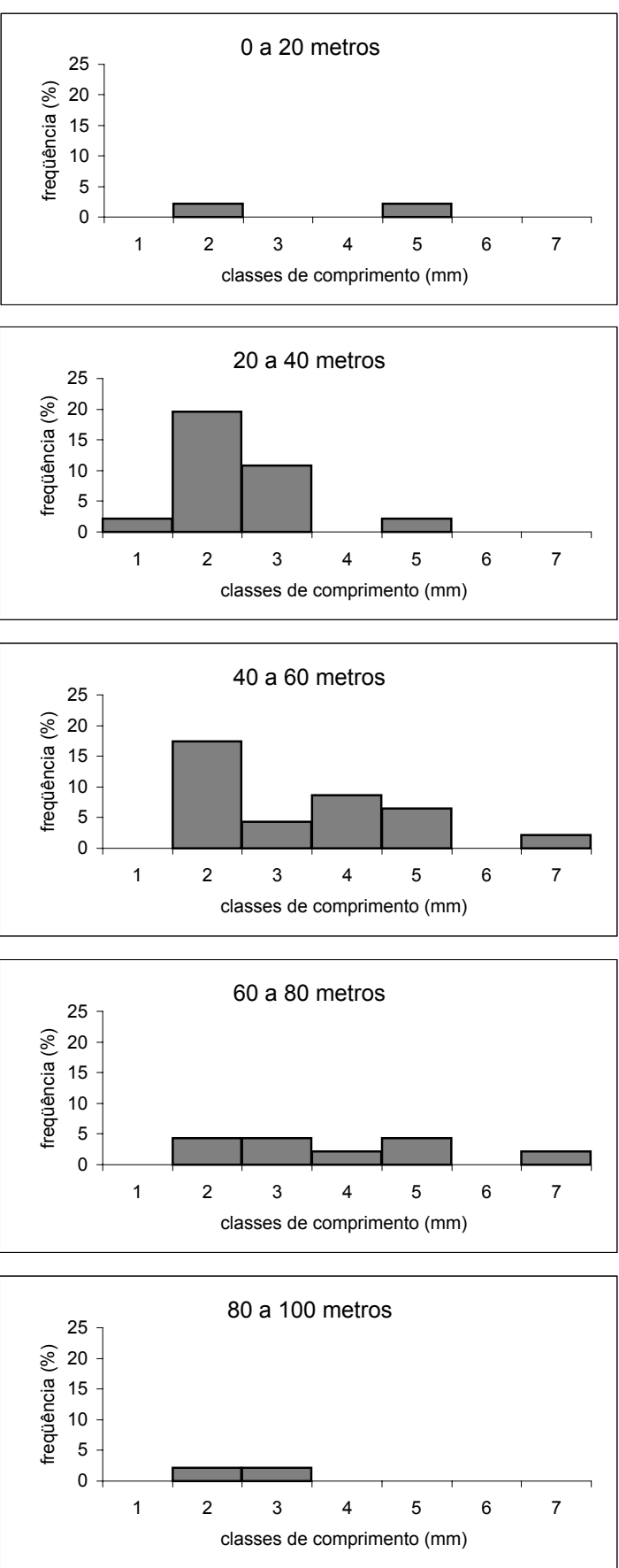

Figura 44. Bregmaceros atlanticus: distribuição da freqüência relativa total de larvas por classe de comprimento nos estratos amostrados no verão de 2001, na região do cabo Frio (RJ). 
estações neríticas $(n=37)$
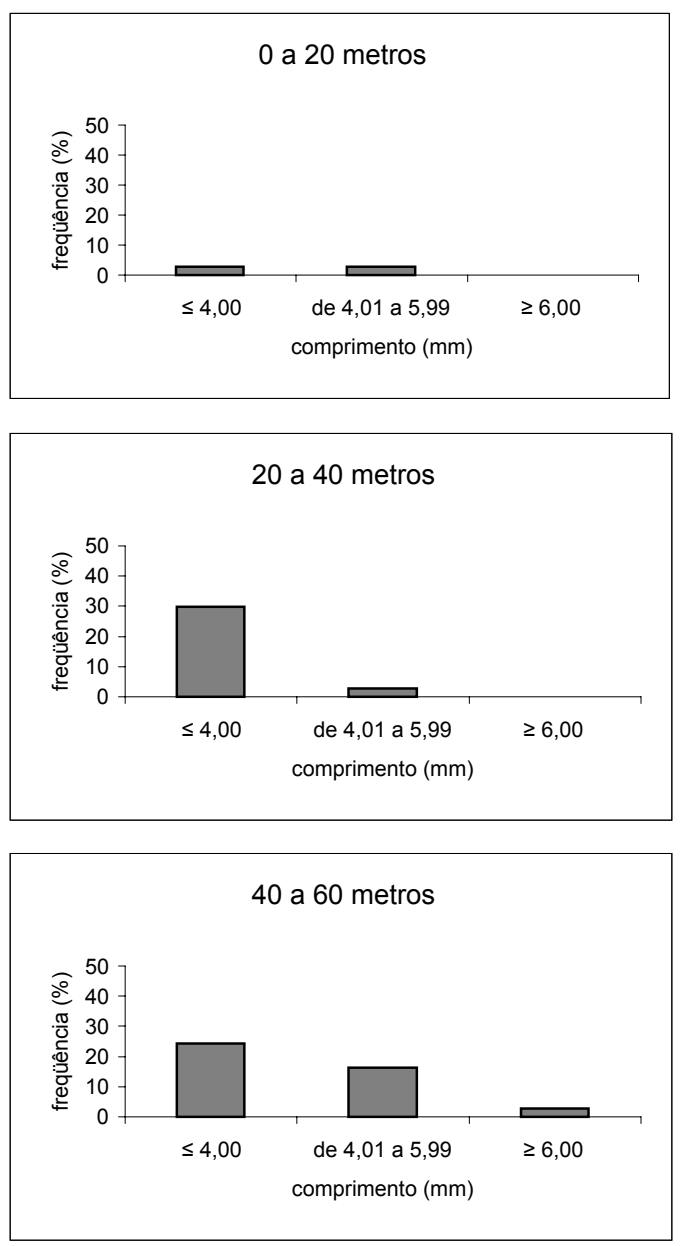

60 a 80 metros
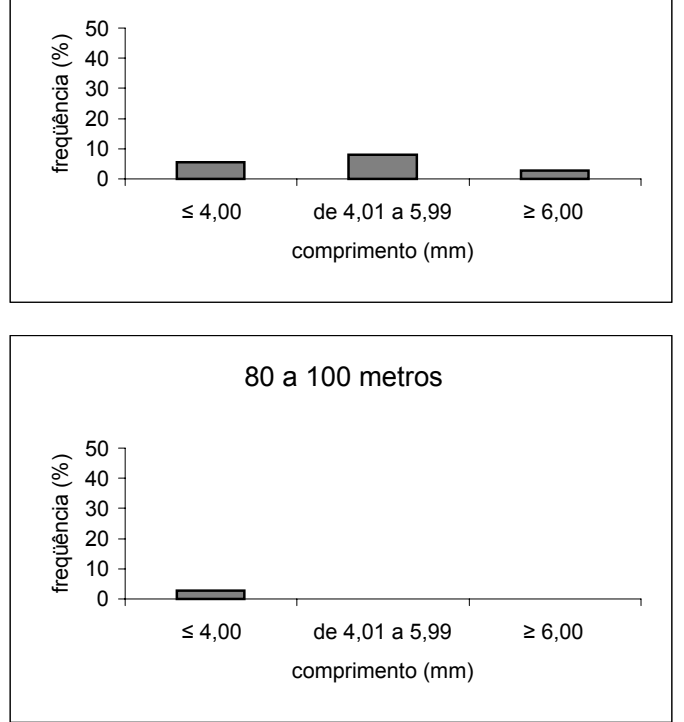

estações oceânicas (n=9)
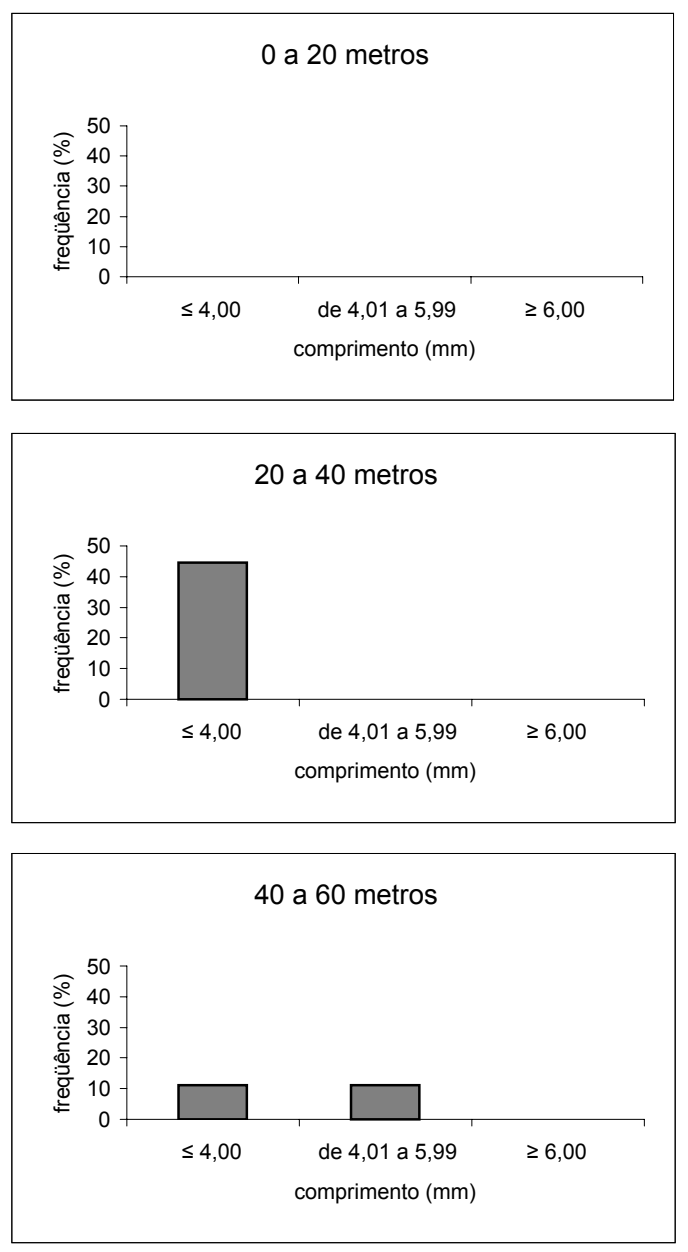

60 a 80 metros
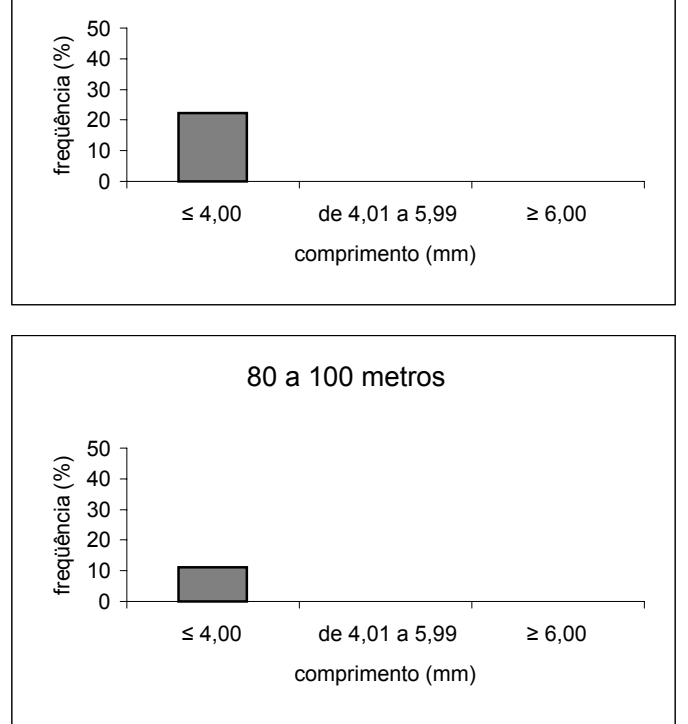

Figura 45. Bregmaceros atlanticus: distribuição da freqüência relativa nerítica e oceânica de larvas por classe de comprimento nos estratos amostrados no verão de 2001 , na região do cabo Frio (RJ) ( $\leq 4 \mathrm{~mm}$ : pré-flexão; 4,01 a 5,99mm: flexão; $\geq 6,00$ : pós-flexão ( Moser \& Ahlstron, 1970)). 
estações diurnas $(n=13)$
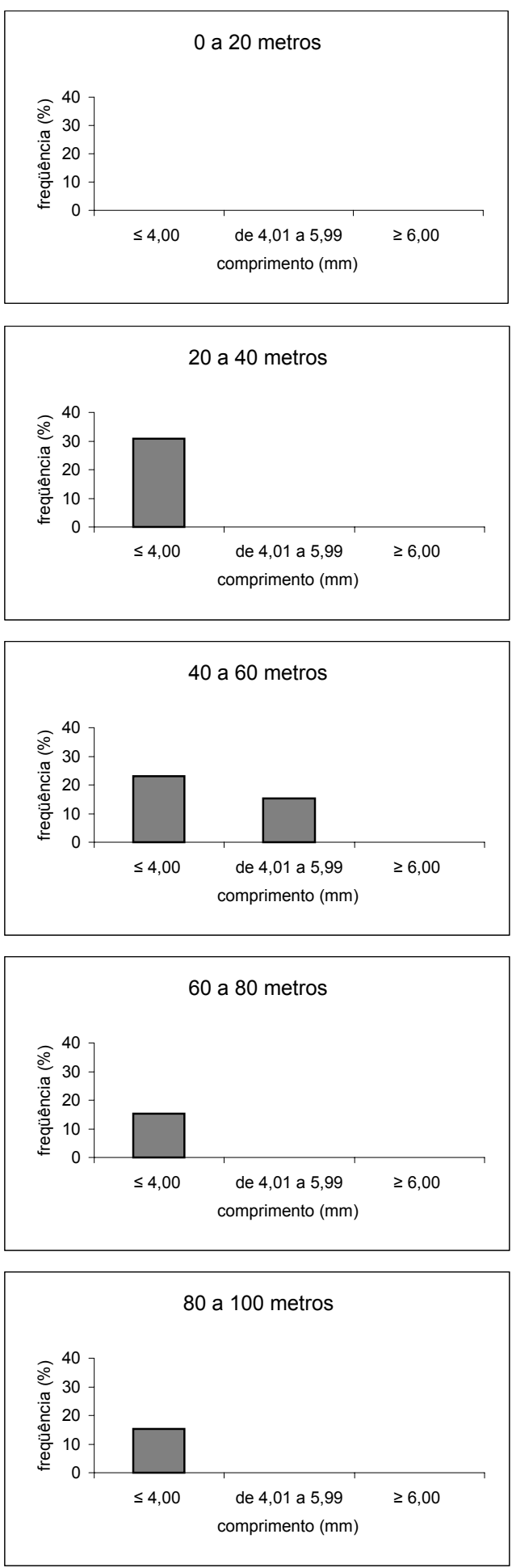

estações noturnas $(n=33)$
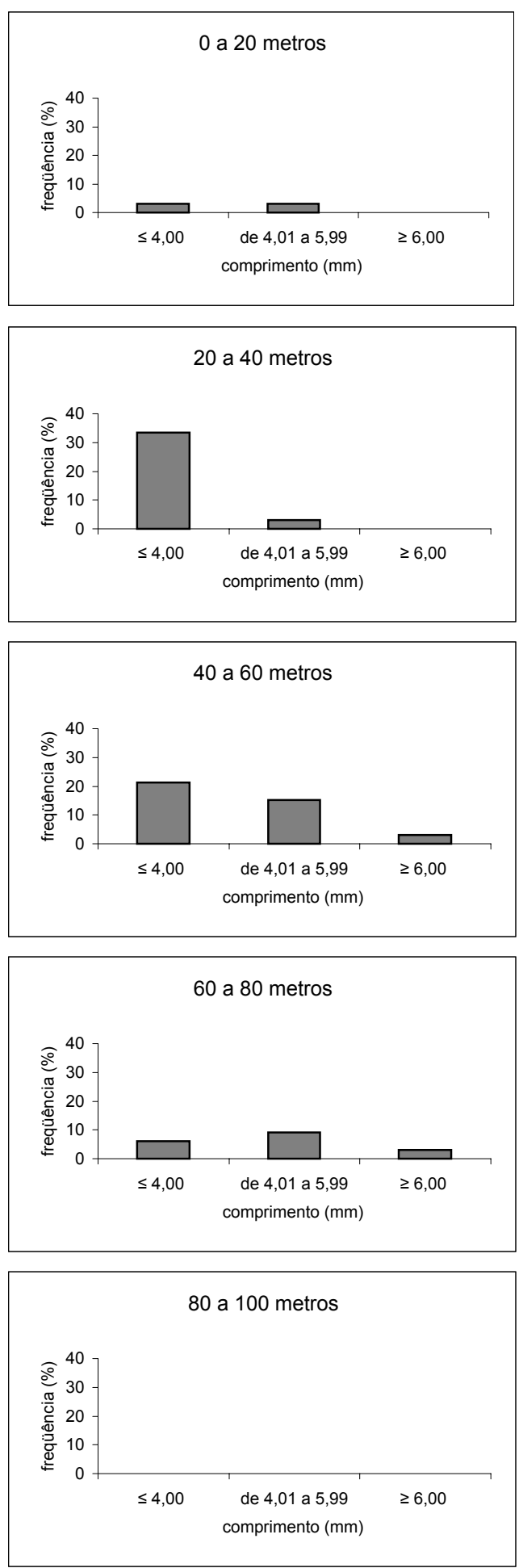

Figura 46. Bregmaceros atlanticus: distribuição da freqüência relativa diurna e noturna de larvas por classe de comprimento nos estratos amostrados no verão de 2001 , na região do cabo Frio (RJ) ( $\leq 4 \mathrm{~mm}$ : pré-flexão; 4,01 a 5,99mm: flexão; $\geq 6,00$ : pós-flexão (Moser \& Ahlstron, 1970)). 

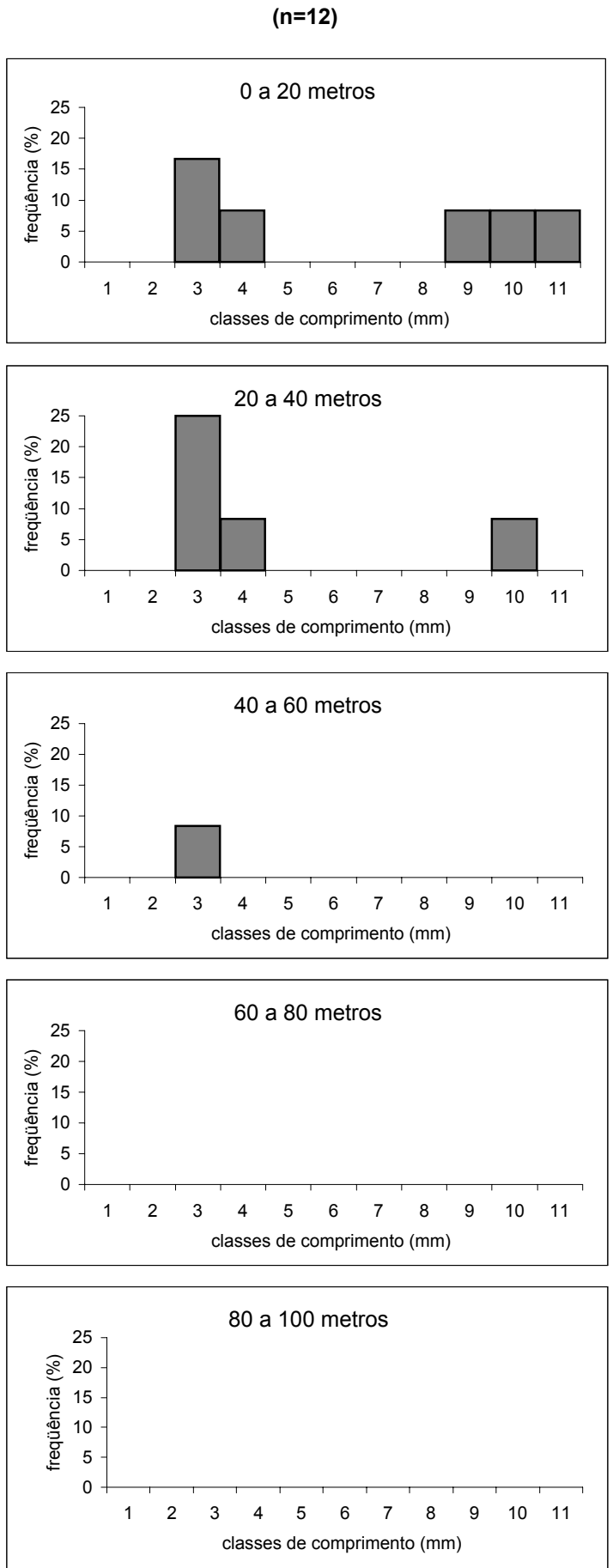

Figura 47. Bregmaceros atlanticus: distribuição da freqüência relativa total de larvas por classe de comprimento nos estratos amostrados no inverno de 2001, na região do cabo Frio (RJ). 
estações neríticas $(n=10)$

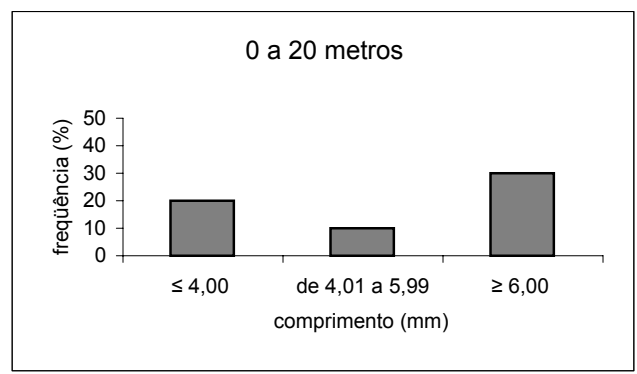

20 a 40 metros

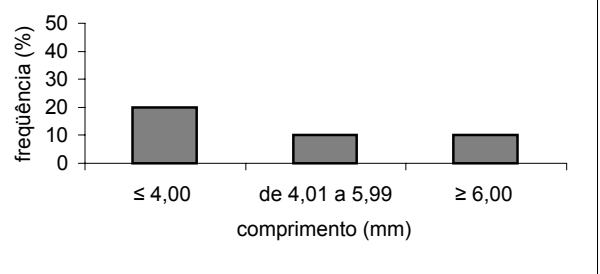

40 a 60 metros

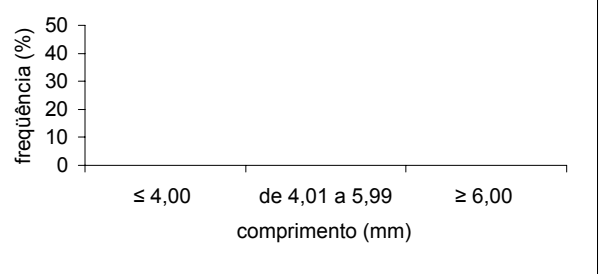

60 a 80 metros

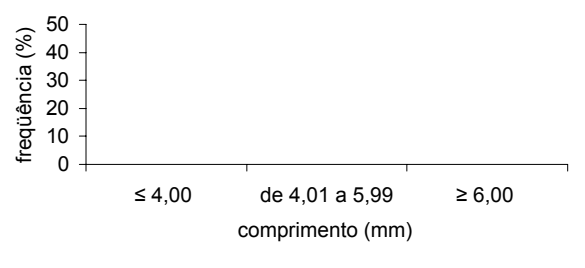

80 a 100 metros

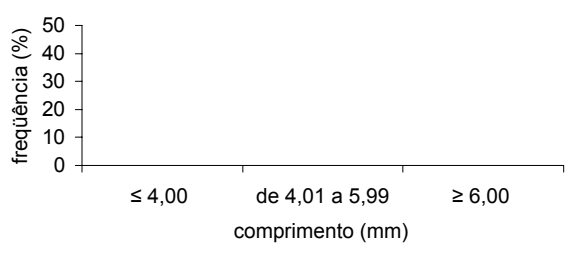

estações oceânicas (n=2)
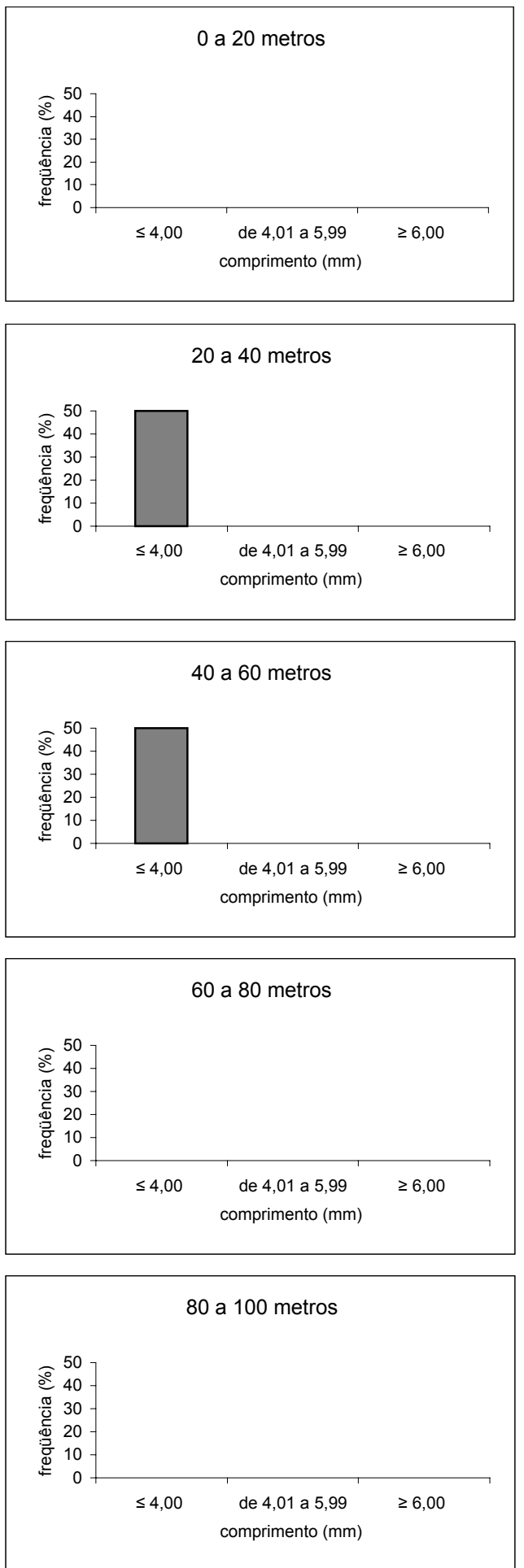

Figura 48. Bregmaceros atlanticus: distribuição da freqüência relativa nerítica e oceânica de larvas por classe de comprimento nos estratos amostrados no inverno de 2001, na região do cabo Frio $(\mathrm{RJ})$ ( $\leq 4 \mathrm{~mm}$ : pré-flexão; 4,01 a 5,99mm: flexão; $\geq 6,00$ : pós-flexão (Moser \& Ahlstron, 1970)). 
estações diurnas $(n=9)$
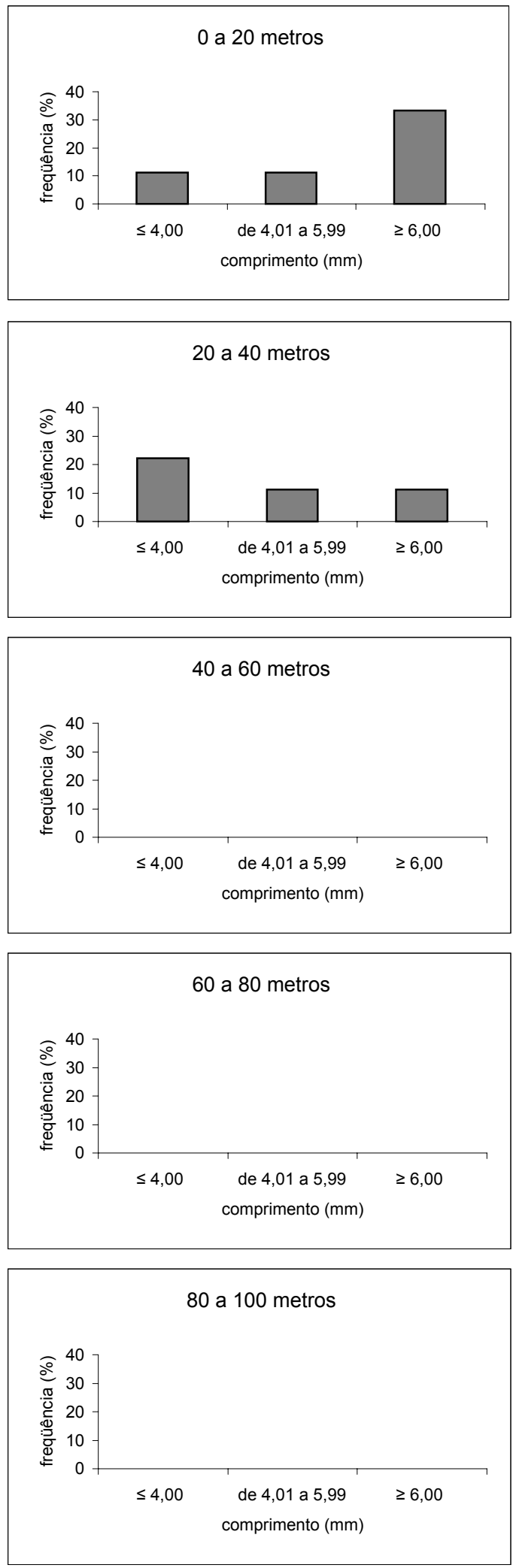

estações noturnas $(n=3)$
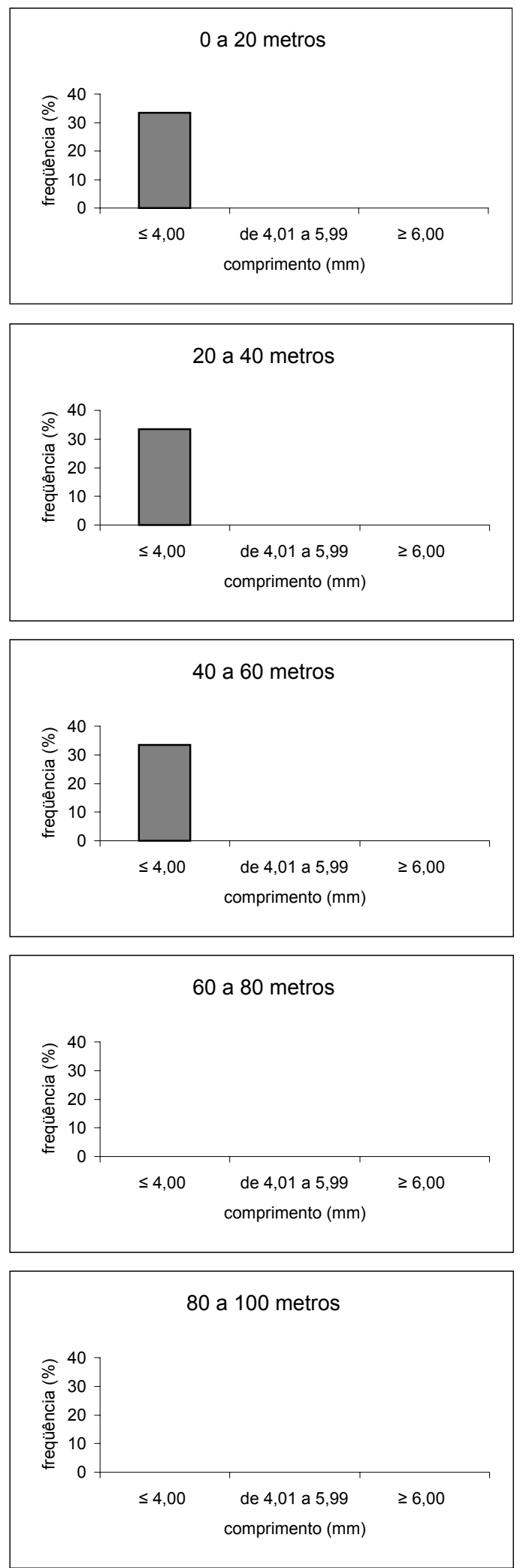

Figura 49. Bregmaceros atlanticus: distribuição da freqüência relativa diurna e noturna de larvas por classe de comprimento nos estratos amostrados no inverno de 2001 , na região do cabo Frio (RJ) ( $\leq 4 \mathrm{~mm}$ : pré-flexão; 4,01 a 5,99mm: flexão; $\geq 6,00$ : pós-flexão (Moser \& Ahlstron, 1970)). 


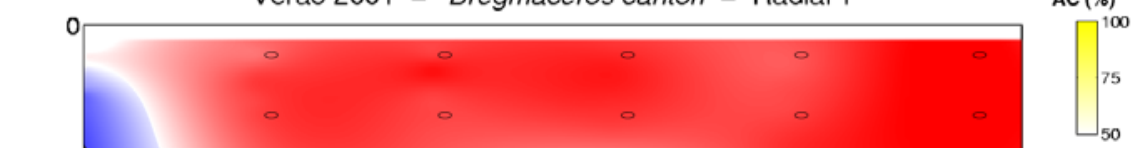

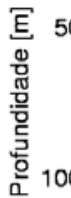
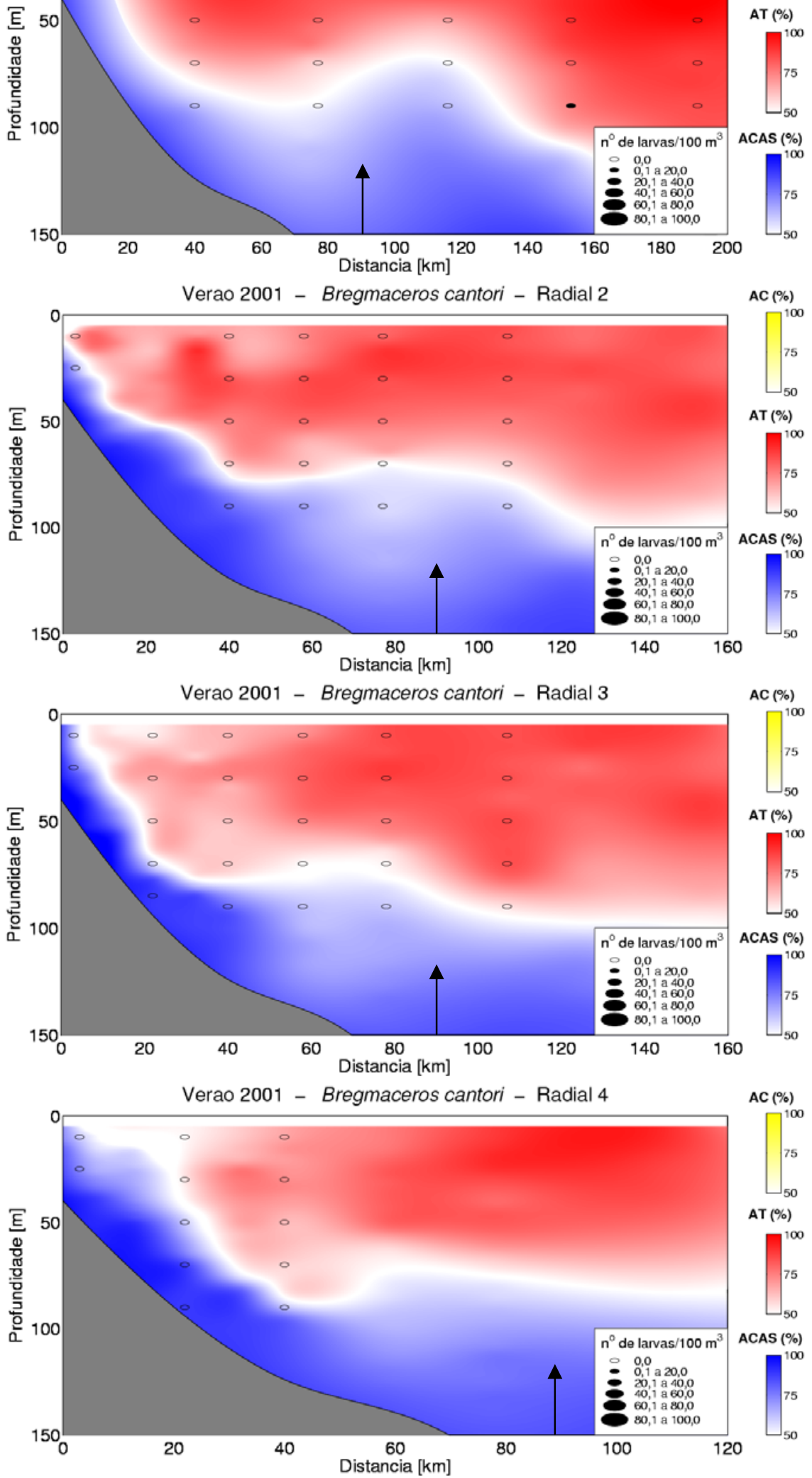

Figura 50. Distribuição de larvas de Bregmaceros cantori coletadas no verão de 2001. na reqião do cabo Frio $(R J)$. A seta no eixo inferior separa as 
$(\mathrm{n}=101)$
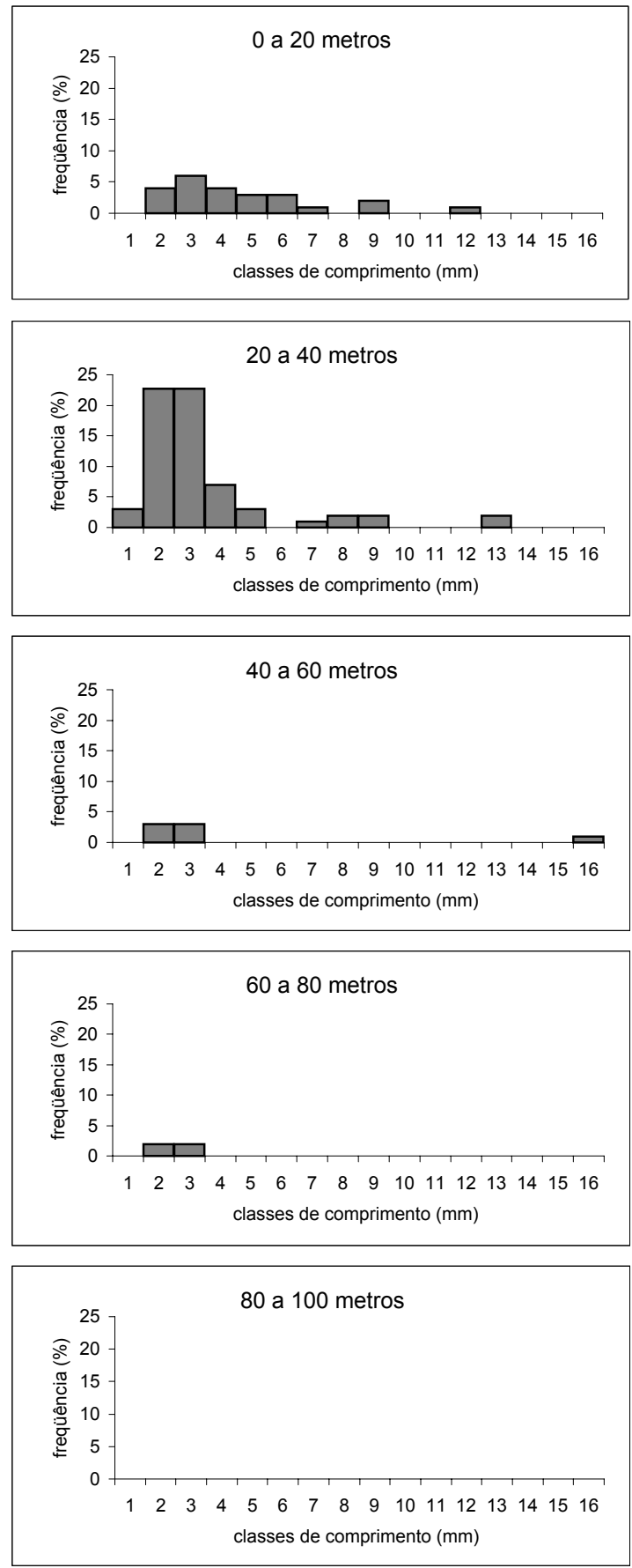

Figura 52. Bregmaceros cantori : distribuição da freqüência relativa total de larvas por classe de comprimento nos estratos amostrados no inverno de 2001 , na região do cabo Frio (RJ). 
estações neríticas $(n=88)$
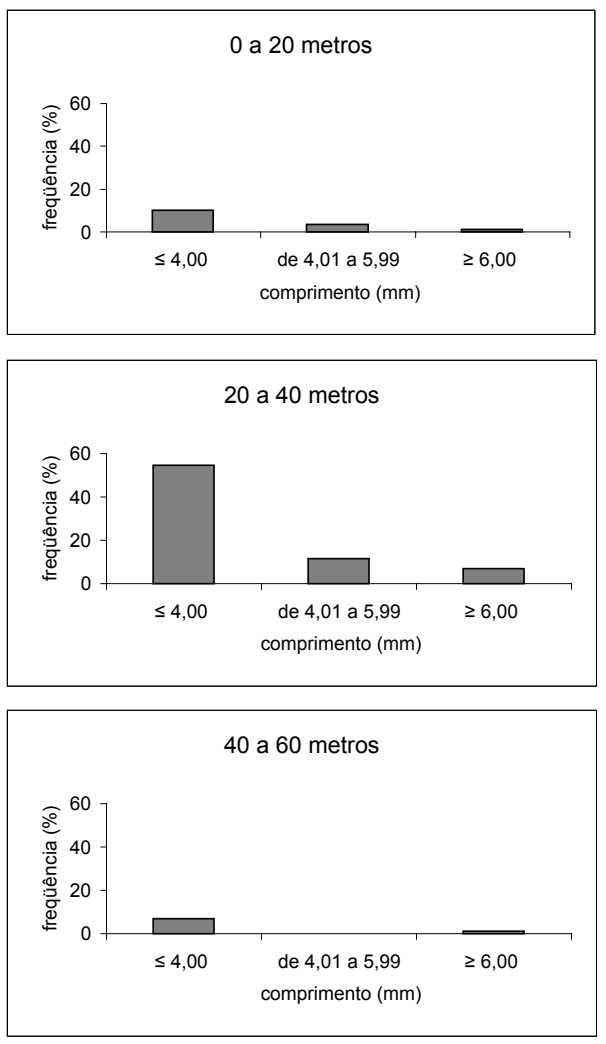

60 a 80 metros
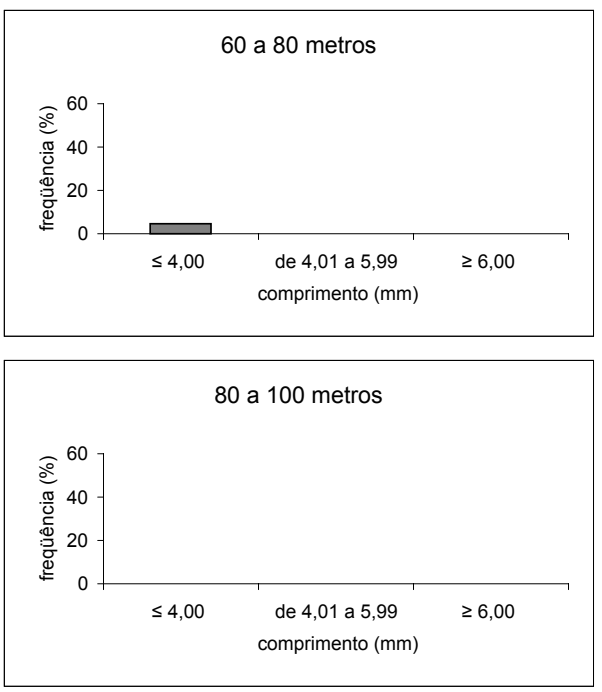

estações oceânicas $(n=13)$
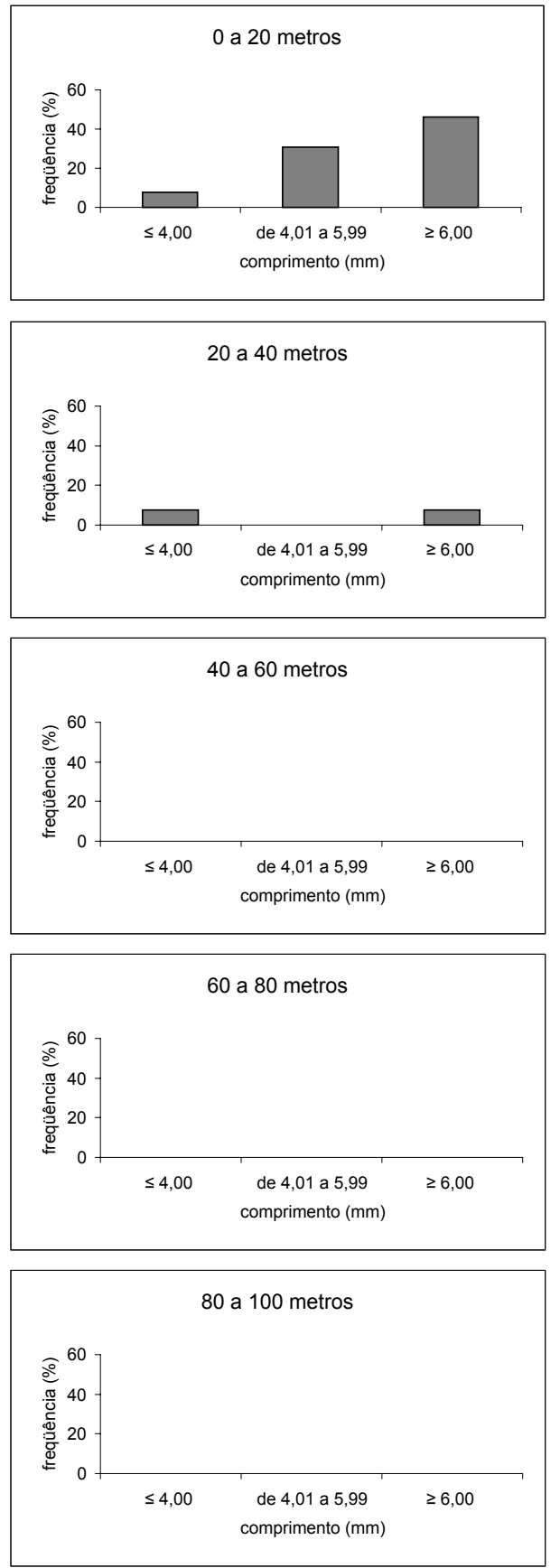

Figura 53. Bregmaceros cantori: distribuição da freqüência relativa nerítica e oceânica de larvas por classe de comprimento nos estratos amostrados no inverno de 2001, na região do cabo Frio (RJ) ( $\leq$ 4mm: pré-flexão; 4,01 a 5,99mm: flexão; 2 6,00: pós-flexão (Moser \& Ahlstron, 1970)). 
estações diurnas $(n=15)$
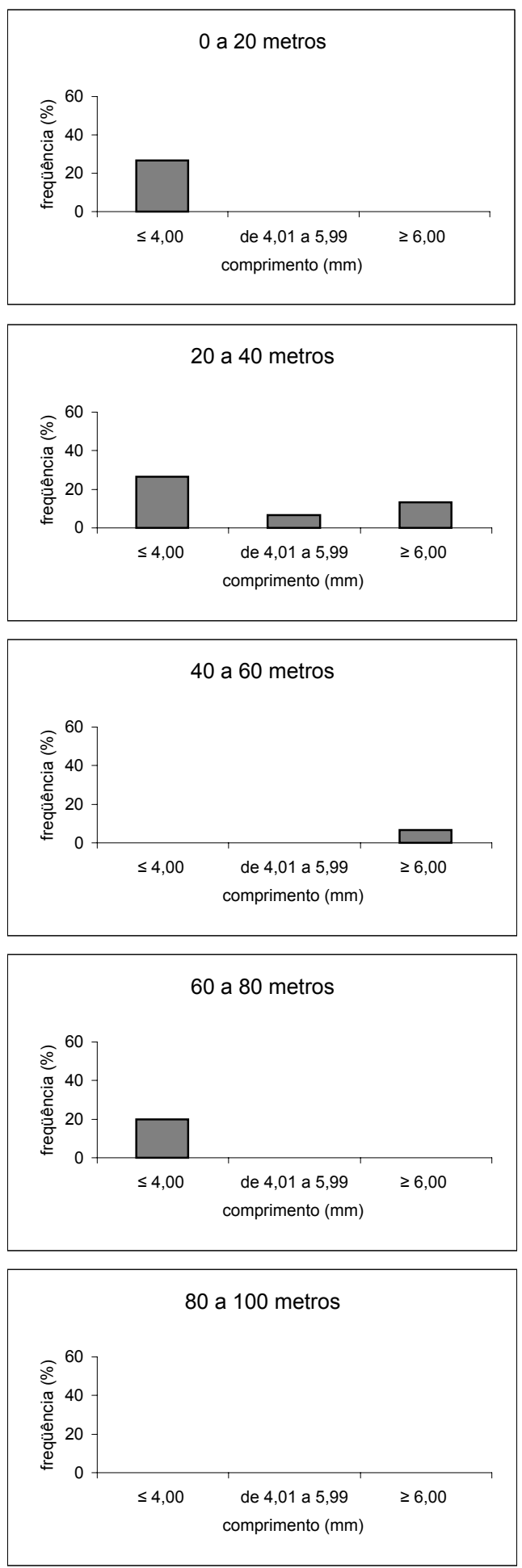

estações noturnas $(n=86)$
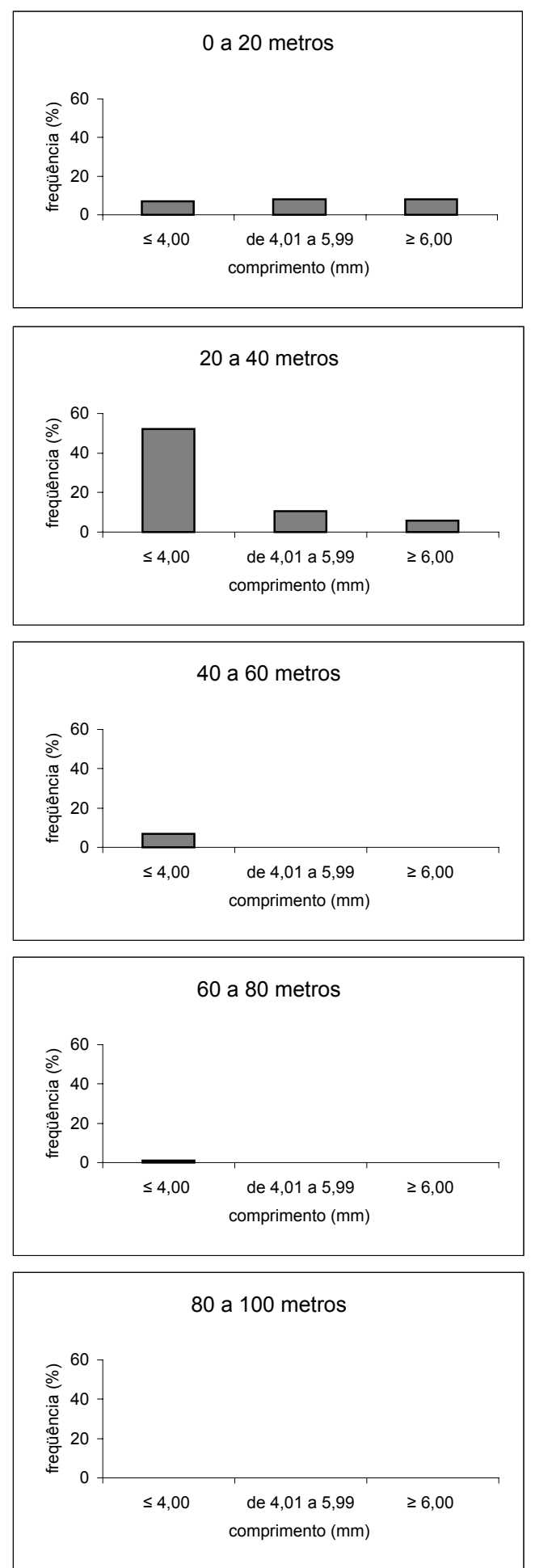

Figura 54. Bregmaceros cantori: distribuição da freqüência relativa diurna e noturna de larvas por classe de comprimento nos estratos amostrados no inverno de 2001, na região do cabo Frio

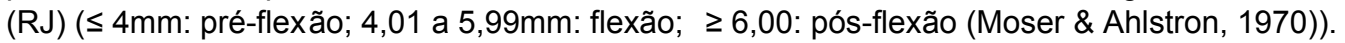



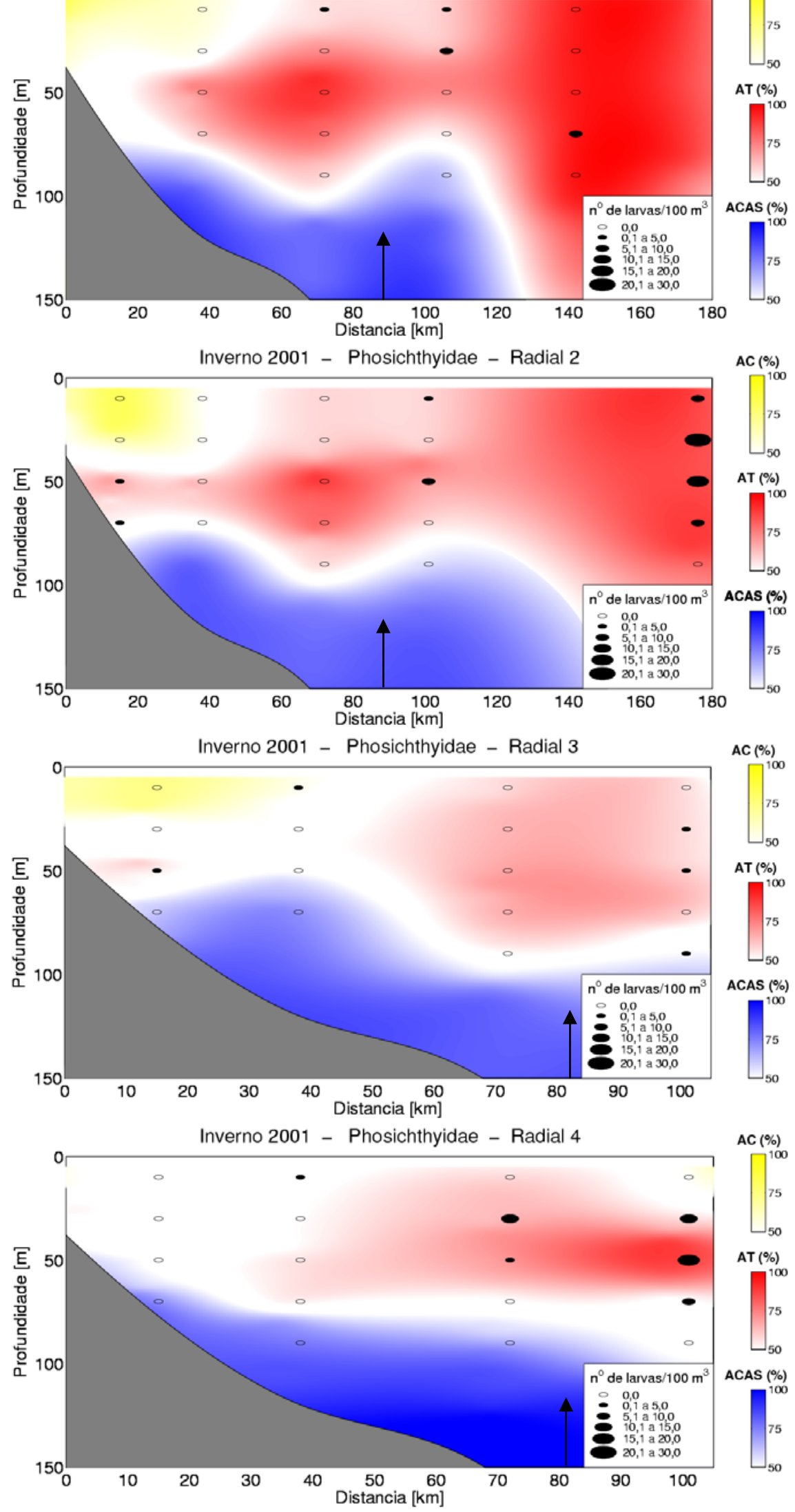

Figura 56. Distribuição espacial de larvas de Phosichthyidae coletadas no inverno de 2001, na região do cabo Frio (RJ). A seta no eixo inferior separa 

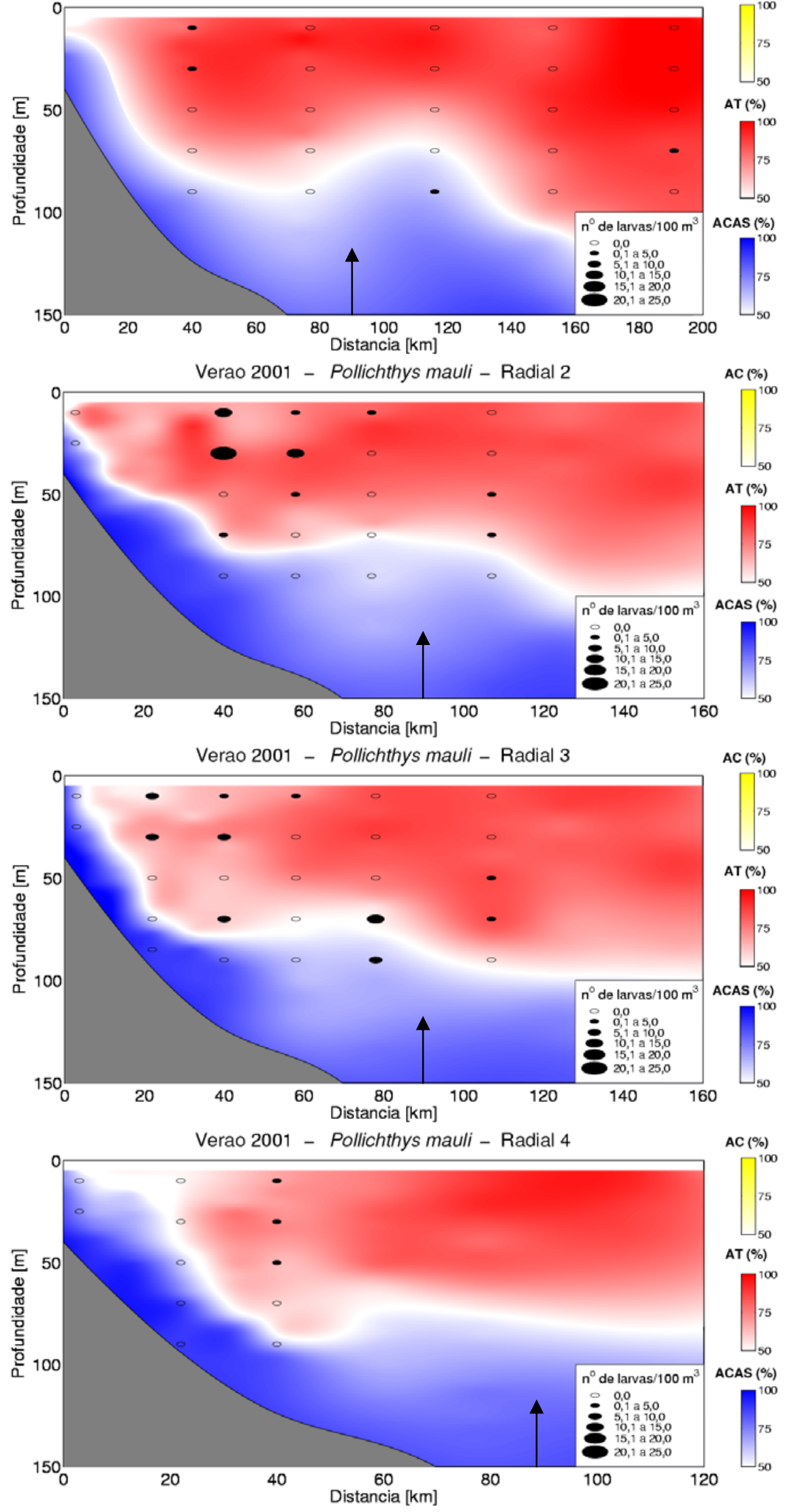

Figura 57. Distribuição espacial de larvas de Pollichthys mauli coletadas no verão de 2001 , na região do cabo Frio $(\mathrm{RJ})$. A seta no eixo inferior separa 
$(\mathrm{N}=52)$
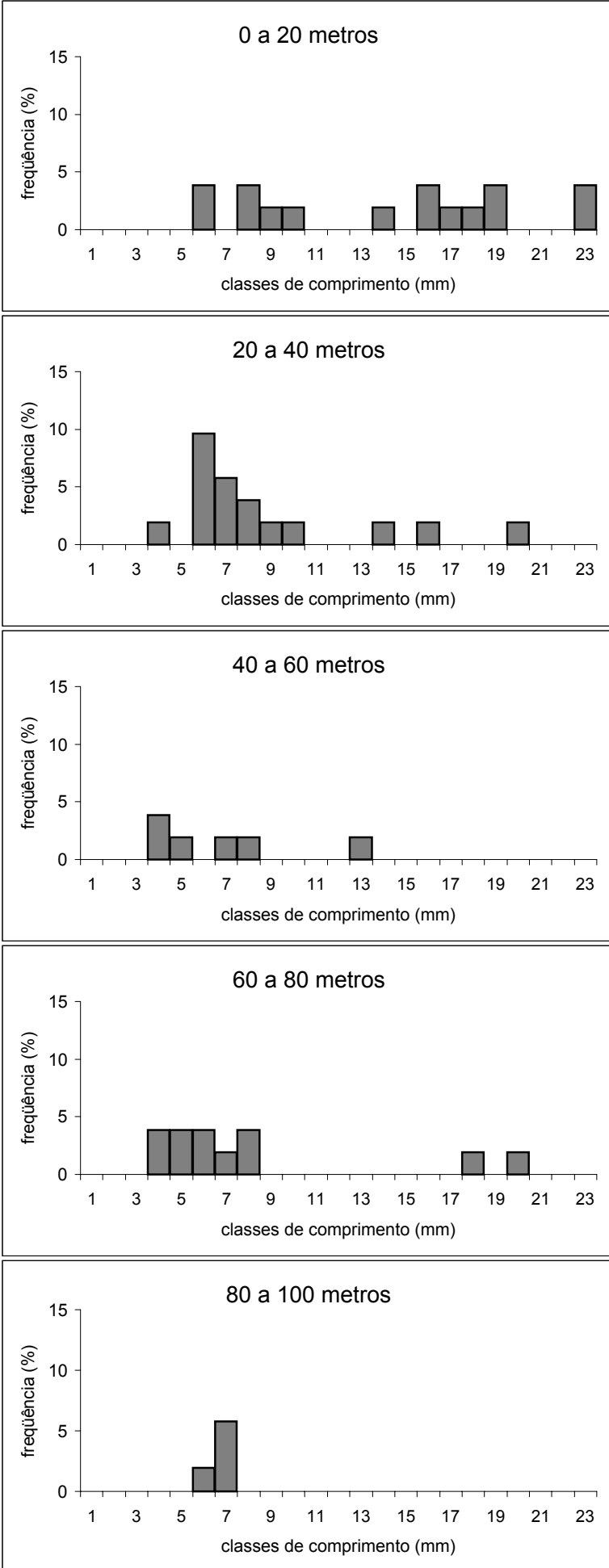

Figura 59. Pollichthys mauli: distribuição da freqüência relativa total de larvas por classe de comprimento nos estratos amostrados no verão de 2001, na região do cabo Frio (RJ). 
estações neríticas $(n=44)$
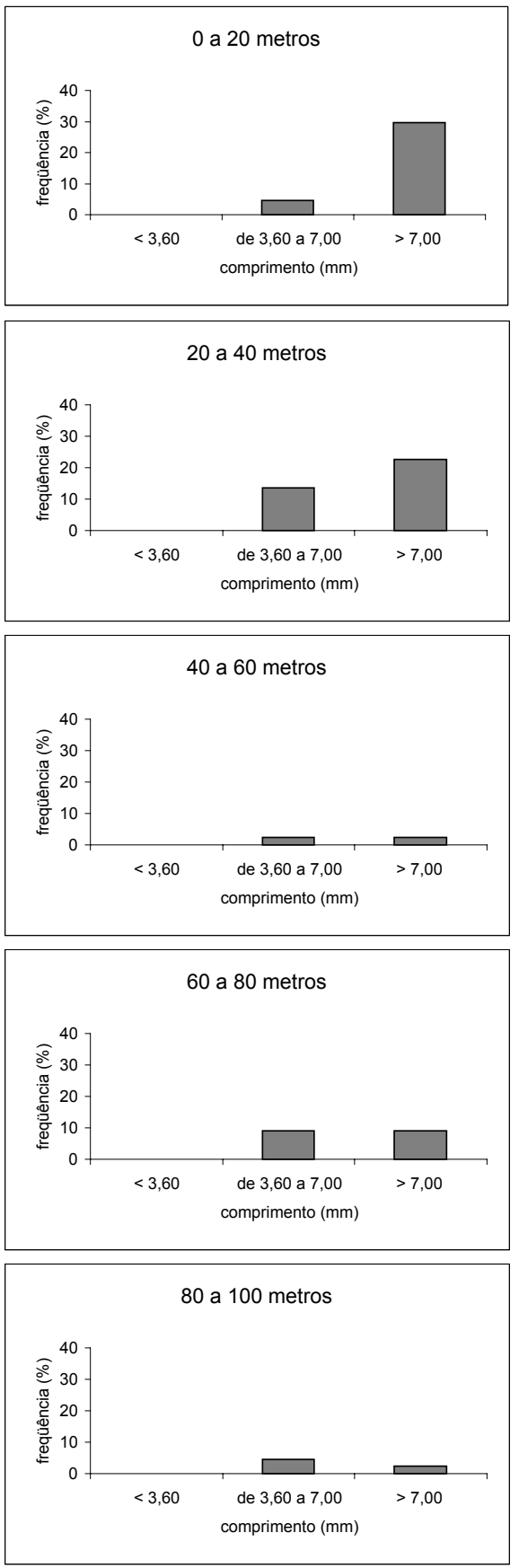

estações oceânicas ( $n=8)$

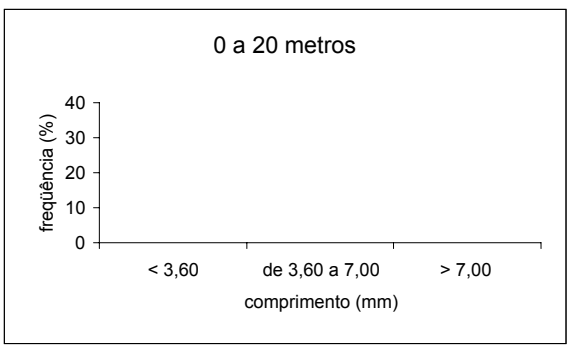

20 a 40 metros
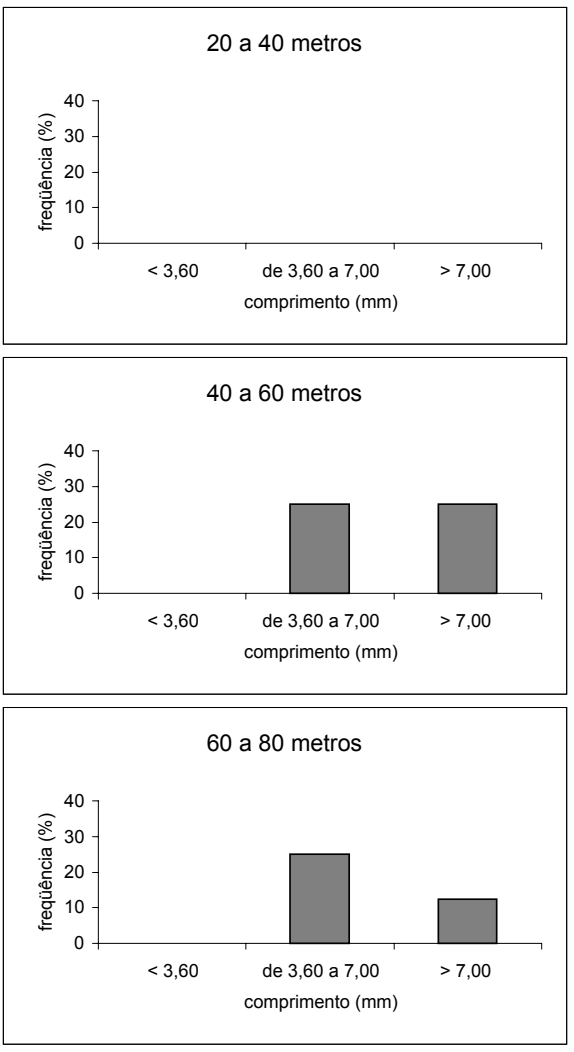

80 a 100 metros

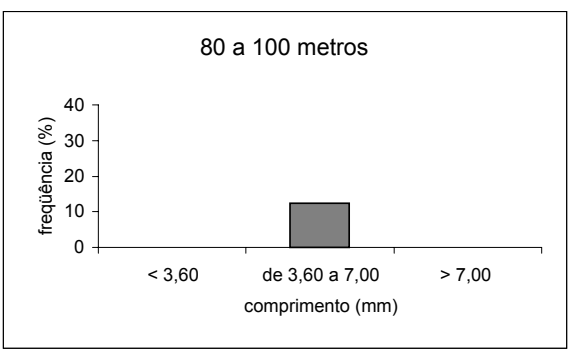

Figura 60. Pollichthys mauli: distribuição da freqüência relativa nerítica e oceânica de larvas por classe de comprimento nos estratos amostrados no verão de 2001, na região do cabo Frio (RJ) (< 3,60mm: pré-flexão; 3,60 a 7,00mm: flexão; > 7,00: pós-flexão (Fahay, 1983)). 
estações diurnas $(n=14)$
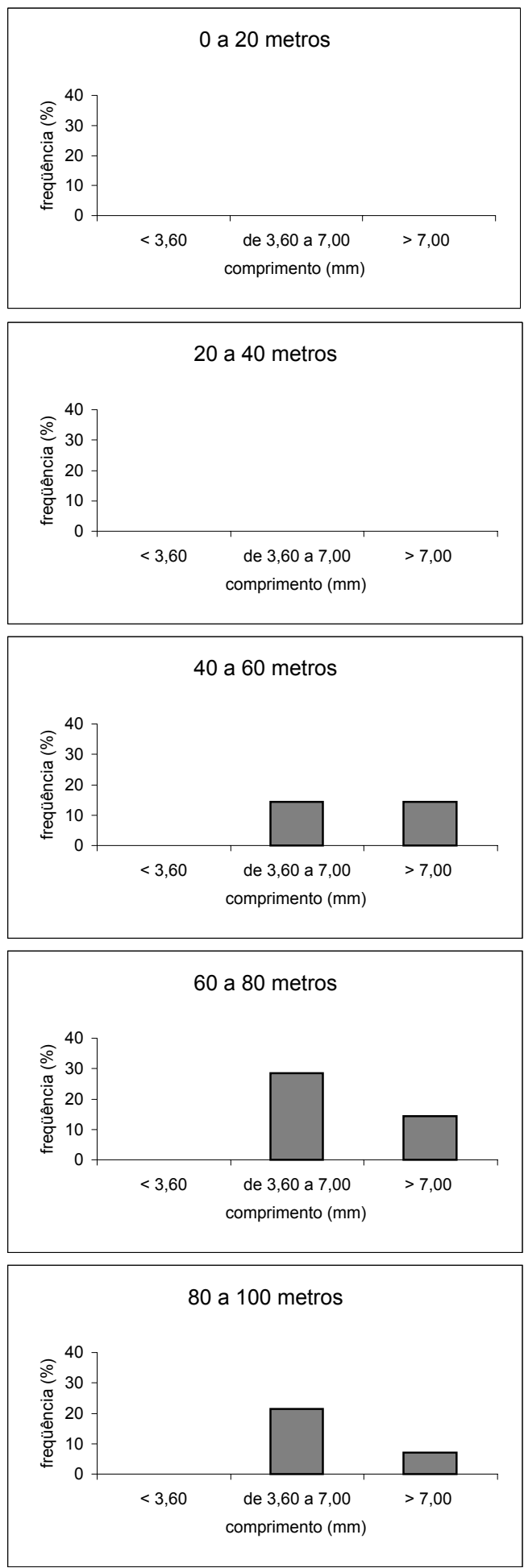

estações noturnas $(n=38)$
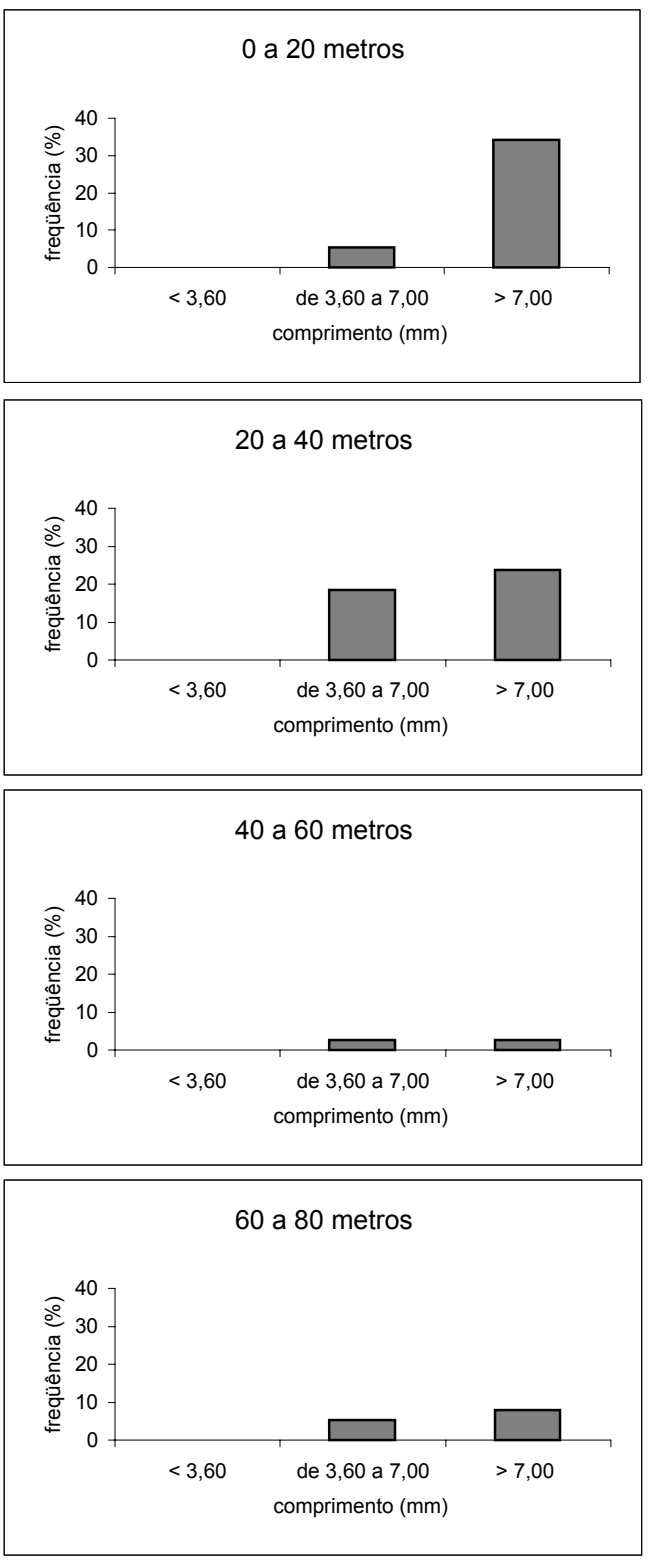

80 a 100 metros

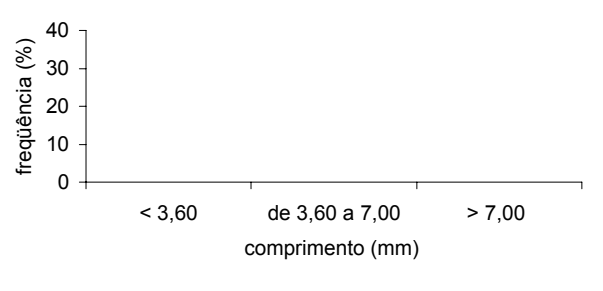

Figura 61. Pollichthys mauli: distribuição da freqüência relativa diurna e noturna de larvas por classe de comprimento nos estratos amostrados no verão de 2001 , na região do cabo Frio (RJ) (<3,60mm: pré-flexão; 3,60 a 7,00mm: flexão; > 7,00: pós-flexão (Fahay, 1983)). 


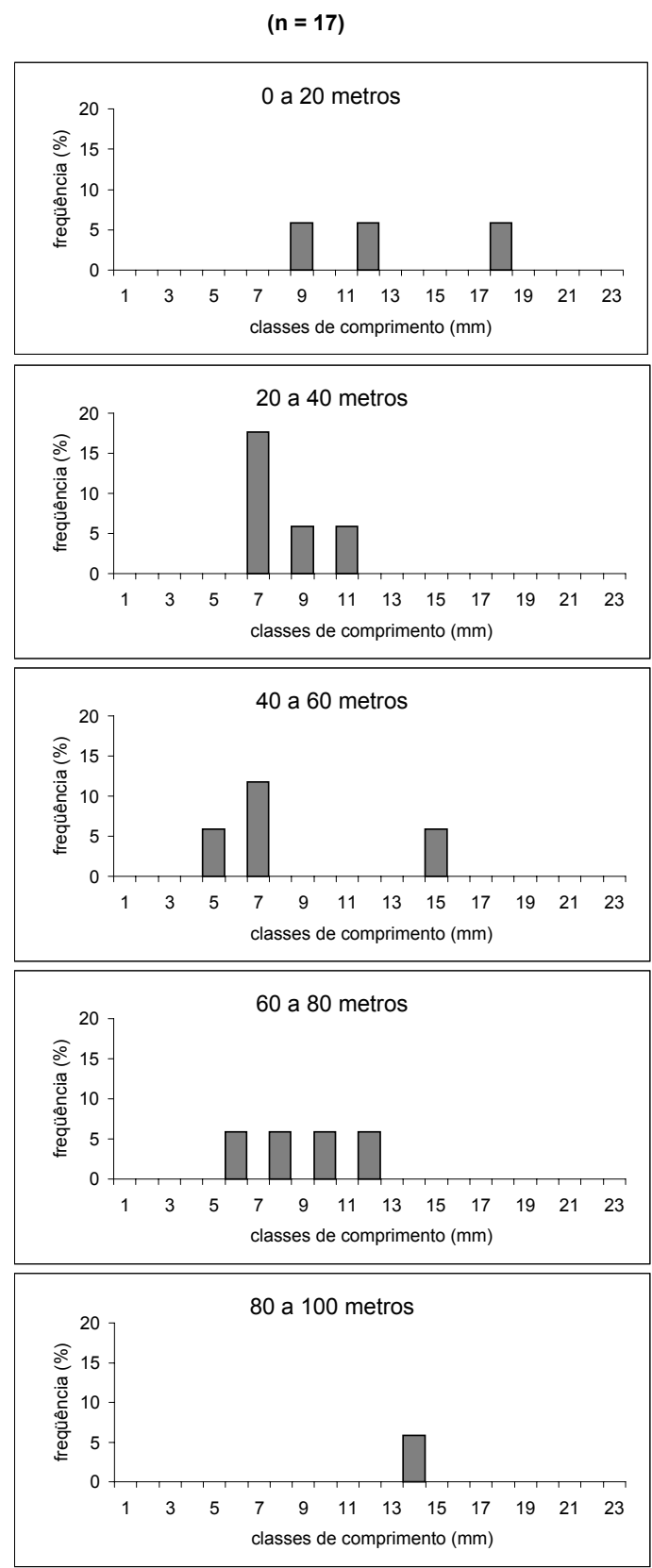

Figura 62. Pollichthys mauli : distribuição da freqüência relativa total de larvas por classe de comprimento nos estratos amostrados no inverno de 2001, na região do cabo Frio (RJ). 
estações neríticas $(n=5)$
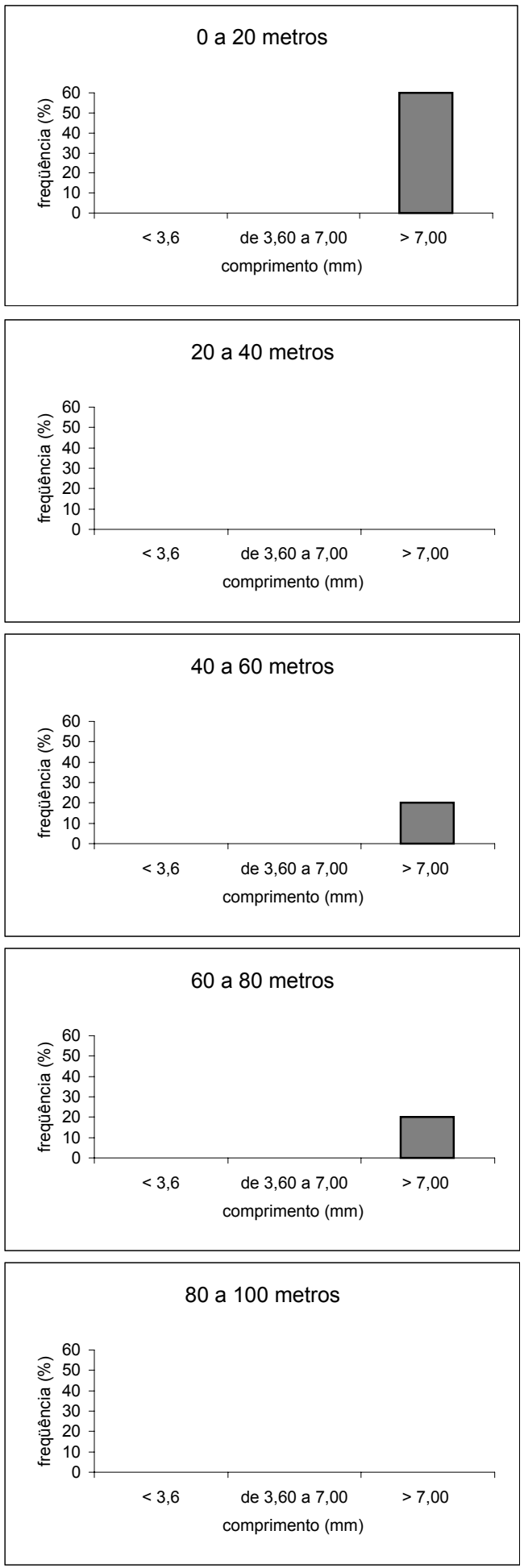

estações oceânicas $(n=12)$
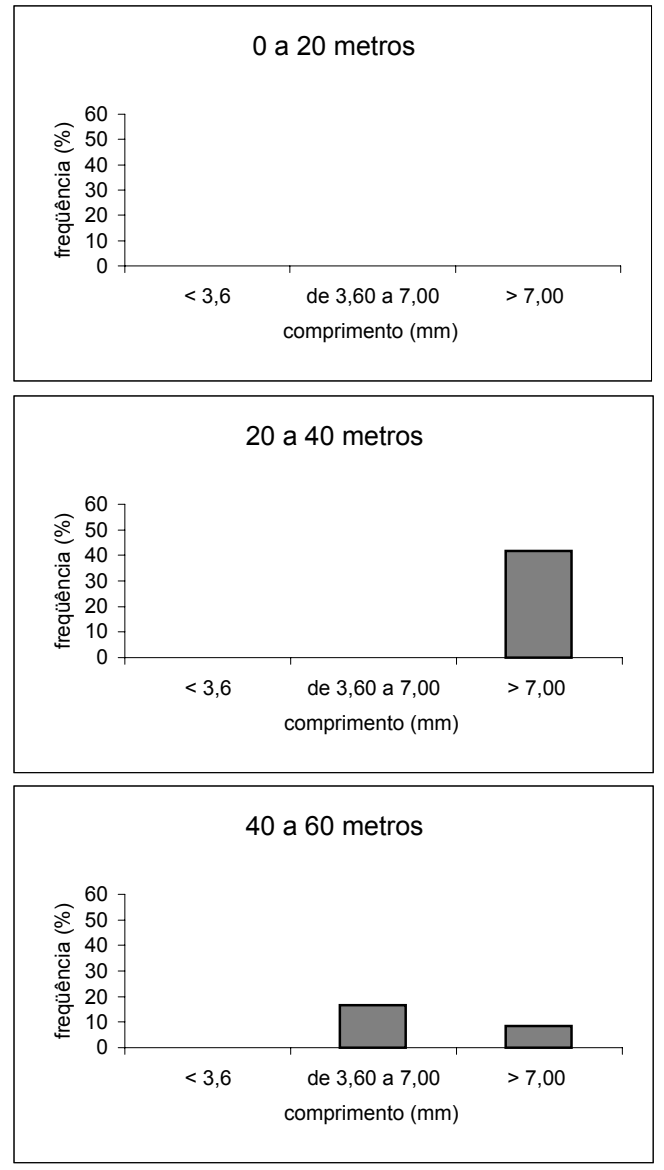

60 a 80 metros

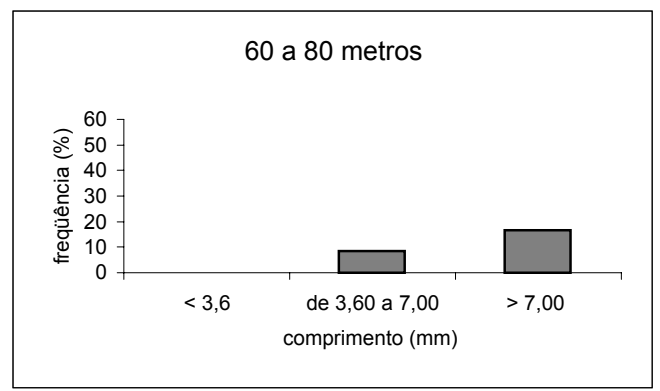

80 a 100 metros

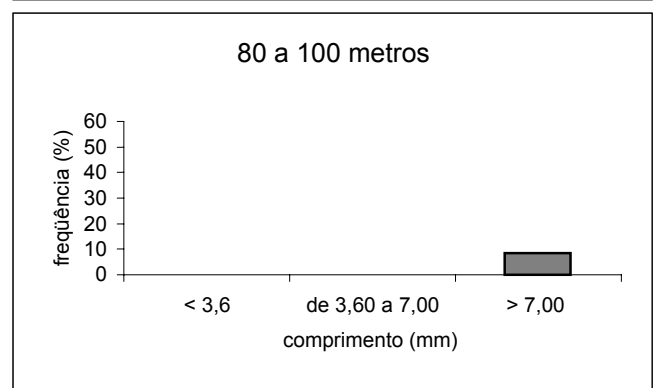

Figura 63. Pollichthys mauli: distribuição da freqüência relativa nerítica e oceânica de larvas por classe de comprimento nos estratos amostrados no inverno de 2001, na região do cabo Frio (RJ) (<3,60mm: pré-flexão; 3,60 a 7,00mm: flexão; > 7,00: pós-flexão (Fahay, 1983)). 

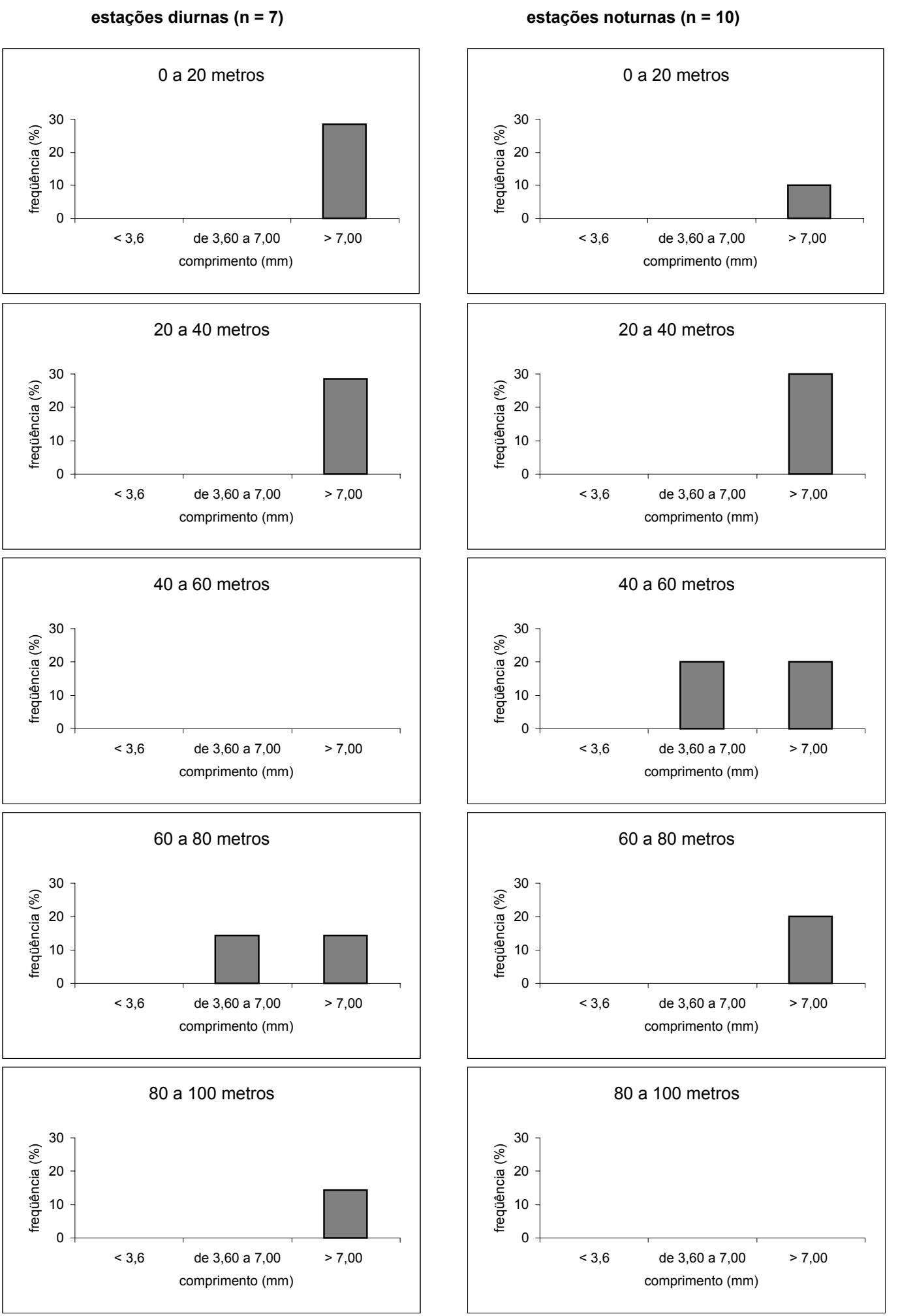

Figura 64. Pollichthys mauli: distribuição da freqüência relativa diurna e noturna de larvas por classe de comprimento nos estratos amostrados no verão de 2001 , na região do cabo Frio (RJ) (<3,60mm: pré-flexão; 3,60 a 7,00mm: flexão; > 7,00: pós-flexão (Fahay, 1983)). 

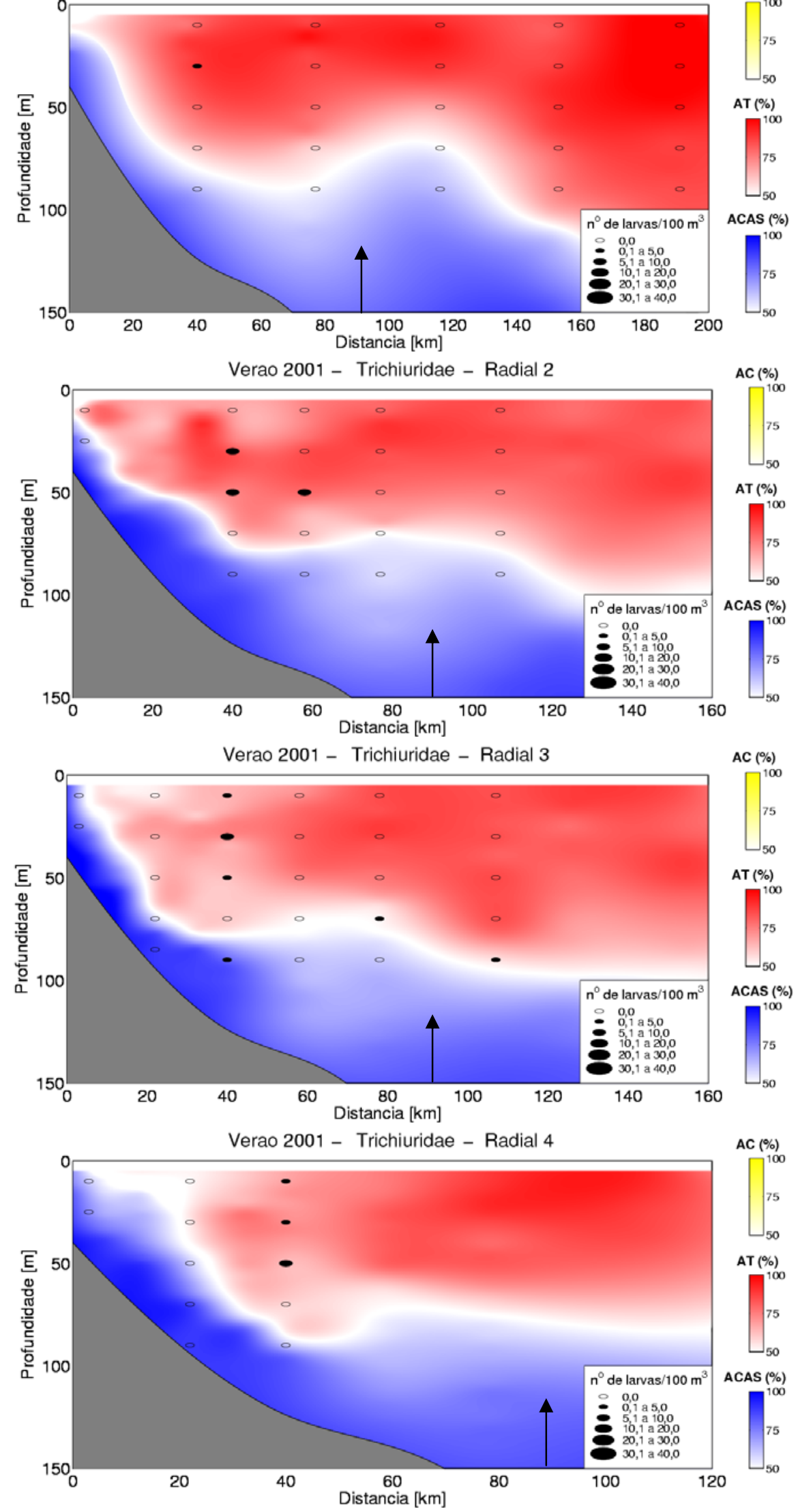

Figura 65. Distribuição espacial de larvas de Trichiuridae coletadas no verão de 2001 , na região do cabo Frio (RJ). A seta no eixo inferior separa as 

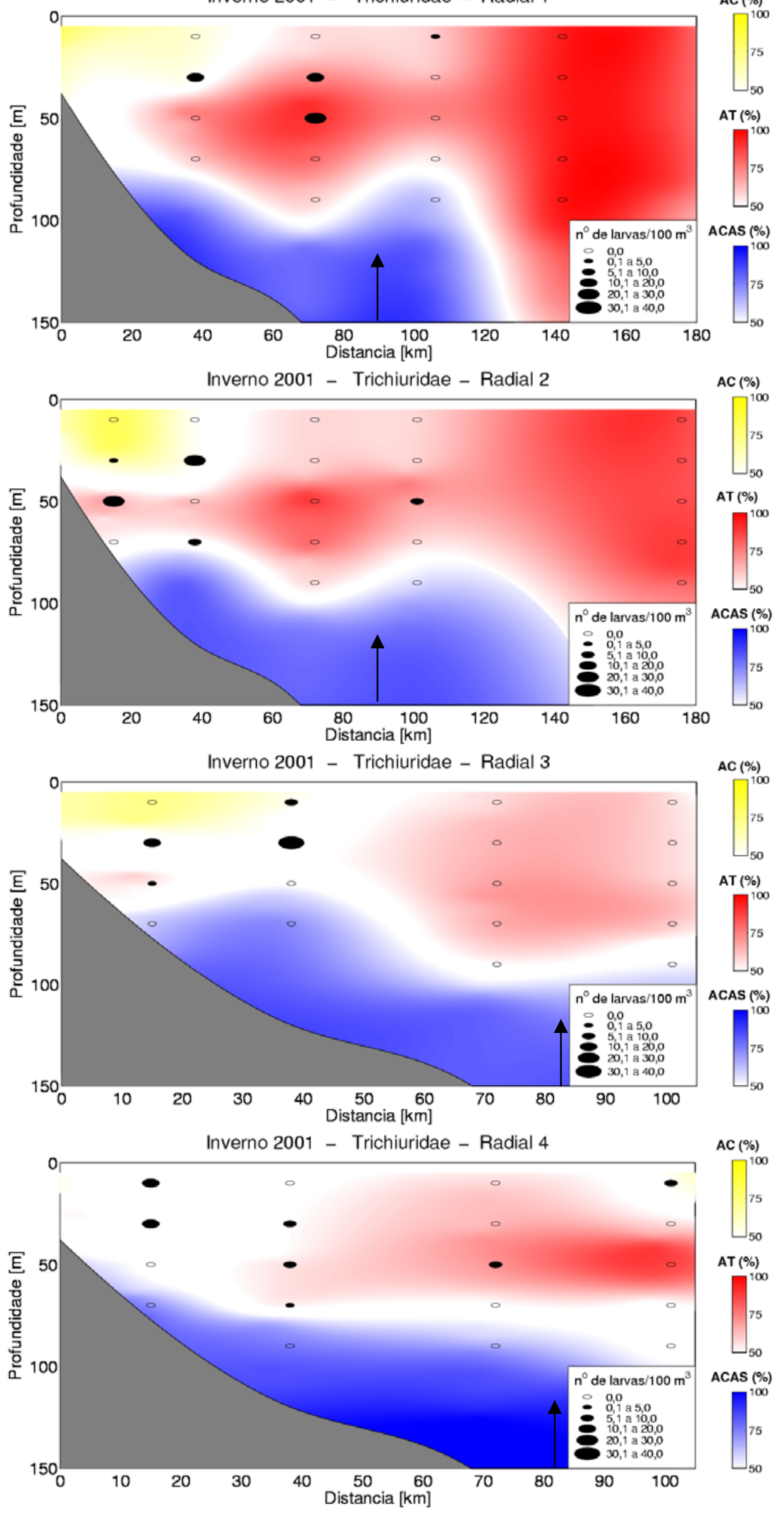

Figura 66. Distribuição espacial de larvas de Trichiuridae coletadas no inverno de 2001. na reaião do cabo Frio (RJ). A seta no eixo inferior separa 


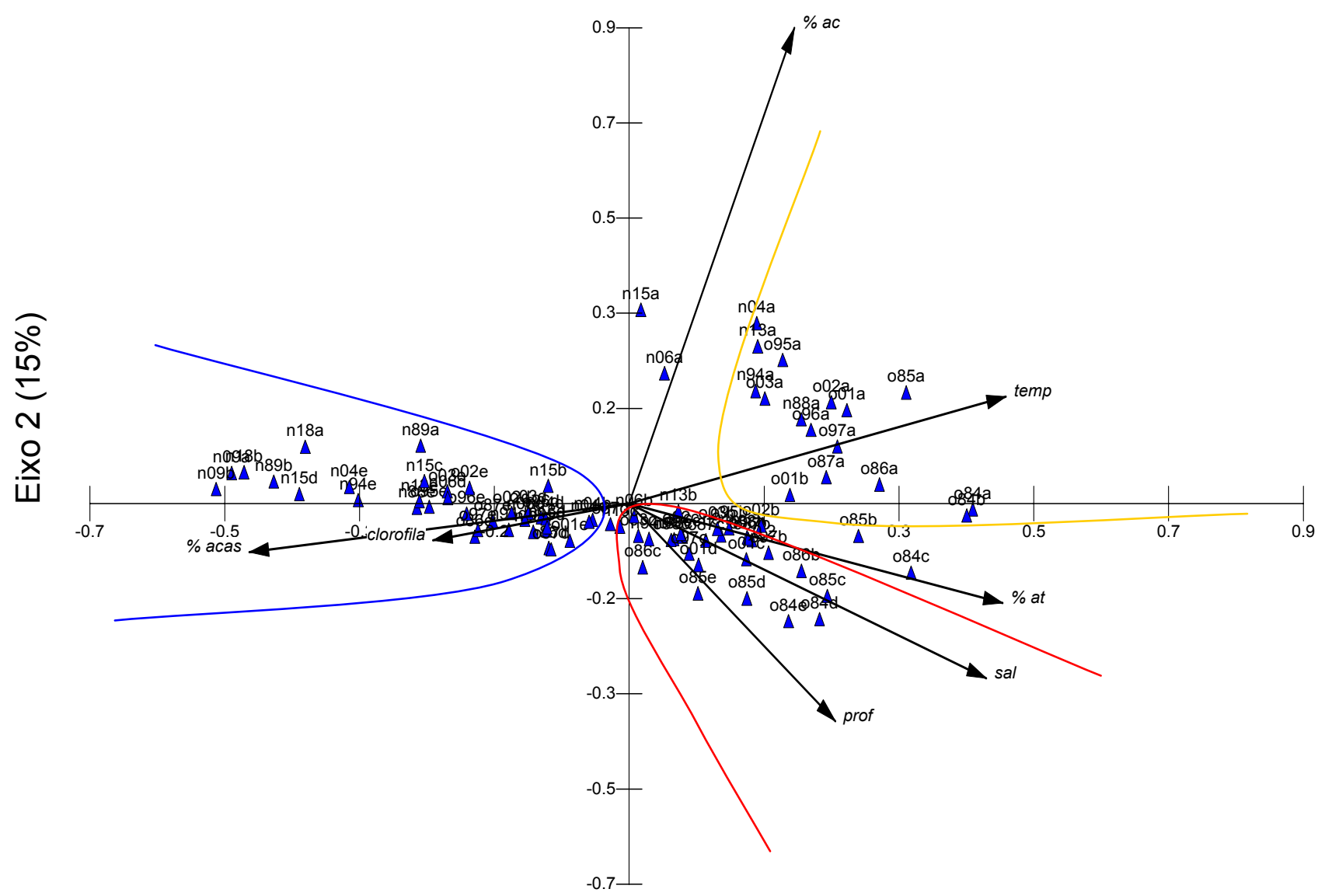

Eixo $1(62 \%)$

Vector scaling: 1.05

Figura 67. Diagrama de ordenação da Análise de Componentes Principais, em função das variáveis ambientais, das amostras do cruzeiro de verão de 2001 , na região do cabo Frio (RJ). 


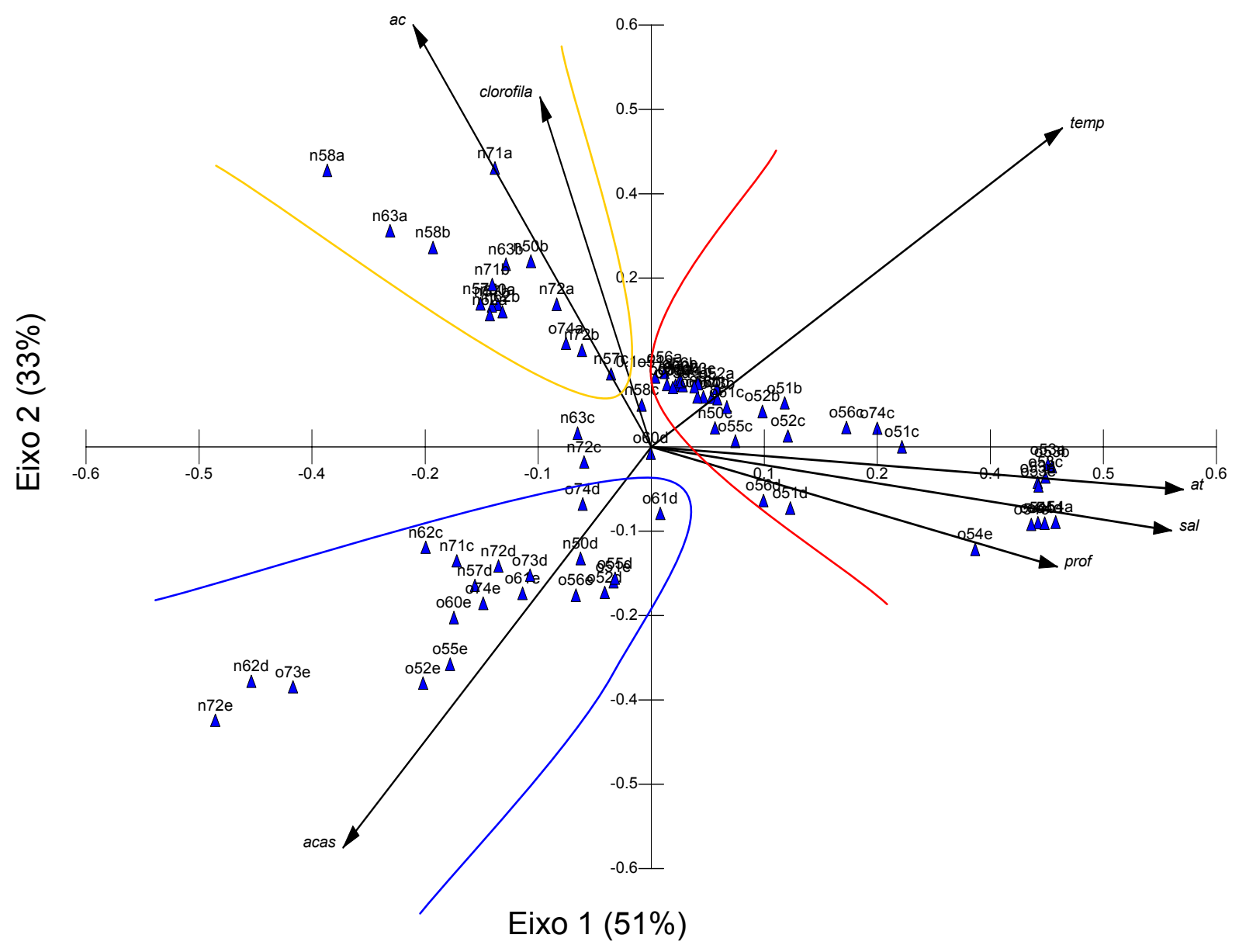

Vector scaling: 1.11

Figura 68. Diagrama de ordenação da Análise de Componentes Principais, em função das variáveis ambientais, das amostras do cruzeiro de inverno de 2001, na região do cabo Frio (RJ). 

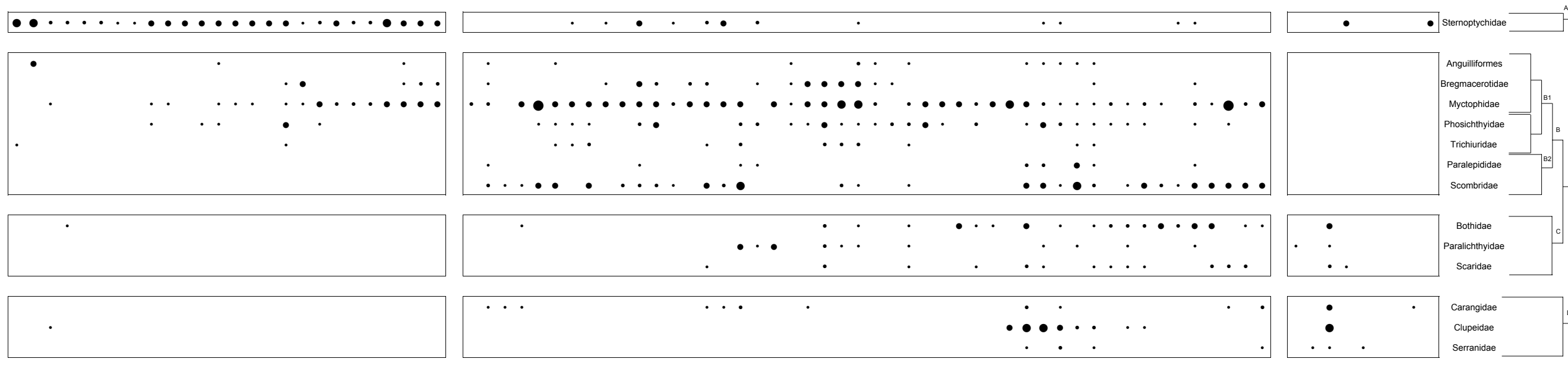

Carangidae
Clupeidae
Serranidae
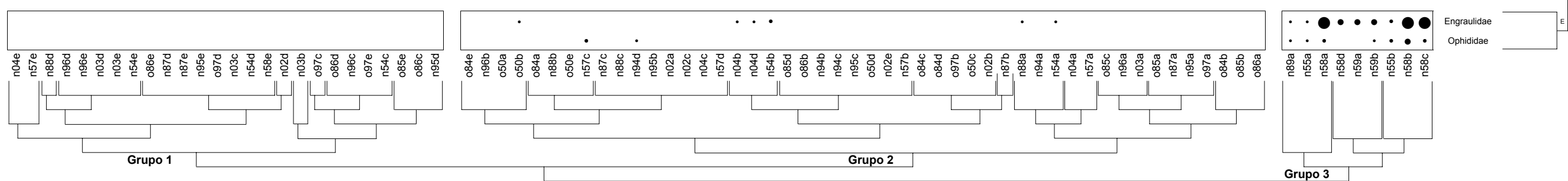

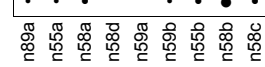

Grupo 1

Grupo 2 


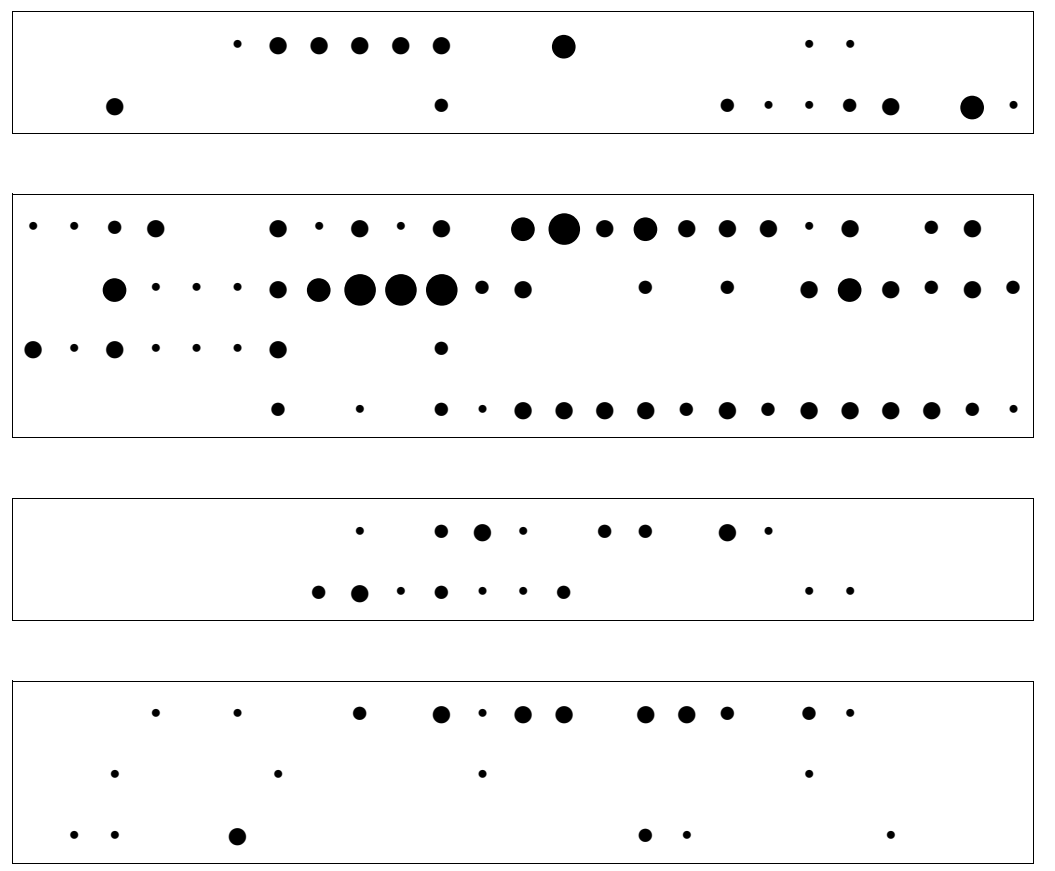

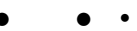

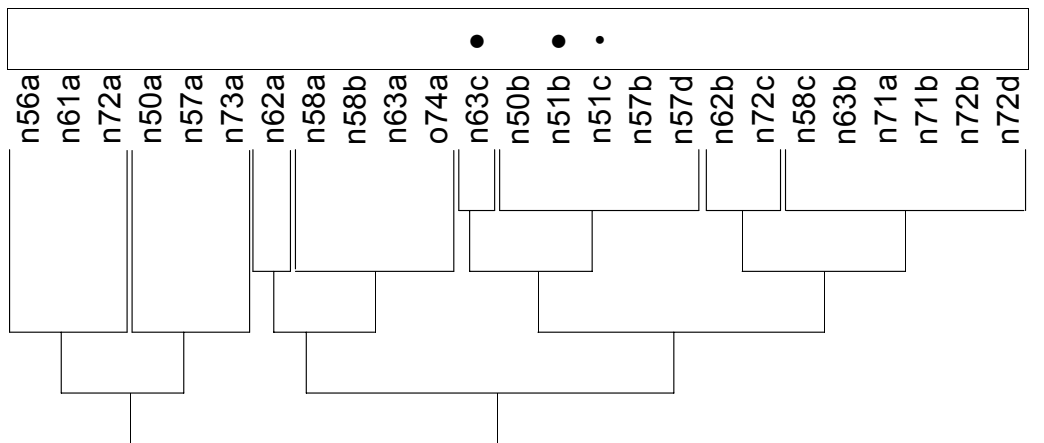

Grupo 1
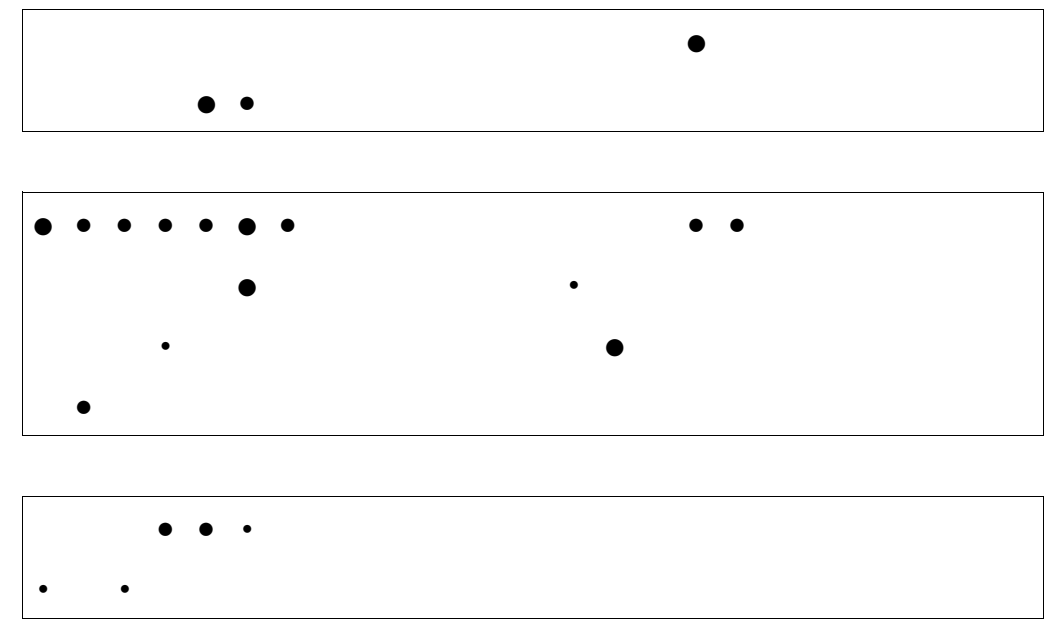

$\bullet \bullet \bullet \bullet \bullet \bullet \bullet \bullet \bullet \bullet \bullet$

............

$\bullet \bullet \bullet \bullet \bullet \bullet \bullet \bullet$

$\bullet \bullet \bullet$

- $\bullet \bullet$

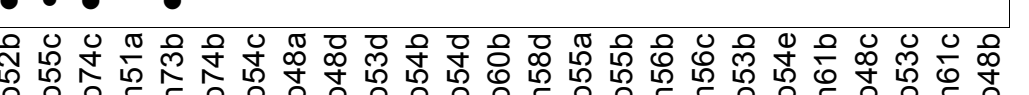

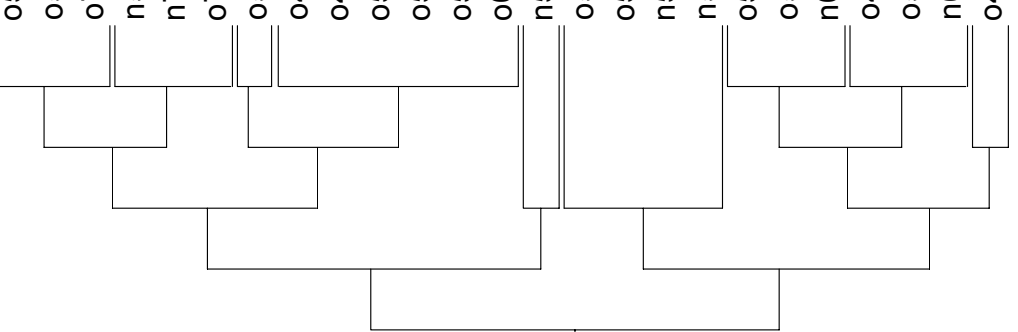

Grupo 2

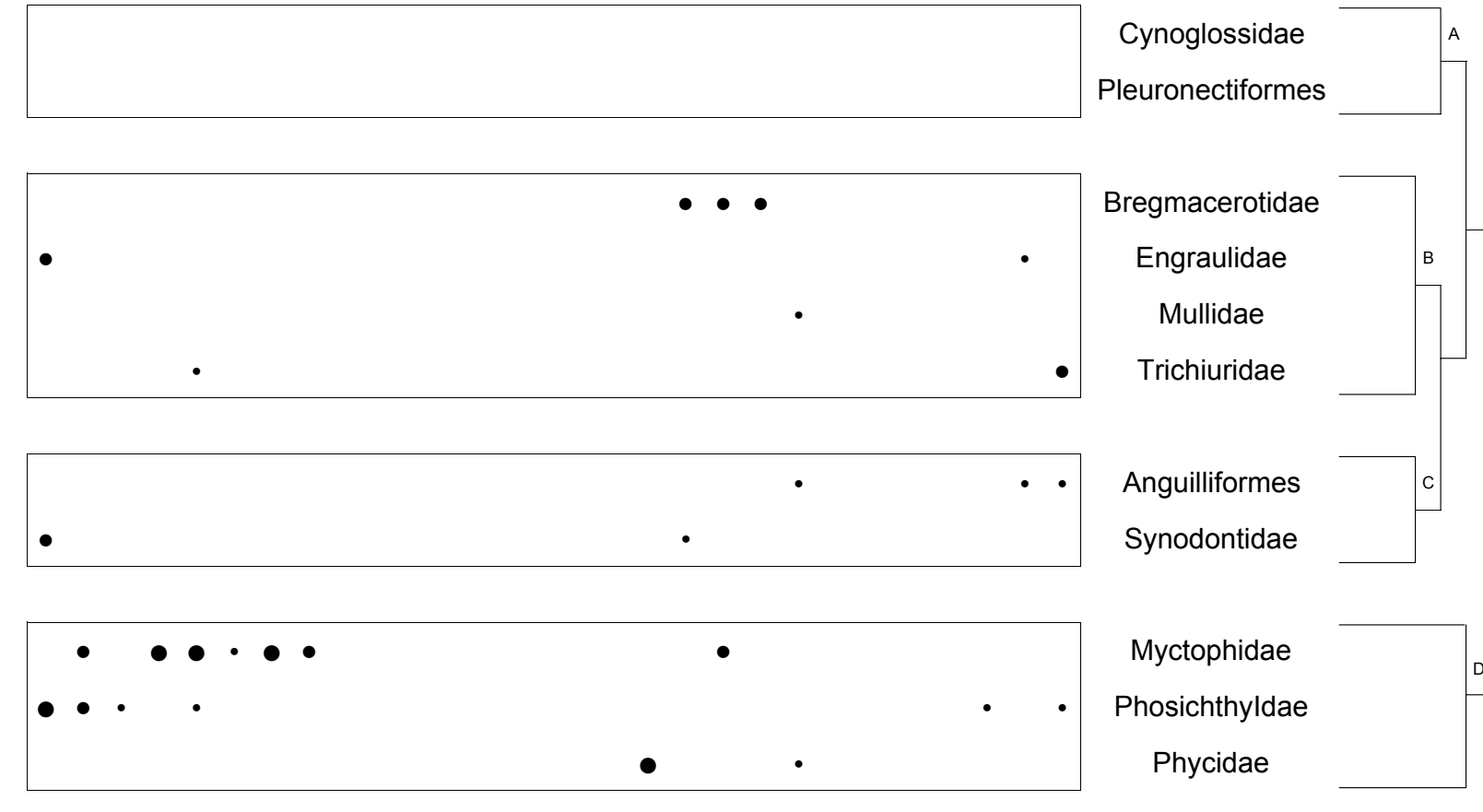

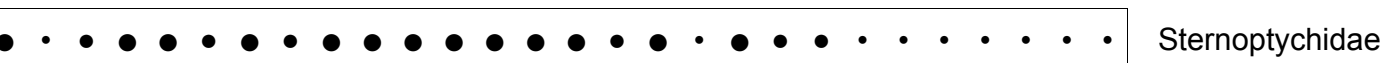

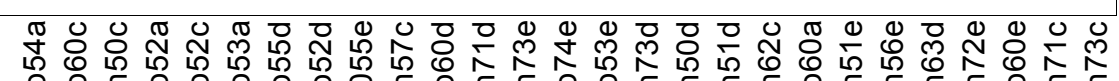

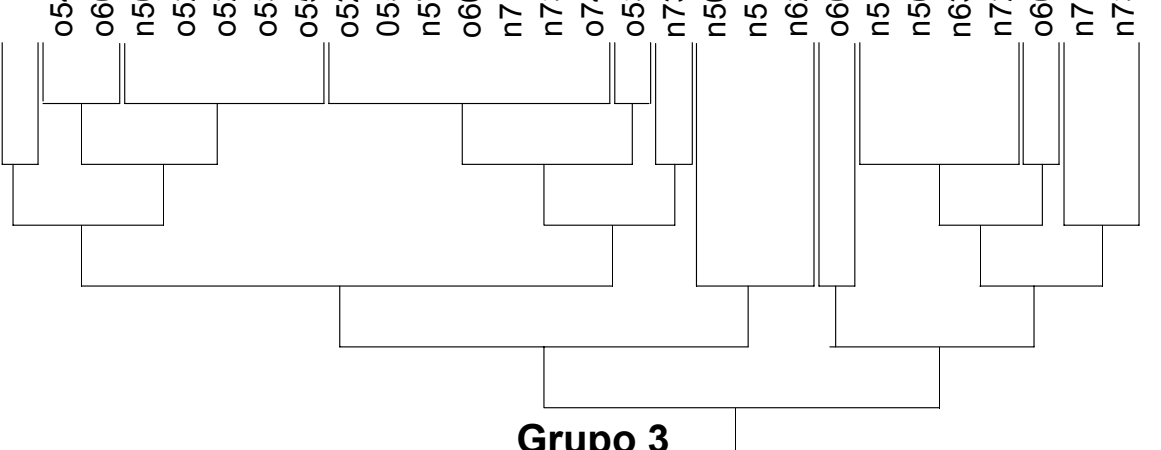

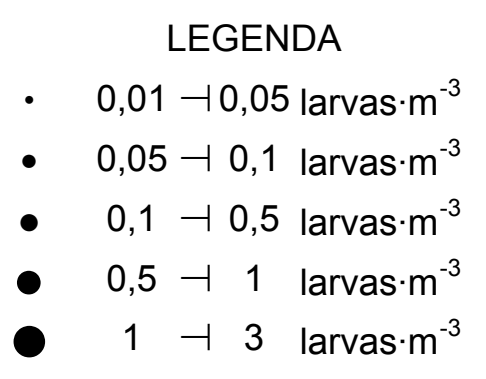

Figura 70. Análise de classificação TWINSPAN, do cruzeiro de inverno de 2001, na região do cabo Frio (RJ) 
Apêndice 1. Dados gerais das estações oceanográficas do Projeto DEPROAS realizadas durante o cruzeiro de verão de 2001, na região do cabo Frio $(\mathrm{RJ})$.

\begin{tabular}{cccccccccc}
\hline Radial & $\begin{array}{c}\text { Número da } \\
\text { estação }\end{array}$ & \multicolumn{2}{c}{$\begin{array}{c}\text { Latitude S } \\
\circ\end{array}$} & $\begin{array}{c}\text { Longitude W } \\
\text { o }\end{array}$ & , & Data & $\begin{array}{c}\text { Profundidade } \\
\text { local }(\mathrm{m})\end{array}$ & $\begin{array}{c}\text { Horário } \\
\text { local }\end{array}$ & $\begin{array}{c}\text { Horário da } \\
\text { Multinet }\end{array}$ \\
\hline 1 & 84 & 24 & 33,20 & 41 & 23,10 & $7 / 2 / 2001$ & 2474 & $12: 55$ & $19: 55$ \\
1 & 85 & 24 & 14,10 & 41 & 31,10 & $8 / 2 / 2001$ & 1960 & $06: 35$ & $10: 18$ \\
1 & 86 & 23 & 55,00 & 41 & 38,80 & $8 / 2 / 2001$ & 1191 & $13: 05$ & $14: 47$ \\
1 & 87 & 23 & 36,00 & 41 & 47,60 & $8 / 2 / 2001$ & 160 & $18: 40$ & $20: 48$ \\
1 & 88 & 23 & 17,20 & 41 & 56,10 & $8 / 2 / 2001$ & 120 & $04: 10$ & $05: 12$ \\
2 & 89 & 22 & 58,50 & 42 & 3,30 & $9 / 2 / 2001$ & 40 & $08: 35$ & $10: 19$ \\
2 & 94 & 23 & 17,30 & 41 & 56,20 & $9 / 2 / 2001$ & 123 & $18: 00$ & $20: 05$ \\
2 & 95 & 23 & 26,50 & 41 & 51,90 & $9 / 2 / 2001$ & 142 & $22: 45$ & $23: 28$ \\
2 & 96 & 23 & 35,90 & 41 & 47,50 & $10 / 2 / 2001$ & 160 & $02: 14$ & $03: 27$ \\
2 & 97 & 23 & 50,80 & 41 & 41,10 & $10 / 2 / 2001$ & 713 & $06: 00$ & $07: 06$ \\
3 & 01 & 23 & 50,80 & 41 & 41,10 & $11 / 2 / 2001$ & 708 & $10: 50$ & $12: 45$ \\
3 & 02 & 23 & 36,00 & 41 & 47,50 & $11 / 2 / 2001$ & 161 & $15: 10$ & $16: 48$ \\
3 & 03 & 23 & 26,50 & 41 & 51,90 & $11 / 2 / 2001$ & 145 & $19: 14$ & $20: 57$ \\
3 & 04 & 23 & 17,30 & 41 & 56,20 & $11 / 2 / 2001$ & 122 & $22: 50$ & $23: 42$ \\
3 & 05 & 23 & 8,20 & 41 & 59,60 & $12 / 2 / 2001$ & 116 & $02: 55$ & $04: 45$ \\
3 & 09 & 22 & 58,50 & 42 & 3,30 & $12 / 2 / 2001$ & 40 & $08: 10$ & $08: 57$ \\
4 & 13 & 23 & 17,30 & 41 & 56,20 & $12 / 2 / 2001$ & 123 & $23: 45$ & $01: 02$ \\
4 & 15 & 23 & 8,30 & 41 & 59,70 & $13 / 2 / 2001$ & 113 & $03: 10$ & $03: 38$ \\
4 & 18 & 22 & 58,50 & 42 & 3,30 & $13 / 2 / 2001$ & 35,8 & $08: 15$ & $09: 25$ \\
\hline
\end{tabular}

Apêndice 2. Dados gerais das estações oceanográficas do Projeto DEPROAS realizadas durante o cruzeiro de inverno de 2001, na região do cabo Frio (RJ).

\begin{tabular}{cccccccccc}
\hline Radial & $\begin{array}{c}\text { Número da } \\
\text { estação }\end{array}$ & \multicolumn{2}{c}{$\begin{array}{c}\text { Latitude S } \\
\circ\end{array}$} & $\begin{array}{c}\text { Longitude W } \\
\text { o }\end{array}$ & , & Data & $\begin{array}{c}\text { Profundidade } \\
\text { local }(\mathrm{m})\end{array}$ & $\begin{array}{c}\text { Horário } \\
\text { local }\end{array}$ & $\begin{array}{c}\text { Horário da } \\
\text { Multinet }\end{array}$ \\
\hline 1 & 50 & 23 & 16,00 & 41 & 55,70 & $14 / 7 / 2001$ & 115 & $18: 00$ & $18: 44$ \\
1 & 51 & 23 & 33,00 & 41 & 47,50 & $14 / 7 / 2001$ & 153 & $22: 10$ & $22: 56$ \\
1 & 52 & 23 & 50,00 & 41 & 40,00 & $15 / 7 / 2001$ & 826 & $6: 30$ & $08: 07$ \\
1 & 53 & 24 & 7,50 & 41 & 31,80 & $15 / 7 / 2001$ & 1669 & $11: 50$ & $14: 10$ \\
2 & 54 & 24 & 24,80 & 41 & 23,90 & $15 / 7 / 2001$ & 2247 & $16: 55$ & $19: 26$ \\
2 & 55 & 23 & 47,28 & 41 & 41,00 & $16 / 7 / 2001$ & 361 & $6: 30$ & $08: 34$ \\
2 & 56 & 23 & 33,00 & 41 & 47,50 & $16 / 7 / 2001$ & 153 & $13: 00$ & $13: 54$ \\
2 & 57 & 23 & 16,00 & 41 & 55,70 & $16 / 7 / 2001$ & 116 & $16: 50$ & $17: 31$ \\
2 & 58 & 23 & 4,60 & 42 & 0,80 & $16 / 7 / 2001$ & 100 & $19: 48$ & $20: 24$ \\
3 & 60 & 23 & 47,28 & 41 & 41,00 & $17 / 7 / 2001$ & 256 & $7: 00$ & $08: 17$ \\
3 & 61 & 23 & 33,00 & 41 & 47,50 & $17 / 7 / 2001$ & 151 & $12: 00$ & $12: 43$ \\
3 & 62 & 23 & 16,00 & 41 & 55,70 & $17 / 7 / 2001$ & 116 & $16: 45$ & $17: 36$ \\
3 & 63 & 23 & 4,60 & 42 & 0,80 & $17 / 7 / 2001$ & 100 & $19: 50$ & $20: 40$ \\
4 & 71 & 23 & 4,60 & 42 & 0,80 & $19 / 7 / 2001$ & 102 & $8: 53$ & $09: 03$ \\
4 & 72 & 23 & 16,00 & 41 & 55,70 & $19 / 7 / 2001$ & 117 & $11: 52$ & $12: 00$ \\
4 & 73 & 23 & 32,90 & 41 & 47,40 & $19 / 7 / 2001$ & 155 & $15: 20$ & $15: 50$ \\
4 & 74 & 23 & 47,28 & 41 & 41,00 & $19 / 7 / 2001$ & 255 & $18: 30$ & $19: 10$ \\
\hline
\end{tabular}


Apêndice 3. Lista filogenética (segundo Nelson, 1994) dos grupos identificados nos cruzeiros de verão e inverno de 2001 do projeto DEPROAS, na região do cabo Frio (RJ).

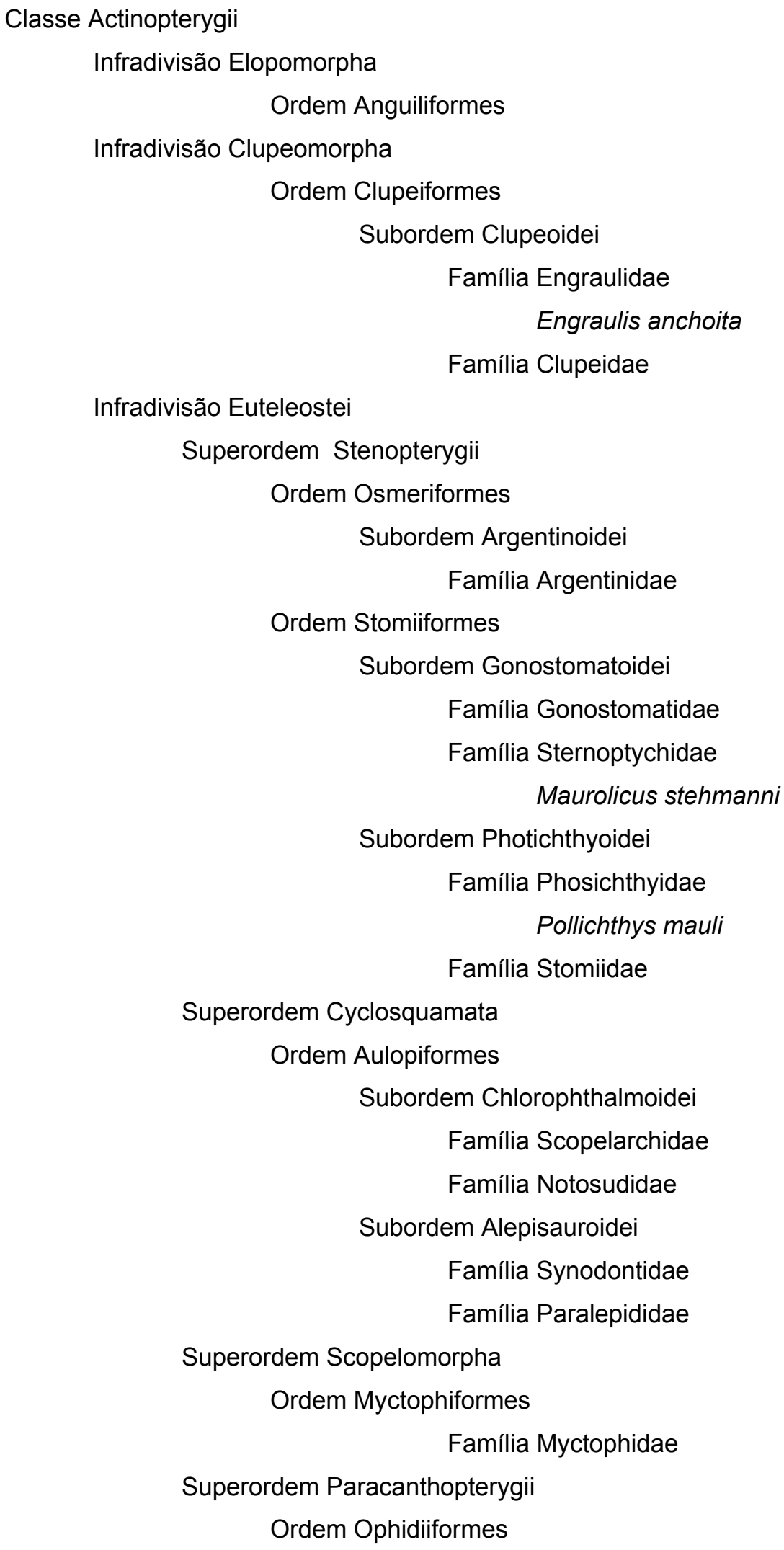


Família Ophidiidae

Ordem Gadiformes

Família Macrouridae

Família Moridae

Família Bregmacerotidae

Bregmaceros atlanticus

Bregmaceros cantori

Família Phycidae

Ordem Lophiiformes

Subordem Lophioidei

Família Lophiidae

Superordem Acanthopterygii

Ordem Mugiliformes

Família Mugilidae

Ordem Beloniformes

Subordem Belonoidei

Família Hemiramphidae

Ordem Stephanoberyciformes

Família Melamphaidae

Ordem Beryciformes

Subordem Holocentroidei

Família Holocentridae

Ordem Gasterosteiformes

Subordem Syngnathoidei

Família Syngnathidae

Família Fistulariidae

Ordem Scorpaeniformes

Subordem Dactylopteroidei

Família Dactylopteridae

Subordem Scorpaenoidei

Família Scorpaenidae

Família Triglidae

Ordem Perciformes

Subordem Percoidei

Família Acropomatidae

Família Serranidae

Família Priacanthidae

Família Malacanthidae

Família Echeneidae

Família Carangidae 
Família Lutjanidae

Família Gerreidae

Família Sparidae

Família Sciaenidae

Família Mullidae

Família Chaetodontidae

Família Pomacanthidae

Subordem Labroidei

Família Labridae

Família Scaridae

Subordem Trachinoidei

Família Pinguipedidae

Família Uranoscopidae

Subordem Blennioidei

Família Blenniidae

Subordem Callionymoidei

Família Callionymidae

Subordem Gobioidei

Família Gobiidae

Subordem Acanthuroidei

Família Acanthuridae

Subordem Scombroidei

Família Gempylidae

Família Trichiuridae

Família Scombridae

Subordem Stromateoidei

Família Nomeidae

Família Stromateidae

Ordem Pleuronectiformes

Subordem Pleuronectoidei

Família Bothidae

Família Paralichthyidae

Família Cynoglossidae

Ordem Tetraodontiformes

Subordem Tetraodontoidei

Família Balistidae

Família Monacanthidae

Família Ostraciidae

Família Tetraodontidae 
Apêndice 4. Estimativa da densidade (larvas. $100 \mathrm{~m}^{-0}$ ) dos grupos taxonômicos com freqüência de ocorrência inferior a $30 \%$ nos diferentes estratos amostrados com a rede Multinet durante o cruzeiro de verão de 2001, na região do cabo Frio.

\begin{tabular}{|c|c|c|c|c|c|c|c|c|c|c|c|c|c|c|c|c|c|c|c|}
\hline 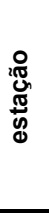 & 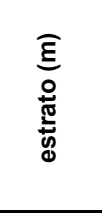 & 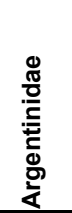 & 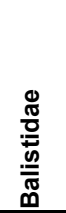 & 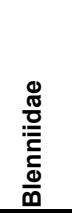 & 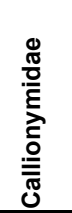 & \begin{tabular}{l}
$\frac{8}{\pi}$ \\
$\frac{\pi}{0}$ \\
\hdashline$\frac{0}{2}$ \\
$\frac{\pi}{\pi}$ \\
0 \\
0
\end{tabular} & 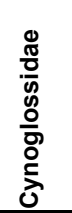 & 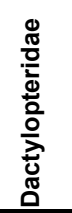 & 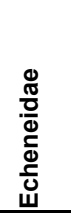 & 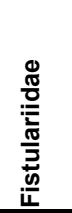 & 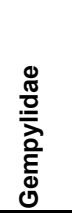 & $\begin{array}{l}0 \\
\frac{\pi}{0} \\
: 0 \\
0 \\
0 \\
0\end{array}$ & $\begin{array}{l}0 \\
\frac{\pi}{0} \\
0 \\
0 \\
0\end{array}$ & 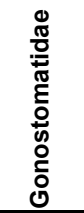 & 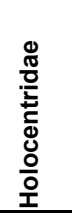 & $\begin{array}{l}\frac{0}{\pi} \\
\frac{\pi}{0} \\
\frac{0}{0} \\
\text { J }\end{array}$ & $\begin{array}{l}\frac{0}{\pi} \\
\frac{\pi}{0} \\
\frac{1}{2} \\
\frac{2}{0} \\
\end{array}$ & 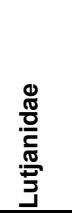 & 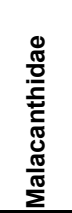 \\
\hline \multirow[t]{5}{*}{84} & $0-20$ & 0,00 & 0,00 & 0,00 & 0,00 & 0,00 & 0,00 & 0,00 & 0,00 & 0,00 & 0,00 & 0,00 & 0,00 & 0,00 & 0,00 & 0,00 & 0,00 & 0,00 & 0,00 \\
\hline & $20-40$ & 0,00 & 0,00 & 0,00 & 0,00 & 0,00 & 0,00 & 0,00 & 0,00 & 0,00 & 0,00 & 0,00 & 0,00 & 20,65 & 0,00 & 0,00 & 0,00 & 0,00 & 0,00 \\
\hline & $40-60$ & 0,00 & 0,00 & 0,00 & 0,00 & 0,00 & 0,00 & 0,00 & 0,00 & 0,00 & 0,00 & 0,00 & 0,00 & 0,00 & 0,00 & 0,00 & 0,00 & 0,00 & 0,00 \\
\hline & $60-80$ & 0,00 & 0,00 & 0,00 & 2,77 & 0,00 & 0,00 & 0,00 & 0,00 & 0,00 & 0,00 & 0,00 & 0,00 & 8,30 & 0,00 & 0,00 & 0,00 & 0,00 & 0,00 \\
\hline & $80-100$ & 0,00 & 0,00 & 0,00 & 0,00 & 0,00 & 0,00 & 0,00 & 0,00 & 0,00 & 0,00 & 0,00 & 0,00 & 0,00 & 0,00 & 0,00 & 0,00 & 0,00 & 0,00 \\
\hline \multirow[t]{5}{*}{85} & $0-20$ & 0,00 & 0,00 & 0,00 & 0,00 & 0,00 & 0,00 & 2,22 & 0,00 & 0,00 & 0,00 & 0,00 & 0,00 & 0,00 & 2,22 & 0,00 & 0,00 & 0,00 & 0,00 \\
\hline & $20-40$ & 0,00 & 0,00 & 0,00 & 0,00 & 0,00 & 0,00 & 0,00 & 0,00 & 0,00 & 0,00 & 0,00 & 0,00 & 0,00 & 0,00 & 0,00 & 3,38 & 0,00 & 0,00 \\
\hline & $40-60$ & 0,00 & 0,00 & 0,00 & 0,00 & 0,00 & 0,00 & 0,00 & 0,00 & 0,00 & 0,00 & 0,00 & 0,00 & 0,00 & 0,00 & 2,59 & 0,00 & 0,00 & 0,00 \\
\hline & $60-80$ & 0,00 & 0,00 & 0,00 & 0,00 & 0,00 & 0,00 & 0,00 & 0,00 & 0,00 & 0,00 & 0,00 & 0,00 & 0,00 & 0,00 & 0,00 & 0,00 & 0,00 & 0,00 \\
\hline & $80-100$ & 0,00 & 0,00 & 0,00 & 1,24 & 0,00 & 0,00 & 0,00 & 0,00 & 0,00 & 0,00 & 0,00 & 0,00 & 0,00 & 0,00 & 0,00 & 0,00 & 0,00 & 0,00 \\
\hline \multirow[t]{5}{*}{86} & $0-20$ & 0,00 & 0,00 & 0,00 & 0,00 & 0,00 & 0,00 & 1,87 & 0,00 & 0,00 & 0,00 & 0,00 & 0,00 & 0,00 & 0,94 & 0,00 & 0,00 & 0,00 & 0,00 \\
\hline & $20-40$ & 0,00 & 0,00 & 0,00 & 0,00 & 0,00 & 0,00 & 0,00 & 0,00 & 0,00 & 0,00 & 0,00 & 0,00 & 0,00 & 0,00 & 0,00 & 0,00 & 0,00 & 0,00 \\
\hline & $40-60$ & 0,00 & 0,00 & 0,00 & 0,00 & 0,00 & 0,00 & 0,00 & 0,00 & 0,00 & 0,00 & 0,00 & 0,00 & 0,00 & 0,00 & 0,00 & 0,00 & 0,00 & 0,00 \\
\hline & $60-80$ & 0,00 & 0,00 & 0,00 & 0,00 & 0,00 & 0,00 & 0,00 & 0,00 & 0,00 & 0,00 & 0,00 & 0,00 & 0,00 & 0,00 & 0,00 & 0,00 & 0,00 & 0,00 \\
\hline & $80-100$ & 0,00 & 0,00 & 0,00 & 0,00 & 0,00 & 0,00 & 0,00 & 0,00 & 0,00 & 0,00 & 0,00 & 0,00 & 0,00 & 0,00 & 0,00 & 0,00 & 0,00 & 0,00 \\
\hline \multirow[t]{5}{*}{87} & $0-20$ & 0,00 & 0,00 & 0,00 & 0,00 & 0,00 & 0,00 & 0,00 & 0,00 & 0,00 & 0,00 & 0,00 & 0,00 & 0,00 & 0,00 & 0,00 & 0,00 & 0,00 & 0,00 \\
\hline & $20-40$ & 0,00 & 0,00 & 0,00 & 0,00 & 0,00 & 0,00 & 0,00 & 0,00 & 0,00 & 0,00 & 0,00 & 0,00 & 0,00 & 0,00 & 0,00 & 0,00 & 0,00 & 0,00 \\
\hline & $40-60$ & 0,00 & 0,00 & 0,00 & 0,00 & 0,00 & 0,00 & 0,00 & 0,00 & 0,00 & 0,00 & 0,00 & 0,00 & 0,00 & 0,00 & 0,00 & 0,00 & 0,00 & 0,00 \\
\hline & $60-80$ & 0,00 & 0,00 & 0,00 & 0,00 & 0,00 & 0,00 & 0,00 & 0,00 & 0,00 & 0,00 & 0,00 & 0,00 & 0,00 & 0,00 & 0,00 & 0,00 & 0,00 & 0,00 \\
\hline & $80-100$ & 0,00 & 0,00 & 0,00 & 0,00 & 0,00 & 0,00 & 0,00 & 0,00 & 0,00 & 0,00 & 0,00 & 0,00 & 0,00 & 0,00 & 0,00 & 0,00 & 0,00 & 0,00 \\
\hline \multirow[t]{5}{*}{88} & $0-20$ & 0,00 & 0,00 & 0,00 & 0,00 & 0,00 & 0,00 & 4,15 & 0,00 & 0,00 & 0,00 & 0,00 & 0,00 & 0,00 & 0,00 & 0,00 & 0,00 & 0,00 & 0,00 \\
\hline & $20-40$ & 0,00 & 0,00 & 0,00 & 0,00 & 4,45 & 0,00 & 0,00 & 0,00 & 0,00 & 0,00 & 0,00 & 0,00 & 4,45 & 0,00 & 0,00 & 0,00 & 0,00 & 0,00 \\
\hline & $40-60$ & 0,00 & 0,00 & 0,00 & 0,00 & 0,00 & 0,00 & 0,00 & 0,00 & 0,00 & 0,00 & 0,00 & 0,00 & 0,00 & 0,00 & 0,00 & 0,00 & 0,00 & 0,00 \\
\hline & $60-80$ & 0,00 & 0,00 & 0,00 & 0,00 & 0,00 & 0,00 & 0,00 & 0,00 & 0,00 & 0,00 & 0,00 & 0,00 & 0,00 & 0,00 & 0,00 & 0,00 & 0,00 & 0,00 \\
\hline & $80-100$ & 4,08 & 0,00 & 0,00 & 0,00 & 0,00 & 0,00 & 0,00 & 0,00 & 0,00 & 0,00 & 0,00 & 0,00 & 0,00 & 0,00 & 0,00 & 0,00 & 0,00 & 0,00 \\
\hline \multirow[t]{2}{*}{89} & $0-20$ & 0,00 & 0,00 & 0,00 & 0,00 & 0,00 & 0,00 & 0,00 & 0,00 & 0,00 & 0,00 & 0,00 & 0,00 & 0,00 & 0,00 & 0,00 & 0,00 & 0,00 & 0,00 \\
\hline & $20-40$ & 0,00 & 0,00 & 0,00 & 0,00 & 0,00 & 0,00 & 0,00 & 0,00 & 0,00 & 0,00 & 0,00 & 0,00 & 0,00 & 0,00 & 0,00 & 0,00 & 0,00 & 0,00 \\
\hline \multirow[t]{5}{*}{94} & $0-20$ & 0,00 & 0,00 & 0,00 & 0,00 & 0,00 & 0,00 & 0,00 & 2,96 & 0,00 & 0,00 & 0,00 & 0,00 & 0,00 & 0,00 & 0,00 & 0,00 & 0,00 & 0,00 \\
\hline & $20-40$ & 0,00 & 0,00 & 0,00 & 0,00 & 0,00 & 0,00 & 0,00 & 0,00 & 0,00 & 0,00 & 0,00 & 0,00 & 0,00 & 0,00 & 0,00 & 0,00 & 0,00 & 0,00 \\
\hline & $40-60$ & 0,00 & 0,00 & 0,00 & 0,00 & 0,00 & 0,00 & 0,00 & 0,00 & 0,00 & 0,00 & 0,00 & 0,00 & 0,00 & 0,00 & 0,00 & 0,00 & 0,00 & 1,91 \\
\hline & $60-80$ & 0,00 & 0,00 & 0,00 & 0,00 & 0,00 & 0,00 & 0,00 & 0,00 & 0,00 & 0,00 & 0,00 & 0,00 & 0,00 & 0,00 & 0,00 & 0,00 & 0,00 & 0,00 \\
\hline & $80-100$ & 0,00 & 0,00 & 0,00 & 0,00 & 0,00 & 0,00 & 0,00 & 0,00 & 0,00 & 0,00 & 0,00 & 0,00 & 0,00 & 0,00 & 0,00 & 0,00 & 0,00 & 0,00 \\
\hline \multirow[t]{5}{*}{95} & $0-20$ & 0,00 & 0,00 & 0,00 & 0,00 & 0,00 & 0,00 & 4,69 & 2,34 & 0,00 & 0,00 & 0,00 & 0,00 & 0,00 & 2,34 & 0,00 & 0,00 & 0,00 & 0,00 \\
\hline & $20-40$ & 0,00 & 0,00 & 0,00 & 0,00 & 0,00 & 0,00 & 0,00 & 0,00 & 0,00 & 0,00 & 0,00 & 0,00 & 0,00 & 0,00 & 0,00 & 0,00 & 0,00 & 0,00 \\
\hline & $40-60$ & 0,00 & 0,00 & 0,00 & 0,00 & 0,00 & 0,00 & 0,00 & 0,00 & 0,00 & 0,00 & 0,00 & 0,00 & 0,00 & 0,00 & 0,00 & 0,00 & 0,00 & 10,76 \\
\hline & $60-80$ & 0,00 & 0,00 & 0,00 & 0,00 & 0,00 & 0,00 & 0,00 & 0,00 & 0,00 & 0,00 & 0,00 & 0,00 & 0,00 & 0,00 & 0,00 & 0,00 & 0,00 & 0,00 \\
\hline & $80-100$ & 0,00 & 0,00 & 0,00 & 0,00 & 0,00 & 0,00 & 0,00 & 0,00 & 0,00 & 0,00 & 0,00 & 0,00 & 0,00 & 0,00 & 0,00 & 0,00 & 0,00 & 0,00 \\
\hline \multirow[t]{5}{*}{96} & $0-20$ & 0,00 & 0,00 & 0,00 & 0,00 & 0,00 & 0,00 & 0,00 & 0,00 & 0,00 & 0,00 & 0,00 & 0,00 & 0,00 & 0,00 & 0,78 & 0,00 & 0,00 & 0,00 \\
\hline & $20-40$ & 0,00 & 0,00 & 0,00 & 0,00 & 0,00 & 0,00 & 0,00 & 0,00 & 0,00 & 0,00 & 0,00 & 0,00 & 0,00 & 0,00 & 0,00 & 0,00 & 0,00 & 0,00 \\
\hline & $40-60$ & 0,00 & 0,00 & 0,00 & 0,00 & 0,00 & 0,00 & 0,00 & 0,00 & 0,00 & 0,00 & 0,00 & 0,00 & 0,00 & 0,00 & 0,00 & 0,00 & 0,00 & 0,00 \\
\hline & $60-80$ & 0,00 & 0,00 & 0,00 & 0,00 & 0,00 & 0,00 & 0,00 & 0,00 & 0,00 & 0,00 & 0,00 & 0,00 & 0,00 & 0,00 & 0,00 & 0,00 & 0,00 & 0,00 \\
\hline & $80-100$ & 0,00 & 0,00 & 0,00 & 0,00 & 0,00 & 0,00 & 0,00 & 0,00 & 0,00 & 0,00 & 0,00 & 0,00 & 0,00 & 0,00 & 0,00 & 0,00 & 0,00 & 0,00 \\
\hline \multirow[t]{5}{*}{97} & $0-20$ & 0,00 & 0,00 & 0,00 & 0,00 & 0,00 & 0,00 & 0,00 & 0,00 & 0,00 & 3,03 & 0,00 & 0,00 & 0,00 & 0,00 & 0,00 & 0,00 & 0,00 & 0,00 \\
\hline & $20-40$ & 0,00 & 0,00 & 0,00 & 0,00 & 0,00 & 0,00 & 0,00 & 0,00 & 0,00 & 0,00 & 0,00 & 0,00 & 0,00 & 0,00 & 0,00 & 0,00 & 0,00 & 0,00 \\
\hline & $40-60$ & 0,00 & 0,00 & 0,00 & 0,00 & 0,00 & 0,00 & 0,00 & 0,00 & 0,00 & 0,00 & 0,00 & 0,00 & 0,00 & 0,00 & 0,00 & 0,00 & 0,00 & 0,00 \\
\hline & $60-80$ & 0,00 & 0,00 & 0,00 & 0,00 & 0,00 & 0,00 & 0,00 & 0,00 & 0,00 & 0,00 & 0,00 & 0,00 & 0,00 & 0,00 & 0,00 & 0,00 & 0,00 & 0,00 \\
\hline & $80-100$ & 0,00 & 0,00 & 0,00 & 0,00 & 0,00 & 0,00 & 0,00 & 0,00 & 0,00 & 0,00 & 0,00 & 0,00 & 0,00 & 0,00 & 0,00 & 0,00 & 0,00 & 0,00 \\
\hline
\end{tabular}


Apêndice 4 (continuação). Estimativa da densidade (larvas.100m ${ }^{-3}$ ) dos grupos taxonômicos com freqüência de ocorrência inferior a $30 \%$ nos diferentes estratos amostrados com a rede Multinet durante o cruzeiro de verão de 2001, na região do cabo Frio.

\begin{tabular}{|c|c|c|c|c|c|c|c|c|c|c|c|c|c|c|c|c|c|c|c|}
\hline & 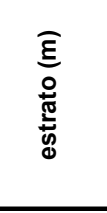 & 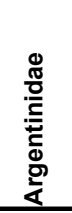 & 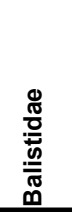 & $\begin{array}{l}\frac{0}{\pi} \\
\frac{\pi}{0} \\
: \frac{1}{E} \\
\frac{0}{0} \\
\end{array}$ & 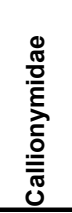 & $\begin{array}{l}\frac{\pi}{\pi} \\
\frac{\pi}{0} \\
\frac{0}{0} \\
\frac{\pi}{\pi} \\
0 \\
\end{array}$ & 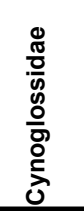 & 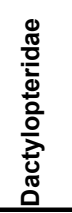 & 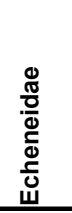 & 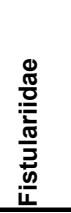 & 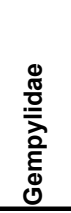 & $\begin{array}{l}0 \\
\frac{\pi}{0} \\
: 0 \\
0 \\
\stackrel{0}{0} \\
0 \\
0\end{array}$ & $\begin{array}{l}0 \\
\frac{\pi}{0} \\
: 0 \\
0 \\
0 \\
0\end{array}$ & 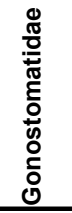 & 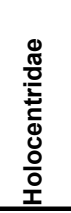 & 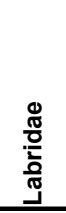 & $\begin{array}{l}\frac{0}{\pi} \\
\frac{\pi}{2} \\
\frac{0}{2} \\
0 \\
\end{array}$ & 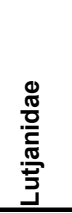 & 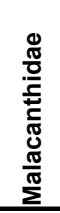 \\
\hline \multirow[t]{5}{*}{1} & $0-20$ & 0,00 & 0,00 & 0,00 & 0,00 & 0,00 & 0,00 & 0,00 & 0,00 & 0,00 & 0,00 & 0,00 & 0,00 & 0,00 & 00 & 0,00 & 0,00 & 0,00 & 0,00 \\
\hline & $20-40$ & 0,00 & 0,00 & 0,00 & 0,00 & 0,00 & 0,00 & 0,00 & 0,00 & 0,00 & 0,00 & 0,00 & 0,00 &, 00 & 0,00 & 0,00 & 0,00 & 0,00 & 0,00 \\
\hline & $40-60$ & 0,00 & ,00 & 0,00 & 0,00 & 0,00 & 00 & & 0,00 & 0,00 & 0,00 & 0,00 & 0,00 & 00 &, 00 & 0,00 & 0,00 & 0,00 & 00 \\
\hline & $60-80$ & 0,00 & 0,00 & 0,00 & 0,00 & 0,00 & 0,00 & 0,00 & 0,00 & 0,00 & 0,00 & 0,00 & 0,00 & 0,00 & 0,00 & 0,00 & 0,00 & 0,00 & 0,00 \\
\hline & $80-100$ & 0,00 & 0,00 & 0,00 & 0,00 & 0,00 & 0,00 & 0,00 & 0,00 & 0,00 & 0,00 & 0,00 & 0,00 & 00 & 0,00 & 0,00 & 0,00 & 0,00 &, 00 \\
\hline \multirow[t]{5}{*}{2} & -20 & 0,00 & 0,00 & 0,00 & 0,00 & 0,00 & 0,00 & 0,00 & 0,00 & 0,00 & 0,00 & 0,00 & 0,00 & 0,00 & , ,00 & 0,00 & 0,00 & 0,00 & 0,00 \\
\hline & $20-40$ & 0,00 & 0,00 & 0,00 & 0,00 & 0,00 & 0,00 & 0,00 & 0,00 & 0,00 & 0,00 & 0,00 & 0,00 & 0,00 & 0,00 & 0,00 & 0,00 & 0,00 & 0,00 \\
\hline & $40-60$ & 0,00 & ,00 & 0,00 & ,00 & 0,00 & 00 & & 00 & 00 & 0,00 & 00 & & & 00 & 00 & 00 & & 00 \\
\hline & $60-80$ & 0,00 & 0,00 & 0,00 & 0,00 & 0,00 & 0,00 & 0,00 & 0,00 & 0,00 & 0,00 & 0,00 & 0,00 & 0,00 & 0,00 & 0,00 & 0,00 & 0,00 & 0,00 \\
\hline & $80-100$ & 0,00 & 0,00 & 0,00 & 2,35 & 0,00 & 00 & 0,00 & 0,00 & 0,00 & 0,00 & 0,00 & 0,00 & 70 & 1,00 & 0,00 & 0,00 & 0,00 & 00 \\
\hline \multirow[t]{5}{*}{3} & $0-20$ & 0,00 & 0,00 & 0,00 & 0,00 & 0,00 & 0,00 & 0,00 & 0,00 & 0,00 & 0,00 & 0,00 & 0,00 & 0,00 & 4,50 & 0,00 & 0,00 & 0,00 & 0,00 \\
\hline & $20-40$ & 0,00 & 0,00 & 0,00 & 0,00 & 0,00 & 0,00 & 0,00 & 0,00 & 0,00 & 0,00 & 0,00 & 0,00 & 0,00 & 0,00 & 0,00 & 0,00 & 0,00 &, 00 \\
\hline & $40-60$ & 0,00 & 0,00 & 0,00 & 4,06 & 0,00 & 0,00 & 0,00 & 0,00 & 0,00 & 0,00 & 0,00 & 0, & & & 0,00 & 0,00 & 0,00 & 00 \\
\hline & $60-80$ & 0,00 & 0,00 & 0,00 & 0,00 & 0,00 & 0,00 & 0,00 & 0,00 & 0,00 & 0,00 & 0,00 & 0,00 & 3,23 & 3,23 & 0,00 & 0,00 & 0,00 & 0,00 \\
\hline & -100 & 00 & ,00 & 0,00 & 0,00 & 0,00 & 00 & & 0,00 & 0,00 & 0,00 & 0,00 & $0, C$ & & & 0,00 & 0,00 & & \\
\hline \multirow[t]{5}{*}{4} & -20 & 0,00 & 0,00 & 0,00 & 0,00 & 0,00 & 0,00 & 0,00 & 0,00 & 2,09 & 0,00 & 2,09 & 0,00 & 0,00 & 0,00 & 4,19 & 0,00 & 0,00 &, 00 \\
\hline & $20-40$ & 0,00 & 0,00 & 0,00 & 0,00 & 0,00 & 0,00 & 0,00 & 0,00 & 0,00 & 0,00 & 0,00 & 3,72 & 00 & ,00 & 0,00 & 0,00 & 0,00 & 00 \\
\hline & -60 & 0,00 & 0,00 & 0,00 & 0,00 & 0,00 & 0,00 & & & 0,00 & 00 & & $0, C$ & & & 00 & 00 & & 00 \\
\hline & $60-80$ & 0,00 & 3,20 & 0,00 & 0,00 & 0,00 & 0,00 & 0,00 & 0,00 & 0,00 & 0,00 & 0,00 & 0,00 & 0,00 & 0,00 & 0,00 & 0,00 & 0,00 & 0,00 \\
\hline & -100 & 0,00 & 0,00 & 0,00 & ,00 & 0,00 & & & & 0,00 & & 0,00 & & & 0,00 & 0,00 & 0,00 & & \\
\hline \multirow[t]{5}{*}{6} & -20 & 0,00 & 2,71 & 0,00 & 0,00 & 0,00 & 0,00 & 0,00 & 0,00 & 0,00 & 0,00 & 0,00 & 10,83 & 0,00 & 0,00 & 0,00 & 0,00 & 0,00 & 0,00 \\
\hline & -40 & 0,00 & 0,00 & 0,00 & 0,00 & 0,00 & 0,00 & & 0,00 & 0,00 & 0,00 & 0,00 & 0, & 0 & 0,00 & 0,00 & 0,00 & 0,00 & 00 \\
\hline & $40-60$ & 0,00 & 0,00 & 0,00 & 0,00 & 0,00 & 0,00 & & & 0,00 & 0,00 & 0,00 & 0.0 & & & 0,00 & 0,00 & &, 00 \\
\hline & -80 & 0,00 & 0,00 & 0,00 & 0,00 & 0,00 & 0,00 & 0,00 & 0,00 & 0,00 & 0,00 & 0,00 & $0, C$ & 0,00 & 0,00 & 0,00 & 0,00 & 0,00 & 0,00 \\
\hline & 100 & & 0,00 & & & 0,00 & & & & & & & & & & 0,00 & & & \\
\hline \multirow[t]{2}{*}{9} & $0-20$ & 0,00 & 0,00 & 6,40 & 0,00 & 0,00 & 0,00 & 0,00 & 0,00 & 0,00 & 0,00 & 0,00 & 0,00 & 0,00 & 0,00 & 1,28 & 0,00 & 0,00 & 0,00 \\
\hline & $20-40$ & & 0,00 & & & & & & & 0,00 & 0,00 & 0,00 & & & & 0,00 & 0,00 & & \\
\hline \multirow[t]{5}{*}{13} & $0-20$ & 0,00 & 1,90 & 0,00 & 0,00 & 0,00 & 0,00 & 0,00 & 0,00 & 0,00 & 0,00 & 2,84 & 1,90 & 0,00 & 0,00 & 0,00 & 0,00 & 0,00 & 0,00 \\
\hline & & 0,00 & 1,65 & 0,00 & 1,65 & 0,00 & 0,00 & & 0,00 & 0,00 & 0,00 & 0,00 & 0,00 & & 0,00 & 0,00 & 0,00 & 0,00 & 0,00 \\
\hline & & 0,00 & 0,00 & 0,00 & 1,90 & 0,00 & 0,00 & & 0,00 & 0,00 & 0,00 & 0,00 & & & 0,00 & 0,00 & 0,00 & 0,00 & \\
\hline & $0-80$ & 0,00 & 0,00 & 0,00 & 0,00 & 0,00 & 0,00 & 0,00 & 0,00 & 0,00 & 0,00 & 0,00 & 0,0 & 0,00 & 0,00 & 0,00 & 1,81 & 0,00 & 1,81 \\
\hline & $80-100$ & 0,00 & 0,00 & & 4,63 & 0,00 & & & & 0,00 & 0,00 & 0,00 & & & 0,00 & 0,00 & 0,00 & 0,00 & 0,00 \\
\hline \multirow[t]{5}{*}{15} & & 0,00 & 4,34 & 13,02 & 0,00 & 0,00 & 0,00 & 0,00 & 0,00 & 0,00 & 0,00 & 0,00 & 0,00 & 0,00 & 0,00 & 4,34 & 0,00 & 2,17 & 0,00 \\
\hline & 2 & 0,00 & 2,92 & 0,00 & 0,00 & 0,00 & 43,85 & 10 & 0,00 & 0,00 & 0,00 & 0,00 & 0,0 & 0,00 & 0,00 & 0,00 & 0,00 & 0,00 & 0,00 \\
\hline & & 0,00 & 0,00 & 0,00 & 0,00 & 0,00 & 0,00 & 0,00 & 0,00 & 0,00 & 0,00 & 0,00 & 0,00 & 0,00 & 0,00 & 0,00 & 0,00 & 0,00 &, 00 \\
\hline & & 0,00 & 0,00 & & 0,0 & 0,0 & 0,00 & & 00 & 0,00 & 0,00 & 0,00 & 0,0 & 0,00 & 0,00 & 0,00 & 0,00 & 0,00 & 0,00 \\
\hline & $80-100$ & 0,00 & 0,00 & 0,00 & 0,00 & 0,00 & 0,00 & 0,00 & 0,00 & 0,00 & 0,00 & 0,00 & 0,00 & 0,00 & 0,00 & 0,00 & 0,00 & 0,00 & 0,00 \\
\hline \multirow[t]{2}{*}{18} & & 0,00 & 0,00 & & 0,0 & 0,0 & 0,0 & 0, & 0,00 & 0,00 & 0,00 & 0,00 & 0,0 & 0,00 & 0,00 & 0,00 & 0,00 & 0,00 & 0,00 \\
\hline & -40 & 0,00 & 00 & 0,00 & 0,00 & 0,00 & 0,00 & 0,00 & 0,00 & 0,00 & 0,00 & 0,00 & 0,00 & 0,00 & 0,00 & 0,00 & 0,00 & 0,00 & 0,00 \\
\hline
\end{tabular}


Apêndice 4 (continuação). Estimativa da densidade (larvas.100m ${ }^{-u}$ ) dos grupos taxonômicos com freqüência de ocorrência inferior a $30 \%$ nos diferentes estratos amostrados com a rede Multinet durante o cruzeiro de verão de 2001, na região do cabo Frio.

\begin{tabular}{|c|c|c|c|c|c|c|c|c|c|c|c|c|c|c|c|c|c|c|c|c|}
\hline 荵 & 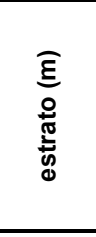 & 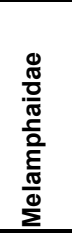 & 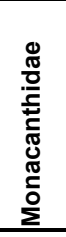 & $\begin{array}{l}0 \\
\frac{\pi}{0} \\
\frac{0}{0} \\
\Sigma\end{array}$ & $\begin{array}{l}\frac{0}{\pi} \\
\frac{\pi}{\underline{\underline{0}}} \\
\bar{\Sigma} \\
\end{array}$ & 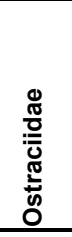 & 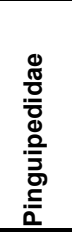 & 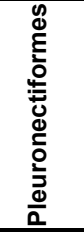 & 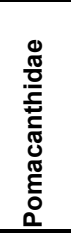 & 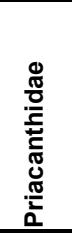 & 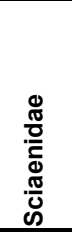 & 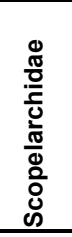 & 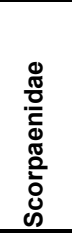 & $\begin{array}{l}\frac{8}{\pi} \\
\frac{\pi}{2} \\
\frac{0}{\pi} \\
\text { ô }\end{array}$ & 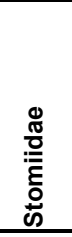 & 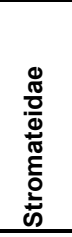 & 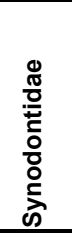 & 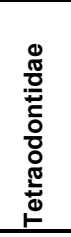 & 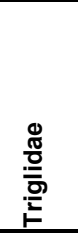 & 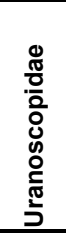 \\
\hline \multirow[t]{5}{*}{84} & $0-20$ & 0,00 & 0,00 & 0,00 & 0,00 & 0,00 & 0,00 & 0,00 & 0,00 & 1,93 & 0,00 & 0,00 & 0,00 & 0,00 & 0,00 & 7,73 & 0,00 & 0,00 & 0,00 & 0,00 \\
\hline & $20-40$ & 00 & 3,44 & 00 & 0,00 & 0,00 & 0,00 & 0,00 & 0,00 & 3,44 & 0,00 & 0,00 & 0,00 & 0,00 & 0,00 & 0,00 &, 00 & 0,00 &, 00 & 0,00 \\
\hline & $40-60$ & 00 & 0,00 & 0,00 & 00 & 00 & 0,00 & 0,00 & 0,00 & 0,00 & 0,00 & 0,00 & 0,00 & 0,00 & 0,00 & 3,50 & 0,00 & 0,00 & 0,00 & 0,00 \\
\hline & $60-80$ &, 00 & 0,00 & 0,00 & 0,00 & 0,00 & 0,00 & 0,00 & 0,00 & 0,00 & 0,00 & 0,00 & 0,00 & 0,00 & 0,00 & 0,00 & 0,00 &, 00 & 0,00 & 0,00 \\
\hline & $80-100$ & 00 & 0,00 & 0,00 & 0,00 & 0,00 &, 00 & 0,00 & 0,00 & 0,00 & 0,00 & 0,00 & 0,00 & 0,00 & 00 & 0,00 &, 00 &, 00 & ,00 & 0,00 \\
\hline \multirow[t]{5}{*}{85} & $0-20$ & 0,00 & 0,00 & 0,00 & 0,00 & 0,00 & 0,00 & 0,00 & 0,00 & 0,00 & 0,00 & 0,00 & 0,00 & 0,00 & 2,22 & 4,44 & 0,00 & 0,00 & 0,00 & 0,00 \\
\hline & -40 & ,00 & 0,00 & 0,00 & 0,00 & 0,00 & 0,00 & 0,00 & 0,00 & 0,00 & 0,00 & 0,00 & 0,00 & 0,00 & 0,00 & 0,00 & 0,00 &, 00 & ,00 & 0,00 \\
\hline & $40-60$ & 0,00 & 0,00 & 0,00 & 0,00 & 0,00 & 0,00 & 0,00 & 0,00 & 0,00 & 0,00 & 0,00 & 0,00 & 0,00 & 2,59 & 0,00 & 0,00 & 0,00 & 0,00 & 2,59 \\
\hline & $60-80$ & 0,00 & 0,00 & 0,00 & 0,00 & 0,00 & 0,00 & 0,00 & 0,00 & 0,00 & 0,00 & 0,00 & 0,00 & 0,00 & 0,00 & 0,00 & 0,00 & 0,00 & 0,00 & 0,00 \\
\hline & o-100 & & & & & & & 00 & & & & & & & & 0 & 00 & 00 & 0 & 0,00 \\
\hline \multirow[t]{5}{*}{86} & $0-20$ & 0,00 & 0,00 & 0,00 & 0,00 & 0,00 & 0,00 & 0,00 & 0,94 & 1,87 & 0,00 & 0,00 & 1,87 & 0,00 & 0,00 & 0,00 & 0,00 & 0,00 & 0,00 & 0,00 \\
\hline & $20-40$ & 0,00 & 0,00 & 0,00 & 0,00 & 00 & 1,00 & 0,00 & 0,00 & 0,00 & 0,00 & 0,00 & 2,69 & 0,00 & 0,00 & 0,00 & 00 & 00 & ,69 & 0,00 \\
\hline & $0-60$ & 0,00 & 0,00 & 0,00 & 0,00 & 0,00 & 0,00 & 0,00 & 0,00 & 0,00 & 0,00 & 0,00 & 0,00 & 0,00 & 0,00 & 0,00 & 1,00 & 1,00 & 0,00 & 0,00 \\
\hline & $60-80$ & 0,00 & 0,00 & 0,00 & 0,00 & 0,00 & 0,00 & 0,00 & 0,00 & 0,00 & 0,00 & 0,00 & 0,00 & 0,00 & 0,00 & 0,00 & 0,00 & 0,00 & 0,00 & 0,00 \\
\hline & -100 & & & & & & & 00 & & & & & & & & & & & & 00 \\
\hline \multirow[t]{5}{*}{87} & 20 & 0,00 & 0,00 & 0,00 & 0,00 & 0,00 & 0,00 & 1,37 & 0,00 & 0,00 & 0,00 & 0,00 & 0,00 & 0,00 & 0,00 & 0,00 & 0,00 & 0,00 & 0,00 & 0,00 \\
\hline & -40 & 0,00 & 0,00 & 0,00 & 0,00 & 0,00 & 0,00 & 10,02 & 0,00 & 0,00 & 0,00 & 0,00 & 0,00 & 0,00 & 0,00 & 0,00 & ,00 & 00 &, 00 & 0,00 \\
\hline & $40-60$ & 1,00 & 0,00 & 0,00 & 0,00 & 0,00 & 0,00 & 0,00 & 0,00 & 0,00 & 0,00 & 0,00 & 0,00 & 0,00 & ,00 & ,00 & ,00 & ,00 & 1,00 & 0,00 \\
\hline & $60-80$ & 0,00 & 0,00 & 0,00 & 0,00 & 0,00 & 0,00 & 0,00 & 0,00 & 0,00 & 0,00 & 0,00 & 0,00 & 0,00 & 0,00 & 0,00 & 0,00 & 0,00 & 0,00 & 0,00 \\
\hline & $80-100$ & 0 & 00 & 0,00 & 00 & & & 0,00 & & & & & & & 00 & & 0 & 00 & 0,00 & 0,00 \\
\hline \multirow[t]{5}{*}{88} & $0-20$ & 0,00 & 0,00 & 0,00 & 2,08 & 0,00 & 0,00 & 12,46 & 0,00 & 2,08 & 0,00 & 0,00 & 0,00 & 0,00 & 0,00 & 0,00 & 0,00 & 0,00 & 0,00 & 0,00 \\
\hline & $0-40$ & 0,00 & 0,00 & 0,00 & 0,00 & 00 & 0,00 & 0,00 & 00 & 0,00 & 0,00 & 0,00 & 0,00 & 0,00 & 00 & ,00 & ,00 & 00 & ,00 &, 00 \\
\hline & $0-60$ & & & & & & & 00 & & & & & 00 & 0,00 & 00 & b0 & 00 & 00 & 00 & 0,00 \\
\hline & $60-80$ & 0,00 & 0,00 & 0,00 & 0,00 & 0,00 & 0,00 & 0,00 & 0,00 & 0,00 & 0,00 & 0,00 & 0,00 & 0,00 & 0,00 & 0,00 & 0,00 & 0,00 & 0,00 & 0,00 \\
\hline & $80-100$ & 00 & 00 & 00 & 00 & 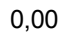 & & 0 & & 0,00 & 0,00 & 0,00 & 0,00 & 0,00 & 00 & 00 & 00 & 00 & 00 & 0,00 \\
\hline \multirow[t]{2}{*}{89} & & 0,00 & 0,00 & 0,00 & 0,00 & 0,00 & 0,00 & 0,00 & 0,00 & 0,00 & 0,00 & 0,00 & 0,00 & 0,00 & 0,00 & 0,00 & 0,00 & 0,00 & 0,00 & 0,00 \\
\hline & -40 & 0,00 & 0,00 & 0,00 & 0,00 & 00 & & 0,00 & 0 & 00 & 0,00 & 0,00 & 0,00 & 0,00 & 00 & 00 & ,00 & 00 & 1,00 &, 00 \\
\hline \multirow[t]{5}{*}{94} & & & & & & & & & & & & & & & & & 00 & 00 & 00 & 0,00 \\
\hline & $0-40$ & 0,00 & 0,00 & 0,00 & 0,00 & 0,00 & 0,00 & 0,00 & 0,00 & 0,00 & 0,00 & 0,00 & 5,74 & 0,00 & 0,00 & 0,00 & 5,74 & 0,00 & 0,00 & 0,00 \\
\hline & $0-60$ & 0,00 & 0,00 & 0,00 & 00 & 00 & & 00 & 0,00 & 0,00 & 0,00 & 0,00 & 0,00 & 0,00 & ,00 & ,00 &, 00 & ,00 &, 00 & 0,00 \\
\hline & & & & & & & & 0,00 & & & & & & & & & 00 & 0 & 00 &, 00 \\
\hline & $80-100$ & 0,00 & 0,00 & 0,00 & 0,00 & 00 & & 0,00 & 0,00 & 0,00 & 0,00 & 0,00 & 0,00 & 0,00 & ,00 & 1,00 & 0,00 & 0,00 & 0,00 & 0,00 \\
\hline \multirow[t]{5}{*}{95} & & & & & & & & & & & & & & & & & & ,00 & 0,00 & \\
\hline & $20-40$ & 3,28 & 0,00 & 0,00 & 0,00 & 0,00 & 0,00 & 32,79 & 0,00 & 0,00 & 0,00 & 0,00 & 0,00 & 0,00 & 0,00 & 0,00 & 0,00 & 0,00 & 0,00 & 0,00 \\
\hline & -60 & 0,00 & 0,00 & 0,00 & 00 & 0 & & & 0,00 & 0,00 & 0,00 & 0,00 & 0,00 & 0,00 & 0,00 & 0,00 & 0,00 & 69 & 0,00 & 0,00 \\
\hline & & & & & & & & & & & & & & & & & 00 & 00 & 00 & ,00 \\
\hline & $80-100$ & 0,00 & 0,00 & 0,00 & 0,00 & 0,00 & 0,0 & 0,00 & 0,00 & 0,00 & 0,00 & 0,00 & 0,00 & 0,00 & 0,00 & 0,00 & 0,00 & 0,00 & 0,00 & 0,00 \\
\hline \multirow[t]{5}{*}{96} & & & 0,00 & 0,00 & & & & & & 0,00 & 0,00 & 0,00 & 0,00 & 0,00 & 0,00 & 0,00 & 0,00 & 0,00 & 0,00 & 0,0 \\
\hline & $20-40$ & 0,00 & 0,00 & 0,00 & 0,00 & 0,00 & 0,00 & 8,48 & 0,00 & 0,00 & 0,00 & 0,00 & 0,00 & 0,00 & 0,00 & 0,00 & 0,00 & 0,00 & 0,00 &, 00 \\
\hline & $0-60$ & 0,00 & 0,00 & 0,00 & 0,00 & 0,00 & 0,0 & 0,00 & 0,00 & 0,00 & 0,00 & 0,00 & 0,00 & 0,00 & 0,00 & 0,00 & 0,00 & 0,00 & 0,00 & 0,00 \\
\hline & & 0,00 & 0,00 & 0,00 & 0,00 & & & & 0,00 & 0,00 & 0,00 & 0,00 & 0,00 & 0,00 & 0,00 & 0,00 & 0,00 & 0,00 & 0,00 & 0,00 \\
\hline & $80-100$ & 0,00 & 0,00 & 0,00 & 0,00 & 0, & 0,0 & 0,00 & 0,00 & 0,00 & 0,00 & 0,00 & 0,00 & 0,00 & 0,00 & 0,00 & 0,00 & 0,00 & 0,00 & 0,00 \\
\hline \multirow[t]{5}{*}{97} & & 0,00 & 0,00 & 0,00 & 0,00 & 0,00 & $0, C$ & 0,00 & 0,00 & 0,00 & 0,00 & 0,00 & 0,00 & 0,00 & 0,00 & 0,00 & 0,00 & 0,00 & 0,00 & 0,00 \\
\hline & $20-40$ & 0,00 & 0,00 & 0,00 & 0,00 & 0,00 & 0,00 & 0,00 & 0,00 & 0,00 & 0,00 & 0,00 & 0,00 & 0,00 & ,00 & 00 &, 00 & ,00 &, 00 &, 00 \\
\hline & $40-60$ & & & & & & 0,0 & 0,0 & 0,00 & 0,00 & 0,00 & 0,00 & 2,38 & 0,00 & 0,00 & 0,00 & 0,00 & 0,00 & 0,00 & 0,00 \\
\hline & & 0,00 & 0,00 & 0,00 & 0,00 & 0,00 & $0, C$ & 0,00 & 0,00 & 0,00 & 0,00 & 0,00 & 0,00 & 0,00 & 0,00 & 0,00 & 0,00 & 0,00 & 0,00 & 0,00 \\
\hline & $80-100$ & 0,00 & 0,00 & 2,79 & 0,00 & 0,00 & 0,00 & 0,00 & 0,00 & 0,00 & 0,00 & 0,00 & 0,00 & 0,00 & 0,00 & 0,00 & 0,00 & 0,00 & 0,00 & 0,00 \\
\hline
\end{tabular}


Apêndice 4 (continuação). Estimativa da densidade (larvas.100m ${ }^{-3}$ ) dos grupos taxonômicos com freqüência de ocorrência inferior a $30 \%$ nos diferentes estratos amostrados com a rede Multinet durante o cruzeiro de verão de 2001, na região do cabo Frio.

\begin{tabular}{|c|c|c|c|c|c|c|c|c|c|c|c|c|c|c|c|c|c|c|c|c|}
\hline 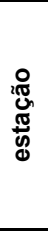 & 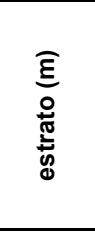 & $\begin{array}{l}\frac{0}{\pi} \\
\frac{\pi}{0} \\
\frac{0}{\pi} \\
\frac{0}{0} \\
\frac{0}{0} \\
\frac{\pi}{0} \\
\Sigma\end{array}$ & 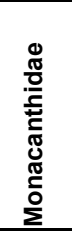 & $\begin{array}{l}\frac{0}{\pi} \\
\stackrel{\pi}{0} \\
0 \\
\Sigma \\
\end{array}$ & $\begin{array}{l}\frac{\mathbb{\pi}}{0} \\
\stackrel{\overline{0}}{\overline{5}} \\
\Sigma \\
\end{array}$ & 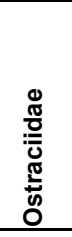 & 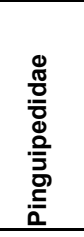 & 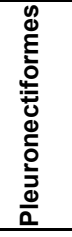 & 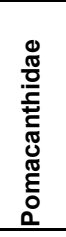 & 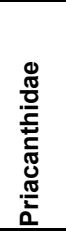 & 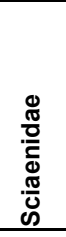 & 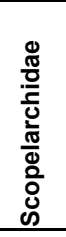 & 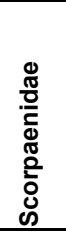 & $\begin{array}{l}\frac{0}{\pi} \\
\frac{\pi}{0} \\
\frac{0}{\pi} \\
\text { की }\end{array}$ & 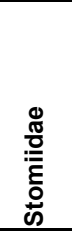 & 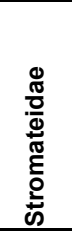 & 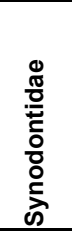 & 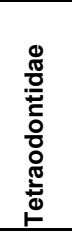 & 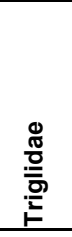 & 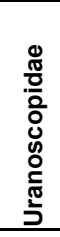 \\
\hline \multirow[t]{5}{*}{1} & $0-20$ & 0,00 & 0,00 & 0,00 & 0,00 & 0,00 & 0,00 & 0,00 & 0,00 & 9,21 & 0,00 & 0,00 & 0,00 & 0,00 & 2,30 & 0,00 & 0,00 & 0,00 & 0,00 & 0,00 \\
\hline & $20-40$ & 0,00 & 0,00 & 0,00 & 0,00 & 0,00 & 0,00 & 0,00 & 0,00 & 0,00 & 0,00 & 0,00 & 0,00 & 0,00 & 0,00 & 0,00 & 0,00 & 0,00 & 0,00 & 0,00 \\
\hline & $40-60$ & 0,00 & 0,00 & 0,00 & 0,00 & 0,00 & 0,00 & 0,00 & 0,00 & 0,00 & 0,00 & 0,00 & 0,00 & 0,00 & 0,00 & 0,00 & 0,00 & 0,00 & 0,00 & 0,00 \\
\hline & $60-80$ & 0,00 & 0,00 & 0,00 & 0,00 & 0,00 & 0,00 & 0,00 & 0,00 & 0,00 & 0,00 & 0,00 & 2,24 & 0,00 & 0,00 & 0,00 & 0,00 & 0,00 & 0,00 & 0,00 \\
\hline & $80-100$ & 0,00 & 0,00 & 0,00 & 0,00 & 0,00 & 0,00 & 0,00 & 0,00 & 0,00 & 0,00 & 0,00 & 2,16 & 0,00 & 0,00 & 0,00 & 0,00 & 0,00 & 0,00 & 0,00 \\
\hline \multirow[t]{5}{*}{2} & $0-20$ & 0,00 & 0,00 & 0,00 & 0,00 & 0,00 & 0,00 & 0,00 & 0,00 & 2,62 & 0,00 & 0,00 & 2,62 & 0,00 & 0,00 & 0,00 & 0,00 & 0,00 & 0,00 & 0,00 \\
\hline & $20-40$ & 0,00 & 0,00 & 0,00 & 0,00 & 0,00 & 0,00 & 0,00 & 0,00 & 0,00 & 0,00 & 0,00 & 0,00 & 0,00 & 0,00 & 0,00 & 0,00 & 0,00 & 0,00 & 0,00 \\
\hline & $40-60$ & 0,00 & 0,00 & 0,00 & 0,00 & 0,00 & 0,00 & 0,00 & 0,00 & 0,00 & 0,00 & 0,00 & 0,00 & 0,00 & 0,00 & 0,00 & 0,00 & 0,00 & 0,00 & 0,00 \\
\hline & $60-80$ & 0,00 & 0,00 & 0,00 & 0,00 & 0,00 & 0,00 & 0,00 & 0,00 & 0,00 & 0,00 & 0,00 & 0,00 & 0,00 & 0,00 & 0,00 & 0,00 & 0,00 & 0,00 & 0,00 \\
\hline & $80-100$ & 0,00 & 0,00 & 0,00 & 0,00 & 0,00 & 0,00 & 0,00 & 0,00 & 0,00 & 0,00 & 0,00 & 0,00 & 0,00 & 0,00 & 0,00 & 0,00 & 0,00 & 0,00 & 0,00 \\
\hline \multirow[t]{5}{*}{3} & $0-20$ & 0,00 & 0,00 & 0,00 & 0,00 & 0,00 & 0,00 & 0,00 & 0,00 & 0,00 & 0,00 & 0,00 & 0,00 & 0,00 & 0,00 & 0,00 & 0,00 & 0,00 & 0,00 & 0,00 \\
\hline & $20-40$ & 0,00 & 0,00 & 0,00 & 0,00 & 0,00 & 0,00 & 0,00 & 0,00 & 0,00 & 0,00 & 0,00 & 0,00 & 0,00 & 0,00 & 0,00 & 0,00 & 0,00 & 0,00 & 0,00 \\
\hline & $40-60$ & 0,00 & 0,00 & 0,00 & 0,00 & 0,00 & 0,00 & 0,00 & 0,00 & 0,00 & 0,00 & 0,00 & 0,00 & 0,00 & 0,00 & 0,00 & 0,00 & 0,00 & 0,00 & 0,00 \\
\hline & $60-80$ & 0,00 & 0,00 & 0,00 & 0,00 & 0,00 & 0,00 & 0,00 & 0,00 & 0,00 & 0,00 & 0,00 & 0,00 & 0,00 & 0,00 & 0,00 & 0,00 & 0,00 & 0,00 & 0,00 \\
\hline & $80-100$ & 0,00 & 0,00 & 0,00 & 0,00 & 0,00 & 0,00 & 0,00 & 0,00 & 0,00 & 0,00 & 0,00 & 0,00 & 0,00 & 0,00 & 0,00 & 0,00 & 0,00 & 0,00 & 0,00 \\
\hline \multirow[t]{5}{*}{4} & $0-20$ & 0,00 & 0,00 & 0,00 & 2,09 & 0,00 & 0,00 & 0,00 & 0,00 & 0,00 & 0,00 & 0,00 & 0,00 & 0,00 & 0,00 & 0,00 & 0,00 & 0,00 & 0,00 & 0,00 \\
\hline & $20-40$ & 0,00 & 0,00 & 0,00 & 0,00 & 0,00 & 0,00 & 0,00 & 0,00 & 0,00 & 3,72 & 0,00 & 0,00 & 0,00 & 0,00 & 0,00 & 0,00 & 0,00 & 0,00 & 0,00 \\
\hline & $40-60$ & 0,00 & 0,00 & 0,00 & 0,00 & 0,00 & 0,00 & 0,00 & 0,00 & 0,00 & 0,00 & 0,00 & 0,00 & 0,00 & 0,00 & 0,00 & 0,00 & 0,00 & 0,00 & 0,00 \\
\hline & $60-80$ & 0,00 & 0,00 & 0,00 & 0,00 & 0,00 & 0,00 & 0,00 & 0,00 & 0,00 & 0,00 & 0,00 & 0,00 & 0,00 & 0,00 & 0,00 & 0,00 &, 00 & 0,00 & 0,00 \\
\hline & $80-100$ & 0,00 & 0,00 & 0,00 & 0,00 & 0,00 & 0,00 & 0,00 & 0,00 & 0,00 & 0,00 & 0,00 & 0,00 & 0,00 & 0,00 & 0,00 & 2,16 & 0,00 & 0,00 & 0,00 \\
\hline \multirow[t]{5}{*}{6} & $0-20$ & 0,00 & 0,00 & 0,00 & 0,00 & 0,00 & 0,00 & 0,00 & 0,00 & 0,00 & 0,00 & 0,00 & 0,00 & 0,00 & 0,00 & 0,00 & 0,00 & 0,00 & 0,00 & 0,00 \\
\hline & $20-40$ & 0,00 & 0,00 & 0,00 & 0,00 & 0,00 & 0,00 & 0,00 & 0,00 & 0,00 & 0,00 & 0,00 & 0,00 & 0,00 & 0,00 & 0,00 & 4,23 & 0,00 & 0,00 & 0,00 \\
\hline & $40-60$ & 0,00 & 0,00 & 0,00 & 0,00 & 0,00 & 0,00 & 0,00 & 0,00 & 0,00 & 0,00 & 0,00 & 0,00 & 0,00 & 0,00 & 0,00 & 0,00 & 0,00 & 0,00 & 0,00 \\
\hline & $60-80$ & 0,00 & 0,00 & 0,00 & 0,00 & 0,00 & 0,00 & 0,00 & 0,00 & 0,00 & 0,00 & 0,00 & 0,00 & 0,00 & 0,00 & 0,00 & 0,00 & 0,00 & 0,00 & 0,00 \\
\hline & $80-100$ & 0,00 & 0,00 & 0,00 & 0,00 & 0,00 & 0,00 & 0,00 & 0,00 & 0,00 & 0,00 & 0,00 & 0,00 & 0,00 & 0,00 & 0,00 & 0,00 & 0,00 & 0,00 & 0,00 \\
\hline \multirow[t]{2}{*}{9} & $0-20$ & 0,00 & 0,00 & 0,00 & 0,00 & 0,00 & 0,00 & 0,00 & 0,00 & 0,00 & 0,00 & 0,00 & 0,00 & 0,00 & 0,00 & 0,00 & 0,00 & 0,00 & 0,00 & 0,00 \\
\hline & $20-40$ & 0,00 & 0,00 & 0,00 & 0,00 & 0,00 & 2,78 & 0,00 & 0,00 & 0,00 & 2,78 & 0,00 & 0,00 & 0,00 & 0,00 & 0,00 & 0,00 & 0,00 & 0,00 & 0,00 \\
\hline \multirow[t]{5}{*}{13} & $0-20$ & 0,00 & 0,00 & 0,00 & 0,00 & 0,95 & 0,00 & 0,00 & 0,00 & 0,00 & 0,00 & 0,00 & 0,00 & 0,00 & 0,00 & 0,00 & 0,00 & 0,00 & 0,00 & 0,00 \\
\hline & $20-40$ & 0,00 & 0,00 & 0,00 & 0,00 & 0,00 & 0,00 & 0,00 & 0,00 & 0,00 & 0,00 & 0,00 & 0,00 & 0,00 & 0,00 & 0,00 & 0,00 & 0,00 & 0,00 & 0,00 \\
\hline & $40-60$ & 0,00 & 0,00 & 0,00 & 0,00 & 0,00 & 0,00 & 0,00 & 0,00 & 0,00 & 0,00 & 0,00 & 0,00 & 0,00 & 0,00 & 0,00 & 0,00 & 0,00 & 1,90 & 0,00 \\
\hline & $60-80$ & 0,00 & 0,00 & 0,00 & 0,00 & 0,00 & 0,00 & 0,00 & 0,00 & 0,00 & 0,00 & 0,00 & 0,00 & 0,00 & 0,00 & 0,00 & 0,00 & 0,00 & 3,63 & 0,00 \\
\hline & $80-100$ & 0,00 & 0,00 & 0,00 & 0,00 & 0,00 & 0,00 & 0,00 & 0,00 & 0,00 & 0,00 & 0,00 & 0,00 & 0,00 & 0,00 & 0,00 & 0,00 & 0,00 & 0,00 & 0,00 \\
\hline \multirow[t]{5}{*}{15} & $0-20$ & 0,00 & 2,17 & 0,00 & 0,00 & 0,00 & 26,05 & 6,51 & 0,00 & 0,00 & 4,34 & 0,00 & 0,00 & 4,34 & 0,00 & 0,00 & 0,00 & 0,00 & 2,17 & 0,00 \\
\hline & $20-40$ & 0,00 & 0,00 & 0,00 & 0,00 & 0,00 & 0,00 & 0,00 & 0,00 & 0,00 & 2,92 & 0,00 & 0,00 & 0,00 & 0,00 & 0,00 & 0,00 & 0,00 & 0,00 & 0,00 \\
\hline & $40-60$ & 0,00 & 0,00 & 0,00 & 0,00 & 0,00 & 0,00 & 8,28 & 0,00 & 0,00 & 2,76 & 5,52 & 0,00 & 0,00 & 0,00 & 0,00 & 0,00 & 0,00 & 0,00 & 0,00 \\
\hline & $60-80$ & 0,00 & 0,00 & 0,00 & 0,00 & 0,00 & 2,67 & 0,00 & 0,00 & 0,00 & 2,67 & 0,00 & 0,00 & 0,00 & 0,00 & 0,00 & 2,67 & 0,00 & 0,00 & 0,00 \\
\hline & $80-100$ & 0,00 & 0,00 & 0,00 & 0,00 & 0,00 & 0,00 & 0,00 & 0,00 & 0,00 & 0,00 & 2,45 & 0,00 & 0,00 & 0,00 & 0,00 & 0,00 & 0,00 & 0,00 & 0,00 \\
\hline \multirow[t]{2}{*}{18} & $0-20$ & 0,00 & 0,00 & 0,00 & 0,00 & 0,00 & 0,00 & 0,00 & 0,00 & 0,00 & 0,00 & 0,00 & 0,00 & 0,00 & 0,00 & 0,00 & 0,00 & 0,00 & 0,00 & 0,00 \\
\hline & $20-40$ & 0,00 & 0,00 & 0,00 & 0,00 & 0,00 & 0,00 & 0,00 & 0,00 & 0,00 & 0,00 & 0,00 & 0,00 & 0,00 & 0,00 & 0,00 & 0,00 & 0,00 & 0,00 & 0,00 \\
\hline
\end{tabular}


Apêndice 5. Estimativa da densidade (larvas. $100 \mathrm{~m}^{-3}$ ) dos grupos taxonômicos com freqüência de ocorrência inferior a $30 \%$ nos diferentes estratos amostrados com a rede Multinet durante o cruzeiro de inverno de 2001, na região do cabo Frio.

\begin{tabular}{|c|c|c|c|c|c|c|c|c|c|c|c|c|c|c|c|c|c|}
\hline & 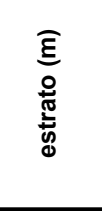 & 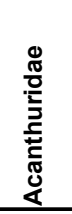 & 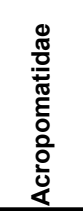 & 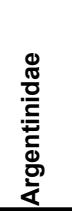 & 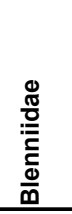 & 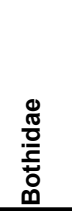 & 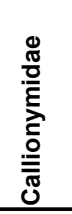 & 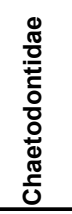 & $\begin{array}{l}\frac{\pi}{\pi} \\
\frac{\pi}{\Phi} \\
\frac{0}{2} \\
0\end{array}$ & $\begin{array}{l}0 \\
\frac{\pi}{0} \\
0 \\
0 \\
0\end{array}$ & 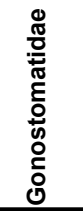 & 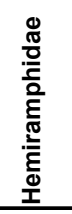 & 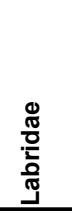 & $\begin{array}{l}\frac{0}{\pi} \\
\frac{\pi}{2} \\
\frac{0}{2} \\
0 \\
\end{array}$ & 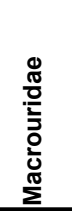 & $\begin{array}{l}\frac{0}{\pi} \\
\frac{\pi}{0} \\
\frac{\pi}{\pi} \\
\frac{0}{2} \\
\frac{\pi}{\pi} \\
\frac{\pi}{0} \\
\sum\end{array}$ & 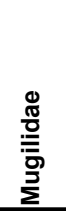 \\
\hline \multirow[t]{4}{*}{50} & $0-20$ & 0,00 & 0,00 & 0,00 & 0,00 & 7,27 & 0,00 & 2,42 & 0,00 & 0,00 & 0,00 & 0,00 & 0,00 & 0,00 & 0,00 & 0,00 & 0,00 \\
\hline & $20-40$ & 0,00 & 0,00 & 0,00 & 0,00 & 7,78 & 0,00 & 0,00 & 0,00 & 0,00 & 0,00 & 0,00 & 0,00 & 0,00 & 0,00 & 0,00 & 0,00 \\
\hline & $40-60$ & 0,00 & 0,00 & 0,00 & 0,00 & 0,00 & 0,00 & 0,00 & 0,00 & 0,00 & 0,00 & 0,00 & 0,00 & 0,00 & 0,00 & 0,00 & 0,00 \\
\hline & $60-80$ & 0,00 & 0,00 & 0,00 & 0,00 & 0,00 & 0,00 & 0,00 & 0,00 & 0,00 & 0,00 & 0,00 & 0,00 & 0,00 & 0,00 & 0,00 & 0,00 \\
\hline \multirow[t]{5}{*}{51} & $0-20$ & 0,00 & 3,80 & 0,00 & 0,00 & 0,00 & 0,00 & 0,00 & 0,00 & 0,00 & 0,00 & 0,00 & 0,00 & 0,00 & 0,00 & 0,00 & 0,00 \\
\hline & $20-40$ & 0,00 & 24,15 & 0,00 & 0,00 & 0,00 & 0,00 & 0,00 & 0,00 & 0,00 & 0,00 & 0,00 & 0,00 & 0,00 & 0,00 & 0,00 & 0,00 \\
\hline & $40-60$ & 0,00 & 4,34 & 0,00 & 0,00 & 0,00 & 0,00 & 0,00 & 0,00 & 0,00 & 0,00 & 0,00 & 0,00 & 0,00 & 0,00 & 0,00 & 0,00 \\
\hline & $60-80$ & 0,00 & 0,00 & 0,00 & 0,00 & 0,00 & 0,00 & 0,00 & 0,00 & 0,00 & 0,00 & 0,00 & 0,00 & 0,00 & 0,00 & 0,00 & 0,00 \\
\hline & $80-100$ & 0,00 & 0,00 & 0,00 & 0,00 & 0,00 & 0,00 & 0,00 & 0,00 & 0,00 & 0,00 & 0,00 & 0,00 & 0,00 & 0,00 & 0,00 & 0,00 \\
\hline \multirow[t]{5}{*}{52} & $0-20$ & 0,00 & 0,00 & 0,00 & 0,00 & 0,00 & 0,00 & 0,00 & 0,00 & 0,00 & 0,00 & 2,36 & 0,00 & 0,00 & 0,00 & 2,36 & 0,00 \\
\hline & $20-40$ & 0,00 & 0,00 & 0,00 & 0,00 & 0,00 & 0,00 & 0,00 & 0,00 & 0,00 & 0,00 & 0,00 & 0,00 & 0,00 & 0,00 & 0,00 & 0,00 \\
\hline & $40-60$ & 0,00 & 0,00 & 0,00 & 0,00 & 0,00 & 0,00 & 0,00 & 0,00 & 0,00 & 0,00 & 0,00 & 0,00 & 0,00 & 0,00 & 0,00 & 0,00 \\
\hline & $60-80$ & 0,00 & 0,00 & 0,00 & 0,00 & 0,00 & 0,00 & 0,00 & 0,00 & 0,00 & 0,00 & 0,00 & 0,00 & 0,00 & 0,00 & 0,00 & 0,00 \\
\hline & $80-100$ & 0,00 & 0,00 & 0,00 & 0,00 & 0,00 & 0,00 & 0,00 & 0,00 & 0,00 & 0,00 & 0,00 & 0,00 & 0,00 & 0,00 & 0,00 & 0,00 \\
\hline \multirow[t]{5}{*}{53} & $0-20$ & 0,00 & 0,00 & 0,00 & 0,00 & 0,00 & 0,00 & 0,00 & 0,00 & 0,00 & 0,00 & 0,00 & 3,36 & 0,00 & 0,00 & 0,00 & 0,00 \\
\hline & $20-40$ & 0,00 & 0,00 & 0,00 & 0,00 & 0,00 & 0,00 & 0,00 & 0,00 & 0,00 & 0,00 & 0,00 & 0,00 & 0,00 & 0,00 & 0,00 & 0,00 \\
\hline & $40-60$ & 0,00 & 0,00 & 0,00 & 0,00 & 0,00 & 0,00 & 0,00 & 0,00 & 0,00 & 0,00 & 0,00 & 0,00 & 0,00 & 0,00 & 0,00 & 0,00 \\
\hline & $60-80$ & 0,00 & 0,00 & 0,00 & 0,00 & 0,00 & 0,00 & 0,00 & 0,00 & 0,00 & 0,00 & 0,00 & 0,00 & 0,00 & 0,00 & 0,00 & 0,00 \\
\hline & $80-100$ & 0,00 & 0,00 & 0,00 & 0,00 & 0,00 & 0,00 & 0,00 & 0,00 & 0,00 & 0,00 & 0,00 & 0,00 & 0,00 & 0,00 & 0,00 & 0,00 \\
\hline \multirow[t]{5}{*}{54} & $0-20$ & 0,00 & 0,00 & 0,00 & 0,00 & 0,00 & 0,00 & 0,00 & 0,00 & 0,00 & 0,00 & 0,00 & 0,00 & 0,00 & 0,00 & 0,00 & 0,00 \\
\hline & $20-40$ & 0,00 & 0,00 & 0,00 & 0,00 & 0,00 & 0,00 & 0,00 & 0,00 & 0,00 & 0,00 & 0,00 & 0,00 & 0,00 & 0,00 & 0,00 & 0,00 \\
\hline & $40-60$ & 0,00 & 0,00 & 0,00 & 0,00 & 0,00 & 0,00 & 0,00 & 0,00 & 0,00 & 0,00 & 0,00 & 0,00 & 0,00 & 0,00 & 0,00 & 0,00 \\
\hline & $60-80$ & 0,00 & 0,00 & 0,00 & 0,00 & 0,00 & 0,00 & 0,00 & 0,00 & 0,00 & 0,00 & 0,00 & 0,00 & 0,00 & 0,00 & 0,00 & 0,00 \\
\hline & $80-100$ & 0,00 & 0,00 & 0,00 & 0,00 & 0,00 & 0,00 & 0,00 & 0,00 & 0,00 & 13,57 & 0,00 & 0,00 & 0,00 & 0,00 & 0,00 & 0,00 \\
\hline \multirow[t]{5}{*}{55} & $0-20$ & 2,48 & 0,00 & 0,00 & 0,00 & 0,00 & 0,00 & 0,00 & 0,00 & 0,00 & 0,00 & 0,00 & 0,00 & 0,00 & 0,00 & 0,00 & 0,00 \\
\hline & $20-40$ & 0,00 & 0,00 & 0,00 & 0,00 & 0,00 & 0,00 & 0,00 & 0,00 & 0,00 & 0,00 & 0,00 & 0,00 & 0,00 & 0,00 & 0,00 & 0,00 \\
\hline & $40-60$ & 0,00 & 0,00 & 0,00 & 0,00 & 0,00 & 0,00 & 0,00 & 0,00 & 0,00 & 0,00 & 0,00 & 0,00 & 0,00 & 0,00 & 0,00 & 0,00 \\
\hline & $60-80$ & 0,00 & 0,00 & 0,00 & 0,00 & 0,00 & 0,00 & 0,00 & 0,00 & 0,00 & 0,00 & 0,00 & 0,00 & 0,00 & 0,00 & 0,00 & 0,00 \\
\hline & $80-100$ & 0,00 & 0,00 & 0,00 & 0,00 & 0,00 & 0,00 & 0,00 & 0,00 & 0,00 & 0,00 & 0,00 & 0,00 & 0,00 & 0,00 & 0,00 & 0,00 \\
\hline \multirow[t]{5}{*}{56} & $0-20$ & 0,00 & 0,00 & 0,00 & 0,00 & 0,00 & 0,00 & 0,00 & 0,00 & 0,00 & 0,00 & 0,00 & 0,00 & 0,00 & 0,00 & 0,00 & 0,00 \\
\hline & $20-40$ & 0,00 & 0,00 & 0,00 & 0,00 & 0,00 & 0,00 & 0,00 & 0,00 & 0,00 & 0,00 & 0,00 & 0,00 & 0,00 & 0,00 & 0,00 & 0,00 \\
\hline & $40-60$ & 0,00 & 0,00 & 0,00 & 0,00 & 0,00 & 0,00 & 0,00 & 0,00 & 0,00 & 0,00 & 0,00 & 0,00 & 0,00 & 0,00 & 0,00 & 0,00 \\
\hline & $60-80$ & 0,00 & 0,00 & 0,00 & 0,00 & 0,00 & 4,86 & 0,00 & 0,00 & 0,00 & 0,00 & 0,00 & 0,00 & 0,00 & 0,00 & 0,00 & 0,00 \\
\hline & $80-100$ & 0,00 & 0,00 & 0,00 & 0,00 & 0,00 & 6,27 & 0,00 & 0,00 & 0,00 & 0,00 & 0,00 & 0,00 & 0,00 & 0,00 & 0,00 & 0,00 \\
\hline \multirow[t]{4}{*}{57} & $0-20$ & 0,00 & 0,00 & 0,00 & 0,00 & 0,00 & 0,00 & 0,00 & 0,00 & 0,00 & 0,00 & 0,00 & 0,00 & 0,00 & 0,00 & 0,00 & 0,00 \\
\hline & $20-40$ & 0,00 & 0,00 & 0,00 & 0,00 & 0,00 & 0,00 & 0,00 & 0,00 & 0,00 & 0,00 & 0,00 & 0,00 & 0,00 & 0,00 & 0,00 & 0,00 \\
\hline & $40-60$ & 0,00 & 0,00 & 0,00 & 0,00 & 0,00 & 0,00 & 0,00 & 0,00 & 0,00 & 0,00 & 0,00 & 0,00 & 0,00 & 0,00 & 0,00 & 0,00 \\
\hline & $60-80$ & 0,00 & 0,00 & 0,00 & 0,00 & 0,00 & 0,00 & 0,00 & 0,00 & 0,00 & 0,00 & 0,00 & 0,00 & 0,00 & 0,00 & 0,00 & 0,00 \\
\hline \multirow[t]{4}{*}{58} & $0-20$ & 0,00 & 0,00 & 0,00 & 0,00 & 0,00 & 0,00 & 0,00 & 0,00 & 0,00 & 0,00 & 0,00 & 0,00 & 0,00 & 0,00 & 0,00 & 0,00 \\
\hline & $20-40$ & 0,00 & 0,00 & 0,00 & 0,00 & 0,00 & 0,00 & 0,00 & 0,00 & 0,00 & 0,00 & 0,00 & 0,00 & 0,00 & 0,00 & 0,00 & 0,00 \\
\hline & $40-60$ & 0,00 & 0,00 & 0,00 & 0,00 & 0,00 & 0,00 & 0,00 & 0,00 & 0,00 & 0,00 & 0,00 & 0,00 & 0,00 & 0,00 & 0,00 & 0,00 \\
\hline & $60-80$ & 0,00 & 0,00 & 0,00 & 0,00 & 0,00 & 0,00 & 0,00 & 0,00 & 0,00 & 0,00 & 0,00 & 0,00 & 0,00 & 0,00 & 0,00 & 0,00 \\
\hline \multirow[t]{5}{*}{60} & $0-20$ & 0,00 & 0,00 & 0,00 & 0,00 & 0,00 & 0,00 & 0,00 & 0,00 & 0,00 & 0,00 & 0,00 & 0,00 & 0,00 & 0,00 & 0,00 & 0,00 \\
\hline & $20-40$ & 0,00 & 0,00 & 0,00 & 0,00 & 0,00 & 0,00 & 0,00 & 0,00 & 0,00 & 0,00 & 0,00 & 0,00 & 0,00 & 0,00 & 0,00 & 0,00 \\
\hline & $40-60$ & 0,00 & 0,00 & 0,00 & 0,00 & 0,00 & 0,00 & 0,00 & 0,00 & 0,00 & 0,00 & 0,00 & 0,00 & 0,00 & 0,00 & 0,00 & 0,00 \\
\hline & $60-80$ & 0,00 & 0,00 & 0,00 & 0,00 & 0,00 & 0,00 & 0,00 & 0,00 & 0,00 & 0,00 & 0,00 & 0,00 & 0,00 & 0,00 & 0,00 & 0,00 \\
\hline & $80-100$ & 0,00 & 0,00 & 0,00 & 0,00 & 0,00 & 0,00 & 0,00 & 0,00 & 0,00 & 0,00 & 0,00 & 0,00 & 0,00 & 0,00 & 0,00 & 0,00 \\
\hline
\end{tabular}


Apêndice 5 (continuação). Estimativa da densidade (larvas.100 $\mathrm{m}^{-3}$ ) dos grupos taxonômicos com freqüência de ocorrência inferior a 30\% nos diferentes estratos amostrados com a rede Multinet durante o cruzeiro de inverno de 2001, na região do cabo Frio.

\begin{tabular}{|c|c|c|c|c|c|c|c|c|c|c|c|c|c|c|c|c|c|}
\hline 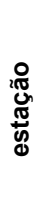 & 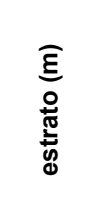 & 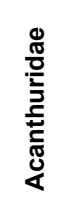 & 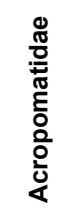 & 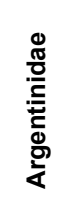 & $\begin{array}{l}\frac{\mathscr{J}}{0} \\
\frac{\overline{0}}{\overline{0}} \\
\frac{0}{0}\end{array}$ & 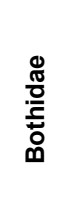 & 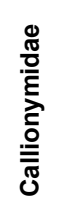 & 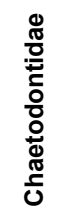 & $\begin{array}{l}\frac{\pi}{\pi} \\
\frac{\pi}{0} \\
\frac{0}{3} \\
\frac{0}{0}\end{array}$ & $\begin{array}{l}\frac{0}{\pi} \\
\frac{\pi}{0} \\
\frac{0}{0} \\
0\end{array}$ & 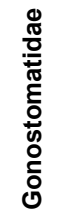 & 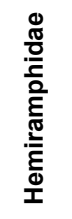 & $\begin{array}{l}\frac{0}{\pi} \\
\frac{\pi}{0} \\
\frac{0}{0}\end{array}$ & 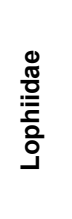 & 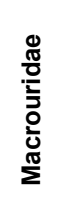 & 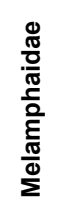 & $\begin{array}{l}\stackrel{0}{\frac{\pi}{\pi}} \\
\stackrel{\overline{0}}{\overline{0}} \\
\stackrel{\bar{\sigma}}{\Sigma}\end{array}$ \\
\hline \multirow[t]{5}{*}{61} & & & & 0,00 & 0,00 & 0,00 & & & & & 0,00 & 0,00 & 0,00 & 0,00 & 0,00 & 0,00 & 0,00 \\
\hline & $20-40$ & 0,00 & 20,51 & 0,00 & 0,00 & 0,00 & 00 & 0.00 & 1,00 & 0,00 & 0,00 & 0,00 & 0,00 & 0,00 & 0,00 & 0,00 & 0,00 \\
\hline & $40-60$ & 0,00 & 0,00 & 0,00 & 0,00 & 0,00 & 0,00 & 0,00 & 0,00 & 0,00 & 0,00 & 0,00 & 0,00 & 0,00 & 0,00 & 0,00 & 0,00 \\
\hline & $60-80$ & 0,0 & 00 & 0,00 & 00 & 00 & & & & 00 & 0,00 & 0,00 & 0,00 & 0,00 & 0,00 & 0,00 & 0,00 \\
\hline & $80-100$ & 0,00 & ,00 & 0,00 & 0,00 & 0,00 & & & & 0,00 & 0,00 & 0,00 & 0,00 & 0,00 & 0,00 & 0,00 & 0,00 \\
\hline \multirow[t]{4}{*}{62} & -20 & & 0,00 & 0,00 & 0,00 & 0,00 & & & & & 0,00 & 0,00 & 0,00 & 0,00 & 0,00 & 0,00 & 0 \\
\hline & $20-40$ & 0,00 & 0,00 & 0,00 & 0,00 & 0,00 & 0,00 & 0.00 & 0,00 & 0,00 & 0,00 & 0,00 & 0,00 & 0,00 & 0,00 & 0,00 & 0,00 \\
\hline & $40-60$ & 0,00 & 0,00 & 0,00 & 0,00 & 0,00 & 0,00 & & & 0,00 & 0,00 & 0,00 & 0,00 & 0,00 & 00 & 00 & 0,00 \\
\hline & $60-80$ & 0,00 & 0,00 & 0,00 & 0,00 & 0,00 & 0,00 & 0,00 & 00 & 0,00 & 0,00 & 0,00 & 0,00 & 0,00 & 0,00 & 0,00 & 0,00 \\
\hline \multirow[t]{4}{*}{63} & & 0,00 & 0,00 & 0,00 & 4,42 & 0,00 & 0,00 & 0,0 & & 4,42 & 0,00 & 0,00 & 0,00 & 0,00 & 0,00 & 0,00 & 0,00 \\
\hline & -40 & & & 0,00 & 0,00 & & & & & & 0,00 & 00 & 0,00 & 00 & 00 & 00 & 000 \\
\hline & $40-60$ & & 0,0 & 0,00 & 0,00 & & & & & & & & 0,00 & & 00 & 00 & \\
\hline & $60-80$ & 0,00 & 0,00 & 0,00 & 0,00 & 0,00 & 0,00 & 0,0 & & 0,00 & 0,00 & 0,00 & 0,00 & 0,00 & 0,00 & 0,00 & 0,00 \\
\hline \multirow[t]{4}{*}{71} & $0-20$ & 0,00 & 0,00 & 0,00 & 10,25 & 0,00 & 0,00 & 0,0 & & 0,00 & 0,00 & 0,00 & 0,00 & 0,00 & 0,00 & 0,00 & 0,0 \\
\hline & $20-40$ & & 0 & 0,00 & 0,00 & 0,00 & 0,00 & & & 00 & 00 & 0,00 & 0,00 & 0,00 & 00 &, 00 & 0,0 \\
\hline & $40-60$ & & & & & & & & & & & & & 00 & 00 & & \\
\hline & $60-80$ & & & 0,00 & 0,00 & & & & & & & & 0,00 & 0,00 & & & \\
\hline \multirow[t]{5}{*}{72} & $0-20$ & 0,00 & 0,00 & 0,00 & 0,00 & 0,00 & 0,00 & 0,0 & 0.00 & 0,00 & 0,00 & 0,00 & 0,00 & 0,00 & 0,00 & 0,00 & 0, \\
\hline & $20-40$ & 0,00 & 0,00 & 0,00 & 0,00 & 0,00 & 0,00 & 0,00 & 0,00 & 0,00 & 0,00 & 0,00 & 0,00 & 0,00 & 0,00 & 0,00 & 0,00 \\
\hline & $40-60$ & 0,00 & 0 & 0,00 & ,00 & 0,00 & & & & 00 & 00 & 0,00 & 00 & 00 & 00 & 00 &, 00 \\
\hline & & & & & & & & & & & & & 0,00 & 0,00 & & & 0,00 \\
\hline & $80-100$ & & & & & & & & & & & & 0,00 & 0,00 & & & \\
\hline \multirow[t]{5}{*}{73} & $0-20$ & 0,00 & 0,00 & 0,00 & 0,00 & 0,00 & 0,00 & 0,00 & 0,00 & 0,00 & 0,00 & 0,00 & 0,00 & 0,00 & 0,00 & 0,00 & 5,80 \\
\hline & $20-40$ & 0,00 & 0,00 & 0,00 & 0,00 & 0,00 & 0,00 & 0,00 & 0,00 & 0,00 & 0,00 & 0,00 & 0,00 & 0,00 & 5,65 & 0,00 & 0,00 \\
\hline & $40-60$ & 0,00 & 4,26 & 0,00 & 0,00 & 0,00 & 0,00 & & & 0,00 & 0,00 & 0,00 & 0,00 & 0,00 & 0,00 & 0,00 & 0,00 \\
\hline & & 0,00 & 0,00 & 0,00 & 0,00 & 0,00 & & & & 0,00 & 0,00 & 0,00 & 0,00 & 0,00 & 0,00 & 0,00 & 0,00 \\
\hline & $80-100$ & 0,00 & 0,00 & 0,00 & 0,00 & 0,00 & & & & & 0,00 & 0,00 & 0,00 & 0,00 & 0,00 & 0,00 & 0,00 \\
\hline \multirow[t]{5}{*}{74} & & 0,00 & 0,00 & 0,00 & 0,00 & 0,00 & 0,00 & 0,00 & 0,00 & 0,00 & 0,00 & 0,00 & 0,00 & 0,00 & 0,00 & 0,00 & 0,00 \\
\hline & $20-40$ & 0,00 & 0,00 & 0,00 & 0,00 & 0,00 & 0,00 & 0,00 & 0,00 & 0,00 & 0,00 & 0,00 & 0,00 & 0,00 & 0,00 & 3,45 & 0,00 \\
\hline & $40-60$ & 0,00 & 0,00 & 0,00 & 0,00 & 0,00 & 0,00 & 0,0 & 0,00 & 0,00 & 0,00 & 0,00 & 0,00 & 0,00 & 0,00 & 0,00 & 0,00 \\
\hline & & 0,00 & 0,00 & 0,00 & 0,00 & 0,00 & 0,00 & 0,00 & 0,00 & 0,00 & 0,00 & 0,00 & 0,00 & 0,00 & 0,00 & 0,00 & 0,00 \\
\hline & $80-100$ & 0,00 & 0,00 & 0,00 & 0,00 & 0,00 & 0,00 & 0,00 & 0,00 & 0,00 & 0,00 & 0,00 & 0,00 & 0,00 & 0,00 & 0,00 & 0,00 \\
\hline
\end{tabular}


Apêndice 5 (continuação). Estimativa da densidade (larvas. $100 \mathrm{~m}^{-3}$ ) dos grupos taxonômicos com freqüência de ocorrência inferior a 30\% nos diferentes estratos amostrados com a rede Multinet durante o cruzeiro de inverno de 2001, na região do cabo Frio.

\begin{tabular}{|c|c|c|c|c|c|c|c|c|c|c|c|c|c|c|c|c|c|}
\hline & 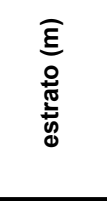 & 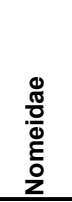 & $\begin{array}{l}\frac{0}{\pi} \\
\frac{\pi}{0} \\
\overline{0} \\
0 \\
0 \\
0 \\
\text { z }\end{array}$ & 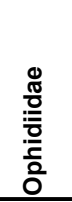 & $\begin{array}{l}\frac{0}{\pi} \\
\frac{\pi}{0} \\
\frac{0}{0} \\
\frac{0}{0} \\
\frac{\pi}{\pi} \\
0 \\
0\end{array}$ & $\begin{array}{l}0 \\
\frac{\pi}{0} \\
\frac{0}{2} \\
\frac{1}{0} \\
\frac{0}{0} \\
\frac{0}{\pi} \\
\frac{\pi}{\pi} \\
0\end{array}$ & 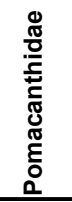 & 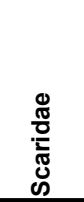 & 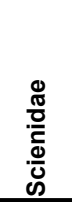 & 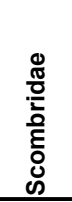 & $\begin{array}{l}\frac{\pi}{\pi} \\
\frac{\pi}{\overline{0}} \\
0 \\
\frac{\pi}{0} \\
\frac{\pi}{0} \\
0 \\
0\end{array}$ & 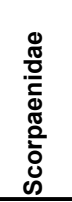 & 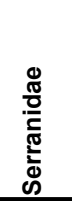 & $\begin{array}{l}\frac{\pi}{\pi} \\
\frac{\pi}{0} \\
\bar{E} \\
\bar{\varepsilon} \\
0 \\
\dot{0}\end{array}$ & 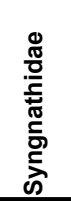 & 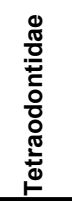 & 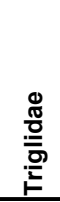 \\
\hline \multirow[t]{4}{*}{50} & & ,00 & 0,00 & 0,00 & 0,00 & 0,00 & 0,00 & 0,00 & 9,69 & 0,00 & 0,00 & 0,00 & 0,00 & 0,00 & 0,00 & 0,00 & 0,00 \\
\hline & $20-40$ & 59 & 00 & 00 & 00 & 00 & 00 & 0,00 & 0,00 & 0,00 &, 00 & 00 & 2,59 & 0,00 &, 00 &, 00 & 2,59 \\
\hline & $0-60$ & 00 & 0,00 & 0,00 & 0,00 &, 00 & 0,00 & 0,00 & 0,00 & 0,00 & 0,00 & 0,00 & 0,00 & 0,00 & 0,00 & 0,00 & 0,00 \\
\hline & $60-80$ & 0,00 & 0,00 & 0,00 & 0,00 & 0,00 & 0,00 & 0,00 & 0,00 & 0,00 & 0,00 & 0,00 & 0,00 & 0,00 & 0,00 & 0,00 & 0,00 \\
\hline \multirow[t]{5}{*}{51} & &, 00 & 0,00 & 0,00 & 0,00 & 0,00 & 0,00 & 0,00 & 0,00 & 0,00 & 0,00 & 3,80 & 0,00 & 0,00 & 0,00 &, 00 & 0,00 \\
\hline & $20-40$ & ,00 & 00 & 0,00 & 0,00 & 0,00 & 0,00 & 12,07 & 0,00 & 0,00 & 0,00 & 0,00 & 0,00 & 0,00 & 0,00 &, 00 & 0,00 \\
\hline & $40-60$ & 0,00 & 0,00 & 0,00 & 0,00 & 0,00 & 0,00 & 0,00 & 0,00 & 4,34 & 0,00 & 0,00 & 0,00 & 0,00 & 0,00 &, 00 & 0,00 \\
\hline & $60-80$ & 0,00 & 0,00 & 0,00 & 0,00 & 0,00 & 0,00 & 0,00 & 0,00 & 0,00 & 0,00 & 0,00 & 0,00 & 0,00 & 0,00 &, 00 & 0,00 \\
\hline & 30-100 & 00 & .00 & 0,00 & ,00 & 00 & 00 & & 00 & 0,00 & 0,00 & 0,00 & 0,00 & 0,00 & 0,00 &, 00 & 0,00 \\
\hline \multirow[t]{5}{*}{52} & 20 & ,00 & 00 & 0,00 & 0,00 & 0,00 & 00 & ,00 & 00 & 0,00 & 0,00 & 0,00 & ,00 & 0,00 &, 00 & ,00 & 1,00 \\
\hline & $20-40$ & 0,00 & 0,00 & 0,00 & 0,00 & 0,00 & 0,00 & 0,00 & 0,00 & 0,00 & 0,00 & 0,00 & 0,00 & 0,00 & 0,00 & 0,00 & 0,00 \\
\hline & $40-60$ & 0,00 & 0,00 & 0,00 & 0,00 & 0,00 & 0,00 & 0,00 & 0,00 & 0,00 & 0,00 & 0,00 & 0,00 & 0,00 & 0,00 & 0,00 & 0,00 \\
\hline & $60-80$ & 00 & 00 & 00 & 0,00 & , 00 & 00 & 0 & 00 &, 00 & 0,00 & ,00 & 0,00 & 0,00 & ,00 & ,00 & , 00 \\
\hline & $80-100$ &, 00 & 0,00 & 0,00 & 0,00 & 0,00 & 0,00 & 0,00 & 0,00 & 0,00 & 0,00 & 0,00 & 0,00 & 0,00 & 0,00 & 0,00 & 0,00 \\
\hline \multirow[t]{5}{*}{53} & -20 & 0,00 & 0,00 & 0,00 & 0,00 & 0,00 & 0,00 & 0,00 & 0,00 & 0,00 & 10,07 & 0,00 & 0,00 & 0,00 & 0,00 & 0,00 & 0,00 \\
\hline & 2 & 00 & 00 & 00 & 0,00 & ,00 & 00 & $0,0 c$ & 00 & 0,00 & 0,00 & 0,00 & 0,00 & 11,74 & 0,00 & 00 & 1,00 \\
\hline & $40-60$ & 00 & 00 & 00 & 0,00 & ,00 & 00 & & & 0,00 & 0,00 & 0,00 & 0,00 & 0,0 & 0,00 & 1,00 & 0,00 \\
\hline & $60-80$ & 0,00 & 0,00 & 0,00 & 0,00 & 0,00 & 0,00 & 0,00 & 0,00 & 0,00 & 0,00 & 0,00 & 0,00 & 0,00 & 0,00 & 0,00 & 0,00 \\
\hline & & 00 & 00 & 00 & 0,00 & 00 & 00 & & 00 & 0,00 & ,00 & ,00 & 0,00 & 0 &, 00 & 1,00 & 0,00 \\
\hline \multirow[t]{5}{*}{54} & & 00 & 00 & 00 & 7,86 & ,00 & 97 & 0,0 & & 0,00 & 0,0 & 0,00 & 0,00 & , & 0,00 & , 00 & 0,00 \\
\hline & $20-40$ & 0,00 & 0,00 & 0,00 & 0,00 & 0,00 & 0,00 & 0,00 & 0,00 & 0,00 & 0,00 & 0,00 & 0,00 & 5,85 & 0,00 & 0,00 & 0,00 \\
\hline & $40-60$ & 0,00 & 0,00 & 0,00 & 11,18 & 0,00 & 0,00 & 0,00 & 0,00 & 0,00 & 0,00 & 0,00 & 0,00 & 0,00 & 0,00 &, 00 & 0,00 \\
\hline & & & 00 & & & 00 & 0 & & & & & 00 & & , & ,00 & 00 & 00 \\
\hline & $80-100$ & 0,00 & 0,00 & 0,00 & 0,00 & 0,00 & 000 & 0,00 & & 0,00 & 0,00 & 0,00 & 0,00 & $0, C$ & 0,00 & 1,00 & 0,00 \\
\hline \multirow[t]{5}{*}{55} & & 0,00 & 0,00 & 0,00 & 0,00 & 0,00 & 0,00 & 0,00 & 0,00 & 0,00 & 0,00 & 0,00 & 0,00 & 0,00 & 0,00 & 0,00 & 0,00 \\
\hline & & 00 & 00 & $J$ & & 00 & 00 & & & 0 & 0, & 0,00 & 0,00 & 0, & 0,00 & 0,00 & 0,00 \\
\hline & $40-60$ & 0,00 & 0,00 & 0,00 & & 0,00 & Oח & & & 0,00 & 0,00 & 0,00 & 0,00 & 00 & 0,00 & ,00 & 0,00 \\
\hline & $60-80$ & 0,00 & 0,00 & 0,00 & 0,00 & 0,00 & 0,00 & 0,00 & 0,00 & 0,00 & 0,00 & 0,00 & 0,00 & 0,00 & 0,00 & 0,00 & 0,00 \\
\hline & & 00 & Do & & & 00 & 00 & & & & c & 0,00 & 0,00 & 0, & 0,00 & , ,00 & 0,00 \\
\hline \multirow[t]{5}{*}{56} & & & & & & & & & & & & & & & 00 & 00 & \\
\hline & $20-40$ & 0,00 & 0,00 & 0,00 & 0,00 & 0,00 & 0,00 & 0,00 & 0,00 & 0,00 & 0,00 & 0,00 & 0,00 & 0,00 & 0,00 & 0,00 & 0,00 \\
\hline & $40-00$ & 00 & 00 & ,00 & 00 & , 00 & ,00 & 0,00 & ,00 & 0,00 & 0,0 & 0,00 & 0,00 & 0,00 & 0,00 & 0,00 & 0,00 \\
\hline & & & & & & & & & & & & & & & & ,00 & \\
\hline & $80-100$ & 0,00 & 0,00 & 0,00 & 0,00 & 0,00 & 0,00 & 0,00 & 0,00 & 0,00 & 0,00 & 0,00 & 0,00 & 0,00 & 0,00 & 0,00 & 0,00 \\
\hline \multirow[t]{4}{*}{57} & & 00 &, 00 & 0,00 & 0,00 & 0,00 & 0,00 & 0,00 & 0,00 & 0,00 & 0,00 & 0,00 & 0,00 & 0,00 & 0,00 & 0,00 & 0,00 \\
\hline & $20-40$ & 0,00 & 00 & & & 0,00 & 00 & & & & & ,00 & 0,00 & &, 00 &, 00 & \\
\hline & $40-60$ & 0,00 & 0,00 & 0,00 & & 0,00 & 0,00 & 0,00 & 0,00 & 0,00 & 0,00 & 0,00 & 0,00 & 0,00 & 0,00 & 0,00 & 0,00 \\
\hline & $60-80$ & 0,00 & 0,00 & 0,00 & 0,00 & 0,00 & 0,00 & 0,00 & 0,00 & 0,00 & 0,00 & 0,00 & 0,00 & 0,00 & 0,00 & 0,00 & 0,00 \\
\hline \multirow[t]{4}{*}{58} & & 0,00 & 0,00 & 0,00 & & 0,00 & 0,00 & & & 0,00 & 0,00 & 0,00 & 0,00 & 0,00 & 0,00 & 0,00 & 0,00 \\
\hline & $20-40$ & 0,00 & 0,00 & 4,02 & 0,00 & 0,00 & 0,00 & 0,00 & 0,00 & 0,00 & 0,00 & 0,00 & 0,00 & 0,00 & 0,00 &, 00 & 8,03 \\
\hline & $40-60$ & 0,00 & 0,00 & 0,00 & 0,00 & 0,00 & 0,00 & 0,00 & 0,00 & 0,00 & 0,00 & 0,00 & 0,00 & 0,00 & 0,00 & 0,00 & 0,00 \\
\hline & $60-80$ & 0,00 & 0,00 & 0,00 & 0,00 & 0,00 & 0,00 & 0,00 & 0,00 & 0,00 & 0,00 & 0,00 & 0,00 & 0,00 & 0,00 & 0,00 & 0,00 \\
\hline \multirow[t]{5}{*}{60} & & 0,00 & 0,00 & 0,00 & 0,00 & 2,44 & 0,00 & 0,00 & 0,00 & 0,00 & 0,00 & 0,00 & 0,00 & 0,00 & 0,00 & 0,00 & 0,00 \\
\hline & $20-40$ & 0,00 & 0,00 & 0,00 & 0,00 & 0,00 & 0,00 & 0,00 & 5,00 & 0,00 & 0,00 & 0,00 & 0,00 & 0,00 & 0,00 &, 00 & 0,00 \\
\hline & & 0,00 & 0,00 & & & 0,00 & 00 & & & 0,00 & 0,00 & 0,00 & 0,00 & 0,00 & 0,00 & 0,00 & 0,00 \\
\hline & & 0,00 & 0,00 & 0,00 & 0,00 & 0,00 & 0,00 & 0,00 & 0,00 & 0,00 & 0,00 & 0,00 & 0,00 & 0,00 & 0,00 & 2,69 & 0,00 \\
\hline & $80-100$ & 0,00 & 0,00 & 0,00 & 0,00 & 0,00 & 0,00 & 0,00 & 0,00 & 0,00 & 0,00 & 0,00 & 0,00 & 0,00 & 0,00 & 0,00 & 0,00 \\
\hline
\end{tabular}


Apêndice 5 (continuação). Estimativa da densidade (larvas. $100 \mathrm{~m}^{-3}$ ) dos grupos taxonômicos com freqüência de ocorrência inferior a $30 \%$ nos diferentes estratos amostrados com a rede Multinet durante o cruzeiro de inverno de 2001, na região do cabo Frio.

\begin{tabular}{|c|c|c|c|c|c|c|c|c|c|c|c|c|c|c|c|c|c|}
\hline 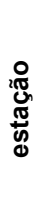 & 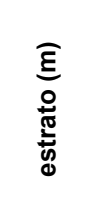 & $\begin{array}{l}\frac{0}{0} \\
\frac{\pi}{0} \\
\text { है } \\
\text { z }\end{array}$ & 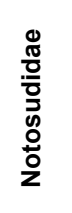 & 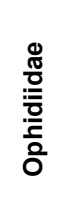 & $\begin{array}{l}\frac{\pi}{\pi} \\
\frac{\pi}{0} \\
\frac{0}{0} \\
\frac{0}{0} \\
\frac{0}{\pi / 0} \\
0\end{array}$ & 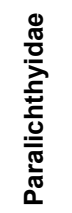 & 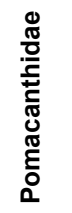 & 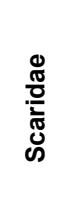 & 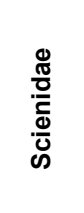 & 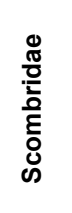 & 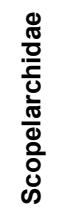 & 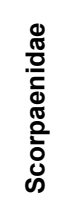 & 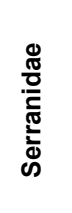 & 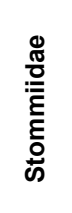 & 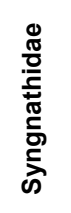 & 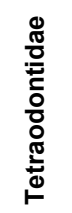 & $\begin{array}{l}\frac{0}{\pi} \\
\frac{\pi}{0} \\
\stackrel{0}{0} \\
\stackrel{3}{1}\end{array}$ \\
\hline \multirow[t]{5}{*}{61} & $0-20$ & 0,00 & 0,00 & 0,00 & 0,00 & 0,00 & 0,00 & 0,00 & 0,00 & 0,00 & 0,00 & 0,00 & 0,00 & 0,00 & 0,00 & 0,00 & 0,00 \\
\hline & $20-40$ & 0,00 & 0,00 & 0,00 & 0,00 & 0,00 & 0,00 & 0,00 & 0,00 & 0,00 & 0,00 & 0,00 & 0,00 & 0,00 & 0,00 & 0,00 & 0,00 \\
\hline & $40-60$ & 0,00 & 0,00 & 0,00 & 0,00 & 0,00 & 0,00 & 0,00 & 0,00 & 0,00 & 0,00 & 0,00 & 0,00 & 0,00 & 0,00 & 0,00 & 0,00 \\
\hline & $60-80$ & 0,00 & 0,00 & 0,00 & 0,00 & 0,00 & 0,00 & 0,00 & 0,00 & 0,00 & 0,00 & 0,00 & 0,00 & 0,00 & 0,00 & 0,00 & 0,00 \\
\hline & $80-100$ & 0,00 & 0,00 & 0,00 & 0,00 & 0,00 & 0,00 & 0,00 & 0,00 & 0,00 & 0,00 & 0,00 & 0,00 & 0,00 & 0,00 & 0,00 & 0,00 \\
\hline \multirow[t]{4}{*}{62} & $0-20$ & 0,00 & 0,00 & 0,00 & 0,00 & 0,00 & 0,00 & 0,00 & 0,00 & 0,00 & 0,00 & 0,00 & 0,00 & 0,00 & 0,00 & 0,00 & 0,00 \\
\hline & $20-40$ & 0,00 & 0,00 & 0,00 & 0,00 & 0,00 & 0,00 & 0,00 & 0,00 & 0,00 & 0,00 & 0,00 & 0,00 & 0,00 & 0,00 & 0,00 & 0,00 \\
\hline & $40-60$ & 0,00 & 0,00 & 0,00 & 0,00 & 0,00 & 0,00 & 0,00 & 0,00 & 0,00 & 0,00 & 0,00 & 0,00 & 0,00 & 0,00 & 0,00 & 0,00 \\
\hline & $60-80$ & 0,00 & 0,00 & 0,00 & 0,00 & 0,00 & 0,00 & 0,00 & 0,00 & 0,00 & 0,00 & 0,00 & 0,00 & 0,00 & 0,00 & 0,00 & 0,00 \\
\hline \multirow[t]{4}{*}{63} & $0-20$ & 0,00 & 0,00 & 0,00 & 0,00 & 2,21 & 0,00 & 0,00 & 15,47 & 0,00 & 0,00 & 0,00 & 0,00 & 0,00 & 0,00 & 0,00 & 0,00 \\
\hline & $20-40$ & 0,00 & 0,00 & 0,00 & 0,00 & 0,00 & 0,00 & 0,00 & 0,00 & 0,00 & 0,00 & 2,53 & 0,00 & 0,00 & 0,00 & 0,00 & 0,00 \\
\hline & $40-60$ & 0,00 & 0,00 & 0,00 & 0,00 & 0,00 & 0,00 & 0,00 & 0,00 & 0,00 & 0,00 & 0,00 & 0,00 & 0,00 & 0,00 & 0,00 & 0,00 \\
\hline & $60-80$ & 0,00 & 0,00 & 0,00 & 0,00 & 0,00 & 0,00 & 0,00 & 0,00 & 0,00 & 0,00 & 0,00 & 0,00 & 0,00 & 0,00 & 0,00 & 0,00 \\
\hline \multirow[t]{4}{*}{71} & $0-20$ & 0,00 & 0,00 & 0,00 & 0,00 & 0,00 & 0,00 & 0,00 & 2,56 & 0,00 & 0,00 & 0,00 & 0,00 & 0,00 & 0,00 & 0,00 & 0,00 \\
\hline & $20-40$ & 0,00 & 0,00 & 0,00 & 0,00 & 2,40 & 0,00 & 0,00 & 4,80 & 0,00 & 0,00 & 0,00 & 2,40 & 0,00 & 0,00 & 0,00 & 4,80 \\
\hline & $40-60$ & 0,00 & 0,00 & 0,00 & 0,00 & 0,00 & 0,00 & 0,00 & 0,00 & 0,00 & 0,00 & 0,00 & 0,00 & 0,00 & 0,00 & 0,00 & 0,00 \\
\hline & $60-80$ & 0,00 & 0,00 & 0,00 & 0,00 & 0,00 & 0,00 & 0,00 & 0,00 & 0,00 & 0,00 & 0,00 & 0,00 & 0,00 & 0,00 & 0,00 & 0,00 \\
\hline \multirow[t]{5}{*}{72} & $0-20$ & 0,00 & 0,00 & 0,00 & 0,00 & 2,18 & 0,00 & 0,00 & 2,18 & 0,00 & 0,00 & 0,00 & 6,54 & 0,00 & 0,00 & 0,00 & 0,00 \\
\hline & $20-40$ & 0,00 & 0,00 & 0,00 & 0,00 & 8,97 & 0,00 & 0,00 & 0,00 & 0,00 & 0,00 & 0,00 & 0,00 & 0,00 & 0,00 & 0,00 & 0,00 \\
\hline & $40-60$ & 0,00 & 0,00 & 0,00 & 0,00 & 0,00 & 0,00 & 0,00 & 0,00 & 0,00 & 0,00 & 0,00 & 0,00 & 0,00 & 3,89 & 0,00 & 0,00 \\
\hline & $60-80$ & 0,00 & 0,00 & 0,00 & 0,00 & 0,00 & 0,00 & 0,00 & 0,00 & 0,00 & 0,00 & 0,00 & 0,00 & 0,00 & 0,00 & 0,00 & 0,00 \\
\hline & $80-100$ & 0,00 & 0,00 & 0,00 & 0,00 & 0,00 & 0,00 & 0,00 & 0,00 & 0,00 & 0,00 & 0,00 & 0,00 & 0,00 & 0,00 & 0,00 & 0,00 \\
\hline \multirow[t]{5}{*}{73} & $0-20$ & 0,00 & 0,00 & 0,00 & 0,00 & 0,00 & 0,00 & 0,00 & 0,00 & 0,00 & 0,00 & 2,90 & 0,00 & 0,00 & 0,00 & 0,00 & 0,00 \\
\hline & $20-40$ & 0,00 & 0,00 & 0,00 & 0,00 & 0,00 & 0,00 & 0,00 & 0,00 & 0,00 & 0,00 & 5,65 & 0,00 & 0,00 & 0,00 & 0,00 & 0,00 \\
\hline & $40-60$ & 0,00 & 4,26 & 0,00 & 0,00 & 0,00 & 0,00 & 0,00 & 0,00 & 0,00 & 0,00 & 0,00 & 0,00 & 0,00 & 0,00 & 0,00 & 0,00 \\
\hline & $60-80$ & 0,00 & 0,00 & 0,00 & 0,00 & 0,00 & 0,00 & 0,00 & 0,00 & 0,00 & 3,57 & 0,00 & 0,00 & 0,00 & 0,00 & 0,00 & 0,00 \\
\hline & $80-100$ & 0,00 & 0,00 & 0,00 & 0,00 & 0,00 & 0,00 & 0,00 & 0,00 & 0,00 & 0,00 & 0,00 & 0,00 & 0,00 & 0,00 & 0,00 & 0,00 \\
\hline \multirow[t]{5}{*}{74} & $0-20$ & 0,00 & 0,00 & 0,00 & 0,00 & 0,00 & 0,00 & 3,20 & 6,40 & 0,00 & 0,00 & 3,20 & 0,00 & 0,00 & 0,00 & 0,00 & 0,00 \\
\hline & $20-40$ & 0,00 & 0,00 & 0,00 & 27,61 & 3,45 & 0,00 & 0,00 & 0,00 & 0,00 & 0,00 & 0,00 & 0,00 & 0,00 & 0,00 & 0,00 & 0,00 \\
\hline & $40-60$ & 0,00 & 0,00 & 0,00 & 0,00 & 0,00 & 0,00 & 0,00 & 0,00 & 0,00 & 0,00 & 0,00 & 0,00 & 0,00 & 0,00 & 0,00 & 0,00 \\
\hline & $60-80$ & 0,00 & 0,00 & 0,00 & 0,00 & 0,00 & 0,00 & 0,00 & 5,00 & 0,00 & 0,00 & 0,00 & 0,00 & 0,00 & 0,00 & 0,00 & 0,00 \\
\hline & $80-100$ & 0,00 & 0,00 & 0,00 & 0,00 & 0,00 & 0,00 & 0,00 & 0,00 & 0,00 & 0,00 & 0,00 & 0,00 & 0,00 & 0,00 & 0,00 & 0,00 \\
\hline
\end{tabular}

